\title{
Speciation, Connectivity and Self-Recruitment Among Mollusc Populations from Isolated Oceanic Islands
}

By

Céline Marie Olivia Reisser

\begin{abstract}
A thesis
submitted to the Victoria University of Wellington in fulfillment of the requirements for the degree of Doctor of Philosophy
\end{abstract}

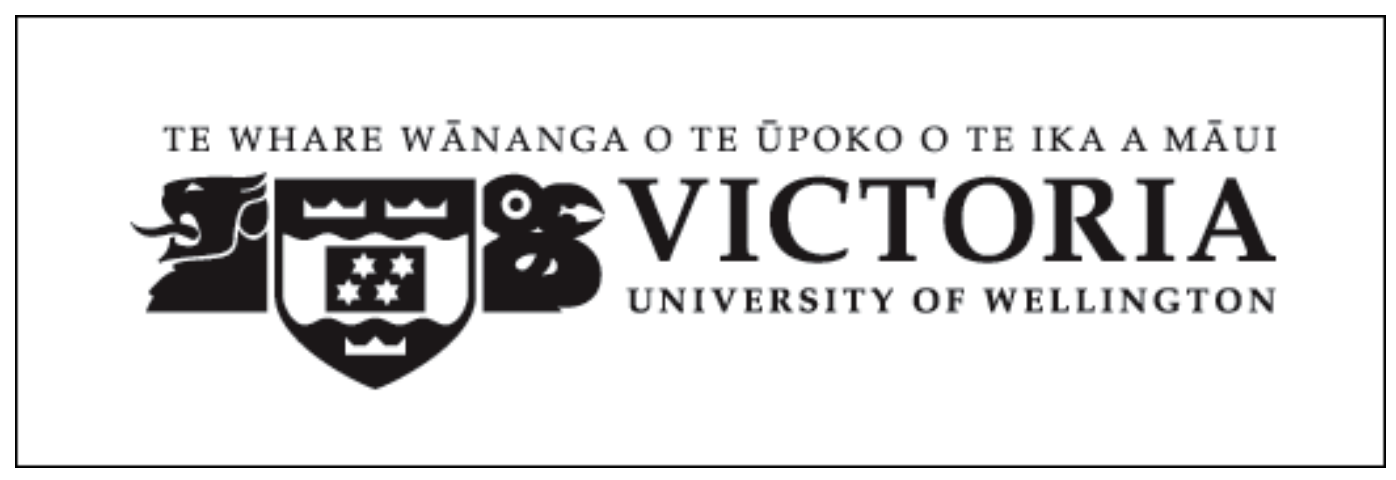



This thesis was conducted under the supervision of:

Prof. Jonathan P.A. Gardner

(Primary supervisor)

Victoria University of Wellington

Wellington, New Zealand

and

Dr. James J. Bell

Victoria University of Wellington

Wellington, New Zealand 

To my father and sister, Xavier and Maud 



\section{ACKNOWLEDGEMENTS}

Many people will tell you that getting a $\mathrm{PhD}$ is not easy; it certainly takes a long time and effort with a lot of frustration along the way. While I agree with this statement, I have to say that the four years I spent on my research project, no matter how stressful and maddening, will remain some of the best years of my life. Many inspiring people contributed to the great experience I had, and although I will keep those acknowledgements to a few selected people, I want to thank everyone whom I met and worked with, for their contribution in making my time in New Zealand so enjoyable.

First of all, I am eternally grateful to my primary supervisor, Prof. Jonathan Gardner, for his support and guidance during those four years. I also want to thank him for his patience toward my "Frenglish", and for all the entertaining conversations that derived from it, requiring the use of an English dictionary. I would like to extend those thanks to my secondary supervisor Dr. James Bell, for his precious support, advice and help with my research projects. To both of them, I express my deepest admiration: it takes some effort to get a $\mathrm{PhD}$, but I believe it takes even more so to supervise one!

Special thanks are also given to Dr. Ben Bell, Dr. Simon Davy, Dr. Peter Ritchie and Dr. Joe Zuccarello, the members of my research committee, for their critical advice and help during the first year of this project. A special mention to Dr. Peter Ritchie, who kindly accepted me in his lab meetings and discussion group on population genetics: it was greatly appreciated.

During my research, I collaborated with many different researchers and scientists. I am grateful to Dr. Christopher Bird, from the University of Hawaii, for the specifically designed primers that I used in one of my chapters, and for the

enriching discussions that ensued. I want to thank James Crampton for having taken the time to explain his shape program and for his help with understanding the output. Many thanks to Bruce Marshall, from The Museum of New Zealand Te Papa Tongarewa, for his large contribution and priceless guidance on the taxonomy part of this PhD. Finally I am grateful to Dr. Ann Wood, for teaching me so much on molecular techniques and statistical analyses. 
This Ph.D. would not have been the same without the very large majority of the School of Biological Sciences staff and students, starting with Mary Murray and Sandra Taylor: their good mood was contagious! I will surely miss them, and the olives on Hunter (Sandra)! To my fellow PhD students, and particularly to Elizabeth, Danielle M, Monica, Ilse, Peter M, Sandra D, Gesine, Gaius, Ryan and many more, thank you heaps for all the good times, venting sessions, Friday nights gathering, weekends fun and nice office time! You guys kept me sane through it all! A particular thank you to Rosalynn (Roz) Anderson-Lederer, for all her support and the lovely Chai dates! Everyone gave me what I needed after a day spent fighting with data (or the lack thereof).

I have been lucky to experience the 'kiwi way of life' while living with many people, who I am convinced, will remain life-long friends. I would like to thank Luwita Hana Randawa, for our "winter grandma nights" spent drinking hot chocolate and watching the infamous wellingtonian 'horizontal rain' through the windows. Thanks to Karla Norton, my gym buddy, for the crazy workouts and the ensuing cooking nights we shared together (damn that curry was spicy!). Last but not least, I want to thank Eda Czarnecki, for giving me a corner of the dining room to sleep in during the last five months of my PhD. I do miss the birds (did you get a new one yet?) and I cherished the Tuesday night's pizza and TV series marathon.

Now is time for me to acknowledge the people who not only supported me during the PhD but made me who I am today: my family. I am eternally grateful to my amazing sister, Maud. She believed in me since day one and still does, she gave me a place to stay when I was back in France, and had to endure my terrible mood swings during the writing stage of this $\mathrm{PhD}$ (God knows how she survived it).

Finally, I am forever indebted to my dad, who passed away during this Ph.D. I will always remember the day he drove me at the airport. He looked at me and told me: "It is a once in a lifetime opportunity, make the most of it, get the degree and most importantly, don't forget to have fun along the way!"

Well dad, that's what I did! 


\section{GENERAL ABSTRACT}

The conventional view that marine populations are demographically 'open' and exchange migrants (juveniles or adults, but mostly larvae) has been challenged by recent genetic studies and the discovery of significant genetic subdivision among populations on small geographic scales. Despite the numerous publications on the matter, the extent to which some/all marine populations rely on self-recruitment and whether this reliance is stable in time and space currently remains unanswered. This is particularly true for populations from isolated oceanic archipelagos, such as the New Zealand (NZ) subantarctic islands and the Kermadec Islands.

The specific objectives of this thesis were to: 1) assess the genetic diversity, phylogeography and contemporary levels of dispersal and self-recruitment in populations of the Cellana strigilis limpet complex, endemic to the NZ subantarctic islands; 2) conduct a morphometric analysis of the $C$. strigilis complex to complement its molecular investigation; 3) develop and optimize specific microsatellite markers for Nerita melanotragus, a marine gastropod of the Kermadec Islands and New Zealand North Island rocky shores; 4) assess the genetic structuring and levels of connectivity of $N$. melanotragus populations within the Kermadec Islands, within NZ North Island, and between the Kermadec Islands and NZ; and 5) compare the genetic structuring of $N$. melanotragus at the Kermadec Islands to that of NZ North Island populations, to test for any "island effect" on connectivity levels, and test for possible gene flow between the two groups.

Genetic investigation of the $C$. strigilis complex confirmed the presence of two distinct lineages, separated by their sister species Cellana denticulata. Morphometric analyses were congruent with molecular analyses, and were used to provide a new taxonomic description of the $C$. strigilis limpet complex: two species were recognized, Cellana strigilis and Cellana oliveri. The role of the subantarctic islands during the last glacial maximum was highlighted, and the colonisation history of the islands by the two Cellana species was explained. Contemporary levels of connectivity (gene flow) among the different populations of the two lineages were low, or non-existant, revealing their high reliability on self-recruitment. However, the analysis detected a recent migration event in one of the two lineages. Considering the geographical distance of the islands and the life history of the Cellana species, the use 
of mediated dispersal means (e.g., rafting on a natural substrate such as kelp) seems very likely.

Ten novel polymorphic microsatellite loci were developed for $N$. melanotragus, and seven of those were used to investigate the levels of connectivity and self-recruitment in six populations from the Kermadec Islands, and nine populations from the east coast of NZ North Island. According to what can be expected for a species with a long pelagic larval duration (PLD), genetic homogeneity was recorded for the Kermadec Islands populations. A lack of genetic structuring was also found for the nine populations on the NZ North Island, which is congruent with the literature in this geographic area. However, what was surprising was the high level of genetic homogeneity found between the Kermadec Islands and the NZ North Island, meaning that the two groups are effectively exchanging individuals. Hence, the Kermadec archipelago can be considered "open" at the scale of the South Pacific, for N. melanotragus populations.

This Ph.D. highlights the importance of having the correct taxonomy for conservation and connectivity studies, and gives a better understanding of the historical and contemporary patterns of genetic connectivity in the NZ offshore islands. It illustrated how historical events, such as the last glacial maximum, can shape local genetic diversity, and how this historical pattern can be maintained because of limited contemporary gene exchange. Also, this thesis demonstrated that remote populations could be strongly connected to mainland populations, contributing to the resilience of both systems and confirming the necessity of integrating remote oceanic habitats in the creation of effective Marine Protected Areas (MPA) networks to protect the marine environment. 


\section{TABLE OF CONTENTS}

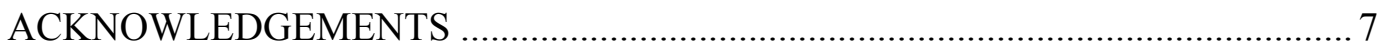

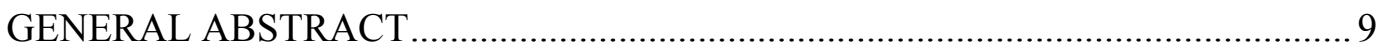

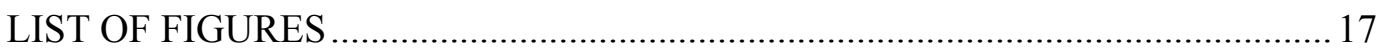

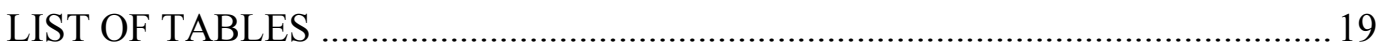

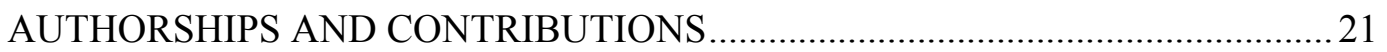

\section{CHAPTER I}

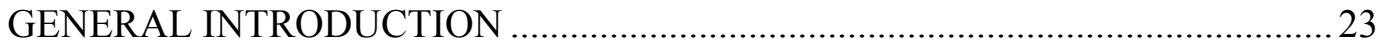

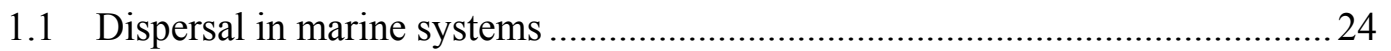

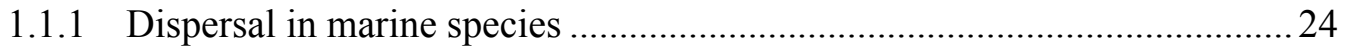

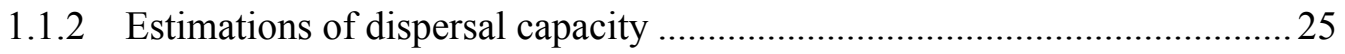

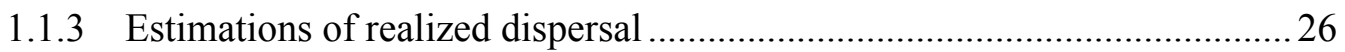

1.2 Isolation and differentiation of marine populations .........................................2 28

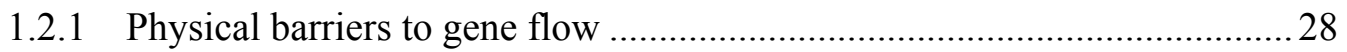

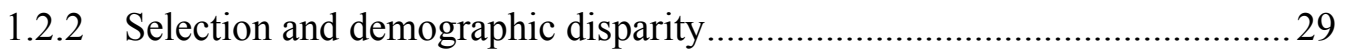

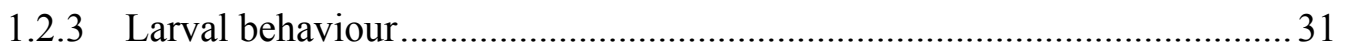

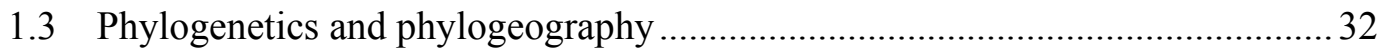

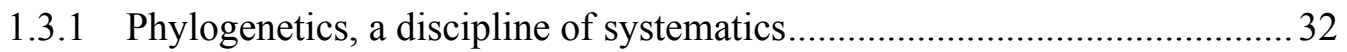

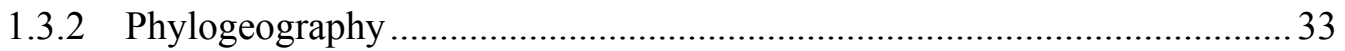

1.4 The NZ offshore islands: remote oceanic archipelagos....................................... 34

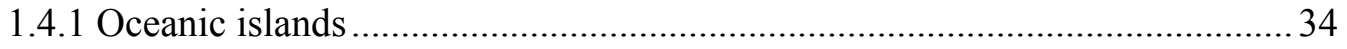

1.4.2 NZ offshore islands and their level of connectivity ...................................34

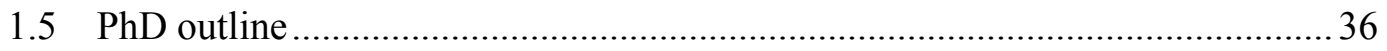

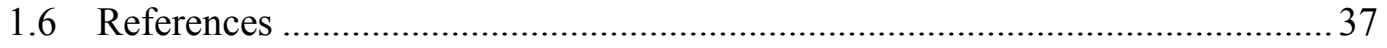

\section{CHAPTER II}

CONNECTIVITY, SMALL ISLANDS AND LARGE DISTANCES: THE CELLANA STRIGILIS LIMPET COMPLEX IN THE SOUTHERN OCEAN ............................ 49

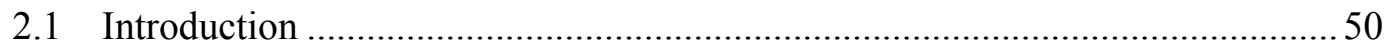

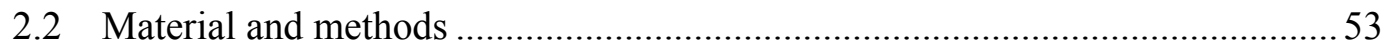

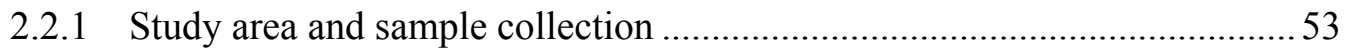




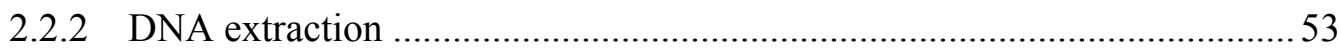

2.2.3 Mitochondrial and nuclear DNA sequence analysis .................................. 53

2.2.4 Randomly Amplified Polymorphic DNA (RAPD) assay ............................54

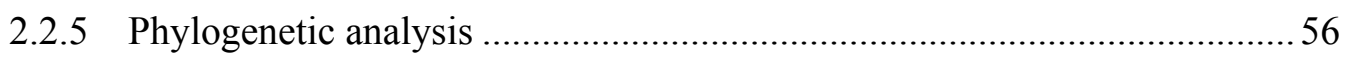

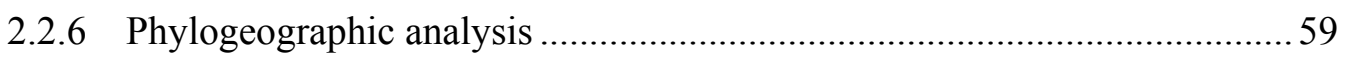

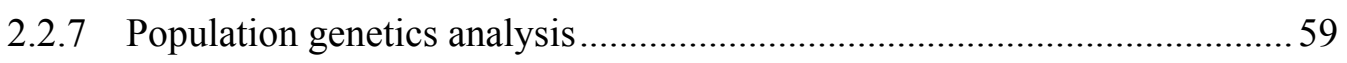

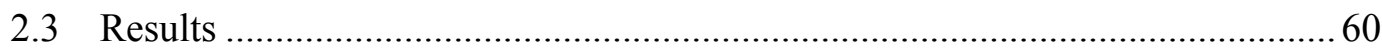

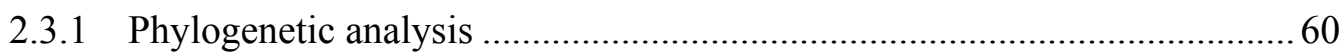

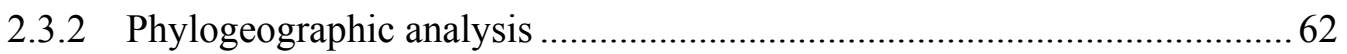

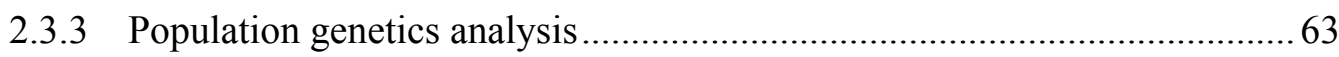

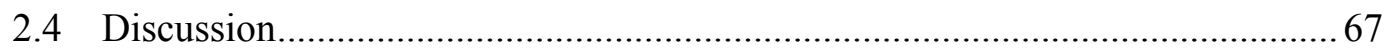

2.4.1 Phylogenetic relationships and taxonomic status of Cellana strigilis .........67

2.4.2 Phylogeography and colonisation of the New Zealand subantarctic islands... 68

2.4.3 Post-glacial demographic expansion 69

2.4.4 Contemporary connectivity among or self-recruitment within the islands? 70

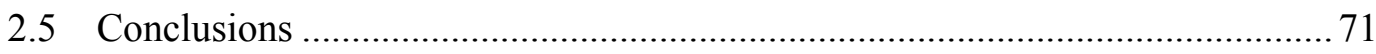

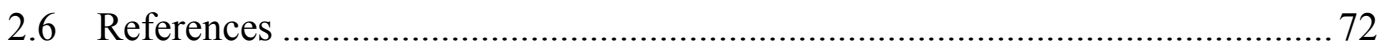

CHAPTER III

TAXONOMY OF THE NEW ZEALAND LIMPETS OF THE CELLANA STRIGILIS COMPLEX (MOLLUSCA: PATELLOGASTROPODA): A COMBINED MORPHOMETRIC AND MOLECULAR APPROACH ........................................ 83

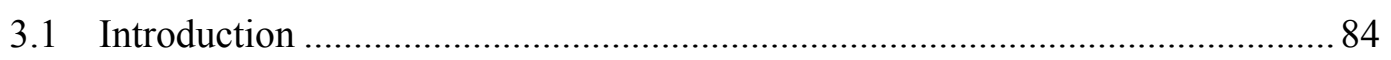

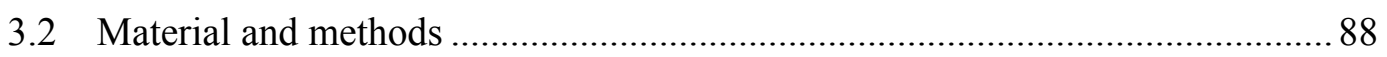

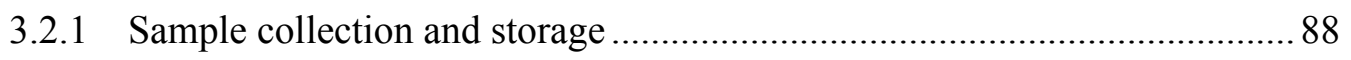

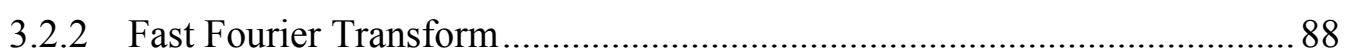

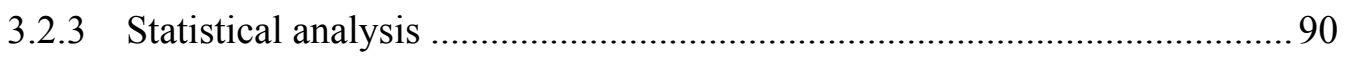

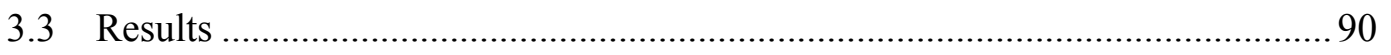

3.3.1 Morphometric differentiation between lineages.......................................... 90

3.3.2 Morphometric differentiation within lineages........................................... 93

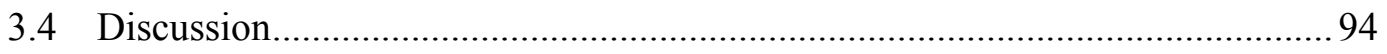


3.4.1 Advantages of Fourier shape analysis for species/population discrimination. .95

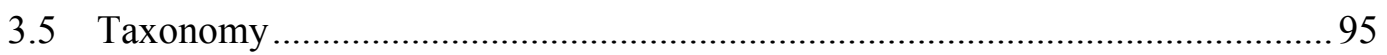

Cellana strigilis (Hombron \& Jacquinot, 1841) .................................................... 96

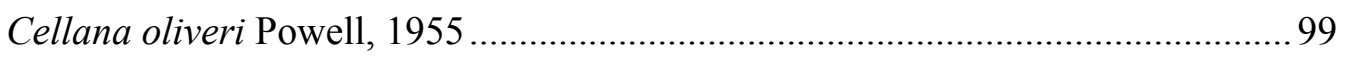

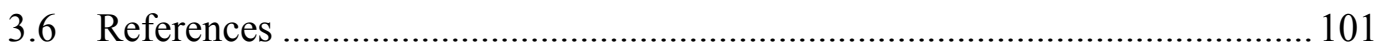

CHAPTER IV

ISOLATION AND CHARACTERIZATION OF POLYMORPHIC MICROSATELLITE MARKERS FOR THE INTERTIDAL SEA SNAIL NERITA

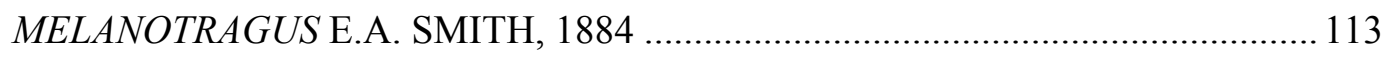

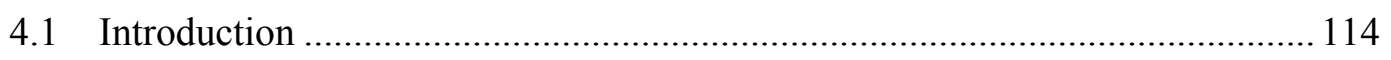

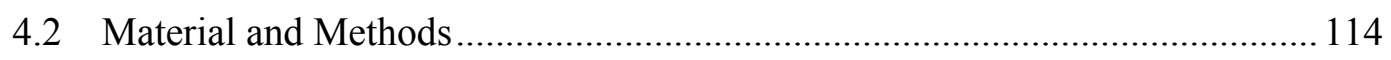

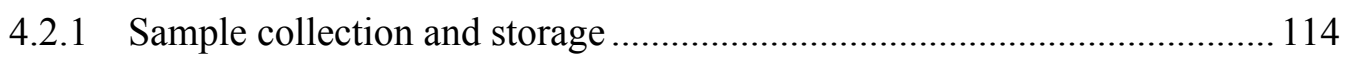

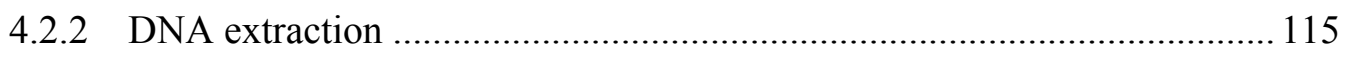

4.2.3 Roche 454 GS FLX template preparation and sequencing ...................... 115

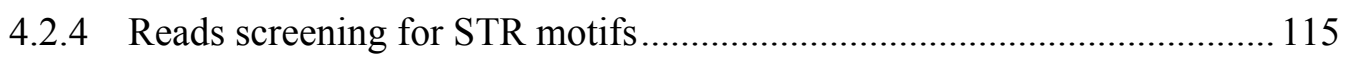

4.2.5 PCR amplification and genotyping ................................................... 117

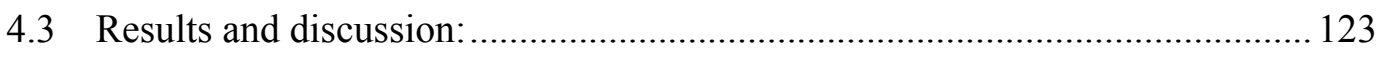

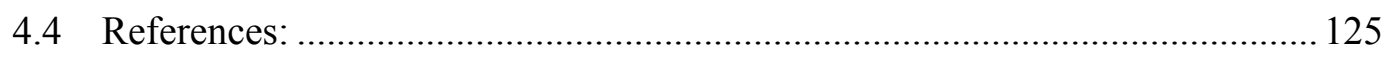

CHAPTER V

MULTI-SCALE SPATIAL CONNECTIVITY OF AN INTERTIDAL GASTROPOD, NERITA MELANOTRAGUS, IN THE SOUTH PACIFIC OCEAN 129

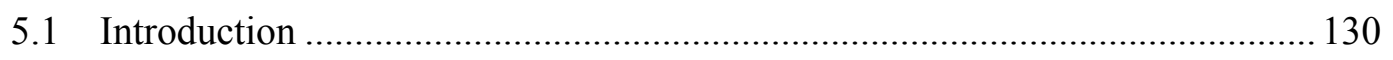

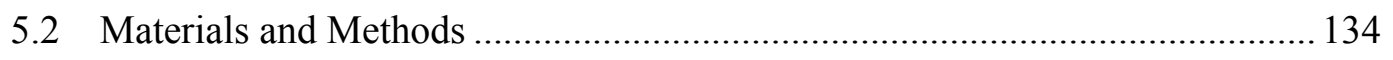

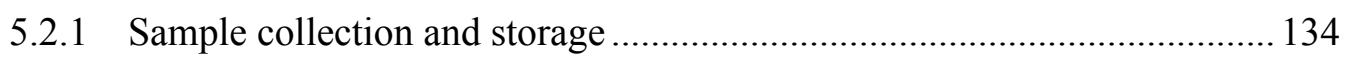

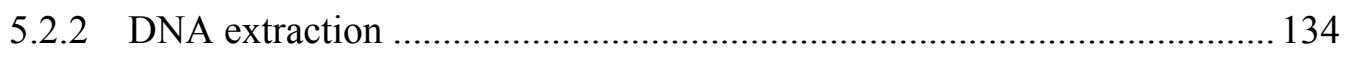

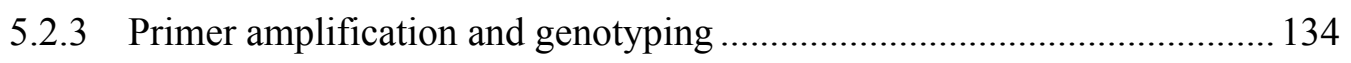

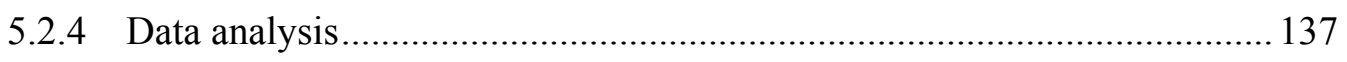

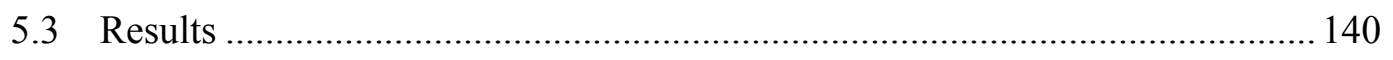

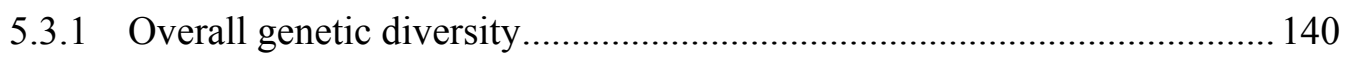

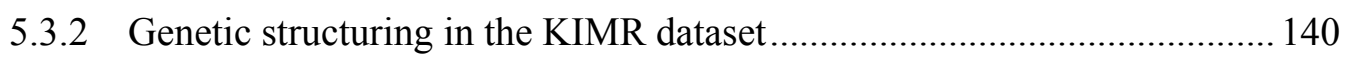




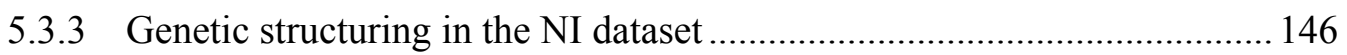

5.3.4 Genetic structuring between KIMR and NI dataset ............................... 148

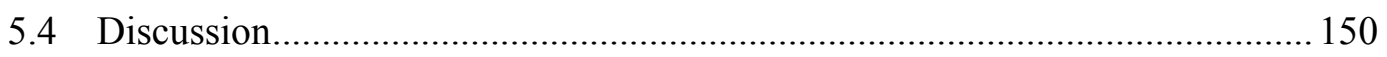

5.4.1 The Kermadec islands: micro-scale connectivity .................................... 150

5.4.3 Across the South Pacific Ocean: macro-scale connectivity ..................... 152

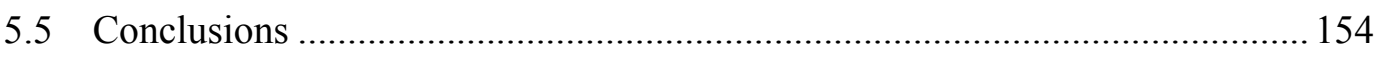

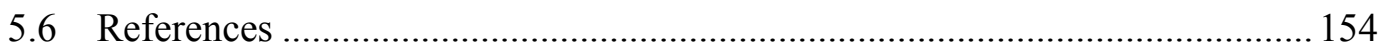

\section{CHAPTER VI}

GENERAL DISCUSSION

6.1 Importance of taxonomy in the management and protection of natural resources.

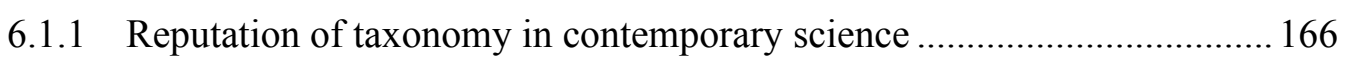

6.1.2 Importance of taxonomy for natural resource management and conservation

6.2 Genetic markers, connectivity and protection of marine species ..................... 168

6.2.1 Genetic markers and their efficiency to detect connectivity ..................... 168

6.2.2 Application of genetics to conservation and management of marine species .

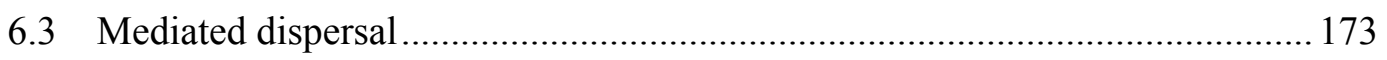

6.3.1 Mediated dispersal, a component to take into account............................ 173

6.3.2 Mediated dispersal as a threat to remote Island biotas ............................. 175

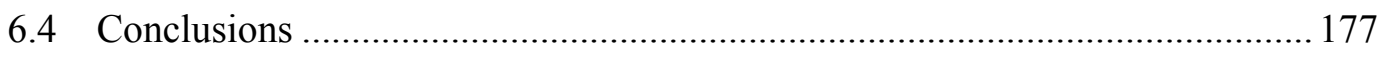

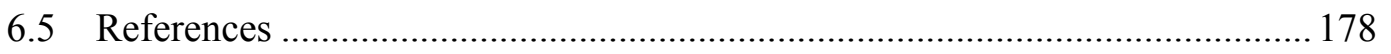

APPENDIX 1

APPLICATION OF TWO MORPHOMETRIC TECHNIQUES, TRAITS MORPHOMETRIC ANALYSIS AND FAST FOURIER TRANSFORM (FFT), FOR THE DESCRIPTION OF NZ SUBANTARCTIC CELLANA SPECIES ................. 191

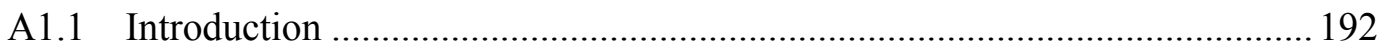

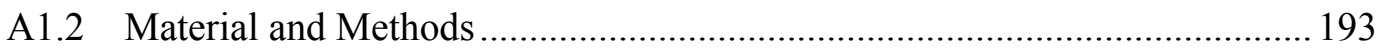

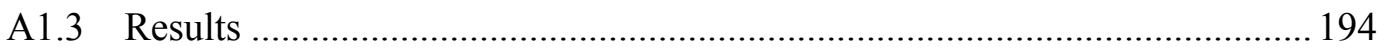

A1.3.1 Morphometric differentiation between lineages ................................... 194 
A1.3.2 Morphometric differentiation within lineages

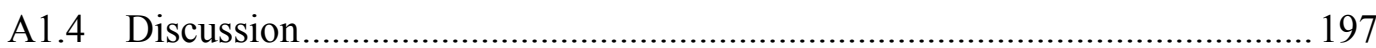

A1.4.1 Traits and shape variation between the southwestern and northeastern lineage 197

A1.4.2 Description and source of shape variation............................................. 198

A1.4.3 Advantages and possible applications of FFT analysis .........................200

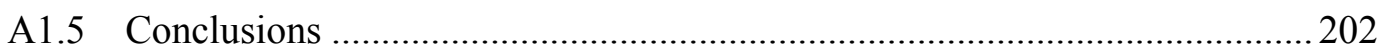

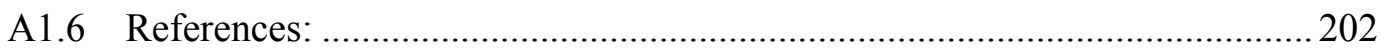





\section{LIST OF FIGURES}

\section{CHAPTER II}

Figure 2.1 Sampling sites and schematic surface circulation in the New Zealand region. The Subtropical Front (STF) and the Sub- Antarctic Front (SAF) are shown in light grey (modified from Chiswell 2009).

Figure 2.2 Phylogram derived from Bayesian analysis in MrBayes of combined COI and 16S DNA sequences. Values at nodes represent posterior probabilities/maximum parsimony support/maximum likelihood support. The scale bar represents the branch length as a measure of substitution per site 61

Figure 2.3 Haplotype network from the concatenated 16S-COI fragment (a) and ATPase b fragment (b), created by TCS v1.21. NE, north- east group; SW, southwest group....

Figure 2.4 Map of haplotype spatial distribution for (a) the 16S- COI fragment and (b) the ATPase b fragment. NE, northeast group; SW, southwest group.

Figure 2.5 Principal component $2(\mathrm{PC} 2)$ as a function of $\mathrm{PC} 1$ from the principal component analysis of the randomly amplified polymorphic DNA data set, within the southwest (top panel) and northeast (bottom panel) groups. Brackets contain the percentage of the total variance associated with the axis. .66

\section{CHAPTER III}

Figure 3.1 Canonical Analysis of Principal Coordinates on Fourier Coefficients for shell shape (a) between lineages, (b) among the southwestern lineage populations and (c) among northeastern lineage populations.

92

Figure 3.2 Outline reconstruction of shell shapes for the two species using HCurve, with (a) (c) and (e) the southwestern individuals extreme, average and most similar shell shape to the northeastern individuals respectively, and (b) (d) and (f) the northeastern individuals extreme, average and most similar shell shape to the southwestern individuals respectively. .93

Figure 3.3 A-Q. Cellana strigilis (Hombron \& Jacquinot, 1841). A, B, E, neotype of Patella strigilis, Enderby Island, Auckland Islands, MNHN 23296. C, D, lectotype of Patella redimiculum Reeve, 1854, Horseshoe Bay, Stewart Island, NHMUK 20100514/1[11.5]. F, G, J, Codfish Island, Stewart Island, NMNZ M.011173. H, I, K, Snares Islands, NMNZ M.132768. L, M, P, Enderby Island, Auckland Islands, NMNZ M.008419 [42.87=11.7]. N, O, Q, Perseverance Harbour, Campbell Island, NMNZ M.047416. Scale bars $10 \mathrm{~mm}$... 97

Figure 3.4 A-H, K. Cellana oliveri Powell, 1955. A, B, E, Hanson Bay, Chatham Islands, NMNZ M.118060. C, D, F, Bounty Islands, NMNZ M.005257. G, H, K, Ringdove Bay, Antipodes Islands, NMNZ M.011160. I, J, L-N. Cellana chathamensis (Pilsbry 1891), locality unknown (possibly Red Sea). I, J, L, lectotype ANSP 50050. M [23.8=19 mm], N, paralectotypes ANSP 425026. Scale bars $10 \mathrm{~mm}$ 100

\section{CHAPTER IV}

Figure 4.1 Map of the sampled area around New Zealand and the Kermadec Islands. NI: North Island, SI: South Island, KIMR: Kermadec Islands Marine Reserve, BOA: Boat Landing, DAY: Dayrell Island, DEN: East Denham, EGE: Egeria Islet, MEY: Meyer Island, MIL: Milne Islet, TAP: Tapotupotu Bay, WHA: Wharau Road, OAK: Oakura, HEK: Waiheke Island, HAH: Hahei. 
Figure 4.2 Length-frequency graph of the 68,758 reads obtained with a $1 / 16^{\text {th }}$ run on a 454 GS FLX machine.

\section{CHAPTER V}

Figure 5.1 Map of the sampled area around New Zealand and the Kermadec Islands. NI: North Island, SI: South Island, KIMR: Kermadec Islands Marine Reserve, BOA: Boat Landing, DAY: Dayrell Island, DEN: East Denham, EGE: Egeria Islet, MEY: Meyer Island, MIL: Milne Islet, TAP: Tapotupotu Bay, WHA: Wharau Road, RUS: Russell Harbour, TAU: Taupiri Bay, OAK: Oakura, HEK: Waiheke Island, HAH: Hahei, MAU: Mt Maunganui, WEL: Wellington.

Figure 5.2 New Zealand major coastal and offshore currents. ACC: Antarctic Circumpolar Current, DC: D’Urville Current, EAUC: East-Auckland Current, ECC: East Cape Current; ECE: East Cape Eddy, NCE: North Cape Eddy, SAF: Subantarctic Front, SC: Southland Current, STF: Subtropical Front, TF: Tasman Front, WAUC: West Auckland Current, WC: Westland Current, WCC: Wairapa Coastal Current, WE: Wairapa Eddy. Taken from Will \& Gemmell (2008), modified from Laing \& Chiswell (2003). 135

Figure 5.3 STRUCTURE analysis of KIMR, NI and KIMR+NI datasets. Results presented here were similar for the three analyses. Results are presented for a theoretical number of populations ranging from 2 to 6 . Vertical bars represent individuals.

146

Figure 5.4 UPGMA tree of the relationship among the different populations in (a) KIMR, (b) NI and (c) KIMR+NI dataset. The scale represents Nei's distance values. Nodes with no values have a bootstrap support of zero.

147

\section{APPENDIX 1}

Figure A1.1 Canonical Analysis of Principal Coordinates on multivariate shell traits (a) between lineage, (b) among the southwestern lineage populations and (c) among the northeastern lineage populations. 


\section{LIST OF TABLES}

\section{CHAPTER II}

Table 2.1 Sample set description indicating the collection location, the number of individuals used for analyses

Table 2.2 Primer list and Polymerase Chain Reaction details for COI, $16 \mathrm{~S}$ and ATPase $\beta$.

Table 2.3 Mismatch analysis results, with Fu's Fs statistic, Ramos-Onsins and Rozas' statistic, Harpending's Raggedness Index (r), values of s estimated from a sudden expansion model with $90 \%$ credibility intervals in brackets, and the estimated starting time of the population expansion in years for the range of mutation rates defined previously. Boldface indicates population expansion.....

Table 2.4 RAPD fragment frequencies per locus per population: bold fragments are *private to one island; **private to the northeast lineage; ***private to the southwest lineage. The mean number of number of polymorphic loci for each population 64-65

Table 2.5 PhiPT estimates (below diagonal) and associated P-values (above diagonal) calculated in GenAlEx V6.3 (a) for the southwest lineage and (b) for the northeast lineage. Boldface values are significantly different to zero at the $5 \%$ level, based on 999 permutations.

65

Table 2.6 Assignment test results: Classification matrix - rows are observed classifications, columns are predicted classifications. Boldface represents correct classification of an individual to its original population. .66

\section{CHAPTER III}

Table 3.1 Shell traits of Cellana strigilis subspecies according to Powell (1979)...................87

Table 3.2 Description and origin of the individuals used in this study.............................89

Table 3.3 Matrix of assignment from DFA of Fourier Coefficients of shell shape, with the percentage of correct assignment for each group (populations or species), and the probability "p" of population affiliation by chance based on population size and global sample size: division by lineages (a), by populations within the soutwestern lineage (b) and by populations within the northeastern lineage (c). Boldface represents successful assignment.

\section{CHAPTER IV}

Table 4.1 Primers retained for PCR amplification, with primer pair name, PCR size, primer pair penalty, forward and reverse primers sequences, melting temperature (Tm) for each primer and the motif and number of repeat of the STR.

118-121

Table 4.2 PCR cycles of both Touchdown (T-down) and gradient PCRs, tested on N. melanotragus

Table 4.3 Fluorescent tagging and multiplex group organization of the 16 primers retained in the analysis....

Table 5.4 Statistics summary of $31 \mathrm{~N}$. melanotragus individuals from Oakura Bay on 10 loci......124

\section{CHAPTER V}

Table 5.1 Sampling sites were samples were collected, along with the coding used in this chapter (code), number of individuals $(\mathrm{N})$, sites coordinates (geometric latitude and longitude), and the sampling date. 
Table 5.2 Fluorescent tagging and multiplex group organization of the 10 primers used in the analysis

Table 5.3 PCR Touchdown cycles used with the ten microsatellite primer pairs....

Table 5.4 Genetic diversity indexes for (a) NI, (b) KIMR and (c) KIMR+NI datasets. Bold values represent significant Fis values...

$141-145$

Table 5.5 Population pairwise Fst values for (a) KIMR, (b) NI, and (c) KIMR+NI dataset. Above diagonal: p-value after correction for FRD; below diagonal: Fst values

Table 5.6 Assignment test results showing percentage of individuals successfully assigned on (a) KIMR, (b) NI, and (c) KIMR+NI datasets. Boldface shows correct assignments. The symbol (*) indicates populations with at least one non-assigned individual.

Table 5.7 First generation migrants at (a) KIMR, (b)NI and (c) KIMR+NI datasets. The table should be read with the population of origin in the first column, and the destination in the first row. The tables also present the percentage of first generation migrants from the total number of recruits per population.

Table 6.8 Dispersal time between New Zealand ports calculated as the 1 percentile dispersal time from inverse-Gaussian fits to temporal kernels (modified from Chiswell et al. 2011)

\section{APPENDIX 1}

Table A1.1 Matrix of assignment from DFA of shell multivariate traits, with the percentage of correct assignment for each group (populations or lineage), and the probability " $p$ " of population affiliation by chance based on population size and global sample size: division by lineage (a), by populations within the southwestern lineage (b) and by populations within the northeastern lineage (c). Boldface represents correct assignment. 196 


\section{AUTHORSHIPS AND CONTRIBUTIONS}

\section{CHAPTER II}

The content of this chapter is the same as the following published paper:

Reisser CMO, Wood AR, Bell JJ, Gardner JPA (2011) Connectivity, small islands and large distances: the Cellana strigilis limpet complex in the Southern Ocean. Molecular Ecology, 20, 3399-3413.

I conducted the research and wrote the manuscript. ARW helped with data analysis and contributed to the writing. JPAG supervised my research and contributed to the writing. JJB contributed to the writing.

\section{CHAPTER III}

This chapter has not been prepared/modified for publication. I conducted the research and wrote the content.

\section{CHAPTER IV}

The content of this chapter has been submitted for publication to Invertebrate Systematics in October 2011:

Reisser CMO, Marshall BA, Gardner JPAG. Taxonomy of the New Zealand limpets of the Cellana strigilis complex (Mollusca: Patellogastropoda): a combined morphometric and molecular approach. In submission.

I conducted the research and wrote the manuscript. BAM did the taxonomic description and contributed to the writing. JPAG supervised my research and contributed to the writing.

\section{CHAPTER V}

This chapter has not been prepared/modified for publication. I conducted the research and wrote the content.

\section{CHAPTER VI}

This chapter has not been prepared/modified for publication. I conducted the research and wrote the content. 



\title{
CHAPTER I
}

\section{GENERAL INTRODUCTION}

\begin{abstract}
"The affinities of all the beings of the same class have sometimes been represented by a great tree. I believe this simile largely speaks the truth. The green and budding twigs may represent existing species; and those produced during each former year may represent the long succession of extinct species ... The limbs divided into great branches, and these into lesser and lesser branches, were themselves once, when the tree was small, budding twigs; and this connexion of the former and present buds by ramifying branches may well represent the classification of all extinct and living species in groups subordinate to groups ... From the first growth of the tree, many a limb and branch has decayed and dropped off, and these lost branches of various sizes may represent those whole orders, families, and genera which have now no living representatives, and which are known to us only from having been found in a fossil state ... As buds give rise by growth to fresh buds, and these, if vigorous, branch out and overtop on all a feebler branch, so by generation I believe it has been with the Tree of Life, which fills with its dead and broken branches the crust of the earth, and covers the surface with its ever branching and beautiful ramifications"
\end{abstract}

Charles Darwin (1859) 


\subsection{Dispersal in marine systems}

\subsubsection{Dispersal in marine species}

Some marine species are known for their spectacular migrations; they are capable of moving thousands of kilometres, to feed, mate or give birth (Lohmann et al. 1999; LeBoeuf et al. 2000). Other species seem permanently locked in the same place, with little or no movement. However, all species have some level of dispersal capability at specific stages of their life cycles (Gaines et al. 2007). Dispersal can be realized during the adult, juvenile, or larval phase. At least $70 \%$ of benthic marine invertebrates have a planktonic larval stage, which represents the primary opportunity for passive dispersal (Jones 1999). In his 1876 work, "On the geographical distribution of animals," Alfred Russell Wallace was among the first to recognize the important dispersal role of larvae; he claimed that larval dispersal is a powerful means to spread over great distances and to colonize every favourable habitat by the means of marine currents and wind-driven circulation Thus, most larval dispersal was believed to be "passive" in nature, with larvae often being viewed as inert particles drifting across oceans (Sheltema 1971).

Thorson (1950) introduced a larval classification based on the mode of nutrition. Planktotrophic larvae feed on the plankton surrounding them, whereas lecithotrophic larvae are born with energy reserves (yolk sacs) that they use throughout their larval life. To efficiently describe larval dispersal potential, Sheltema completed this classification in 1988 by introducing the terms teleplanic, actaeplanic, anchiplanic and aplanic. Planktotrophic larvae that can survive as long as they have access to planktonic sources are classified as teleplanic (spending over 2 months in the water column) or actaeplanic (spending between 1 week and 2 months in the water column). Lecithotrophic larvae have a limited energy reserve and thus spend limited time in the water column. They are classified as anchiplanic, spending only hours or days in the water column, or aplanic, not entering the water column at all (such as brooders). 


\subsubsection{Estimations of dispersal capacity}

Species are not equal with respect to their dispersal potential, the differences in dispersal capabilities leading to population division (Palumbi 1994). The degree to which different geographic populations of a species are linked by the exchange of adults, juveniles or larvae is called connectivity (Palumbi 2003). Connectivity is an important concept contributing to our understanding of species dynamics and conservation (Palumbi 2003, Taylor \& Hellberg 2003). Larvae of some coastal marine species have been found in mid-ocean plankton (Palumbi 2003), suggesting that both long distance dispersal is not a rare phenomenon and that larvae have the potential to move great distances. However, the microscopic size of larvae makes direct tracking very difficult and most publications in this field lack supportive data on realized dispersal distances (Levin 1990, Jenkins et al. 2007). Dispersal potential is associated with pelagic larval duration (PLD) and species with the longest PLD are expected to exhibit the highest dispersal potential (providing that at the end of their PLD, larvae are in a favourable environment in which they are able to settle and survive). PLD has been measured in laboratories, and modelled under biotic and abiotic forces (Cowen et al. 2006, Siegel 2008), but mathematical tools have proven to be limited, as the complexity and stochasticity of the forces driving natural ecosystems remain uncertain and hard to model. Thus, while dispersal potential may be high, we still lack a complete understanding of actual dispersal distances for most species.

Recent efforts have focused on trying to assess dispersal by direct or indirect tagging of larvae or eggs. Direct methods use artificial markers in order to tag larvae and observe their settlement along the coast; an example of such markers includes fluorescent tags (Jones 1999). Researchers have also adapted the use of tetracycline, already widely used to mark and validate age rings in fish otoliths. However, this technique only focuses on one spawning event, and needs to be repeated for every event in order to have replicated data over time. A relatively new exciting technique solves this issue by allowing for transgenerational marking of embryonic otoliths. This approach developed by Thorrold et al. (2006) is based on maternal transmission of a stable barium isotope $\left({ }^{137} \mathrm{Ba}\right)$ from spawning females to egg material that will be ultimately incorporated into the otoliths of embryos produced by an individual after exposure to the isotope. The advantage of this technique is that females continue to 
produce marked larvae over multiple clutches and for at least 90 days after a single injection (observed for Amphiprion melanopus fish). Also, different combinations of stable ${ }^{137} \mathrm{Ba}$ isotopes can be used on different populations, providing a new means of mass-marking larvae of benthic- and pelagic-spawning species over extended spawning periods. However, these techniques require a considerable time investment and extensive fieldwork. Other studies have used naturally occurring particle-reactive trace elements to track larval dispersion patterns, eliminating the need to apply some sort of artificial tag to individuals (Swearer 1999, Thorrold et al. 1997). Another advantage is that every individual within the population already possess a form of the marker (here a specific combination of trace elements). This indirect tagging method uses microchemical signatures in hard parts on an organism (e.g., otoliths and shells). Some trace elements found in the surrounding seawater can substitute for calcium and become permanently incorporated into the larval (or juveniles) otoliths. With this method, larvae that dispersed before settling in a population will show a reduced concentration of the trace elements compared to locally produced larvae, because they have developed in the nutrient-poor open ocean waters, as opposed to the nutrient-rich coastal areas.

\subsubsection{Estimations of realized dispersal}

The common disadvantage of many direct larval tagging methods is that it generally proves difficult to capture/recapture larvae, given the high dilution rates of larvae in the ocean (see Almany et al. 2007 for a practical example). One could easily miss larvae that successfully dispersed to a population. Moreover, even if a larva does arrive in a population, this does not mean it will survive and contribute to the demography and genetic structuring of the population. Hence, dispersal potential estimated using larval sampling is not necessarily the best indicator of realized dispersal leading to gene flow. However, those techniques, in combination with the distribution of genetic variation within and between populations, can provide a more accurate estimation of realized dispersal leading to gene flow. Molecular markers have been used extensively in the marine environment to show the influence of life history on population connectivity and gene flow and indirectly to estimate larval dispersal by comparing genetic structuring between populations (see Hellberg et al. 
2002, Palumbi 2003, Hellberg 2007, Hedgecock et al. 2007). Populations may differ in the different forms (alleles) one locus can have, in the frequency of these alleles in the population and in the associations of alleles at different loci (Hellberg 2007).

Different types of molecular markers and techniques have been used to estimate levels of connectivity among populations, including allozymes (Apte \& Gardner 2001), Randomly Amplified Polymorphic DNA markers (RAPDs) (Wood \& Gardner 2007), Amplified Fragment Length Polymorphism (AFLPs) (Hoffman et al. 2011) mitochondrial DNA (Crandall et al. 2010), , and microsatellites (Will \& Gemmell 2011). The use of microsatellites has increased over the last five years. Microsatellites are generally located in highly variable non-coding regions of nuclear DNA, and consist of repeats of one to six base pairs in length (Queller et al. 1993). Variation in the number of these repeats constitutes the different alleles and can be used to determine differences in population genetic structure. Microsatellite markers are generally species-specific, but can sometimes show successful cross-species amplification (generally for closely related species, e.g. Panova et al. 2008). Microsatellites have been successfully used in many marine species to assess the level of connectivity between their populations (Bell \& Okamura 2005, Bell 2008, Wei et al. 2011). For example, Bell \& Okamura (2005) used microsatellite markers to determine levels of genetic diversity and connectivity between populations of the dog whelk Nucella lapillus within Lough Hyne Marine Nature Reserve (Ireland) using different spatial scales. Wei et al. (in submission) used microsatellites to investigate historical levels of population connectivity and contemporary levels of selfrecruitment in the endemic New Zealand greenshell mussel, Perna canaliculus. They found high levels of self-recruitment that maintain the genetic discontinuity observed between northern and southern population groups.

RAPD markers have been in use for over 20 years and have been widely applied in studies of population genetics, hybridization, genome mapping, species identifications and phylogenetics of bacteria, plants and animals. (Jones et al. 2008, Peredo et al. 2009, Blair et al. 2011, Dlusskaya et al. 2011). RAPD analysis allows for the study of the whole genome rather than only a restricted part, and does not require any previous knowledge of DNA sequences, unlike microsatellites. Hence, RAPD markers allow for a fast and effective way to characterise genetic differences among populations. Concerns about the dominant nature of this marker type, its 
reproducibility and its interpretation (e.g., number of loci represented by bands scored) have been raised, but these may be addressed by rigorous data quality control with independent and replicate band scoring, as well as new software that helps with the interpretation of bands (Apte et al. 2003, Star et al. 2003, Wood \& Gardner 2007, Reisser et al. 2011).

\subsection{Isolation and differentiation of marine populations}

According to Sheltema's classification, teleplanic and actaeplanic larvae are expected to disperse over the greatest distances (Sheltema 1988). It was typically assumed that marine populations operated as 'open systems', with recruitment of larvae from other populations, and export of local larvae via ocean circulation (Jones 1999). However, despite the extent of system connectedness in the oceans, several studies have shown how marine systems may not be as 'open' as previously thought (Swearer et al. 1999, Cowen 2000, Taylor \& Hellberg 2003, Wood \& Gardner 2007). Numerous species do not realize their full dispersal potential (Cowen 2006, Gaines et al. 2007, Jenkins 2007).

\subsubsection{Physical barriers to gene flow}

Isolation of populations can originate from physical or biological 'barriers' separating the populations and restricting gene flow long enough for genetic drift to cause divergence between them (Hellberg, 1998). If the 'barrier' is substantial in time (hence historical) and space, and restricts all migration or dispersal, then isolated populations slowly differentiate to the point of reproductive isolation (impossibility to interbreed) and become two different species by allopatric speciation. If a barrier is recent, 'leaky' or ephemeral in nature, then population sub-division can be observed (Avise 2001). The level of subdivision/isolation among populations can be determined by the analysis of genetic structure between populations to determine the distribution of genetic variation. This approach has been widely used to identify dispersal barriers for marine populations (Benzie \& Williams 1997).

Ocean circulation can be a means of dispersal, but also a barrier to larval and individual exchange between populations (Palumbi 1994). In coastal waters where 
oceanographic features are often complicated by eddies and upwelling, asymmetry in directional transport can occur and generate pronounced barriers that eliminate or restrict gene flow (Gaines et al. 2007). In the open ocean, dominant strong currents can also physically restrict dispersal. For example, in the Atlantic Ocean, two major genetic breaks in adult habitat have been recognised: the broad zone of AmazonOrinoco discharge, and the deep expanse of ocean that forms the mid-Atlantic barrier (Briggs 1974, Floeter \& Gasparini 2000, Rocha 2003, Floeter et al. 2008). In the Pacific, Point Conception (California, USA) is a region at which upwelling events and directional currents have been reported to cause both species and population discontinuities (Gaylord \& Gaines, 2000). Emergence of new land barriers, such as the Florida Peninsula and the Isthmus of Panama, are another example of physical barriers to gene flow (Jackson et al. 1993, Knowlton et al. 1993, Lessios et al. 1999).

Isolation by distance occurs when two populations are separated such that no or limited contact is possible between them owing to the distance between areas of suitable habitat (Avise 2001). Oceanic islands provide an example of isolation by distance leading to speciation. Oceanic islands, by definition, have never been connected to any landmass. All the species present on those islands colonized it via exceptional events of long distance dispersal, and then diverged from their mainland source populations, sometimes leading to new endemic species (see Whittaker \& Palacios 2007 for a full discussion).

\subsubsection{Selection and demographic disparity}

Even if populations have the opportunity to exchange larvae it does not mean that those larvae will necessarily settle or recruit successfully (Swearer 1999, Barber et al. 2002). Settled larvae face selection. During open ocean transport, there is a high rate of larval mortality and larvae that do survive may be more physiologically stressed and therefore less able to recruit successfully than self-recruiting larvae that stayed in nearby coastal waters (Morgan 1995). Coastal environments are the most productive regions of the world's ocean, where nutrient inputs can enhance local food resources for planktonic coastal larvae. Thus, larvae that are retained in coastal waters during their development should have a faster development rate and should therefore settle earlier and be in better condition than larvae of coastal species that have spent 
time in the open ocean. This phenomenon operates as a selection against dispersive/migrant larvae and could potentially lead to a genetic disparity between populations (Barber 2002, Swearer 1999). Another type of selection takes place in Elacatinus evelynae, a Caribbean reef fish species that shows surprisingly strong genetic and geographic structuring among populations across the Bahamas and the Caribbean Sea (Taylor \& Hellberg 2003). In this case, 78.6\% of the observed genetic variation was explained by colour forms. These authors linked the subdivision with a possible sweepstakes effect: "the genetic drift observed among larval cohorts is the result of the random reproductive success of different small subsets of adults over time' (pp108). Thus, we also have to consider possible selection against adult migrants in favour of the local adult population from the same species.

Demographic disparity also plays a role in the perceived genetic structure of a population. A population receives a mixture of locally retained and incoming dispersed larvae. The proportion of retained versus dispersing larvae changes between populations according to species ecology and environmental conditions. Spawning does not occur all year round; larvae are released by pulses at a particular time and under particular conditions (Swearer 1999, Gaudette et al. 2006). Any disparity between two populations will lead to community-level responses: it will affect the time of release or dispersal direction due to differences in wind-driven circulation and modify the proportion of retained versus dispersing larvae in the mixture. Studies of different gastropods and of other taxa have shown that spawning time can be affected by rough seas, tidal amplitude, and moon phase (Shanks 1998). A difference in the timing of gamete release is called "isolation-by-time," as an analogy to isolation-bydistance (Hendry \& Day 2005). Thus, spawning asymmetries can lead to a disparity in the rate of evolution between populations and create misleading genetic structuring.

Differential mortality of larvae and juvenile life-stages will also act on the genetic variation between populations and the estimation of their dispersal abilities. Some environments do not offer equal chances in the face of natural selection, with larvae from one population being able to disperse to another population and later being selected against and die. This selection against migrants could lead to population genetic diversity that is not representative of the real biodiversity and connectivity potential of a species. Gardner and Kathiravetpillai (1997) found spatial variation in the distribution of the leucine aminopeptidase (LAP) allele in the mussel 
Perna canaliculus. The frequency shift in alleles was correlated with variation in water salinity, leading to differential mortality in settling larvae, and thus geographic genetic structuring among that species. Larval dispersal was not limited in that example, but differential mortality after settlement created geographic structuring among populations.

\subsubsection{Larval behaviour}

Recent studies reveal possible active self-recruiting behaviour for larvae. In isolated islands particularly, because not locating a reef is fatal, one might expect the evolution of "active behavioural adaptations" facilitating retention and homing. For example, pomacentrid (fish) larvae are able to determine and control their swimming direction by using vertical migration in the water column in response to different currents (Robertson et al. 2001, Leis 2007).

Different hypotheses exist to explain the processes implied in the active behaviour of larvae, including land-derived cues such as reef sounds and "smell". Reef sounds and acoustic guidance may be limited to a relatively short distance of only a few kilometres (Mann et al. 2007). Species can discriminate water "odours" from several reefs and show a settlement preference for their natal reef (Gerlach et al. 2007). This behaviour increases the probability of larvae staying close to their source reef. Indeed, it implies that during their entire development, larvae can consistently detect and select the freshest home reef water current and go back to their home reef once they attain the settlement stage. There is a lot of speculation about the chemical substances that trigger olfactory preferences in larvae. Although no current study explains this larval ability, either larvae use the odour of their natal reef species assemblage or they use pheromones (Gerlach et al. 2007). Other hypotheses given to explain land-derived cues are differences in wave patterns, and/or the existence of a reference point that would permit larvae to detect movements in the prevailing currents.

Other hypotheses to account for active philopatric behaviour include magnetic and visual cues. Several marine animals like adult salmon and sea turtles have the capacity to detect magnetic patterns (Lohmann \& Lohmann 1994, 1996), though it remains uncertain if larvae of any taxa have that capacity. A new hypothesis has 
recently been proposed to explain long-distance natal homing; species would imprint the magnetic field of their natal areas and later use this information to direct natal homing (Lohmann et al. 2008). This seems possible considering that different areas along continental coastlines have distinctive magnetic fields. However, these studies involved adult specimens, and further investigations are required regarding the capacity of larvae to imprint the magnetic field and then to use it as a cue.

\subsection{Phylogenetics and phylogeography}

\subsubsection{Phylogenetics, a discipline of systematics}

Systematics refers to the field of biology that deals with the diversity of organisms, their relationships and their evolution (Mayr 1982, 1997). Under this approach, unique characters of some kinds of organisms (species or higher taxa) are considered as the basic facts on which our understanding of their relatedness and evolution is based. For systematics, a character is not an attribute as such, but a grouping of attributes that is judged by the systematist to be "the same" or complementary, and can comprise any heritable attributes that may be compared among taxa and show group-defining variation (biological systematics). Characters may be composed of variation on a theme, such as "small versus large", or "A", "T", "C" or "G"; or they may represent logical complements, such as "present/absent". Different types of data are used in systematic studies, such as molecular markers, anatomical, developmental and behavioural traits, endo- or exo-skeleton structure/composition (e.g. shell microstructure), and even more methods and algorithms are used to analyse each type (e.g. Maslin 1952, Camin \& Sokal 1965, Fitch 1971, Farris 1970, 1977, O’Grady \& Deets 1987, Swofford \& Olsen 1990, Mickevich \& Lipscomb 1991, Lipscomb 1992, Felsenstein 2004). Systematics requires a multidisciplinary approach, using different types of characters to try to uncover the "true phylogeny". Molecular phylogenetics is the analysis of hereditary molecular differences, mainly in DNA sequences, to gain information on an organism's evolutionary relationships. Molecular phylogenetics is one aspect of molecular systematics, a broader term that also includes taxonomy and biogeography (see Suárez-Diaz \& Anaya-Muñoz 2008 for a full discussion). 


\subsubsection{Phylogeography}

Although Avise (1987) was the first to introduce the concept of phylogeography, this field of study was already in existence but with a different title. For example, historical biogeography focused on historical, geological, climatic and ecological conditions that influenced the current geographic distribution of species. During the 1970s, the introduction of plate tectonic theory (DeQuiroz 2005 and references therein) resulted in the concept of vicariance biogeography. Under vicariance interpretations, related populations or taxa become separated when the more-or-less continuous ranges of ancestral forms are disrupted by environmental events (Nelson \& Rosen 1981). I previously explained that phylogenetics investigates relatedness among species. Phylogeography combines biogeography and phylogenetics, and uses contemporary adult populations to determine the patterns and processes behind speciation and population connectivity that shape the spatial distribution of organismal traits (Avise 2001, 2004).

Phylogeographic structuring can be the result of both present and past geographic discontinuities linked with limited or inexistent gene flow as explained above. For example, genetic structuring that occurred during the Pleistocene glaciations is still visible today. During those events, the sea level dropped, isolating marine populations and creating genetic structuring. Today, even if there is no identifiable physical barrier remaining, the genetic structuring is still visible because the Holocene ocean currents failed to obliterate it (Barber et al. 2000). Population size tends to vary throughout time and displays a sinusoidal pattern according to its past demographic history, influencing its genetic composition. Climatic variation or disease will challenge the physical or biotic environment, and can lead species toward a bottleneck event by dramatically reducing the number of reproductively mature individuals involved in the genetic variation of that species and, by definition, reducing the effective population size, Ne (Harding, 1996, Jesus et al. 2006). With a reduction in the effective population size, the coalescence time tends to indicate species had separated earlier than they actually did. Population size will also vary when new ecological opportunities arise and/or during the recovery from a population bottleneck, with an exponential population growth leading to a star phylogeny (many 
genealogical lineages tracing back to a restricted span of time near the initial population expansion) (Galtier et al. 2000, Shriner et al. 2003, Jesus et al. 2006).

\subsection{The NZ offshore islands: remote oceanic archipelagos}

\subsubsection{Oceanic islands}

Because of their isolation and natural resources, islands have an important position in conservation programmes all over the world. Remote island biotas differ from those of continents in a number of ways, being generally species-poor and peculiar in taxonomic composition, yet rich in species found nowhere else (Whittaker \& Fernandez-Palacios 2007). Isolation is defined in terms of the dispersal potential of the organism under consideration (Gaines et al. 2007). Islands, especially archipelagos, can disrupt and complicate the flow of currents around them, creating barriers to connectivity with other populations (Johnson \& Black 2006; Bell 2008).

Sometimes, ecological connections may be extended to isolated places by extreme dispersal events in which unusually high numbers of larvae are exported to a distant location (Cowen et al. 2006). Those events occur infrequently, but if larvae settle successfully, then the newly established population will have to maintain itself through self-recruitment. This process is important in the creation of new species. A newly settled population will slowly diverge from the founder population and become genetically differentiated until becoming a new species, often endemic to the isolated area it settled in. This phenomenon explains why island ecosystems often include endemic species. The sustainability of those endemic species, without any future genetic input from the source population, depends on the survival of settled larvae to adulthood, and the production by these adults of larvae that ultimately self-recruit (Gaines et al. 2007).

\subsubsection{NZ offshore islands and their level of connectivity}

In New Zealand, two groups of oceanic offshore islands are administered by the Department of Conservation: the Subantarctic islands and the Kermadec islands. In the Southern Ocean, the NZ Subantarctic islands group is composed of five island 
groups: the Bounty Islands, the Antipodes Islands, the Snares Islands, the Auckland Islands and Campbell Island. They are the surface-breaking tips of the Campbell and Bounty Plateau and the Chatham Rise (Adams 1981, Michaux \& Leschen 2005) and are remote from all major landmasses. These two regions are part of the now nearly submerged Zealandia Continent (also known as Tasmantis), derived from the breakup of Gondwana $80 \mathrm{Ma}$ (Lewis et al. 2007). Latitudinally, the islands range from the 'roaring forties' to the 'furious fifties'. New Zealand's subantarctic islands are deemed to be of special value: in 1998 they were classified as World Heritage Areas by the United Nations and described as "the most diverse and extensive of all the subantarctic archipelagos" by the United Environmental Program (IUCN/WCPA, 2008). The islands themselves have the highest level of protection in New Zealand (National Nature Reserves) to ensure safe breeding grounds for the different species and to protect their diverse ecological community. Marine protection around NZ's subantarctic islands is represented by a single marine reserve/marine mammal sanctuary 12 nautical miles around Auckland/Motu Maha islands, and commercial fishing restrictions and legal protection to various marine animals in New Zealand waters.

The most remarkable feature of the Pacific Ocean floor in the vicinity of New Zealand is the long, narrow, and very deep Kermadec Trench that runs north-easterly towards Tonga in the general direction of the main mountain axis of the North Island. The Kermadec islands lie within $29^{\circ}$ to $31.5^{\circ}$ south latitude and $178^{\circ}$ to $179^{\circ}$ west longitude, 800-1,000 km (500-620 miles) northeast of New Zealand's North Island, and a similar distance southwest of Tonga. The 11 islands comprising the Kermadec archipelago have a volcanic origin, and are approximately 0.6 to $1.4 \mathrm{M}$ yr old (Gabites Appendix 2 in Lloyd \& Nathan 1981). They are divided into three groups: the northern group $\left(29^{\circ} 15^{\prime} \mathrm{S}, 177^{\circ} 55^{\prime} \mathrm{W}\right)$ with Raoul Island and its outlying islets, the middle group $\left(30^{\circ} 14^{\prime} \mathrm{S}, 178^{\circ} 25^{\prime} \mathrm{W}\right)$ comprising the Curtis and Macauley Islands, and the southern group ( $\left.31^{\circ} 21^{\prime} \mathrm{S}, 178^{\circ} 48^{\prime} \mathrm{W}\right)$ with L'Esperance Rock. The Kermadec marine biota is recognized as unique and species-rich, its marine environment providing important links between the temperate waters of mainland New Zealand and tropical waters. The islands have been protected by the Department of Conservation (DOC) since 1990 through the designation of the Kermadec Islands 
Marine Reserve (KIMR). It is NZ's largest marine reserve and the protection zone covers 745,000 hectares $\left(7450 \mathrm{~km}^{2}\right)$.

As for many remote habitats, marine biological studies of the subantarctic islands or the Kermadec Islands have been scarce, and are challenging in terms of logistics. Research expeditions need to be planned sometimes years in advance, and the success of sampling a population depends greatly on the weather conditions. These facts explain why very little is known of the biodiversity, and genetic connectivity of the Kermadec and the subantarctic islands. Most importantly, the presence of potential genetic breaks and/or barriers to gene flow has not been investigated among those islands, and between the two groups and mainland. Much remains to be learned from these islands.

\subsection{PhD outline}

This $\mathrm{PhD}$ is presented as a collection of individual chapters (published articles or manuscripts submitted or to be submitted for publication), independent from each other. As such, the chapters may contain some degree of overlap in terms of common background material. This $\mathrm{PhD}$ focuses on the genetic diversity, population structuring, and levels of connectivity existing among gastropod populations from the New Zealand (NZ) subantarctic islands and the Kermadec islands, and is thus divided into two parts.

The first part of this PhD contains Chapters II, III and IV and focuses on the genetic structuring and levels of connectivity of the NZ subantarctic islands, using the Cellana strigilis complex as a model group. A previous genetic investigation revealed that the complex was actually made of two geographically and genetically isolated lineages, among which no genetic structuring was detected.

Objectives of this section include:

- To confirm the presence of two (or more) distinct lineages within the $C$. strigilis complex, and the need for taxonomic reconsideration of this complex.

- To investigate the levels of genetic structuring, connectivity and selfrecruitment among the islands, using appropriate molecular markers. 
- To analyse shell morphometric characteristics of the Cellana species to test for congruence between morphometry and phylogenetics.

The second part of this $\mathrm{PhD}$ thesis includes chapters $\mathrm{V}$ and VI, and aims to quantify levels of gene flow within the Kermadec Islands, and to test for possible connectivity between New Zealand North Island and the Kermadec Islands. To do so, I used Nerita melanotragus as a model species, because this intertidal gastropod is present both in the Kermadec islands and in the NZ North Island.

Objectives for this section include:

- To develop, test and optimize specific microsatellite markers for $N$. melanotragus.

- To assess levels of connectivity within the Kermadec islands, and between the Kermadec islands and NZ North island.

\subsection{References}

Adams CJ (1981) Migration of late Cenozoic volcanism in the South island of New Zealand and the Campbell plateau. Nature, 294, 153-155.

Almany GR, Berumen ML, Thorrold SR, Planes S, Jones GP (2007) Local replenishment of coral reef fish populations in a marine reserve. Science, 316, 742-744.

Apte S, Gardner JPA (2001) Absence of population genetic differentiation in the New Zealand greenshell mussell Perna canaliculatus (Gmelin 1791). Aquaculture, 219, 193-220.

Apte S, Star B, Gardner JPA (2003) A comparison of genetic diversity between cultured and wild populations, and a test of genetic introgression in the New Zealand greenshell mussel, Perna canaliculus (Gmelin 1791). Aquaculture, 219, 193-220. 
Avise JC, Arnold J, Ball Jr. RM, Bermingham E, Lamb T, Neigel JE, Reed CA, Saunders NC (1987) Intraspecific phylogeography: the mitochondrial DNA bridge between population genetics and systematics. Annual Review of Ecology and Systematics, 18, 489-522.

Avise JC (2001) Phylogeography, the history and formation of species. Harvard University Press, Cambridge, MA.

Avise JC (2004) Molecular Markers, Natural History, and Evolution. Sinauer Associates, Inc, Sunderland, Massachussetts, USA.

Barber PH, Palumbi SR, Erdmann M., Moosa MK (2000) A marine Wallace's line? Nature, 406, 692-693.

Barber PH, Palumbi SR, Erdmann MV, Moosa MK (2002) Sharp genetic breaks among populations of Haptosquilla pulchella (Stomatopoda) indicate limits to larval transport: patterns, causes, and consequences. Molecular Ecology, 11, 659-674.

Bell JJ, Okamura B (2005) Low genetic diversity in a marine reserve: reevaluating diversity criteria in reserve design. Proceedings of the Royal Society: B, 272, 1067-1074.

Bell JJ (2008) Similarity in connectivity patterns for two gastropods species lacking pelagic larvae. Marine Ecology Progress Series, 357, 185-194.

Benzie JAH, Williams ST (1997) Genetic structure of giant clam (Tridacna maxima) populations in the West Pacific is not consistent with dispersal by present-day ocean currents. Evolution, 51, 768-783. 
Blair MW, Astudillo C, Rengifo J, Beebe SE, Graham R (2011) QTL analyses for seed iron and zinc concentrations in an intra-genepool population of Andean common beans (Phaseolus vulgaris L.). Theoretical and Applied Genetics, 122, 511-521.

Briggs JC (1974) Marine zoogeography. McGraw-Hill, NewYork

Camin JH, Sokal RR (1965) A method for deducing branching sequences in phylogeny. Evolution, 19, 311-326.

Cowen RK, Lwiza KMM, Sponaugle S, Paris CB, Olson DB (2000) Connectivity of Marine Populations: Open or Closed? Science, 287, 857-859.

Cowen RK, Paris CB, Srinivasan A (2006) Scaling of connectivity in marine populations. Science, 311, 522-527.

Crandall ED, Taffel JR, Barber PH (2010) High gene flow due to pelagic larval dispersal among South Pacific archipelagos in two amphidromous gastropods (Neritomorpha: Neritidae). Heredity, 104, 563-572.

DeQueiroz A (2005) The resurrection of oceanic dispersal in historical biogeography. Trends in Ecology and Evolution, 20, 68-73.

Dlusskaya EA, McMullen LM, Ganzle MG (2011) Characterization of an extremely heat-resistant Escherichia coli obtained from a beef processing facility. Journal of Applied Microbiology, 110, 840-849.

Farris JS (1970) Methods for computing Wagner trees. Systematic Zoology, 19, 83-92.

Farris JS (1977) Phylogenetic analysis under Dollo’s law. Systematic Zoology, 26, 7788. 
Felsenstein J (2004) Inferring phylogenies. Sinauer Associates, Sunderland, Massachussetts.

Fitch WM (1971) Toward defining the course of evolution: minimum change for a specific tree topology. Systematic Zoology, 20, 406-416.

Floeter SR, Gasparini JL (2000) The southwestern Atlantic fish fauna: composition and zoogeographic patterns. Journal of Fish Biology, 56, 1099-1114.

Floeter SR, Rocha LA, Robertson DR, Joyeux JC, Smith-Vaniz WF, Wirtz P, Edwards AJ, Barreiros JP, Ferreira CEL, Gasparini JL, Brito A, Falcon JM, Bowen BW, Bernardi G (2008) Atlantic reef fish biogeography and evolution. Journal of Biogeography, 35, 22-47.

Gaines SD, Gaylord B, Gerber AHR, Hastings A, Kinlan BP (2007) Connecting places: the ecological consequences of dispersal in the sea. Oceanography, 20, 90-99.

Galtier N, Depolis F, Barton NH (2000) Detecting bottlenecks and selective sweeps from DNA sequence polymorphisms. Genetics, 155, 981-987.

Gardner JPA, Kathiravetpillai G (1997) Biochemical genetic variation at a leucine aminopeptidase (LAP) locus in blue (Mytilus galloprovincialis) and greenshell (Perna canaliculus) mussel populations along a salinity gradient. Marine Biology, 128, 619-625.

Gaudette J, Richard A, Wahle JH, Himmelman (2006) Spawning events in small and large populations of the green sea urchin Strongylocentrotus droebachiensis as recorded using fertilization assays. Limnology and Oceanography, 51, 14851496.

Gaylord B, Gaines SD (2000) Temperature or Transport? Range limits in marine species mediated solely by flow. American Naturalist, 155, 769-789. 
Gerlach G, Atema J, Kingsford MJ, Black KP, Sims-Miller V (2007) Smelling home can prevent dispersal of reef fishes larvae. Proceedings of the National Academy of Science, 104, 858-863.

Harding RM (1996) New Phylogenies: an introductory look at the coalescent. In: Harvey PH, Brown AJL, Maynard Smith J, Nee S. New Uses for New Phylogenies. Oxford University Press, New York, pp. 16- 22.

Hedgecock D, Launey S, Pudovkin AI, Naciri Y, Lapègue S, Bonhomme F (2007) Small effective number of parents $(\mathrm{Nb})$ inferred for a naturally spawned cohort of juvenile European flat oysters Ostrea edulis. Marine Biology, 150, 1173-1182.

Hellberg ME (1998) Sympatric sea shells along the sea's shore: the geography of speciation in the marine gastropod Tegula. Evolution, 52, 1311-1324.

Hellberg ME, Burton RS, Neigel JE, Palumbi SR (2002) Genetic assessment of connectivity among marine populations. Bulletin of Marine Science, 70, 273290.

Hellberg ME (2007) Footprints on water: the genetic wake of dispersal among reefs. Coral Reefs, 26, 463-473.

Hendry AP, Day T (2005) Population structure attributable to reproductive time: isolation by time and adaptation by time. Molecular Ecology, 14, 901-916.

Hoffman JI, Peck LS, Linse K, Clarke A (2011) Strong population genetic structure in a broadcast-spawning Antarctic marine invertebrate. Journal of Heredity, 102, 55-66. 
IUCN/WCPA (2008) Establishing Marine Protected Areas Networks. Making it happen. IUCN World Commission on Protected Areas, National Oceanic and Atmospheric Administration and the Nature Conservancy. Washington DC. USA. $118 \mathrm{pp}$.

Jackson BCC, Jung P, Coates A, Collins LS (1993) Diversity and extinction of tropical American molluscs and emergence of the Isthmus of Panama. Science, 260, 1624-1626.

Jenkins DG, Brescacin CR, Duxbury CV, Elliott JA, Evans JA, Grablow KR, Hillegass M, Lyon BN, Metzger GA, Olandese ML, Pepe D, Silvers GA, Suresch HN, Thompson TN, Trexler CM, Williams GE, Williams NC, Williams SE (2007) Does size matter for dispersal distance? Global Ecology and Biogeography, 16, 415-425.

Jesus FF, Wilkins JF, Solferini VN, Wakeley J (2006) Expected coalescence times and segregating sites in a model of glacial cycles. Genetics and Molecular Research, 5, 466-474

Johnson MS, Black R (2006) Islands increase genetic subdivision and disrupt patterns of connectivity of intertidal snails in a complex archipelago. Evolution, 60, 2498-2506.

Jones GP, Milicich MJ, Emslie MJ, Lunow C (1999) Self-recruitment in a coral reef fish population. Nature, 402, 802-804.

Jones TC, Gemmill CEC, Pilditch CA (2008) Genetic variability of New Zealand seagrass (Zostera muelleri) assessed at multiple spatial scales. Aquatic Botany, 88, 39-46.

Knowlton N, Weigt LA, Solorzano LA, Mills DK, Bermingham E (1993) Divergence in proteins, mitochondrial DNA, and reproductive compatibility across the Isthmus of Panama. Science, 260, 1629-1632. 
LeBoeuf BJ, Crocker DE, Costa DP, Blackwell SB, Webb PM, Houser DS (2000) Foraging ecology of northern elephant seals. Ecological monographs, 70, 353382.

Leis ML, Wright KJ, Johnson RN (2007) Behaviour that influences dispersal and connectivity in the small, young larvae of a reef fish. Marine Biology, 153, 103-117.

Lessios HA, Kessing BD, Robertson DR, Paulay G (1999) Phylogeography of the pantropical sea urchin Eucidaris in relation to land barriers and ocean currents. Evolution, 53, 806-817.

Levin L (1990) A review of methods for labelling and tracking marine invertebrate larvae. Ophelia, 32, 115-144

Lewis K, Nodder SD, Carter L (2007) Zealandia: the New Zealand continent. Te Ara - The Encyclopedia of New Zealand. Available from: http://www.teara.govt.nz/EarthSeaAndSky/OceanStudyAndConservation/Sea FloorGeology/1/en.

Lipscomb DL (1992) Parsimony, homology, and the analysis of multistate characters. Cladistics, 8, 45-65.

Lohmann KJ, Hester JT, Lohmann CMF (1999) Long-distance navigation in sea turtles. Ethology, Ecology \& Evolution, 11, 1-23.

Lohmann KJ, Lohmann CMF (1994) Detection of magnetic inclination angle by sea turtle: a possible mechanism for determining latitude. Journal of Experimental Biology, 194, 23-32.

Lohmann KJ, Lohmann CMF (1996) Detection of magnetic-field intensity by sea turtle. Nature, 380, 59-61. 
Lohmann KJ, Putman NF, Lohmann CMF (2008) Geomagnetic imprinting: a uniform hypothesis of long-distance natal homing in salmon and sea turtles. Proceedings of the National Academy of Science, 105, 19906-19101.

Lloyd EF, Nathan S (1981) Geology and tephrochronology of Raoul Island, Kermadec Group, New Zealand. NZ Geological Survey Bulletin, 95, 1-105.

Mann DA, Casper BM, Boyle KS, Tricas TC (2007) On the attraction of larvae fishes to reef sounds. Marine Ecology Progress Series, 338, 307-310.

Maslin TP (1952) Morphological criteria of phyletic relationships. Systematics Zoology, 1, 49-70.

Mayr E (1982) The Growth of Biological Thought, Belknap Press, Cambridge, Mass. \& London.

Mayr E (1997) This is Biology: the Science of the Living World, Belknap Press, Cambridge, Mass. \& London.

Michaux B, Leschen RAB (2005) East meets west: biogeology of the Campbell Plateau. Biological Journal of the Linnean Society, 86, 95-115.

Mickevich MF, Lipscomb DL (1991) Parsimony and the choice between different transformations of the same character set. Cladistics, 7, 111-139.

Morgan SA (1995) Life and death in the plankton: larval mortality and adaptation. In: Ecology of Marine Invertebrates Larvae, eds McEdwards L, CRC Press, New York.

Nelson GJ, Rosen DE (1981) Vicariance Biogeography: A critique. Columbia University Press, New York. 
O’Grady RT, Deets GB (1987) Coding multistate characters, with special reference to the use of parasites as characters of their hosts. Systematic Zoology, 36, 268279.

Palumbi SR (1994) Genetic divergence, reproductive isolation, and marine speciation. Annual Reviews of Ecology and Systematics, 25, 547-572.

Palumbi SR (2003) Population genetics, demographic connectivity, and the design of marine reserves. Ecological Applications, 13, 146-158.

Panova1 M, Mäkinen T, Fokin M, André C, and Johannesson K (2008) Microsatellite cross-species amplification in the genus Littorina and detection of null alleles in Littorina saxatilis. Journal of Molluscan Studies, 74, 111-117.

Peredo EL, Revilla MA, Jimenez-Alfaro B, Bueno A, Prieto JAF, Abbott RJ (2009) Historical biogeography of a disjunctly distributed, Spanish alpine plant, Senecio boissieri (Asteraceae). Taxon, 58, 883-892.

Queller DC, Strassmann JE, Hughes CR (1993) Microsatellites and Kinship. Trends in Ecology and Evolution, 8, 285-288.

Robertson DR (2001) Population maintenance among tropical reef fishes: Inference from small-island endemics. Proceedings of the National Academy of Science, 98, 5667-5670.

Rocha LA (2003) Patterns of distribution and processes of speciation in Brazilian reef fishes. Journal of Biogeography, 30, 1161-1171.

Scheltema RS (1971) Larval dispersal as a means of genetic exchange between phylogeographically separated populations of shallow-water benthic marine gastropods. Biological Bulletin, 140, 284-322. 
Scheltema RS (1988) Initial evidence for the transport of teleplanic larvae of benthic invertebrates across the East Pacific barrier. Biological Bulletin, 174, 145-152.

Shanks AL (1998) Apparent oceanographic triggers to the spawning of the limpet Lottia digitalis (Rathke). Journal of Experimental Biology and Ecology, 222, 31-41.

Shriner D, Nickle DC, Jensen MA, Mullins JI (2003) Potential impact of recombination on sitewise approaches for detecting positive natural selection. Genetical Research, 81, 115-121.

Siegel DA, Mitarai S, Costello SD, Kendall BE, Warner RR, Winters KB (2008) The stochastic nature of larval connectivity among nearshore marine populations. Proceedings of the National Academy of Science, 105, 8974-8979.

Star B, Apte S, Gardner JPA (2003) Genetic structuring among populations of the greenshell mussel Perna canaliculus (Gmelin 1791) revealed by analysis of Randomly Amplified Polymorphic DNA. Marine Ecology Progress Series, 249, 171-182.

Suárez-Díaz E, Anaya-Muñoz VH (2008) History, objectivity, and the construction of molecular phylogenies. Studies in History and Philosophy of Biological and Biomedical Sciences, 39, 451-468.

Swearer SE, Caselle JE, Lea DW, Warner RR (1999) Larval retention and recruitment in an island population of a coral-reef fish. Nature, 402, 799-802.

Swofford DL, Olsen GJ (1990) Phylogeny reconstruction. In Hillis DM and C Moritz, Molecular Systematics. $1^{\text {st }}$ ed. Sinauer Associates, Sunderland, Massachusetts.

Taylor MS, Hellberg ME (2003) Genetic evidence for local retention of pelagic larvae in a Caribbean reef fish. Science, 299, 107-109. 
Thorrold SR, Jones CM, Campana SE (1997) Response of otoliths microchemistry to environmental variation experienced by larval and juvenile Atlantic croaker (Micropogonias undulates). Limnology and Oceanography, 42, 103-111.

Thorrold SR, Jones GP, Planes S, and Hare JA (2006) Transgenerational marking of embryonic otoliths in marine fishes using barium stable isotopes. Canadian Journal of Fisheries and Aquatic Sciences. 63, 1193-1197.

Thorson G (1950) Reproductive and larval ecology of marine bottom invertebrates. Biological Reviews, 25, 1-45.

Wallace AR (1876) The Geographical Distribution of Animals. Edition Harper and brothers.

Wei K, Wood AR, Gardner JPA (2011) High levels of self-recruitment in a continuously distributed taxon help maintain a pronounced genetic discontinuity. In submission

Whittaker RJ, Fernandez-Palacios JM (2007) Island Biogeography: Ecology, Evolution, and Conservation. Oxford University Press, Oxford, United Kingdom.

Will, M., Hale, M. L., Schiel, D. R., \& Gemmell, N. J. (2011). Low to moderate levels of genetic differentiation detected across the distribution of the New Zealand abalone, Haliotis iris. Marine Biology, 158, 1417-1429.

Wood AR, Gardner JPA (2007). Small spatial scale population genetic structure in two limpet species endemic to the Kermadec Islands, New Zealand. Marine Ecology Progress Series, 349, 159-170. 



\title{
CHAPTER II
}

\section{CONNECTIVITY, SMALL ISLANDS AND LARGE DISTANCES: \\ THE CELLANA STRIGILIS LIMPET COMPLEX IN THE SOUTHERN OCEAN}

\begin{abstract}
:
The Southern Ocean contains some of the most isolated islands on Earth and fundamental questions remain regarding their colonisation and the connectivity of their coastal biotas. Here I conduct a genetic investigation of the Cellana strigilis (limpet) complex that was originally classified based on morphological characters into six subspecies, five of which are endemic to the New Zealand (NZ) subantarctic and Chatham islands $\left(44^{\circ}\right.$ to $\left.52^{\circ} \mathrm{S}\right)$. Previous genetic analyses of $C$. strigilis from six of the seven island groups revealed two lineages with little or no within-lineage variation. I analysed $C$. strigilis samples from all seven island groups using two mitochondrial (COI and 16S), one nuclear (ATP synthetase $\beta$ ) and 58 loci from 4 randomly amplified polymorphic DNA markers (RAPDs), and confirmed the existence of two distinct lineages. The pronounced genetic structuring within each lineage and the presence of private haplotypes in individual islands are the result of little genetic connectivity and therefore very high self-recruitment. This study supports the significance of the subantarctic islands as refugia during the Last Glacial Maximum and adds to the knowledge of contemporary population connectivity among coastal populations of remote islands in large oceans, and the distance barrier to gene flow that exists in the sea (despite its continuous medium) for most taxa.
\end{abstract}




\subsection{Introduction}

The Southern Ocean is an uninterrupted body of water surrounding Antarctica, where many small and highly isolated islands occur. The origin of the biota of these islands has been of long-standing interest to biogeographers. Different hypotheses have been proposed to explain the distributions of species across the Southern Ocean; the two most important are long-distance dispersal and vicariance (Fell 1962; McDowall 1978; Pole 1994; Garbary 1987; Waters \& Roy 2004, Waters 2008). Longdistance dispersal is the result of the strong westerly winds and the resulting West Wind Drift (WWD) flowing from west to east around Antarctica. It is the dominant circulation feature of the Southern Ocean and with an estimated flow of 125 Sverdrups $\left(125 \times 10^{6} \mathrm{~m}^{3} \mathrm{~s}^{-1}\right)$ is one of the ocean's strongest currents (Klinck \& Nowland 2001). This current has long been described as a potential means for "stepping-stone" dispersal and therefore may explain the homogeneous distribution and genetic characteristics of many taxa in the Southern Ocean (Fell 1962; McDowall 1970; Fevolden \& Schneppenheim 1989; Hunter \& Halanych 2008; Macaya Horta \& Zuccarello 2010). This WWD-mediated dispersal may also explain the progressive decline in downstream species richness (McDowall 1978; Pole 1994). However, longdistance dispersal as the sole explanation for biogeographic differences was soon challenged by plate tectonic theory, which revealed that the Southern Hemisphere landmasses have historically been connected, forming a single supercontinent called Gondwana. While species differentiated among the different continents by vicariant events (break up of Gondwana into multiple landmasses), the taxonomic composition of these continents remained similar reflecting their gondwanan ancestry (Rosen 1978; Knox 1980; Garbary 1987; Nelson \& Latiges 2001; Lee et al. 2001; Heads 2005).

Recent studies have demonstrated that many related taxa in the southern hemisphere diverged long after the break-up of Gondwana, indicating that longdistance dispersal is an important contributor to biogeographic patterns (O'Loughlin \& Waters 2004; Waters \& Roy 2004; Waters 2008). This contribution is particularly evident when working with isolated oceanic islands, some of which have recent volcanic origins and have never been physically connected to other land masses. The presence on such islands of both endemic and non-endemic terrestrial and marine taxa 
provides evidence that long distance dispersal must have taken place over a relatively recent geological timescale. Such a finding has implications for our understanding of the origin of isolated coastal marine island faunas all over the world. In addition, it contributes to the ongoing debate regarding the importance of scale in connectivity among coastal marine populations, ranging from self-recruitment to long distance dispersal (Hellberg et al. 2002; Cowen et al. 2006; Wood \& Gardner 2007; Bradbury et al. 2008).

In the Southern Ocean, 22 island groups are scattered across the subantarctic region. Located between 44 and $52^{\circ} \mathrm{S}$, the New Zealand (NZ) subantarctic islands (Snares, Campbell, Auckland, Antipodes and Bounty islands) and Chatham Islands are the surface-breaking tips of the Campbell and Bounty Plateau and the Chatham Rise, respectively (Adams 1981; Michaux \& Leschen 2005) and are remote from all major land masses (Fig.2.1). These two regions are part of the now nearly submerged Zealandia Continent (also known as Tasmantis), derived from the break-up of Gondwana $80 \mathrm{Ma}$ (Lewis et al. 2007). The Snares and Bounty islands are composed of metamorphic rocks and coarse basement granite and are thought to have been formed early in the Jurassic period (180 Ma; Wasserburg et al. 1963; Denison \& Coombs 1977), whereas the other islands have a post-Oligocene volcanic origin (Michaux \& Leschen 2005). The Antipodes Islands are the youngest of the subantarctic islands and are the remains of a Pleistocene volcano, with some regions being less than 1 million years old. The volcanic formation dates of the other islands are estimated at 12-25 Ma for the Auckland Islands, 6-8 Ma for Campbell Island and 2.6-5 Ma for the Chatham Islands (Adams 1981; Michaux \& Leschen 2005). As such, these island groups represent a model system to test hypotheses about colonisation of remote locations (dispersal versus vicariance), speciation, genetic structuring of small populations, and historical/contemporary connectivity of coastal biotas among distant islands.

Because of the isolation of remote islands, it is often the case that very little is known about the genetic structuring and connectivity of their marine coastal taxa. Exceptions to this include the kelp study of Fraser et al. (2009) and the study of Goldstien et al. (2009) that examined the Cellana strigilis limpet subspecies complex from islands in the Southern Ocean. Cellana (Mollusca: Gastropoda) is an ancient taxonomic unit of ecologically important intertidal sedentary grazers within the 
Patellogastropoda. They have an actaeplanic larval stage that spends 3 to 10 days in the water column, although some species can delay settlement for at least 18 days after fertilization (Corpuz 1983; Bird et al. 2007). These limpets are broadly distributed in Asia, Indonesia, India, Australia and Africa, as well as remote IndoPacific and subantarctic islands. Goldstien et al. (2009) investigated the phylogenetics and phylogeography of the $C$. strigilis subspecies at six of the seven subantarctic islands and reported two genetically distinct lineages separating the northeast island group (Antipodes, Bounty, Chathams) and southwest island group (Auckland, Campbell, Stewart) with little or no genetic variation within them (they did not analyse samples from Snares Island). The conjointly published study of Chiswell (2009) employed satellite-derived ocean circulation data to simulate larval dispersal trajectories and estimate dispersal times among the islands. The model indicated that the dispersal time between pairs of islands ranges from 4 days to more than 100 days, with some island pairwise combinations showing no likely exchange of larvae. For $C$. strigilis, the likelihood of genetic homogeneity arising due to larval dispersal among islands is therefore very low. Consequently, Goldstien et al. (2009) concluded that the islands had experienced recent colonisation, rather than ongoing gene flow, to explain the genetic homogeneity of limpets among islands within lineages. Bottleneck events were also proposed by the authors to account for the complete lack of variation within each lineage. However, the three mitochondrial DNA gene markers (cytochrome $b$, $12 \mathrm{~S}$ and 16S) used by Goldstien et al. (2009) for their phylogenetic and phylogeographic study are unlikely to be highly informative for the study of population genetics and connectivity of recently diverged species (Avise 2000). Given the possibility of genetic divergence among at least some of the island populations, connectivity estimations and identification of putative migrants may be better addressed by the use of highly variable markers.

The present study uses mitochondrial and nuclear DNA sequence data plus highly variable randomly amplified polymorphic DNA (RAPD) markers to characterize genetic variation in populations of all seven subantarctic island locations of Cellana strigilis. With the ultimate purpose of increasing our understanding of the mode and timing of colonisation, and the population genetic structure of coastal marine taxa of remote islands, this study has three main aims: (1) to test for the presence of two or more lineages within the Cellana strigilis complex and estimate 
their time of divergence, (2) to test for within-lineage genetic variation and historical demographic changes in population size (such as expansions or bottlenecks), and (3) to test for contemporary connectivity among island populations and identify putative genetic migrants.

\subsection{Material and methods}

\subsubsection{Study area and sample collection}

The NZ subantarctic islands, Stewart Island and the Chatham Islands are located in the Southern Ocean and are influenced by several major oceanographic features (Fig.2.1). A total of 166 individuals from the Cellana strigilis complex was sampled from Stewart Island, the Chatham Islands and the five subantarctic islands (Table 2.1) between 2003 and 2008. Individuals of C. flava, C. radians, C. denticulata and $C$. ornata were included as outgroups for the phylogenetic analysis (Table 2.1).

\subsubsection{DNA extraction}

Total DNA was extracted from $\sim 2$ to $4 \mathrm{~mm}^{3}$ of foot tissue from each limpet using the DNeasy tissue extraction kit (Qiagen) following the manufacturer's instructions. DNA concentration was estimated by running each sample against a High DNA Mass ladder (Invitrogen) on an ethidium bromide-stained 1\% agarose gel. DNA was stored at $-20^{\circ} \mathrm{C}$.

\subsubsection{Mitochondrial and nuclear DNA sequence analysis}

Partial fragments of COI and 16S mitochondrial DNA (mtDNA), as well as ATP synthetase $\beta$ subunit (ATPase $\beta$ ) nuclear DNA (nDNA) were obtained using Cellana-specific COI primers (Christopher Bird, University of Hawaii), 16S universal primers (Palumbi et al. 1991) and ATPase $\beta$ primers (Jarman et al. 2002) (Table 2.2). Polymerase Chain Reaction (PCR) amplifications were conducted using a $25 \mu \mathrm{L}$ volume reaction mixture composed of $10 \mathrm{mM}$ Tris- $\mathrm{HCl}, 50 \mathrm{mM} \mathrm{KCl}, 1.5 \mathrm{mM} \mathrm{MgCl}$ (Standard Taq Reaction buffer from NEB), $0.1 \mathrm{mM}$ of each dNTP, $0.2 \mu \mathrm{M}$ of both 
forward and reverse primers, 1 unit Taq DNA polymerase (from NEB) and $\sim 15 \mathrm{ng}$ of template DNA (refer to Table 2.2 for PCR cycles). All amplifications were carried out

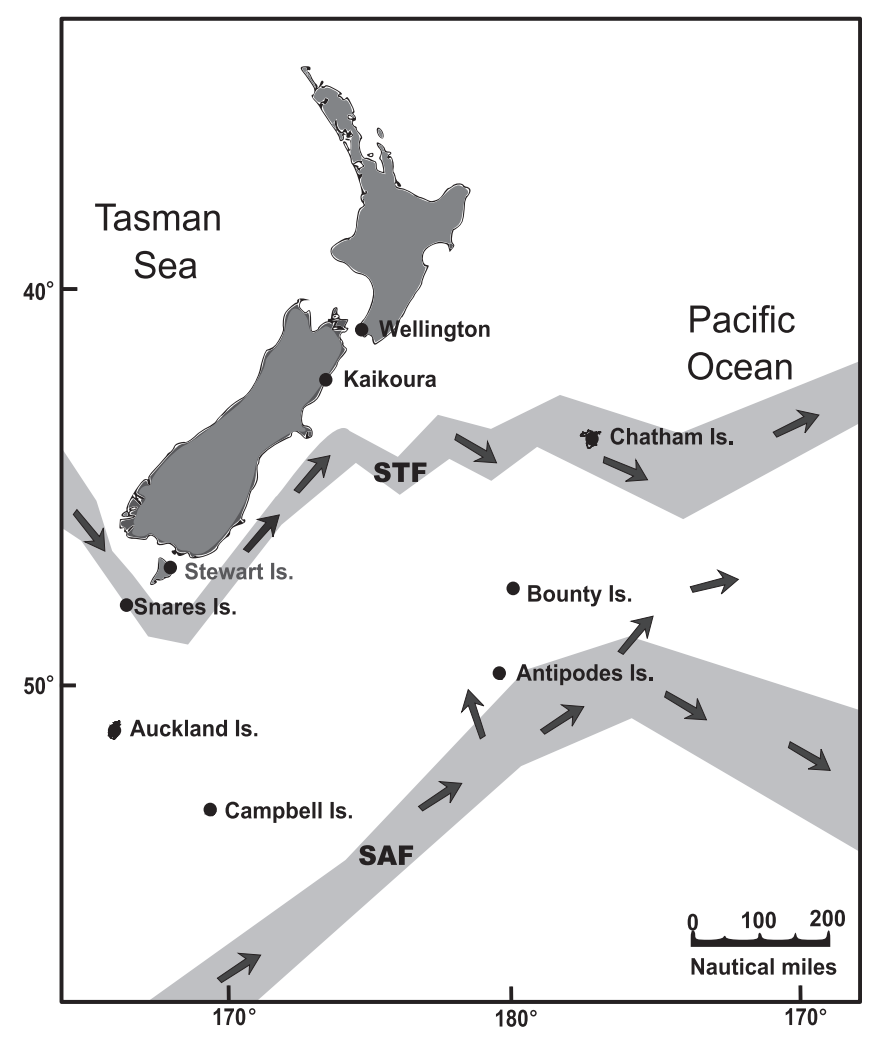

Figure 2.1.

Sampling sites and schematic surface circulation in the New Zealand region. The Subtropical Front (STF) and the Sub- Antarctic Front (SAF) are shown in light grey (modified from Chiswell 2009).

using an Applied Biosystems GeneAmp 2700 Thermocycler. PCR products were purified using either the EXOSAP-IT ${ }^{\mathrm{TM}}$ PCR Clean-up method or the Roche High Pure PCR Product Purification kit, following manufacturer's directions. Purified products were sequenced on an ABI3730 DNA Analyser (Allan Wilson Centre Genome Service, Palmerston North, NZ).

\subsubsection{Randomly Amplified Polymorphic DNA (RAPD) assay}

The RAPD technique employs a single decamer primer with an arbitrary sequence to generate genome-specific fingerprints of multiple amplification products. RAPD analysis permits a study of genetic differences at a finer scale than that often 
obtained using nuclear and mitochondrial DNA sequencing and it allows for the study of the whole genome rather than only a restricted part. RAPD markers have been in

Table 2.1.

Sample set description indicating the collection location, the number of individuals used for analyses

\begin{tabular}{llcc}
\hline \multicolumn{1}{c}{ Species } & \multicolumn{1}{c}{ Location } & N RAPD & $\begin{array}{c}\text { N } \\
\text { Sequencing }\end{array}$ \\
\hline Cellana strigilis subspecies & & & \\
Cellana strigilis strigilis & Auckland Island, Ranui Cove & 54 & 21 \\
Cellana strigilis strigilis & Campbell Island, Perseverance Harbour & 23 & 21 \\
Cellana strigilis bollonsi & Antipodes Islands, Jerry's Cove & 24 & 23 \\
Cellana strigilis flemingi & Snares Islands, Ho Ho Bay & 22 & 22 \\
Cellana strigilis oliveri & Bounty Islands, Proclamation Island & 20 & 18 \\
Cellana strigilis chathamensis & Chatham Island, Kaingaroa Harbour & 18 & 18 \\
Cellana strigilis redimiculum & Stewart Island, Halfmoon Bay & 5 & 5 \\
Outgroup species & $\quad$ & & \\
Cellana ornata & $\quad$ Stewart Island, Halfmoon Bay & 0 & 1 \\
Cellana flava & South Island, Kaikoura & 0 & 2 \\
Cellana radians & North Island, Wellington & 0 & 2 \\
Cellana denticulata & South Island, Kaikoura & 0 & 5 \\
\hline RAPD, randomly amplified polymorphic DNA. & &
\end{tabular}

use for $\sim 20$ years and are widely applied in studies of population genetics, hybridisation, genome mapping, species identifications and phylogenetics of bacteria, plants and animals (Jones et al. 2008; Peredo et al. 2009; Samantaray et al. 2010; Blair et al. 2011; Dlusskaya et al. 2011; Matoba et al. 2001). Concerns about the dominant nature of this marker type, its reproducibility and its interpretation (e.g., number of loci represented by bands scored) have been raised, but these may be addressed by rigorous data quality control with independent and replicate band scoring, as well as new software (see later sections) which helps with interpretation of bands.

The protocol followed in this study has been used successfully on mussels (Apte et al. 2003; Star et al. 2003) and limpets (Wood and Gardner 2007). In total, 59 RAPD primers (Operon Technologies, Inc) from the primer kits C, E, G and I were tested on three individuals of each island. I selected four primers based on their capacity to generate a large number of reproducible and unambiguously scorable bands in all populations. These primers were (5' to 3'): OPC-20 (ACTTCGCCAC), 


\section{OPE-15 (ACGCACAACC), OPG-16 (AGCGTCCTCC) and OPI-07 (CAGCGACAAG).}

Only strong and easily scorable bands were used, and reproducibility was confirmed by amplifying three individuals from each population a second time and comparing amplification products. The $25 \mu \mathrm{L}$ PCR reaction mix was composed of 10 $\mathrm{mM}$ Tris- $\mathrm{HCl}, 50 \mathrm{mM} \mathrm{KCl}, 1.5 \mathrm{mM} \mathrm{MgCl}_{2}$ (Standard Taq reaction Buffer from NEB), $0.2 \mathrm{mM}$ of each dNTP, $0.2 \mu \mathrm{M}$ of a single decamer primer, 1 unit Taq DNA polymerase (from NEB) and $\sim 10 \mathrm{ng}$ of template DNA. All amplifications were carried out using an Applied Biosystems GeneAmp 2700 Thermocycler, over 40 cycles: 4 initial cycles of $3 \mathrm{~min}$ at $94^{\circ} \mathrm{C}, 3 \mathrm{~min}$ at $36^{\circ} \mathrm{C}$ and $3 \mathrm{~min}$ at $72^{\circ} \mathrm{C}$, followed by 36 cycles of $30 \mathrm{sec}$ at $94^{\circ} \mathrm{C}, 1 \mathrm{~min}$ at $36^{\circ} \mathrm{C}$, and $2 \mathrm{~min}$ at $72^{\circ} \mathrm{C}$. Electrophoresis of the PCR products was performed on a $2 \%$ agarose gel stained with ethidium bromide and visualized using UV illumination. Gels were photographed using a Kodak gel logic system. All gel images were inverted and contrast increased using Microsoft Photo Editor. Each image was laser printed and all bands (375 - $2750 \mathrm{bp}$ ) were scored under blind test conditions for their presence or absence on two separate occasions by the same researcher (Céline Reisser). When scoring for the second time, 5 of 2656 bands belonging to two different loci were not scored consistently. Those two loci were removed from the analysis, leaving 58 loci with 2534 bands, all of which were scored consistently between the first and second scoring events.

\subsubsection{Phylogenetic analysis}

A concatenated fragment of 852 bp (427 bp of mtDNA 16S and 425 bp of mtDNA COI) was analysed. ATPase $\beta$ was not included in the phylogeny because of the lack of data availability regarding the outgroup species. Sequences for the Cellana strigilis complex individuals and for all other species were aligned in Geneious v4.8.5 (Drummond et al. 2009). Cellana ornata was defined as the outgroup based on a previous phylogenetic analysis (Goldstien et al. 2006; Nakano \& Osawa 2007). The presence of stop codons for COI was also investigated by Geneious by translating each sequence into the corresponding amino acids. Modeltest v1.2 (Posada \& Crandall 1998) was used to infer the most appropriate substitution model for each marker using the Akaike Information Criterion (AIC). 


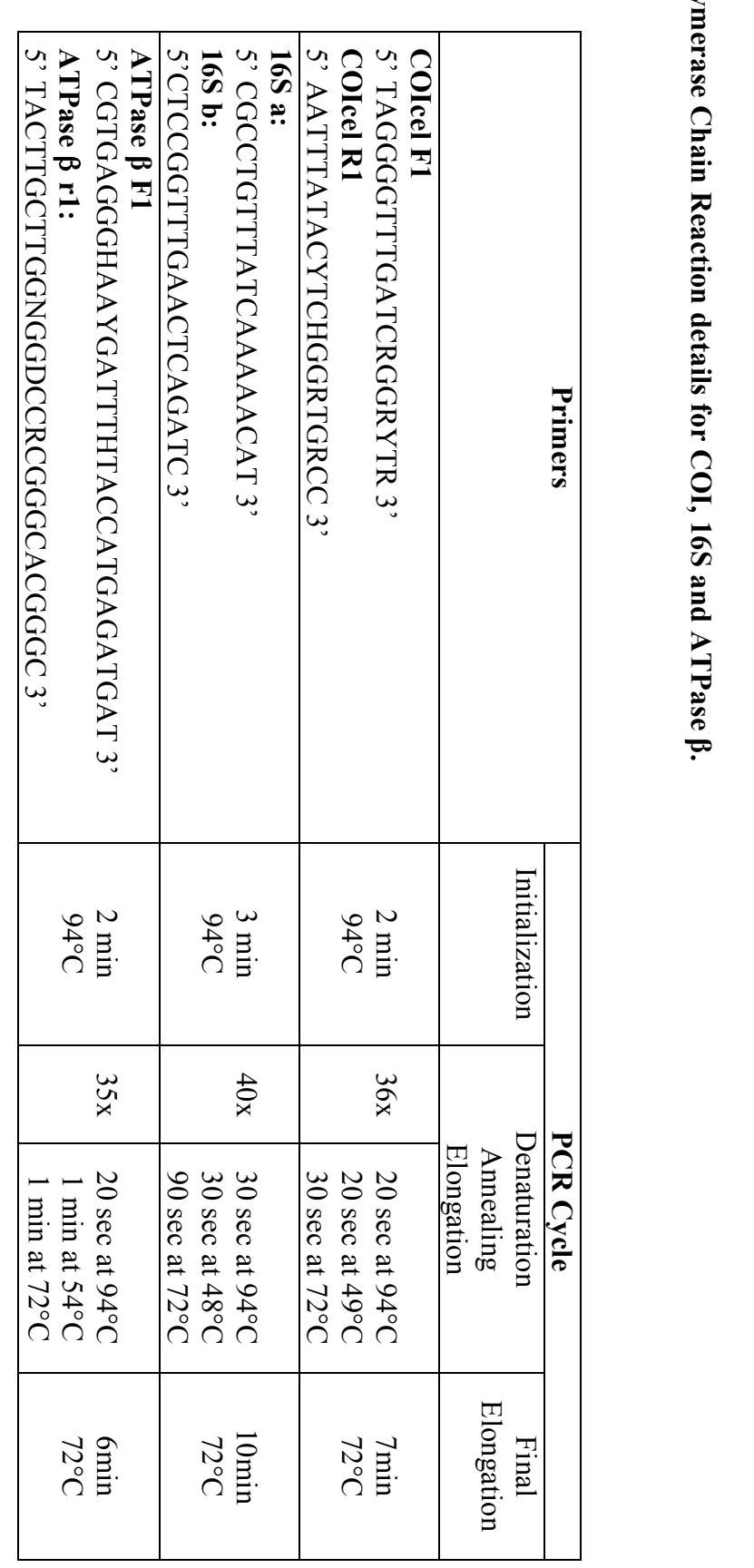


Analysis of transitions versus tranversions in DAMBE revealed no substitution saturation and thus no need to partition the data according to the codon position. Bayesian analysis was conducted in MrBayes 3.1.2 (Huelsenbeck \& Ronquist 2001) under the HKY+I substitution model for COI and the GTR+I model for 16S. Two replicate analyses of four simultaneous chains (1 cold) were run for 5,000,000 generations, sampling trees every 100 generations. Convergence and mixing were assessed using plots of log-likelihood values against generation and the average standard deviation of split frequencies: the first 5000 trees were discarded as burn-in. Trees sampled from the stationary phase of each replicate analysis were pooled to construct a single 50\% majority rule consensus tree with Bayesian posterior probabilities. Maximum parsimony (MP) analysis was conducted in TNT (Goloboff et al. 2008) on the concatenated data set using symmetric resampling of 100 replicates. Maximum likelihood (ML) analysis was carried out in GARLI (Zwickl 2006) on the concatenated data set with the same substitution models as described above for MrBayes. For ML, a bootstrap analysis using 100 repetitions of 10 different runs was employed to determine branch support, and a bootstrap consensus tree was generated using the majority rule extended consensus type implemented in the CONSENSE package in PHYLIP 3.69 (Felsenstein 2005).

Bayesian estimation of divergence times was implemented in BEAST v1.5.4 (Drummond \& Rambaut 2007) using an uncorrelated lognormal relaxed clock. A larger dataset of $16 \mathrm{~S}, 12 \mathrm{~S}$ and $\mathrm{COI}$ sequences from a wider range of Patellogastropoda taxa was used for this analysis (A.R. Wood \& J.P.A. Gardner, unpublished data, paper in prep.). For this larger dataset, COI $3^{\text {rd }}$ codon positions were excluded from the analysis due to substitution saturation. Prior distributions were defined for 2 fossil-based calibration points. The divergence of Nacella and Cellana was set to a minimum of $38 \mathrm{Ma}$ (lognormal distribution, offset $=38$, mean $=$ $1.0, \mathrm{SD}=1.0$ ), based on the earliest known Cellana fossil (Lindberg \& Hickman 1986). The divergence of Eoacmaea from other Patellogastropoda was set to a minimum of $100 \mathrm{Ma}$ (lognormal distribution, offset $=100$, mean $=1.5, \mathrm{SD}=1.0$ ), based on the earliest known Eoacmaea fossil (Akpan et al. 1982). Four analyses were run for 10 million generations each, with a sample frequency of 1000. After discarding the burn in of the first 1 million generations for each analysis, the 
remaining $36,004,000$ states $(36,004$ trees) were combined to obtain divergence time estimates. Effective sample sizes (ESS values) were all greater than 400 .

\subsubsection{Phylogeographic analysis}

Mitochondrial and nuclear DNA haplotype networks were constructed with TCS (Clement et al. 2000) using a concatenated mtDNA fragment of $851 \mathrm{bp}$ (425 bp of COI, $426 \mathrm{bp}$ of $16 \mathrm{~S}$ ) and a separate ATPase $\beta$ nDNA fragment of $338 \mathrm{bp}$. AMOVA analysis was performed in Arlequin V3.2 (Excoffier et al. 2005) for the nuclear and mitochondrial fragments separately. Nei's nucleotide diversity $(\pi)$, the mean number of nucleotide differences between groups and the number of shared mutations between groups was calculated in DNAsp v5.0 (Librado \& Rozas 2009).

Historical population expansion was tested using Fu's neutrality test with the concatenated 16S-COI fragment, calculated R2 (Ramos-Onsins and Rozas 2002) with DNAsp v5.0 and tested the significance of these statistics with 10,000 simulated samples. Additionally, a mismatch analysis was carried out (Rogers \& Harpending 1992) in Arlequin. Harpending's Raggedness Index (r; Harpending 1994) was calculated to evaluate any deviation from the sudden expansion model and the significance of $\mathrm{r}$ was tested with 10,000 bootstrap replicates. Intra-lineage coalescence time (i.e., time since the start of population expansion) was estimated with the formula $\mathrm{t}=\tau / 2 \mu$, where $\mathrm{t}$ is the number of years since a population expansion, $\tau$ a demographic parameter obtained with Arlequin, and $\mu$ is the mutation rate per locus per year. Confidence intervals for estimates of $\tau$ were obtained using 10,000 bootstrap replicates in Arlequin. I obtained $\mu$ from the BEAST analysis carried out on the larger Patellogastropod dataset. The 95\% Higher Posterior Density (HPD) values were used to estimate the time since population expansion.

\subsubsection{Population genetics analysis}

Each RAPD band was treated as an individual locus with two alleles (present or absent). Allele frequencies were estimated using the software AFLPSurv1.0 (Vekemans 2002a, 2002b) employing the Bayesian method of Zhivotovsky (1999) with a non-uniform prior distribution, under the assumption that bands of the same size were the same allele and that each RAPD locus is in Hardy Weinberg 
Equilibrium (HWE). The Zhivotovsky method permits computation of the frequency of each null allele (one absent band per observed band) from the sample size and the number of individuals in the sample that lack the band. Allelic frequencies were calculated assuming HWE.

Analysis of Molecular Variance (AMOVA) was carried out using GenAlEx v6 (Peakall \& Smouse 2006) by calculating an Fst analogue, PhiPT, which represents the proportion of variance among populations relative to total variance; this analogue is particularly suitable for the analysis of binary data (Peakall \& Smouse 2006). Ordination (Principal Component Analysis (PCA) - SPSS v17) was employed to explore the relationships (i.e., groupings) among all individuals based on the variation in the RAPD data set. Assignment tests were employed to determine what percentage of each population could be assigned correctly to their population of origin (= observed classification) based on RAPD variation, using the Doh assignment test calculator (http://www.biology.ualberta.ca/jbrzusto/Doh.php).

\subsection{Results}

\subsubsection{Phylogenetic analysis}

Bayesian analysis of $16 \mathrm{~S}$ and COI sequence data divided the Cellana strigilis complex into two lineages with a high support (Fig.2.2). One lineage has a posterior probability of 0.90 and is composed of the southwestern islands (Stewart, Snares, Auckland and Campbell islands), whereas the other lineage which has a posterior probability of 0.96 includes the northeastern islands (Antipodes, Bounty and Chatham islands). The grouping of the southwest lineage with Cellana denticulata was also well supported with a posterior probability of 0.99 . The BEAST analysis showed a mean rate of 0.00498 mutations per site per million years (95\% HPD: 0.00392 0.0612). The $95 \%$ confidence divergence time of the two C. strigilis lineages was estimated to be 1.85 to $7.06 \mathrm{Ma}$ (mean = 4.19 Ma). The MP and ML analyses were consistent with the Bayesian analyses (Fig.2.2 - refer to support values at nodes). 


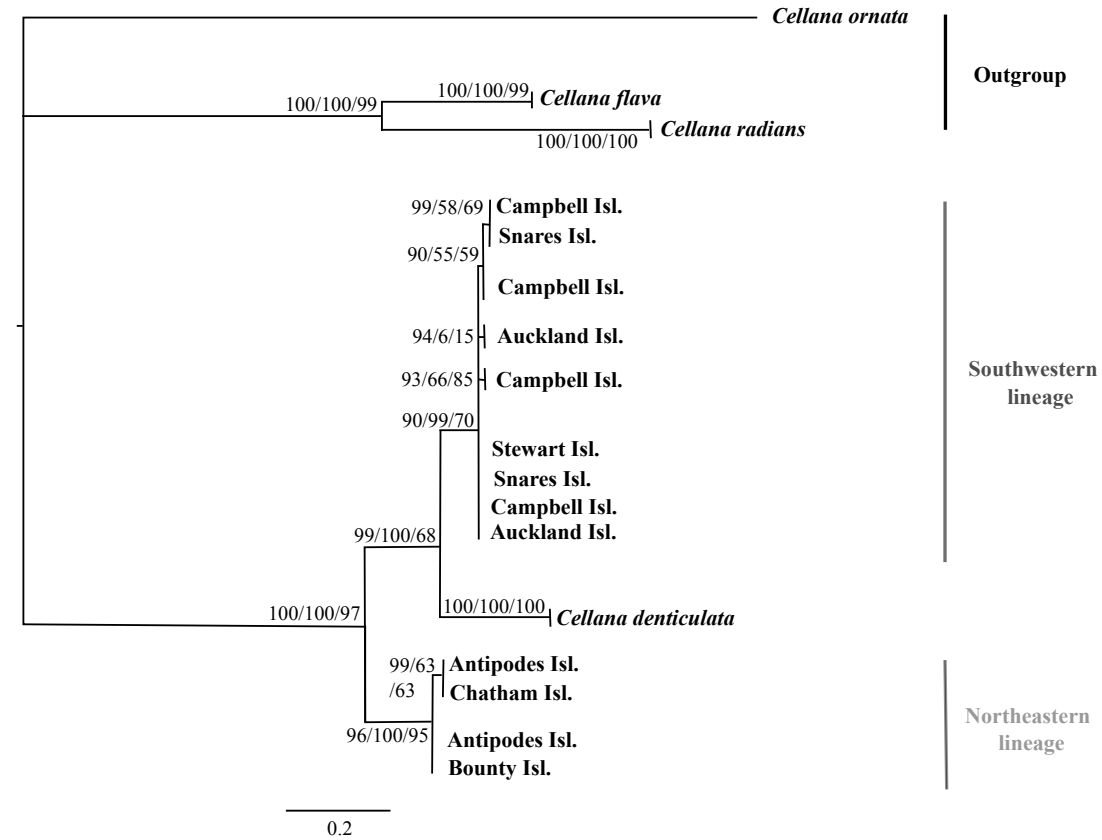

Figure 2.2.

Phylogram derived from Bayesian analysis in MrBayes of combined COI and 16S DNA sequences. Values at nodes represent posterior probabilities/maximum parsimony support/maximum likelihood support. The scale bar represents the branch length as a measure of substitution per site.

(a)
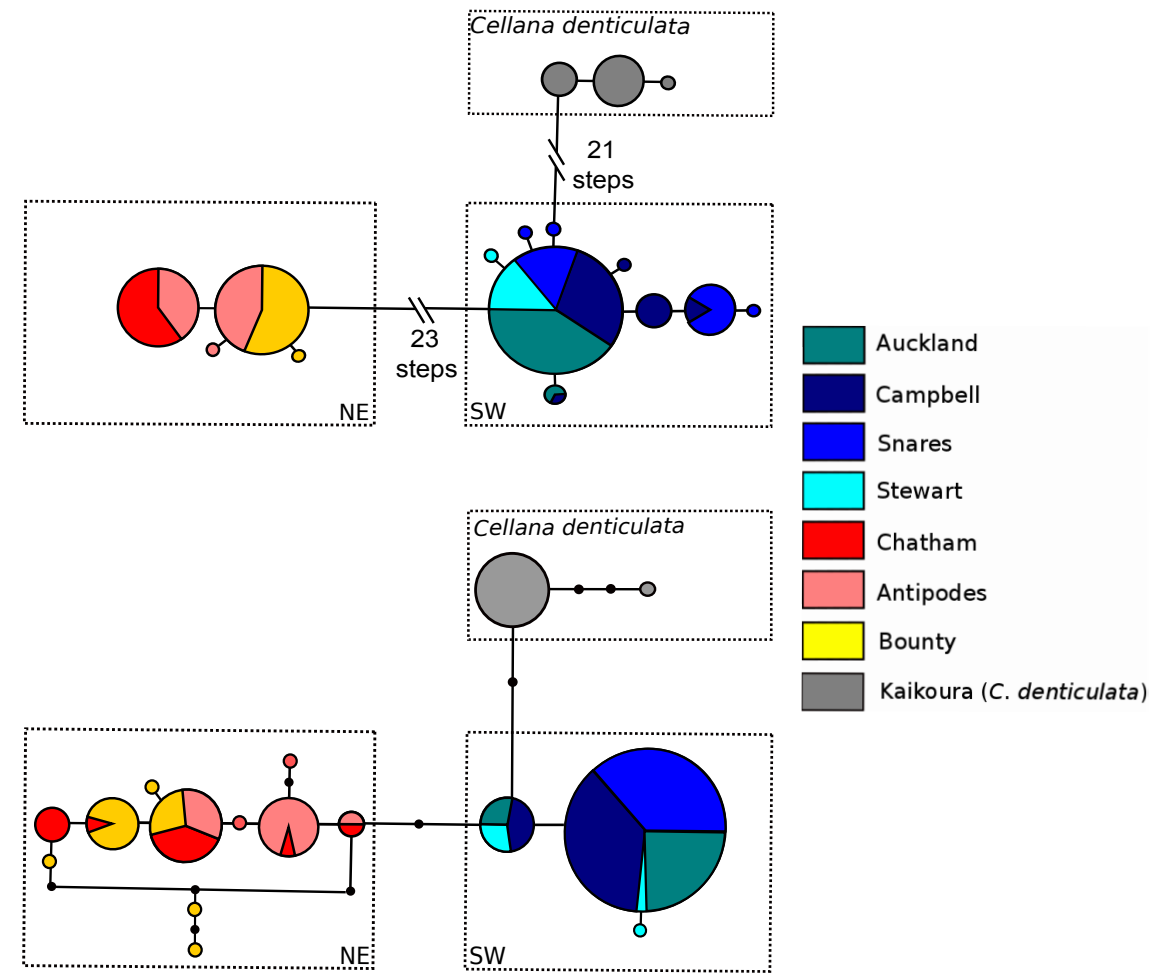

(b)

Figure 2.3.

Haplotype network from the concatenated 16S-COI fragment (a) and ATPase b fragment (b), created by TCS v1.21. NE, northeast group; SW, southwest group. 

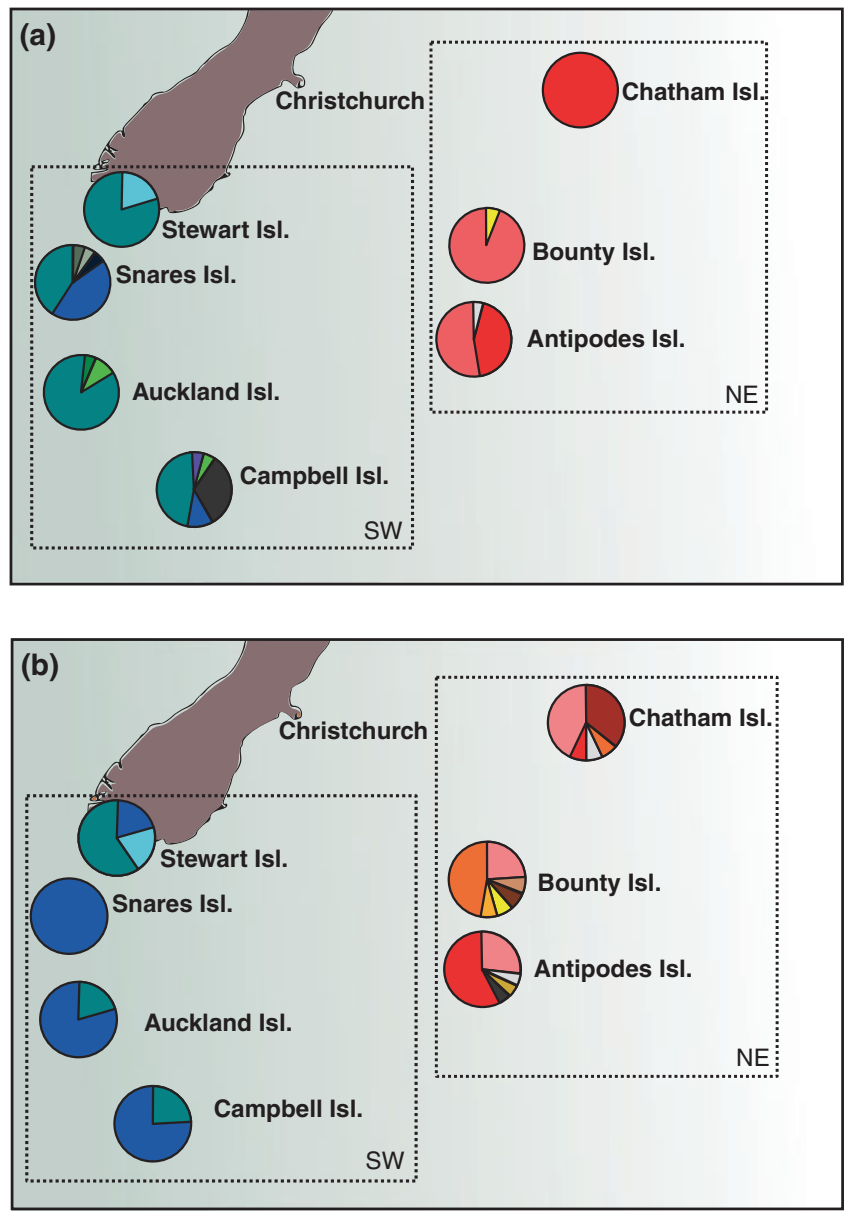

Figure 2.4.

Map of haplotype spatial distribution for (a) the 16S - COI fragment and (b) the ATPase b fragment. NE, northeast group; SW, southwest group.

\subsubsection{Phylogeographic analysis}

The concatenated 16S and COI network showed a total of 13 haplotypes, with 5 haplotypes shared by at least two islands and the remaining 8 haplotypes unique to a given island (Fig.2.3a). The haplotype network was split into two main groups, separated by 23 mutation steps. The first group corresponded to the southwest lineage with 9 different haplotypes (6 private), while the second group corresponded to the northeast lineage, with a total of 4 haplotypes ( 2 private). Overall nucleotide diversity was low $(\pi=0.014)$ and no mutation was shared between the two lineages. In the ATPase $\beta$ network (Fig.2.3b), 14 haplotypes were found, 8 of which were private to 
the island they belong to ( 1 in the southwest and 7 in the northeast). The two lineages segregated clearly, with 3 and 11 haplotypes for the southwest and northeast lineages respectively (Fig.2.4a and b). The overall nucleotide diversity was low $(\pi=0.00855)$ and no mutation was shared between the two lineages. The northeast lineage did not exhibit signs of historical population expansion, whereas population expansion was evident for the southwest lineage $(\mathrm{R} 2=0.088 ; \mathrm{Fs}=-29.43$ with $\mathrm{p}<0.001$; Table 2.3). The non-significant Harpending's Raggedness Index value supported these results $(\mathrm{r}=0.043 ; \mathrm{p}=0.826)$. Intra-lineage coalescence time was calculated with the $90 \%$ confidence range of $\tau$ (here $0.230<\tau<2.570$; Table 2.3) and was estimated to have occurred between 10,544 and 183,954 years ago depending on the assumed mutation rate (Table 2.3).

Table 2.3.

Mismatch analysis results, with Fu's Fs statistic, Ramos-Onsins and Rozas' statistic, Harpending's Raggedness Index (r), values of s estimated from a sudden expansion model with $90 \%$ credibility intervals in brackets, and the estimated starting time of the population expansion in years for the range of mutation rates defined previously. Boldface indicates population expansion.

\begin{tabular}{|c|cccc|ccc|}
\hline Lineage & Fs & R2 & r & $\tau$ & \multicolumn{3}{c|}{ Time of expansion (years) } \\
\cline { 2 - 8 } & & & & & $\mu=0.00392$ & $\mu=0.00498$ & $\mu=0.00612$ \\
\hline Northeast & 0.135 & 0.267 & 0.289 & 0.828 & - & - & - \\
& & & & $(0.063-1.748)$ & & & \\
Southwest & $\mathbf{- 2 7 . 7 5 2}$ & $\mathbf{0 . 0 8 8}$ & $\mathbf{0 . 0 4 3}$ & $\mathbf{1 . 3 8 3}$ & 16,462 & 12,958 & 10,544 \\
& & & & $\mathbf{( 0 . 2 3 0 - 2 . 5 7 0 )}$ & 183,954 & 144,799 & 117,826 \\
\hline
\end{tabular}

\subsubsection{Population genetics analysis}

In total, 58 loci were scored for 166 individuals (Table 2.4) and the number of RAPD bands scored for each primer ranged from 11 to 18 . Four multilocus genotypes were private to Antipodes, three to Stewart, one to Snares and one to Bounty. Eight and nine multilocus genotypes were private to the northeast and southwest lineages, respectively (Table 2.4). For the southwest lineage, AMOVA revealed that $54 \%$ of the 
variation of the RAPD data set was attributable to differences within each island and $46 \%$ among islands. For the northeast lineage, AMOVA showed that $62 \%$ of the

Table 2.4.

RAPD fragment frequencies per locus per population: bold fragments are *private to one island; **private to the northeast lineage; ***private to the southwest lineage. The mean number of number of polymorphic loci for each population

\begin{tabular}{|c|c|c|c|c|c|c|c|c|c|}
\hline & \multirow[b]{4}{*}{ Locus } & \multirow{4}{*}{$\begin{array}{l}\text { Overall } \\
\text { freq }\end{array}$} & \multicolumn{4}{|l|}{ Southwest } & \multicolumn{3}{|l|}{ Northeast } \\
\hline & & & Stewart & Auckland & Campbell & Snares & Antipodes & Bounty & Chathams \\
\hline & & & $N=5$ & $N=54$ & $N=23$ & $N=22$ & $N=24$ & $N=20$ & $N=18$ \\
\hline & & & freq_frag & & & & freq_frag & & \\
\hline \multirow[t]{13}{*}{ OPC_20 } & 750 & 0.596 & - & 0.907 & 1.000 & 0.727 & - & - & 0.611 \\
\hline & 833 & 0.169 & - & 0.296 & - & - & 0.500 & - & - \\
\hline & 1000 & 0.560 & 0.400 & 0.648 & 0.565 & 0.364 & 0.375 & 0.650 & 0.722 \\
\hline & 1125 & 0.277 & - & 0.389 & - & 0.545 & - & - & 0.722 \\
\hline & 1167 & 0.434 & 0.800 & 0.759 & 0.565 & - & - & 0.700 & - \\
\hline & 1250 & 0.301 & - & - & 0.783 & 0.545 & 0.833 & - & - \\
\hline & 1375 & 0.488 & - & 0.852 & - & 0.864 & - & 0.450 & 0.389 \\
\hline & 1417 & 0.223 & - & - & 1.000 & - & 0.583 & - & - \\
\hline & 1500 & 0.181 & 0.400 & - & - & 0.500 & 0.333 & 0.450 & - \\
\hline & $1675^{*}$ & 0.054 & - & - & - & - & 0.375 & - & - \\
\hline & $1750^{* * *}$ & 0.223 & - & - & - & - & 0.750 & 0.500 & 0.500 \\
\hline & $2250^{* *}$ & 0.554 & 1.000 & 0.907 & 1.000 & 0.682 & - & - & - \\
\hline & $2500^{* * *}$ & 0.241 & - & - & - & - & 1.000 & 0.800 & - \\
\hline \multirow[t]{11}{*}{ OPE_15 } & $375^{* *}$ & 0.054 & - & 0.056 & 0.261 & - & - & - & - \\
\hline & 625 & 0.560 & 1.000 & 0.852 & 0.826 & 0.455 & - & 0.650 & - \\
\hline & 750 & 0.620 & 0.600 & 1.000 & 1.000 & 1.000 & - & 0.050 & - \\
\hline & 1000 & 0.970 & 0.800 & 1.000 & 1.000 & 1.000 & 0.875 & 0.950 & 1.000 \\
\hline & 1167 & 0.042 & 0.200 & - & - & - & 0.083 & 0.200 & - \\
\hline & 1250 & 0.205 & - & - & - & 0.045 & 0.583 & 0.750 & 0.222 \\
\hline & $1375^{* *}$ & 0.488 & 1.000 & 1.000 & 0.957 & - & - & - & - \\
\hline & 1417 & 0.175 & - & - & - & 0.682 & - & - & 0.778 \\
\hline & $1500^{* *}$ & 0.428 & 0.800 & 0.741 & 0.565 & 0.636 & - & - & - \\
\hline & $1750^{*}$ & 0.012 & 0.400 & - & - & - & - & - & - \\
\hline & $2250^{* *}$ & 0.133 & - & 0.204 & 0.478 & - & - & - & - \\
\hline \multirow[t]{18}{*}{ OPI_07 } & $383^{* * *}$ & 0.024 & - & - & - & - & 0.083 & - & 0.111 \\
\hline & 440 & 0.795 & 0.800 & 0.981 & 1.000 & 0.955 & 0.375 & 0.500 & 0.667 \\
\hline & $470^{*}$ & 0.036 & - & - & - & - & 0.250 & - & - \\
\hline & $500^{* * *}$ & 0.096 & - & - & - & - & 0.042 & 0.550 & 0.222 \\
\hline & 583 & 0.084 & - & - & - & 0.182 & 0.083 & 0.350 & 0.056 \\
\hline & 625 & 0.090 & - & 0.130 & - & 0.273 & 0.083 & - & - \\
\hline & 667 & 0.741 & - & 0.759 & 0.391 & 0.864 & 0.875 & 0.900 & 0.833 \\
\hline & $690^{*}$ & 0.006 & 0.200 & - & - & - & - & - & - \\
\hline & $750^{* * *}$ & 0.084 & - & - & - & - & 0.208 & 0.150 & 0.333 \\
\hline & 833 & 0.500 & - & 0.907 & - & - & 0.875 & 0.150 & 0.556 \\
\hline & $875^{* *}$ & 0.542 & - & 0.944 & 0.957 & 0.773 & - & - & - \\
\hline & 917 & 0.133 & 0.800 & - & - & 0.045 & - & 0.850 & - \\
\hline & 1000 & 0.584 & 0.200 & 0.944 & 0.652 & 0.909 & 0.083 & 0.350 & 0.056 \\
\hline & $1125^{*}$ & 0.024 & 0.800 & - & - & - & - & - & - \\
\hline & $1250^{* * *}$ & 0.054 & - & - & - & - & 0.042 & - & 0.444 \\
\hline & $1325^{* * *}$ & 0.133 & - & - & - & - & 0.167 & 0.900 & - \\
\hline & $1625^{* *}$ & 0.090 & - & 0.093 & 0.435 & - & - & - & - \\
\hline & 1750 & 0.084 & 0.600 & - & - & 0.455 & 0.042 & - & - \\
\hline \multirow[t]{6}{*}{ OPG_16 } & $440^{*}$ & 0.024 & - & - & - & 0.182 & - & - & - \\
\hline & $688^{* *}$ & 0.367 & - & 0.667 & 0.565 & 0.545 & - & - & - \\
\hline & 750 & 0.024 & - & - & - & - & 0.083 & - & 0.111 \\
\hline & 875 & 0.133 & - & - & - & 0.773 & - & 0.250 & - \\
\hline & 938 & 0.482 & 0.600 & 0.722 & 1.000 & - & 0.125 & 0.600 & - \\
\hline & 1000 & 0.651 & 1.000 & 0.889 & 0.783 & 0.273 & 0.500 & 0.300 & 0.722 \\
\hline
\end{tabular}


Table 2.4 (Continued)

\begin{tabular}{|c|c|c|c|c|c|c|c|c|c|}
\hline \multirow[b]{4}{*}{ Locus } & \multirow{4}{*}{\multicolumn{2}{|c|}{ Overall freq }} & \multicolumn{4}{|l|}{ Southwest } & \multicolumn{3}{|l|}{ Northeast } \\
\hline & & & \multirow{2}{*}{$\begin{array}{l}\text { Stewart } \\
N=5\end{array}$} & \multirow{2}{*}{$\begin{array}{l}\text { Auckland } \\
N=54\end{array}$} & \multirow{2}{*}{$\begin{array}{l}\text { Campbell } \\
N=23\end{array}$} & \multirow{2}{*}{$\begin{array}{l}\text { Snares } \\
N=22\end{array}$} & \multirow{3}{*}{$\begin{array}{l}\text { Antipodes } \\
N=24 \\
\text { freq_frag }\end{array}$} & \multirow{3}{*}{$\begin{array}{l}\text { Bounty } \\
N=20\end{array}$} & \multirow{3}{*}{$\begin{array}{l}\text { Chathams } \\
N=18\end{array}$} \\
\hline & & & & & & & & & \\
\hline & & & \multicolumn{4}{|l|}{ freq_frag } & & & \\
\hline 1083 & 0.042 & \multicolumn{2}{|c|}{0.200} & - & - & - & 0.250 & - & - \\
\hline $1125^{* * *}$ & 0.139 & \multicolumn{2}{|c|}{-} & - & - & - & 0.333 & 0.250 & 0.556 \\
\hline 1250 & 0.193 & \multicolumn{2}{|l|}{ - } & 0.259 & 0.348 & 0.045 & 0.167 & 0.150 & 0.111 \\
\hline $1375^{*}$ & 0.018 & \multicolumn{2}{|l|}{-} & - & - & - & - & 0.150 & - \\
\hline 1500 & 0.633 & \multicolumn{2}{|c|}{1.000} & 0.981 & 0.826 & - & 0.583 & 0.700 & - \\
\hline 1625 & 0.187 & \multicolumn{2}{|c|}{-} & - & - & 0.091 & 0.792 & 0.500 & - \\
\hline $1750^{* * *}$ & 0.084 & \multicolumn{2}{|l|}{-} & - & - & - & - & 0.150 & 0.611 \\
\hline $2000^{*}$ & 0.048 & \multicolumn{2}{|l|}{-} & - & - & - & 0.333 & - & - \\
\hline 2250 & 0.096 & - & & 0.130 & 0.304 & - & - & 0.100 & - \\
\hline $2500^{*}$ & 0.054 & - & & - & - & - & 0.375 & - & - \\
\hline Number of polym & orphic loci & & $21(36.2 \%)$ & $22(37.9 \%)$ & $24(41.4 \%)$ & $28(39.7 \%)$ & $25(43.1 \%)$ & $29(50 \%)$ & $20(34.5 \%)$ \\
\hline $\begin{array}{l}\text { Mean number of } \mathrm{f} \\
\text { per individual }\end{array}$ & ragments & & $13.60 \pm 1.35$ & $18.01 \pm 2.53$ & $17.26 \pm 1.80$ & $14.41 \pm 3.23$ & $13.04 \pm 2.73$ & $14.00 \pm 3.72$ & $10.33 \pm 3.00$ \\
\hline
\end{tabular}

RAPD, randomly amplified polymorphic DNA.

Table 2.5.

PhiPT estimates (below diagonal) and associated P-values (above diagonal) calculated in GenAIEx V6.3 (a) for the southwest lineage and (b) for the northeast lineage. Boldface values are significantly different to zero at the $5 \%$ level, based on 999 permutations.

(a)

\begin{tabular}{|l|cccc|}
\hline & Stewart Isl. & Auckland Isl. & Campbell Isl. & Snares Isl. \\
\hline Stewart Isl. & - & 0.01 & 0.01 & 0.01 \\
Auckland Isl. & $\mathbf{0 . 5 2 0}$ & - & 0.01 & 0.01 \\
Campbell Isl. & $\mathbf{0 . 4 9 3}$ & $\mathbf{0 . 3 7 7}$ & - & 0.01 \\
Snares Isl. & $\mathbf{0 . 5 3 4}$ & $\mathbf{0 . 4 8 3}$ & $\mathbf{0 . 5 0 4}$ & - \\
\hline
\end{tabular}

(b)

\begin{tabular}{|l|ccc|}
\hline & Antipodes Isl. & Bounty Isl. & Chatham Isl. \\
\hline Antipodes Isl. & - & 0.01 & 0.01 \\
Bounty Isl. & $\mathbf{0 . 3 3 0}$ & - & 0.01 \\
Chatham Isl. & $\mathbf{0 . 3 9 7}$ & $\mathbf{0 . 4 2 0}$ & - \\
\hline
\end{tabular}




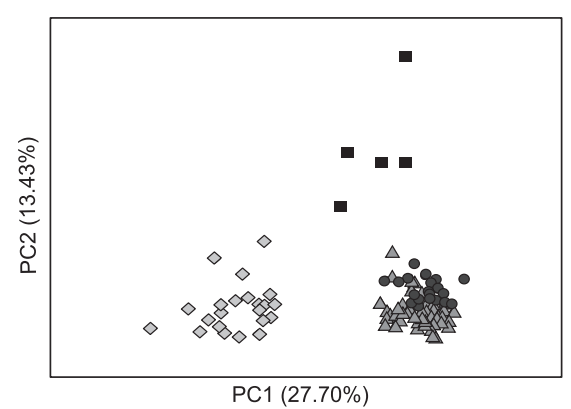

- Stewart IsI.

- Campbell Isl.

$\diamond$ Snares Is|.

$\triangle$ Auckland Isl.

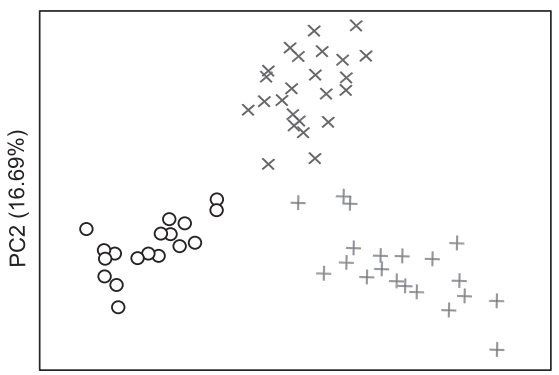

+ Bounty IsI

$\times$ Antipodes IsI

Chatham IsI

PC1 $(19.03 \%)$

Figure 2.5.

Principal component 2 (PC2) as a function of PC1 from the principal component analysis of the randomly amplified polymorphic DNA data set, within the southwest (top panel) and northeast (bottom panel) groups. Brackets contain the percentage of the total variance associated with the axis.

Table 2.6.

Assignment test results: Classification matrix - rows are observed classifications, columns are predicted classifications. Boldface represents correct classification of an individual to its original population.

\begin{tabular}{|l|lllllll|}
\hline & Stewart & Bounty & Chathams & Auckland & Campbell & Snares & Antipodes \\
\hline Stewart & $\mathbf{5}$ & & & & & & \\
Bounty & & $\mathbf{2 0}$ & & & & & \\
Chathams & & & $\mathbf{1 8}$ & & & & \\
Auckland & 1 & & & $\mathbf{5 2}$ & 1 & $\mathbf{2 2}$ & $\mathbf{2 4}$ \\
Campbell & & & & & $\mathbf{2 3}$ & & \\
Snares & & & & & & & \\
Antipodes & & & & & & & \\
\end{tabular}


variation was located within islands and 38\% among islands. Pairwise PhiPT estimates were significant for all islands in both lineages (Table 2.5). Principal Component Analysis (PCA) of RAPD bands from limpets of the southwest lineage separated successfully Snares Island and Stewart Island from the rest. However, Campbell and Auckland island individuals overlapped and thus could not be separated by the analysis (Fig.2.5). The plot represents $35.13 \%$ of the variation in the data set. For the northeastern lineage, all three islands were separated from each other. The plot represents $35.72 \%$ of the variation in the data set (Fig.2.5). The assignment test conducted on the RAPD data set showed that each individual was attributed to its island of origin, with the exception of two individuals collected from the Auckland Islands that were assigned to Stewart Island and to Campbell Island, respectively (Table 2.6). Overall classification success rate was 164 of 166 individuals (98.8\%).

\subsection{Discussion}

\subsubsection{Phylogenetic relationships and taxonomic status of Cellana strigilis}

Based on shell ovality, colour, pattern, number of ribs, radula aspect and apex position, Powell (1979) described six subspecies of Cellana strigilis from coastal regions of subantarctic islands of the Southern Ocean. Subsequently Goldstien et al. (2009) used molecular methods to identify two genetically distinct lineages separating the northeast island group (Antipodes - C. s. bollonsi, Bounty - C. s. oliveri, Chathams - C. s. chathamensis) and southwest island group (Auckland and CampbellC. s. strigilis, Stewart and the lower part of the South Island of NZ - C. s. redimiculum) at six of the seven islands.

The partial sequences of the mitochondrial genes COI and 16S as well as the nuclear gene confirm the existence of the two lineages. The addition of individuals from Snares Island (C. s. flemingi) completes the sampling of the species complex and confirms the position of this population within the southwest group, consistent with its geographical location. The present study also shows strong support for the grouping of $C$. denticulata with the southwest lineage of $C$. strigilis, in contrast to the proposed weak grouping with the northeast lineage reported by Goldstien et al. (2009). Despite the disagreement on the positioning of C. denticulate, both studies 
indicate that the $C$. strigilis complex is not monophyletic and highlights the need to reconsider the taxonomic status of the C. strigilis complex, which forms a paraphyletic group, comprised of two different evolutionary lineages.

\subsubsection{Phylogeography and colonisation of the New Zealand subantarctic islands}

Both nuclear (nDNA) and mitochondrial (mtDNA) haplotype networks show completely separate northeast and southwest lineages, with no shared haplotypes, indicating the absence of recent gene flow between them. Whilst the mitochondrial and nuclear networks have very similar overall haplotype diversities, they show contrasting patterns of diversity within the two lineages. In the southwest lineage, haplotype diversity is higher for mtDNA than for nDNA, but vice versa in the northeast lineage. While further research is required to better understand this difference, it is possible that the ATPase $\beta$ or the DNA region where it is located is under selective pressure, although variation due to sample sizes per island may also be important. The clear differentiation between the two lineages and the presence of multiple private haplotypes among islands within each lineage suggests that only one or a few infrequent colonisation events have occurred for each of the two island groups (northeast and southwest), and that subsequently each individual island has been largely or totally isolated (in terms of genetic connectivity) from all other islands. The low nucleotide diversity of the two lineages indicates a recent colonisation, as suggested by Goldstien et al. (2009). The fact that some islands, like Antipodes and Chatham, are younger than 5 million years old also points to a geologically recent colonisation which most probably post-dates the colonisation of islands such as Snares and Bounty, which date to $180 \mathrm{Ma}$.

The respective island ages, the phylogenetic analyses and the surface hydrography of the Southern Ocean support the hypothesis of a single colonisation event to the southwest islands and another independent colonisation event to the northeast island group. Subsequently, radiations or range expansions within each group (northeast and southwest) coupled with ongoing geographic isolation (both within and between island groups) and a possible selection (nuclear DNA in the southwest group) have given rise to the genetically distinct island-specific limpet taxa. However, it is impossible to know where the founder population was from and if 
it was the same population which founded both island groups, leading to each lineage. This study illustrates the impact of isolation by distance on population genetic structure leading ultimately to speciation. Here, limpet populations from each island have their own allelic composition and history, and should therefore be considered as different from each other.

\subsubsection{Post-glacial demographic expansion}

Demographic variation, such as reduction in the number of reproductively active individuals in a population (e.g., bottlenecks), followed by population expansion may modify the primary genetic signal left by a colonisation event. Since the establishment of a permanent ice sheet in the Antarctic approximately $34 \mathrm{Ma}$ (Tripati et al. 2005), glacial/interglacial episodes have shaped the distributions of many species across the Southern Ocean. However, little is known about the actual effect of the last glacial maximum (LGM - about 23,000 years ago) on the Southern Hemisphere biota, other than the occurrence of species range contractions into icefree refugia during glacial maxima, followed by massive population expansions during the interglacial periods (Rogers 2007; Fraser et al. 2009). For example, a recent study of the bull kelp, Durvillea antarctica, showed that the coastal biota of NZ subantarctic islands display a significantly more pronounced genetic structuring than all other subantarctic islands (Fraser et al. 2009). The authors hypothesised that the use of the NZ subantarctic islands as an ice-free refugium during the last glaciation event resulted in a distinct "refuge area genetic signature" (high diversity across small spatial scales) as opposed to a "recolonised area genetic signature" (low diversity across large spatial scales).

Evidence of pronounced genetic structuring for the Cellana strigilis complex among the Southern Ocean islands is consistent with the genetic signal expected from the sea ice refugium hypothesis (Fraser et al. 2009). Mismatch analysis gives an indication of population expansion within the southwest lineage of C. strigilis (Auckland, Campbell, Snares and Stewart islands) with a coalescence time dating from 10,544 to 183,954 ya. This expansion occurred long after the minimum estimated divergence time (1.85 Ma) of the two lineages and cannot be attributed to it. It is thus impossible to assess with certainty the geographic location of the source 
population and colonisation time of the NZ subantarctic islands. However, this coalescent time of population expansion encompasses the LGM, one of the coldest glacial peaks of the late Pleistocene. Although sea ice did not reach the NZ subantarctic islands during the LGM, evidence from deposits on Auckland and Campbell islands points to extensive land ice coverage of the southwest islands, with glaciers nearly completely covering the current emergent landmass of the Auckland Islands and a considerable portion of Campbell Islands (McGlone 2002). The Chatham, Snares, Bounty and Antipodes islands do not have glacial deposits, which is consistent with their lower latitude and elevation (McGlone et al. 2000; McGlone 2002). Although intertidal and shallow subtidal species such as $C$. strigilis strigilis and D. antarctica were able to survive on the Auckland and Campbell islands, their effective population sizes may have been reduced as they experienced habitat loss and/or increased physiological stress. The final retreat of the land ice would have permitted new colonisation of the intertidal and shallow subtidal regions and an increase in population size, leading to the present observation of shared haplotypes. The estimated time range for population expansion in the southwest lineage encompasses the successive glaciation events of the late Pleistocene $(126,000$ to 10,000 years ago) and is thus congruent with the LGM hypothesis. The absence of a signal of population expansion within the northeast island group is also consistent with their ice-free status during the LGM.

\subsubsection{Contemporary connectivity among or self-recruitment within the islands?}

Dispersal for many marine taxa is most usually achieved via a pelagic larval stage and there is a reasonably strong correlation between pelagic larval duration (PLD) and population genetic structure (e.g., Bradbury et al. 2008; Ross et al. 2009; Kelly \& Palumbi 2010; White et al. 2010). Oceanographic modelling of surface currents and the known PLD of Cellana limpets strongly indicates that there is likely to be little contemporary larval connectivity between island-pairs (Chiswell 2009). It was noted that the larval dispersal time from Antipodes to Bounty islands falls within the PLD of the $C$. strigilis complex. However, given their isolation, it seems likely that larval dispersal between the islands is rare. 
Although it is very unlikely that pelagic larval dispersal among the islands does occur, dispersal can be achieved in other ways. For example, there is increasing evidence of the importance of rafting (e.g. on macroalgae) as a means of dispersal for adults and juveniles (Thiel \& Gutow 2005; Nikula et al. 2010). Directly relevant to the present study, Fraser et al. (2010) reported multiple juvenile C. strigilis individuals on bull kelp drifting $13 \mathrm{~km}$ off the Campbell Islands shoreline. They also observed a $C$. strigilis individual on a raft collected from Dunedin (South Island, New Zealand) that they identified genetically as being from either Snares or Auckland islands. These observations emphasise the potential for $C$. strigilis to disperse by rafting, even if only as a rare event.

There was a pronounced within-lineage genetic differentiation, which contrast to the absence of genetic differentiation within the two lineages reported by Goldstien et al. (2009). The mtDNA and nDNA haplotype analyses and the RAPDs analyses both point strongly to island-specific allelic composition for the limpet populations. Such identities can only be maintained with very limited gene flow among islands, which in turn emphasises the role of self-recruitment in maintaining populations and their individual identities. In a contemporary sense this is most apparent from the assignment tests which were able to correctly classify all northwest lineage individuals and all but two of the southwest limpets to their populations of origin. While these results provide evidence of self-recruitment for each island population and an island-specific genetic signature, the RAPD assignment analyses suggest that there may be some very recent (possibly ongoing) limited gene flow among islands within the southwest group, most probably via kelp rafting rather than larval exchange. These results confirm the findings of other studies of the coastal marine biota of small, remote islands that despite limited population sizes and pelagic larval dispersal can exhibit self-recruitment and genetic structuring on small spatial scales (e.g., Rivera et al. 2004; Johnson \& Black 2006; Bird et al. 2007; Wood \& Gardner 2007; DeBoer et al. 2008).

\subsection{Conclusions}

Analysis of six putative island-endemic limpet taxa has confirmed the existence of two distinct evolutionary lineages within which there is pronounced 
island-specific genetic diversity. My analyses support two (or only a very small number of) independent colonisation events, one to the northeast and one to the southwest island groups, with subsequent range expansion within these groups. The significance of these islands as refugia during the LGM and the importance of rafting as a means of long-distance dispersal are highlighted. The genetic isolation of each population of limpets has given rise to island-endemic taxa that are supported by selfrecruitment. This study illustrates how historical factors such as geological age of islands and past climatic events impact and shape the genetic structuring of natural populations. These findings add to a small but growing body of knowledge about contemporary population connectivity among coastal populations of remote islands in large oceans, and the distance barrier to gene flow that exists in the sea (despite its continuous medium) for most taxa.

\subsection{References}

Adams CJ (1981) Migration of late Cenozoic volcanism in the South island of New Zealand and the Campbell plateau. Nature, 294, 153-155.

Akpan EB, Farrow GE, Morris N (1982) Limpet grazing on Cretaceous algal-bored ammonites. Paleobiology, 25, 361-367.

Apte S, Star B, Gardner JPA (2003) A comparison of genetic diversity between cultured and wild populations, and a test of genetic introgression in the New Zealand greenshell mussel, Perna canaliculus (Gmelin 1791). Aquaculture, 219, 193-220.

Avise JC (2000) Phylogeography: the history and formation of species. Harvard University Press, Cambridge, MA. pp 447.

Bird CE, Holland BS, Bowen BW, Toonen RJ (2007) Contrasting phylogeography in three endemic Hawaiian limpets (Cellana spp.) with similar life histories. Molecular Ecology, 16, 3173-3186. 
Blair MW, Astudillo C Rengifo J, Beebe SE, Graham R (2011) QTL analyses for seed iron and zinc concentrations in an intra-genepool population of Andean common beans (Phaseolus vulgaris L.). Theoretical and Applied Genetics, 122, $511-521$.

Bradbury IR, Laurel B, Snelgrove PVR, Bentzen P, Campana SE (2008) Global patterns in marine dispersal estimates: the influence of geography, taxonomic category and life history. Proceedings of the Royal Society of London B, 275, 1803-1809.

Chiswell SM (2009) Colonisation and connectivity by intertidal limpets among New Zealand, Chatham and Sub-Antarctic Islands. II. Oceanographic connections. Marine Ecology Progress Series, 388, 121-135.

Clement M, Posada D, Crandall KA (2000) TCS: a computer program to estimate gene genealogies. Molecular Ecology, 9, 1657-1660.

Corpuz GC (1983) Life history traits influencing vertical zonation in the Hawaiian intertidal species of Cellana. University of Hawaii. Honolulu.

Cowen RK, Paris CB, Srinivasan A. (2006) Scaling of connectivity in marine populations. Science, 311, 522-527.

DeBoer TS, Subia MD, Erdmann MV, Kovitvongsa K, Barber PH (2008) Phylogeography and limited genetic connectivity in the endangered giant boring clam, Tridacna crocea, across the Coral Triangle. Conservation Biology, 22, 1255-1266.

Denison RE, Coombs DS (1977) Radiometric ages for some rocks from Snares and Auckland Islands, Campbell Plateau. Earth and Planetary Science Letters, 34, 23-29. 
Dlusskaya EA, McMullen LM, Ganzle MG (2011) Characterization of an extremely heat-resistant Escherichia coli obtained from a beef processing facility. Journal of Applied Microbiology, 110, 840-849.

Drummond AJ, Rambaut A (2007) BEAST: Bayesian evolutionary analysis by sampling trees. BMC Evolutionary Biology, 7, 214-221.

Drummond AJ, Ashton B, Cheung M, Heled J, Kearse M, Moir R, Stones-Havas S, Thierer T, Wilson A (2009) Geneious v 4.7, Available from http://www.geneious.com/

Excoffier L, Laval G, Schneider S (2005) ARLEQUIN V 3.0: an integrated software package for population genetics data analysis. Evolutionary Bioinformatics Online, 1, 47-50.

Fell HB (1962) West-Wind-Drift dispersal of Echinoderms in the Southern Hemisphere. Nature, 193, 759-761.

Felsenstein J (2005) PHYLIP (Phylogeny Inference Package) version 3.6. Distributed by the author. Department of Genome Sciences, University of Washington, Seattle.

Fevolden SE, Schneppenheim R (1989) Genetic Homogeneity of Krill (Euphausia superba Dana) in the Southern Ocean. Polar Biology, 9, 533-539.

Fraser CI, Nikula R, Spencer HG, Waters JM (2009) Kelp genes reveal effects of subantarctic sea ice during the Last Glacial Maximum. Proceedings of the National Academy of Sciences USA, 106, 3249-3253.

Fraser CI, Nikula R, Waters JM (2011) Oceanic rafting of a coastal community. Proceedings of the Royal Society of London, B, 278, 649-655. 
Garbary D (1987) A critique of traditional approaches to seaweed distribution in light of the development of vicariance biogeography. Helgolander Meeresunters, 41, 235-244.

Goldstien SJ, Gemmell NJ, Schiel DR (2006) Molecular phylogenetics and biogeography of the nacellid limpets of New Zealand (Mollusca: Patellogastropoda). Molecular Phylogenetics and Evolution, 38, 261-265.

Goldstien SJ, Gemmell NJ, Schiel DR (2009) Colonisation and connectivity by intertidal limpets among New Zealand, Chatham and Sub-Antarctic Islands. I. Genetic connections. Marine Ecology Progress Series, 388, 111-119.

Goloboff PA, Farris JS, Nixon KC (2008) TNT, a free program for phylogenetic analysis. Cladistics, 24, 774-786.

Harpending HC (1994) Signature of ancient population growth in a low-resolution mitochondrial DNA mismatch distribution. Human biology, 66, 591-600.

Heads, M (2005) Towards a panbiogeography of the seas. Biological Journal of the Linnean Society, 84, 675-723.

Hellberg ME, Burton RS, Hedgecock D, Neigel JE, Palumbi SR (2002) Genetic assessment of connectivity among marine populations. Bulletin of Marine Science, 70, 273-290.

Huelsenbeck JP, Ronquist F (2001) MRBAYES: Bayesian inference of phylogenetic trees. Bioinformatics, 17, 754-755.

Hunter RL, Halanych KM (2008) Evaluating Connectivity in the Brooding Brittle Star Astrotoma agassizii across the Drake Passage in the Southern Ocean. Journal of Heredity, 99, 137-148.

Jarman SN, Ward RD, Elliott NG (2002) Oligonucleotide primers for PCR amplification of Coelomate introns. Marine Biotechnology, 4, 347-355. 
Johnson M, Black R (2006) Islands increase genetic subdivision and disrupt patterns of connectivity of intertidal snails in a complex archipelago. Evolution, 60 , 2498-2506.

Jones TC, Gemmill CEC, Pilditch CA (2008) Genetic variability of New Zealand seagrass (Zostera muelleri) assessed at multiple spatial scales. Aquatic Botany, 88, 39-46.

Kelly RP, Palumbi SR (2010) Genetic structure among 50 species of the northeastern Pacific rocky intertidal community. PLoS One, 5, 1-13.

Klinck JM, Nowland WD Jr (2001) Antarctic Circumpolar Current. Encyclopedia of Ocean Science, Academic Press, Waltham, Massachusetts, 151-159.

Knox GA (1980) Plate tectonics and the evolution of intertidal and shallow-water benthic biotic distribution patterns of the Southwest Pacific. Palaeogeography Palaeoclimatology Palaeoecology, 31, 267-297.

Lee DE, Lee WG, Mortimer N (2001) Where and why have all the flowers gone? Depletion and turnover in the New Zealand Cenozoic angiosperm flora in relation to palaeogeography and climate. Australian Journal of Botany, 49, 341-356.

Lewis K, Nodder SD, Carter L (2007) Zealandia: the New Zealand continent. Te Ara the Encyclopedia of New Zealand. http://www.teara.govt.nz/EarthSeaAndSky/OceanStudyAndConservation/Sea FloorGeology/1/en.

Librado P, Rozas J (2009) DnaSP v5: A software for comprehensive analysis of DNA polymorphism data. Bioinformatics, 25, 1451-1452.

Lindberg DR, Hickman CS (1986) A new anomalous giant limpet from the Oregon Eocene (Mollusca: Patellida). Journal of Paleontology, 60, 661-668. 
Macaya Horta EC, Zuccarello GC (2010) DNA barcoding and genetic divergence in the giant kelp Macrocystis (Laminariales). Journal of Phycology, 46, 736742.

Matoba H, Inaba K, Nagano K, Uchiyama H (2001) Use of RAPD analysis to assess the threat of interspecific hybridization to the critically endangered Polemonium kiushianum in Japan. Journal of Plant Research, 124, 125-130.

McDowall RM (1970) The galaxiid fishes of New Zealand. Bulletin of the Museum of Comparative Zoology, 139, 341-432.

McDowall RM (1978) Generalized Tracks and Dispersal in Biogeography. Systematic Zoology, 27, 88-104.

McGlone MS (2002) The Late Quaternary peat, vegetation and climate history of the Southern Oceanic Islands of New Zealand. Quaternary Science Reviews, 21, 683-707.

McGlone MS, Wilmshurst JM, Wiser SK (2000) Late glacial and Holocene vegetation and climatic change on Auckland Island, Subantarctic New Zealand. The Holocene, 10, 719-728.

Michaux B, Leschen RAB (2005) East meets west: biogeology of the Campbell Plateau. Biological Journal of the Linnean Society, 86, 95-115.

Nakano T, Osawa T (2007) Worldwide phylogeography of limpets of the order Patellogastropoda: molecular, morphological and paleontological evidence. Journal of Molluscan Studies, 73, 79-99.

Nelson G, Latiges PY (2001) Gondwana, vicariance biogeography and the New York school revisited. Australian Journal of Botany, 49, 389-409. 
Nikula R, Fraser CI, Spencer HG, Waters JM (2010) Circumpolar dispersal by rafting in two subantarctic kelp-dwelling crustaceans. Marine Ecology Progress Series, 405, 221-230.

O'Loughlin PM, Waters JM (2004) A molecular and morphological revision of genera of Asterinidae (Echinodermata: Asteroidea). Memoirs of Museum Victoria, 61, 1-40.

Palumbi SR, Martin A, Romano S, McMillan WS, Stice S, Grabowski G (1991) The Simple Fools Guide to PCR, University of Hawaii Press, Honolulu, HI.

Peakall R, Smouse PE (2006) Genalex 6: genetic analysis in Excel. Population genetic software for teaching and research. Molecular Ecology Notes, 6, 288295.

Peredo EL, Revilla MA, Jimenez-Alfaro B, Bueno A, Prieto JAF, Abbott RJ (2009) Historical biogeography of a disjunctly distributed, Spanish alpine plant, Senecio boissieri (Asteraceae). Taxon, 58, 883-892.

Pole M (1994) The New Zealand Flora-Entirely Long-Distance Dispersal? Journal of Biogeography, 21, 625-635.

Posada D, Crandall KA (1998) Modeltest: testing the model of DNA substitution .Bioinformatics, 14, 817-818.

Powell AWB (1979) New Zealand Mollusca - Marine, Land and Freshwater Shells, Ed. Collins, Auckland.

Ramos-Onsins SE, Rozas J (2002) Statistical properties of new neutrality tests against population growth. Molecular Biology and Evolution, 19, 2092-2100.

Rogers AR, Harpending H (1992) Population growth makes waves in the distribution of pairwise genetic differences. Molecular Biology and Evolution, 9, 552-569. 
Rivera M, Kelley C, Roderick G (2004) Subtle population genetic structure in the Hawaiian Grouper, Epinephelus quernus as revealed by mitochondrial DNA analyses. Biological Journal of the Linnean Society, 81, 449-468.

Rogers AD (2007) Evolution and biodiversity of Antarctic organisms: a molecular perspective. Philosophical Transaction of the Royal Society B, 362, 21912214.

Rosen DE (1978) Vicariant patterns and historical explanation in biogeography. Systematic Zoology, 27, 159-188.

Ross PM, Hogg ID, Pilditch CA, Lundquist CJ (2009) Phylogeography of New Zealand's coastal benthos. New Zealand Journal of Marine and Freshwater Research, 43, 1009-1027.

Samantaray S, Dhagat UM, Maiti S (2010) Evaluation of genetic relationships in Plantago species using Random Amplified Polymorphic DNA (RAPDS) markers. Plant Biotechnology, 27, 297-303.

Star B, Apte S, Gardner JPA (2003) Genetic structuring among populations of the greenshell mussel Perna canaliculus (Gmelin 1791) revealed by analysis of Randomly Amplified Polymorphic DNA. Marine Ecology Progress Series, 249, 171-182.

Tripati A, Backman J, Elderfield H, Ferretti P (2005) Eocene bipolar glaciation associated with global carbon cycle changes. Nature, 436, 341-346.

Thiel M, Gutow L (2005) The ecology of rafting in the marine environment. II The rafting organisms and community. Oceanography and Marine Biology: An Annual Review, 43, 279-418. 
Vekemans X (2002a) AFLP-SURV version 1.0, Distributed by the author. Laboratoire de Génétique et Ecologie Végétale, Université Libre de Bruxelles, Belgium.

Vekemans X, Beauwens T, Lemaire M, Roldan-Ruiz I (2002b) Data from amplified fragment length polymorphism (AFLP) markers show indication of size homoplasy and of a relationship between degree of homoplasy and fragment size. Molecular Ecology, 11, 139-151.

Wasserburg GJ, Craig H, Menard HW, Engel AEJ, Engel CG (1963) Age and Composition of a Bounty Islands Granite and Age of a Seychelles Islands Granite. The Journal of Geology, 71, 785-789.

Waters JM (2008) Driven by the West Wind Drift? A synthesis of southern temperate marine biogeography, with new directions for dispersalism. Journal of Biogeography, 35, 417-427.

Waters JM, Roy MS (2004) Out of Africa: The Slow Train to Australasia. Systematic Biology, 53, 18-24.

White C, Selkoe KA, Watson J, Siegal DA, Zacherl DC, Toonen RJ (2010) Ocean currents help explain population genetic structure. Proceedings of the Royal Society of London B, 277, 1685-1694.

Wood AR, Gardner JPA (2007) Small spatial scale population genetic structure in two limpet species endemic to the Kermadec Islands, New Zealand. Marine Ecology Progress Series, 349, 159-170.

Zhivotovsky LA (1999) Estimating population structure in diploids with multilocus dominant DNA markers. Molecular Ecology, 8, 907-913. 
Zwickl DJ (2006) Genetic algorithm approaches for the phylogenetic analysis of large biological sequence datasets under the maximum likelihood criterion. Ph.D. dissertation, The University of Texas at Austin 



\title{
CHAPTER III
}

\section{TAXONOMY OF THE NEW ZEALAND LIMPETS OF THE CELLANA STRIGILIS COMPLEX (MOLLUSCA: PATELLOGASTROPODA): A COMBINED MORPHOMETRIC AND MOLECULAR APPROACH}

\begin{abstract}
The New Zealand Cellana strigilis complex has been traditionally divided into six subspecies. Recent molecular investigations, however, revealed that the complex comprises two lineages that are geographically isolated. In the present study, an additional morphometric analysis on 160 shells from the two clades confirms the need for taxonomic reconsideration of the $C$. strigilis complex. Here, two species are recognised in the Cellana strigilis group, a southwestern species, C. strigilis (Hombron \& Jacquinot 1841), from South, Stewart, Snares, Auckland and Campbell islands, with Patella redimiculum Reeve, 1854 and C. strigilis flemingi Powell, 1955 as synonyms; and a northeastern species, C. oliveri Powell, 1955, from Chatham, Bounty Islands and Antipodes Islands, with C. strigilis bollonsi Powell, 1955 and $C$. chathamensis of authors (not Pilsbry 1891) as synonyms. Acmaea chathamensis Pilsbry, 1891 is based on mislocalised foreign shells, probably C. rota (Gmelin, 1791) from the Red Sea. A neotype is designated for P. strigilis Hombron \& Jacquinot, 1841, lectotypes are designated for $P$. redimiculum Reeve, 1854 and A. chathamensis Pilsbry, 1891, and a type locality is selected for P. redimiculum.
\end{abstract}




\subsection{Introduction}

Morphological and geometric descriptions of organisms have long been fundamental to defining species, the basic unit of classification in biology, and have been central to the development of taxonomic classification schemes. As many recent studies have shown, however, the description and designation of species based on their morphological appearance alone is not always straight forward. With recent advances in technology, molecular investigations have led to the accumulation of an extensive genetic database across many taxa and biogeographic regions. Such investigations have often uncovered patterns of molecular variation that conflict with earlier classifications based on morphological characters. This has led to the description of new (cryptic) species that were previously unrecognised (Bickford et al. 2007; Pfenninger and Schwenk 2007; Vrijenhoek 2009 among many others), or the identification of phenotypic plasticity in a single species (Teske et al. 2007; Demes et al. 2009; Reisser et al. 2011).

The order Patellogastropoda is monophyletic and its members are commonly found on seashores throughout the world oceans from tropical to polar regions, and occur mostly on intertidal rocky shores, where they play an important role in intertidal marine ecosystems (Branch 1985a, b). They have also colonized other littoral habitats and can be observed on the seagrass Zostera (Lindberg 1979, 1988; Carlton et al. 1991), on limestone in the supralittoral zone (Lindberg and Vermeij 1985; Kirkendale and Meyer 2004), on coralline algae (Sasaki and Okutani 1993; Sasaki 2000), on sunken wood in the deep sea (Marshall 1985; Lindberg 1990), and in association with vents or seeps (Sasaki et al. 2003). The order Patellogastropoda is currently divided into seven families: Acmaeidae, Eoacmaeidae, Lepetidae, Lottiidae, Nacellidae, Patellidae and Pectinodontidae (Nakano \& Sasaki 2011).

The family Nacellidae is comprisestwo genera: Nacella Schumacher, 1817 and Cellana H. Adams, 1869. Nacella contains 15 species and subspecies that occur in the high latitudes of the Southern Hemisphere and in the Southern Ocean (Powell 1973). They are one of the dominant group of intertidal and benthic macroinvertebrates of the rocky shore biota, although some species colonize other substrates (e.g. N. mytilina on macroalgae; Valdovinos \& Rüth 2005; Gonzalez- 
Wevar et al. 2011). Cellana comprises more than 37 species and subspecies that dominate rocky shores throughout the world (Lindberg and Hickman, 1986). MostCellana species havetropical distributions, extending north to Japan, East to Juan Fernandez and Hawaii, south to South Africa, Madagascar, others inAustralia, New Zealand and the sub-Antarctic Islands, includingCampbell Island where a Cellana and Nacella species coexist (Powell 1973).

Patellogastropods (including Cellana species) are known for their phenotypic plasticity, defined as the ability of an organism with a given genetic background (genotype) to generate a range of sizes and shapes (phenotypes) in response to environmental cues (West-Eberhard 2005), which often leads to taxonomic confusion (Nakano \& Spencer 2007; Lindberg 2008, Nakano et al. 2011). This paper focuses on the taxonomy of the Cellana strigilis complex from isolated islands in the Southern Ocean (see Reisser et al. 2011). Previous nomenclature based on shell morphology divided the complex into six subspecies (Powell 1955, 1973), with specimens from the different islands being differentiated on external shell colour, shell ovality and position of the apex (Table 3.1). Recent genetic studies, however, have challenged these taxonomic designations. Studies of molecular variation (Goldstien et al. 2009; Reisser et al. 2011) have revealed that the C. strigilis complex comprises two genetically and geographically distinct lineages: a southwestern island group and a northeastern island group. In addition, the sister species C. denticulata (Martyn, 1784) has been described as the sister species of the southwestern lineage in a phylogenetic sense, thus providing evidence that the $C$. strigilis complex is not monophyletic (Reisser et al. 2011). There are no shared haplotypes between lineages, and multiple population-specific private haplotypes are observed (Reisser et al. 2011). Population genetic study suggests that connectivity (exchange of migrants) is probably nonexistent between the two lineages and limited within them (Reisser et al. 2011).

Shell characteristics such as colour, presence of ribs and apex position may be hard to determine in individuals from natural populations because the shell may be eroded and/or covered in epibionts. One trait used by Powell (1979), however, is generally well conserved in natural populations, specifically the shell ovality or aperture shape of the shell. According to Powell (1979), specimens from Auckland, Campbell, Stewart and South islands have a broadly ovate shell, whereas those from the Snares, Antipodes, Bounty and Chatham islands have more narrowly ovate shells. 
Thus, shell ovality seems to be a trait allowing discrimination between the two lineages defined by Reisser et al. (2011), with the exception of Snares Island individuals. To date, no formal morphometric analyses (involving statistical comparison of shape and traits measurements) have been carried out, and shells from both lineages are hard to distinguish with the naked eye (personal observations of all three authors).

Analyses of morphometry have moved from relatively simple measurement and comparison of individual metric traits or ratios of traits that may provide a crude approximation of shape, to more complex determinations of shape itself (the Mytilus edulis species complex provides a particularly good example of this progression of analytical approaches - Skibinski 1983; Ferson et al. 1985; Beaumont et al. 1989; McDonald et al. 1991; Gardner 1995, 1996, 2004; Innes \& Bates 1999; Krapivka et al. 2007; Gardner \& Thompson 2009). Here, our work addresses the question of differences in shell aperture shape between lineages of Southern Ocean Cellana using a Fast Fourier Transform (FFT) analysis, and its taxonomic implications and applications. Fourier analysis is particularly suitable for the detection of differences in oval shapes and as a result has been used for analysing the shape of diverse organismal features, ranging from fish otoliths to flower petals and ventricular shape in human hearts (Kass et al. 1987; Yoshioka et al. 2004; Costa et al. 2008; SchulzMirbach et al. 2010), as well as in numerous bivalve and gastropods species (Gardner \& Thompson 2009, Preston et al. 2010) including Nacellidae (de Arenzamendi et al. 2010; Hoffman et al. 2010; Gonzalez-Wevar et al. 2011). Additionally, I performed a traits morphometric analysis to compare the efficientcy of traits measurement and Fourier analysis. The analysis and its results can be found as an appendix to this chapter (Appendix 1).

We describe morphometric analysis of shells from the two lineages of Southern Ocean Cellana (Goldstien et al. 2009; Reisser et al. 2011) to test for shape differences between them and to test for concordance between morphological and previously described molecular variation. We take a combined evidence approach to review and revise the taxonomy of these limpets, and in so doing demonstrate the utility of the FFT approach to addressing questions of taxonomy in gastropod molluscs. 
Table 3.1.

Morphometric traits of Cellana strigilis subspecies according to Powell (1979).

\begin{tabular}{|l|l|l|}
\hline Subspecies & Distribution & Shell morphometric characters \\
\hline C. s. strigilis & $\begin{array}{l}\text { Auckland Islands } \\
\text { Campbell Island }\end{array}$ & $\begin{array}{l}\text { Shell very large } \\
\text { Broadly ovate } \\
\text { High profile } \\
\text { Apex at anterior 4th }\end{array}$ \\
\hline C. s. redimiculum & Southern South and Stewart Islands & $\begin{array}{l}\text { Shell large } \\
\text { Broadly ovate } \\
\text { Apex at about anterior 4th or 5th }\end{array}$ \\
\hline C. s. flemingi & Snares Islands & $\begin{array}{l}\text { Shell narrowly ovate } \\
\text { Apex at anterior 4th or 5th }\end{array}$ \\
\hline C. s. bollonsi & Antipodes Islands & $\begin{array}{l}\text { Shell rather large } \\
\text { Ovate to narrowly ovate } \\
\text { Apex at about anterior 5th to 7th }\end{array}$ \\
\hline C. s. chathamensis & Chatham Islands & $\begin{array}{l}\text { Shell large and solid } \\
\text { Ovate to narrowly ovate } \\
\text { Apex at about anterior 5th to 7th }\end{array}$ \\
& & $\begin{array}{l}\text { Shell of moderate size } \\
\text { Narrowly ovate } \\
\text { Apex very near to anterior end }\end{array}$ \\
\hline C. s. oliveri & Bounty Islands &
\end{tabular}

\section{Abbreviations and text conventions}

ANSP - Academy of Natural Sciences of Philadelphia; GNS - Institute of Geological and Nuclear Sciences, Lower Hutt; MNHN - Muséum National d'Histoire Naturelle, Paris; NHMUK - The Natural History Museum, London; NMNZ - Museum of New Zealand Te Papa Tongarewa, Wellington; USNM - National Museum of Natural History, Washington D.C.). All specimens are at NMNZ unless specified (registration numbers preceded by M.). 


\subsection{Material and methods}

\subsubsection{Sample collection and storage}

Specimens were collected between 2004 and 2008 (Table 3.2) across all the subantarctic islands where they have been recorded. Individuals were preserved in ethanol. For shape analysis, the body of each individual was entirely removed from its shell. Shells were cleaned, dried and placed in a plastic bag containing a tagging number referring to the individual's DNA signature. A total of 119 shells collected between 2004 and 2008 with no damage and no epibiota were used in the analysis. In addition, 41 shells from the collection of Museum of New Zealand Te Papa Tongarewa were used to complete the sample set and adjust population sizes (grand total $=160$ shells).

\subsubsection{Fast Fourier Transform}

Fourier Transform is a mathematical procedure that transforms a function from the time/space domain to the frequency domain. Fourier Transform operates on continuous functions, defined at all values of time $t$ or space s. For digital signals, such as image processing, the analysis involves discrete functions (Discrete Fourier Transform: DFT), resulting in a set of sine and cosine coefficients recorded at regular intervals of time/space (i.e. at every pixel constituting the outline of an image). However, DFT is not an efficient calculation method and has rarely been used in practical applications, considering the number of complex mathematical operations required to obtain Fourier Coefficients (FCs). Cooley and Tukey (1965) described a numerical algorithm that allowed the DFT calculation to be obtained more rapidly and efficiently. This algorithm, called Fast Fourier Transform (FFT) decomposes the DFT. H $_{\text {SHAPE }}$ software uses the FFT to generate two FCs per harmonic per individual, describing the size (amplitude) and angular offset relative to the starting position (phase angle) of each harmonic curve (Haines and Crampton 2000). 


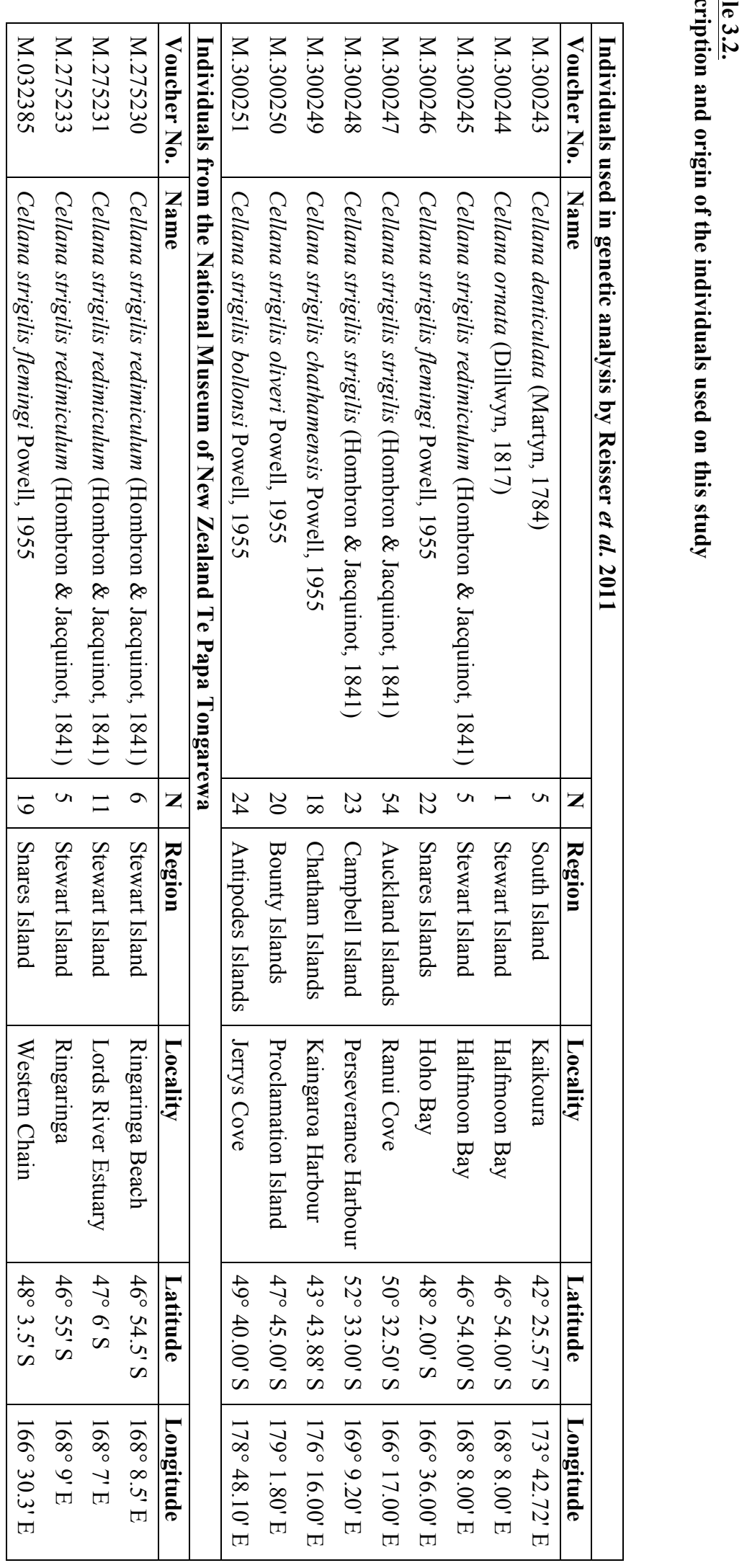


Digital pictures of shells were binarized and shell outline was extracted for each shell under the form of $(x, y)$ coordinates using ImageJ (Rasband 2008). Shape analysis was carried out using $\mathrm{H}_{\mathrm{SHAPE}}$, a package containing three program codes

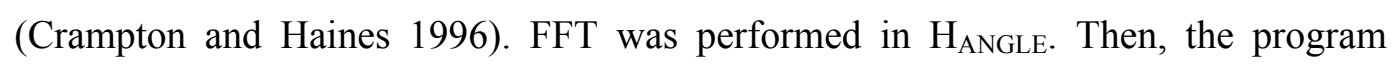
$\mathrm{H}_{\text {TREE }}$ normalised the FCs for starting position and therefore orientation of the trace based on properties of the entire sample population and allowing maximum overlap, as per authors' recommendations for organisms such as limpets with no obvious landmark (Crampton and Haines 1996; Haines and Crampton 2000). Finally, the outline of each shell was reconstructed according to the Fourier descriptors using $\mathrm{H}_{\text {CURVE. }}$ A total of $14 \mathrm{FCs}$ from the $2^{\text {nd }}$ to the $8^{\text {th }}$ harmonics were retained for the analysis. Coefficients from the $1^{\text {st }}$ harmonic were discarded because they contain size information.

\subsubsection{Statistical analysis}

Fourier Coefficients were subject to Discriminant Function Analysis (DFA) using Statistica (Statsoft 1994) and Canonical Analysis of Principal Component Coefficients (CAPCC, Anderson and Willis 2003) using CAP12 (Anderson 2004). Matrices of assignment and scatter plots of individuals grouped according to island population and according to lineage were obtained from the DFA and CAPCC, respectively. Outlines corresponding to the extreme shell shapes, the average shell shape and the most similar shell shape of the two lineages were reconstructed.

\subsection{Results}

\subsubsection{Morphometric differentiation between lineages}

CAPCC revealed an almost complete separation between the two lineages, with positive canonical values for the northeastern group and negative canonical values for the southwestern group (Fig.3.1a). These results are confirmed by the DFA $(\lambda=0.140, F=63.41, p<0.0001)$, which discriminated between the lineages with $99.37 \%$ overall assignment success. Only one individual from the northeastern group was misassigned to the southwestern group (Table 3.3a). The reconstruction of shape 
average for both lineages shows that the difference resides in the width, with the northwestern individuals being narrower on average than the southwestern individuals (Fig.3.2).

Table 3.3.

Matrix of assignment from DFA of Fourier Coefficients of shell shape, with the percentage of correct assignment for each group (populations or species), and the probability "p" of population affiliation by chance based on population size and global sample size: division by lineages (a), by populations within the soutwestern lineage (b) and by populations within the northeastern lineage (c). Boldface represents successful assignment.

(a)

\begin{tabular}{|l|ccc|}
\hline Lineage & $\begin{array}{c}\text { Percent } \\
\text { correct }\end{array}$ & $\begin{array}{c}\text { Soutwestern } \\
p=0.700\end{array}$ & $\begin{array}{c}\text { Northeastern } \\
p=0.300\end{array}$ \\
\hline Southwestern & 100.00 & $\mathbf{1 1 2}$ & 0 \\
Northeastern & 97.92 & 1 & $\mathbf{4 7}$ \\
\hline Total & 99.38 & 113 & 47 \\
\hline
\end{tabular}

(b)

\begin{tabular}{|l|ccccc|}
\hline & $\begin{array}{c}\text { Percent } \\
\text { correct }\end{array}$ & $\begin{array}{c}\text { Auckland } \\
p=0.393\end{array}$ & $\begin{array}{c}\text { Campbell } \\
p=0.143\end{array}$ & $\begin{array}{c}\text { Snares } \\
p=0.223\end{array}$ & $\begin{array}{c}\text { Stewart } \\
p=0.241\end{array}$ \\
\hline Auckland & 75.00 & $\mathbf{3 3}$ & 3 & 2 & 6 \\
Campbell & 37.50 & 6 & $\mathbf{6}$ & 3 & 1 \\
Snares & 56.00 & 7 & 2 & $\mathbf{1 4}$ & 2 \\
Stewart & 44.44 & 12 & 1 & 2 & $\mathbf{1 2}$ \\
\hline Total & 58.04 & 58 & 12 & 21 & 21 \\
\hline
\end{tabular}

(c)

\begin{tabular}{|l|cccc|}
\hline & $\begin{array}{c}\text { Percent } \\
\text { correct }\end{array}$ & $\begin{array}{c}\text { Antipodes } \\
p=0.479\end{array}$ & $\begin{array}{c}\text { Bounty } \\
p=0.292\end{array}$ & $\begin{array}{c}\text { Chatham } \\
p=0.229\end{array}$ \\
\hline Antipodes & 100.00 & $\mathbf{2 3}$ & 0 & 0 \\
Bounty & 92.86 & 1 & $\mathbf{1 3}$ & 0 \\
Chatham & 63.64 & 4 & 0 & $\mathbf{7}$ \\
\hline Total & 89.58 & 28 & 13 & 7 \\
\hline
\end{tabular}


(a)

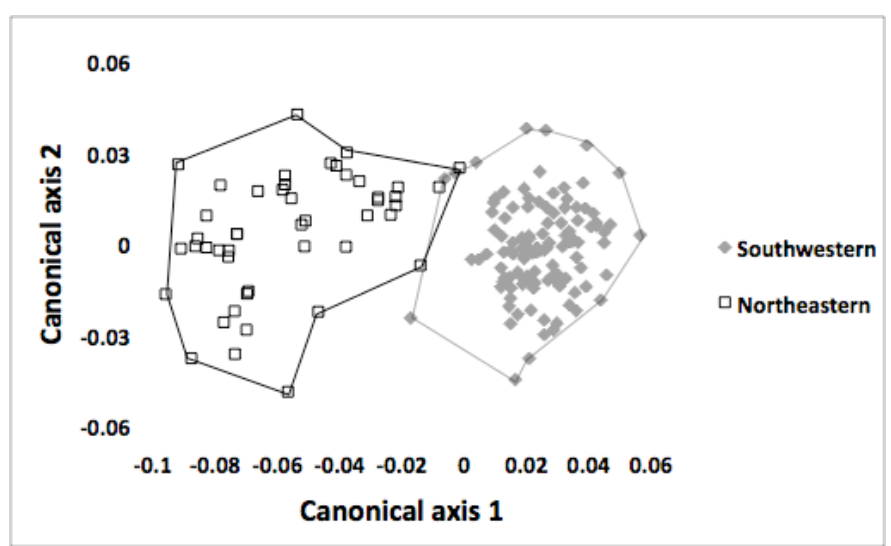

(b)

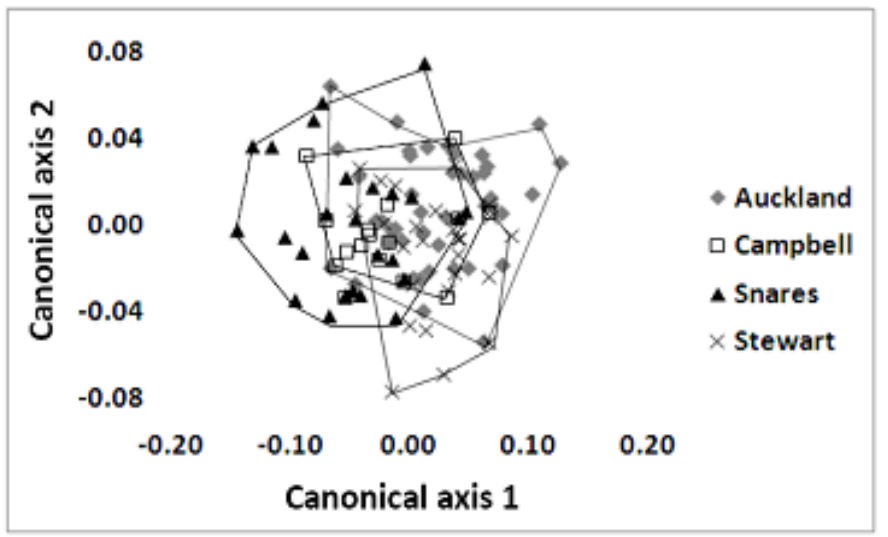

(c)

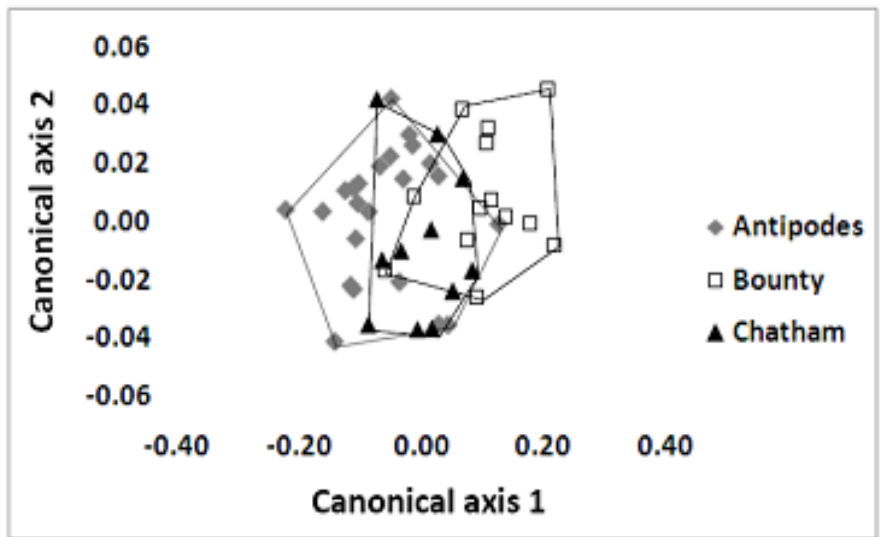

Figure 3.1.

Canonical Analysis of Principal Coordinates on Fourier Coefficients for shell shape (a) between lineages, (b) among the southwestern lineage populations and (c) among northeastern lineage populations. 
(a)

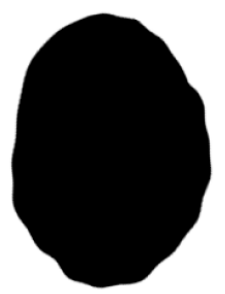

(c)

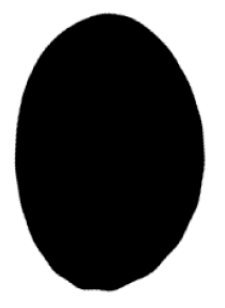

(e)

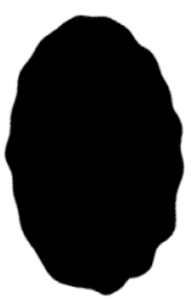

C. strigilis (b)

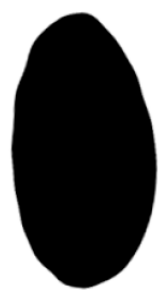

(d)

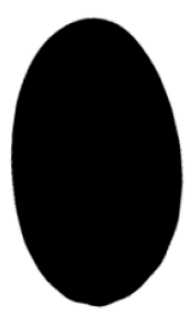

(f)

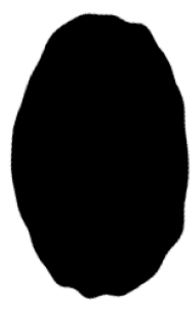

C. oliveri

Figure 3.2.

Outline reconstruction of shell shapes for the two species using HCurve, with (a) (c) and (e) the southwestern individuals extreme, average and most similar shell shape to the northeastern individuals respectively, and (b) (d) and (f) the northeastern individuals extreme, average and most similar shell shape to the southwestern individuals respectively.

\subsubsection{Morphometric differentiation within lineages}

The CAPCC on the southwestern individuals did not separate the different populations (Fig.3.1b). The DFA reflected this uncertainty, and although there was a significant difference among the populations $(\lambda=0.511, \mathrm{~F}=1.709, \mathrm{p}<0.0062)$, the overall assignment success was only $58.03 \%$. The highest assignment success was $75 \%$ for Auckland Island individuals and the lowest was 37.5\% for Campbell Island (Table 3.3b).

The CAPCC on the northeastern individuals revealed partial separation of the three populations, with Antipodes and Bounty Islands individuals separated from each 
other and Chatham Island individuals in between (Fig 3.1c). The DFA confirmed this observation $(\lambda=0.05, \mathrm{~F}=2.763, \mathrm{p}<0.0004)$, with $100 \%$ and $92.86 \%$ of successful assignment for Antipodes and Bounty islands individuals respectively, and 63.58\% assignment success for Chatham Island individuals. The overall assignment success was $89.58 \%$ (Table $3.3 \mathrm{c}$ ). As observed with molecular data, morphometric analysis revealed a reasonable amount of variation within species, in particular for the southwestern lineage, and to a lesser extent for the northeastern lineage (Fig.3.1 and Table 3.3).

\subsection{Discussion}

\subsubsection{Two lineages genetically and morphometrically distinct from each other}

There is a strong concordance between molecular and morphometric results at the species level, with high levels of discrimination success between the two lineages defined by Goldstien et al. 2009 and Reisser et al. 2011. This congruence highlights the need for a taxonomic reconsideration of the $C$. strigilis limpet complex. The new taxonmy is presented below, and the two lineages will now be reffered to as Cellana strigilis (southwestern lineage) and Cellana oliveri (northeastern lineage).

Reconstruction of each lineage "average" shape clearly shows that the difference resides in the width of the shell compared to the length, with $C$. oliveri being narrower than $C$. strigilis. As with molecular data, morphometric analysis revealed a reasonable amount of variation within species, in particular for $C$. strigilis, and to a lesser extent $C$. oliveri.

A phylogram based on combined COI and 16S (mitochondrial) gene partial sequences places $C$. denticulata between $C$. oliveri and $C$. strigilis, with high levels of bootstrap support (Reisser et al. 2011), consistent with the findings of Goldstien et al. (2009). This tree topology points to two different speciation events for the limpets of the $C$. strigilis complex via long distance dispersal followed by speciation in isolation. The timing of the divergence of $C$. oliveri and $C$. strigilis is estimated to have occurred 1.85 to $7.06 \mathrm{Ma}($ mean $=4.19 \mathrm{Ma})$, there is no evidence for genetic exchange between the lineages, and evidence of only limited exchange within them (Reisser et al. 2011). 


\subsubsection{Advantages of Fourier shape analysis for species/population discrimination}

The present paper emphasizes the utility of the FFT approach in helping to recognise shape-based differences between/among species. It is a rapid, easy to use and efficient technique that provides reliable results at little extra cost, particularlywhere molecular studies are not possible (e.g. shells, fossils, poorly preserved soft tissue). Although the technique is efficient in the application described here, we suggest that it could be improved by increased analysis automation and new software development that groups and links the subroutines. As a general approach to the analysis of shape differences FFT is an appropriate analytical choice for work in diverse fields.

\subsection{Taxonomy}

From the published molecular data (Goldstien et al. 2009; Reisser et al. 2011) and the present morphometric study, it is now clear that two species group taxa are involved, a southwestern one from South, Stewart, Snares, Campbell and Auckland Islands (C. s. strigilis, C. s. redimiculum and C. s. flemingi), and a northeastern one from Chatham, Bounty and Antipodes Islands (C. s. chathamensis, C. s. oliveri and C. s. bollonsi).

Whereas the use of strigilis for the southwestern species is straight forward, the appropriate name to be used for the northeastern one is not the oldest synonym involved, namely Acmaea chathamensis Pilsbry, 1891, described from "Chatham Is.", but rather C. oliveri Powell, 1955, as discussed below.

Patellogastropoda Lindberg, 1988

Nacellidae Thiele, 1929

Cellana H. Adams, 1869

Cellana H. Adams, 1869: 273. Type species (monotypy): Nacella (Cellana) cernica H. Adams, $1869=$ Patella livescens Reeve, 1855; Recent, Mauritius.

Helcioniscus Dall, 1871: 277. Type species (by original designation): Patella variegata Reeve, $1842=$ P. capensis Gmelin, 1791; Recent, South Africa. 


\section{Cellana strigilis (Hombron \& Jacquinot, 1841)}

Fig.3.3A-Q

Patella strigilis Hombron \& Jacquinot, 1841: 190.

Patella illuminata Gould, 1846: 149; Gould, 1852: 340, pl. 28, figs 441a, b.

Patella radians.- Reeve, 1854: pl. 12, figs 25a, b. Not Gmelin, 1791.

Patella redimiculum Reeve, 1854: pl. 20, figs 50a, b; Hutton, 1878: 36; Hutton, 1880:

107. New synonymy.

Patella pottsi Hutton, 1873: 44.

Patella redimiculum.-Smith, 1874: 4, pl. 1, fig. 24.

Patella magellanica.- Hutton, 1880: 107; Filhol, 1885: 528. Both not Gmelin, 1791.

Patinella strigilis.- Hutton, 1884: 374.

Patinella redimiculum.- Hutton, 1884: 374.

Helcioniscus redimiculum.- Pilsbry, 1892: 136, pl. 23, figs 1-3, 5; Suter, 1905: 351 (in part $=$ C. oliveri Powell, 1955); Suter, 1909: 7 (in part $=$ C. oliveri); Suter, 1913: 85, pl. 7, fig. 20 (in part $=$ C. oliveri $)$.

Helcioniscus strigilis.- Pilsbry, 1892: 137; Suter, 1905: 351 (in part $=$ C. oliveri); Suter, 1909: 7 (in part $=$ C. oliveri $)$; Suter, 1913: 87, pl. 7, fig. $22($ in part $=C$. oliveri).

Helcioniscus illuminata.- Pilsbry, 1892: 142, pl. 70, figs 40-42.

Patella strigilis.- Suter, 1904: 84.

Patella strigilis var. redimiculum.- Suter, 1904: 84.

Patella illuminata.- Suter, 1904: 85.

Helcioniscus radians affinis.- Suter, 1905: 349; Suter, 1909: 6. Both in part not Reeve, $1855=$ C. oliveri .

Nacella illuminata.- Suter, 1913: 77. In part $=$ C. oliveri .

Cellana strigilis.- Iredale, 1915: 432.

Cellana (Helcioniscus) strigilis.- Odhner, 1924: 11.

Cellana (Helcioniscus) radians.- Odhner, 1924: 11. In part not Gmelin, 1791.

Nacella strigilis.- Finlay, 1927: 337.

Nacella redimiculum.- Finlay, 1927: 337. 


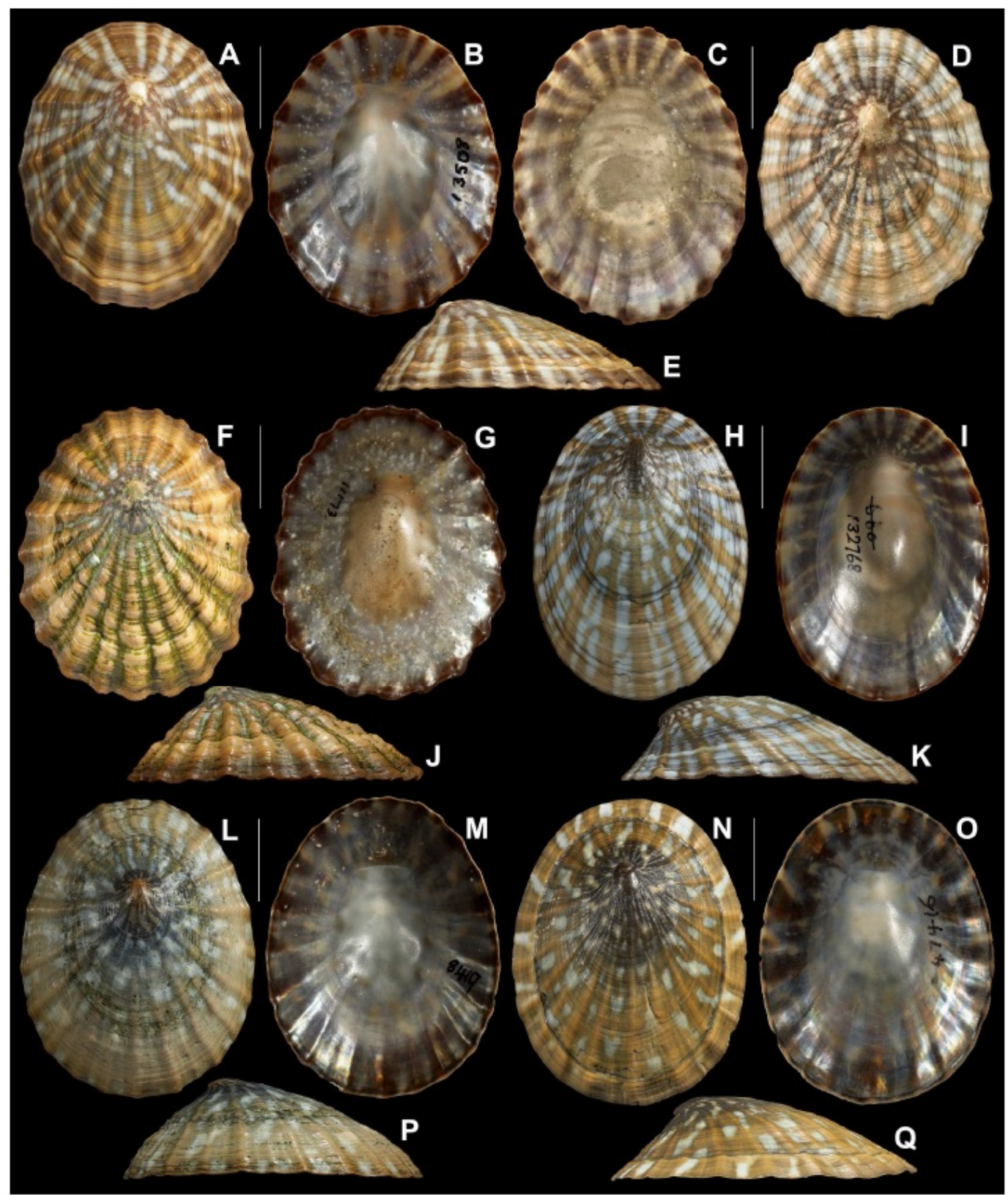

Figure 3.3.

A-Q. Cellana strigilis (Hombron \& Jacquinot, 1841). A, B, E, neotype of Patella strigilis, Enderby Island, Auckland Islands, MNHN 23296. C, D, lectotype of Patella redimiculum Reeve, 1854, Horseshoe Bay, Stewart Island, NHMUK 20100514/1[11.5]. F, G, J, Codfish Island, Stewart Island, NMNZ M.011173. H, I, K, Snares Islands, NMNZ M.132768. L, M, P, Enderby Island, Auckland Islands, NMNZ M.008419 [42.87=11.7]. N, O, Q, Perseverance Harbour, Campbell Island, NMNZ M.047416. Scale bars $10 \mathrm{~mm}$. 
Cellana redimiculum.- Powell, 1933: 197; Powell, 1937: 67, pl. 1, fig. 9; Powell, 1946: 69, pl. 1, fig. 9

Cellana strigilis strigilis.- Powell, 1955: 70, text fig. B3; Powell, 1973: 184, pl. 70, figs 14, 15, pl. 164, figs 1-4, pl. 168, fig. 1, pl. 170, fig. 3.

Cellana strigilis redimiculum.- Powell, 1955: 71, text fig. B1; Powell, 1957: 86, pl. 1, fig. 9; Powell, 1962: 78, pl. 1, fig. 9; Powell, 1973: 188, pl. 70, figs 17-19, pl. 169, figs. 1-4, pl. 170, fig.1; Powell, 1976: 82, pl. 1, fig. 9; Powell, 1979: 45, pl. 9 , fig. 6 , pl. 15 , fig. 8 .

Cellana strigilis flemingi Powell, 1955: 72, pl. 5, figs 45-47, text fig. B2; Powell, 1973: 186, pl. 168, fig. 3, pl. 169, figs 5-7, pl. 170, fig. 2; Powell, 1979: 44. New synonymy.

Cellana strigilis strigilis.- Powell, 1979: 44, pl. 15, fig. 9

Type material

Patella strigilis: No original material traced at MNHN (V. Héros, pers. comm., 13 Oct. 2010), neotype here selected (Figs 1A, B, E) MNHN 23296 (ex NMNZ M.008419), Sandy Bay, Enderby Island, Auckland Islands, R.K. Dell, 18 Mar. 1954. Patella illuminata: Holotype USNM 5831, Auckland Islands. Patella redimiculum: Lectotype here selected NHMUK 20100514/1 (Figs 1C, D), the specimen figured by Reeve (1854, pl. 50a, b), and 2 paralectotypes NHMUK 20100514/2, 3, "New Zealand", type locality here selected as Horseshoe Bay, Stewart Island. Patella pottsi: Holotype NMNZ M.000247, South Island, west coast. Cellana strigilis flemingi: Holotype GNS TM600, Snares Islands, boat harbour, intertidal, C.A. Fleming, 27 Nov. 1947.

Distribution

South Island from Kaikoura southwards, Stewart Island and Snares Islands.

\section{Remarks}

Specimens of C. strigilis identified by Reeve (1854) as C. radians (Gmelin, 1791) are at NHMUK (1975023/1-3, figured specimen 1975023/1). Macquarie Island records (Pilsbry 1891, p. 143; Suter 1913, p. 77) are either Nacella macquariensis (Finlay, 1927) or mislocalised specimens. For additional remarks, see below. 


\section{Cellana oliveri Powell, 1955}

Fig.3.4 A-H, K

Helcioniscus redimiculum.- Suter, 1905: 351; Suter, 1909: 7; Suter, 1913: 85, pl. 7, fig. 20. All in part not Reeve, 1854.

Helcioniscus strigilis.- Suter, 1905: 351; Suter, 1909: 7; Suter, 1913: 87, pl. 7, fig. 22. All in part not Hombron \& Jacquinot, 1841.

Helcioniscus radians affinis.- Suter, 1905: 349; Suter, 1909: 6; Suter, 1913: 83. All in part not Reeve, 1855.

Nacella illuminata.- Suter, 1913: 77. In part not Gould, 1846.

Cellana chathamensis.- Finlay, 1928: 240; Powell, 1933: 196, pl. 36, figs 1-4 (in part not Pilsbry, 1891).

Cellana strigilis oliveri Powell, 1955: 73, pl. 5, figs 48-50, text fig. B4; Powell, 1973: 187, pl. 165, figs 3-5, pl. 170, fig. 4; Powell, 1979: 45, pl. 15, fig. 10.

Cellana strigilis bollonsi Powell, 1955: 73, pl. 5, figs 51-53, text fig. B5; Powell, 1973; 185, pl. 165, figs 1, 2, pl. 170, fig. 5; Powell, 1979: 44, pl. 15, figs 11,

\section{New synonymy.}

Cellana strigilis chathamensis.- Powell, 1955: 73 (not Pilsbry); Powell, 1973: 186, pl. 167, figs 1-4, pl. 168, fig. 2 (in part not Pilsbry); Powell, 1979: 44, pl. 15, fig. 7 (in part not Pilsbry).

NOT Acmaea chathamensis Pilsbry, 1891: 56, pl. 35, figs $43-46=$ based on a mislocalised foreign Cellana species, apparently C. rota (Gmelin, 1791), and possibly from the Red Sea.

Type material

Cellana strigilis oliveri: Holotype NMNZ M.008565, Bounty Islands, W.R.B. Oliver, Apr. 1927. Cellana strigilis bollonsi: Holotype NMNZ M.008560, Antipodes Islands, W.R.B. Oliver, Apr. 1927.

Distribution

Chatham, Antipodes and Bounty islands. 


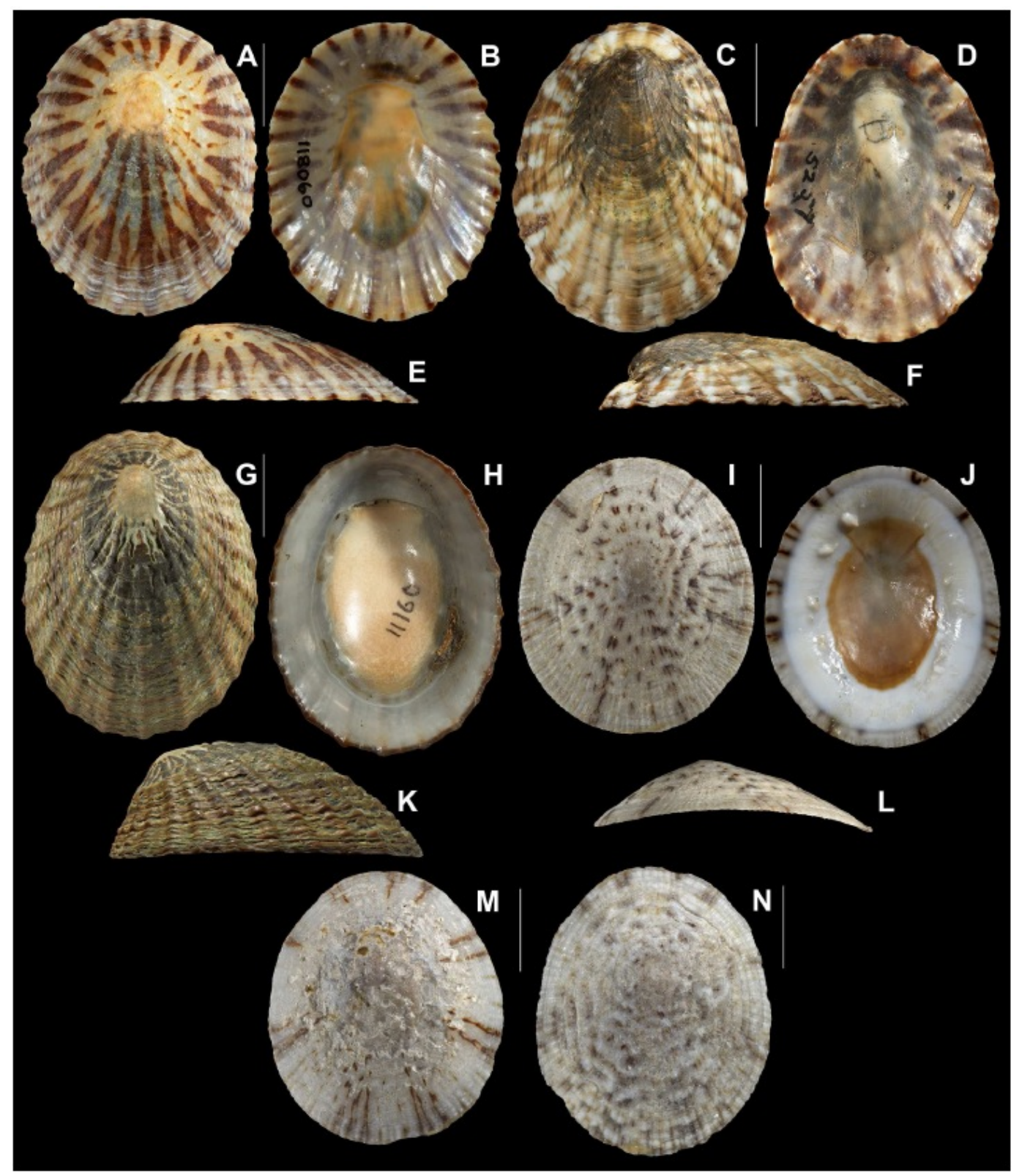

Figure 3.4.

A-H, K. Cellana oliveri Powell, 1955. A, B, E, Hanson Bay, Chatham Islands, NMNZ M.118060. C, D, F, Bounty Islands, NMNZ M.005257. G, H, K, Ringdove Bay, Antipodes Islands, NMNZ M.011160. I, J, L-N. Cellana chathamensis (Pilsbry 1891), locality unknown (possibly Red Sea). I, J, L, lectotype ANSP 50050. M [23.8= $19 \mathrm{~mm}]$, N, paralectotypes ANSP 425026. Scale bars 10 mm. 
Remarks

The original description and illustrations of A. chathamensis (Pilsbry 1891, p.56, pl. 35, figs 43-46) are of shells differing markedly from any member of the strigilis group in the combination of sculpture, colour and colour pattern. Suter (1913) and Finlay (1930) thought that A. chathamensis must be based on a form of the highly variable species Cellana radians (Gmelin, 1791), which is common and widely distributed around the North and South Islands. Aware that only a single Cellana species occurs at the Chatham Islands, Powell (1933) concluded that A. chathamensis must be based on juveniles, the dimensions of which do not coincide with those reported by Pilsbry (lengths $30 \mathrm{~mm}$ and $24 \mathrm{~mm}$ ), but indicated that "actual specimens agree with these measurements exactly". First hand examination of type specimens of A. chathamensis (8 syntypes ANSP 50050, Fig. 3.4. I, J, L-N) confirms that they do indeed differ markedly in sculpture, colour, and colour pattern from members of the strigilis group, but also from all other limpets occurring in the New Zealand region.

The closest match with a localised specimen we are able to find in the literature is that illustrated by Powell (1973 pl. 119, compare with Fig. 3.4. N herein), as Cellana eucosmia Pilsbry, 1891, from Ras Banas, Red Sea, which, according to Christiaens $(1986,1987)$ is really a form of Cellana rota (Gmelin, 1791). The precise distribution of C. rota is unclear, though Christiaens $(1986,1987)$ recorded it as occuring throughout the Red Sea as well as in the Gulf of Oman, and adventive in the eastern Mediterranean. Since A. chathamensis is based on material of foreign origin, as first revisers we choose $C$. s. oliveri Powell, 1955 from among the two next available names (oliveri and bollonsi, introduced simultaneously) as the name to be used for the species from the Antipodes, Bounty and Chatham Islands. We choose the larger of the two syntypes Acmaea chathamensis illustrated by Pilsbry (1891, pl. 35, figs 43, 44, 46, ANSP 50050) as lectotype (Fig 3.4. I-L).

\subsection{References}

Adams H (1869) Descriptions of a new genus and fourteen new species of marine shells. Proceedings of the Zoological Society of London, 1869, 272-275. 
Anderson MJ, Willis TJ (2003) Canonical analysis of principal coordinates: a useful method of constrained ordination for ecology. Ecology, 84, 511-525.

Anderson MJ (2004) CAP: a FORTRAN computer program for canonical analysis of principal coordinates. Department of Statistics, University of Auckland, New Zealand.

Branch GM (1985a) Limpets: evolution and adaptation. In The Mollusca, 10 (Eds Trueman, E.R. and Clarke, M.R.). Academic Press, New York.

Branch GM (1985b) Limpets: their role in littoral and sublittoral community dynamics. In The ecology of rocky coasts (Eds Moore, P.G. and Seed, R.). Hodder and Stoughton, London.

Beaumont AR, Seed R, Garcia-Martinez P (1989) Electrophoretic and morphometric criteria for the identification of the mussels Mytilus edulis and $M$. galloprovincialis. In Proceedings of the 23rd European Marine Biology Symposium (Eds Ryland J.S. and Tyler, P.A.). Fredensborg, Denmark: Olsen and Olsen, pp 251-258.

Bickford D, Lohman DJ, Sodhi NS, Ng PKL, Meier R, Winker K, Ingram KK, Das I (2007) Cryptic species as window on diversity and conservation. Trends in Ecology and Evolution, 22, 148-155.

Carlton JT, Vermeij GJ, Lindberg DR, Carlton DA, Dudley EC (1991) The first historical extinction of a marine invertebrate in an ocean basin: the demise of the eelgrass limpet Lottia alveus. Biological Bulletin, 180, 72-80.

Christiaens J (1986) Notes sur quelques Patellidae (Gastropoda) de l'Ocean Indien. Apex. Informations Scientifiques de la Société Belge de Malacologie, 1, 97128. 
Christiaens J (1987) Revision of the limpets of the Red Sea. Patellidae, Fissurellidae and the genus Hemitoma. Gloria Maris, 26, 17-54.

Cooley JW, Tukey JW (1965) An algorithm for the machine calculation of complex Fourier Series. Mathematics of Computation, 19, 297-303.

Costa C, Aguzzi J, Menesatti P, Antonucci F, Rimatori V, Mattoccia M (2008) Shape analysis of different populations of clams in relation to their geographical structure. Journal of Zoology, 276, 71-80.

Crampton JS, Haines AJ (1996) Users' manual for programs HANGLE, HMATCH and HCURVE for the Fourier Shape analysis of two-dimensional outlines. New Zealand Institute of Geological and Nuclear Sciences Science Report 96, 37, 1-28.

Dall WH (1871) On the limpets; with special reference to the species of the West Coast of America, and to a more natural classification of the group. American Journal of Conchology, 6, 227-282.

De Aranzamendi MC, Martinez JJ, Sahade R (2010) Shape differentiation and characterization in the two morphotypes of the Antarctic limpet Nacella concinna using Elliptical Fourier analysis of shells. Polar Biology, 33, 11631170.

Demes KW, Graham MH, Suskiewicz TS (2009) Phenotypic plasticity reconciles incongruous molecular and morphological taxonomies: the giant kelp Macrocystis (Laminariales, Phaeophyceae), is a monospecific genus. Journal of Phycology, 45, 1266-1269.

Ferson S, Rohlf FJ, Koehn RK (1985) Measuring shape variation of two-dimensional outlines. Systematic Zoology, 34, 59-68. 
Filhol H (1885) Mollusques. Recueil de mémoires, rapports et documents relatifs a l'observation du passage de Vénus sur le soleil, 3. Gauthier-Villars, Paris, $517-571$.

Finlay HJ (1927) A further commentary on New Zealand molluscan systematics. Transactions of the New Zealand Institute, 57, 320-485.

Finlay HJ (1928) The Recent Mollusca of the Chatham Islands. Transactions of the New Zealand Institute, 59, 232-286.

Gardner JPA (1995) Developmental stability is not disrupted by extensive hybridization and introgression among populations of the marine bivalve molluscs Mytilus edulis (L.) and M. galloprovincialis (Lmk.) from south-west England. Biological Journal of the Linnean Society, 54, 71-86.

Gardner JPA (1996) The Mytilus edulis species complex in southwest England: effects of hybridization and introgression upon interlocus associations and morphometric variation. Marine Biology, 125, 385-399 (with erratum for Fig. 9. Marine Biology 1997 127, 712-713).

Gardner JPA (2004) A historical perspective of the genus Mytilus (Bivalvia: Mollusca) in New Zealand: multi-variate morphometric analyses of fossil, midden and contemporary blue mussels. Biological Journal of the Linnean Society, 82, 329-344.

Gardner JPA, Thompson RJ (2009) Influence of genotype and geography on shell shape and morphometric trait variation among North Atlantic blue mussels (Mytilus spp.) populations. Biological Journal of the Linnean Society, 96, 875-897.

Goldstien, S.J., Gemmell, N.J. and Schiel, D.R. (2009). Colonisation and connectivity by intertidal limpets among New Zealand, Chatham and Sub-Antarctic Islands. I. Genetic connections. Marine Ecology Progress Series 388, 111119. 
González-Wevar CA, Nakano T, Cañete JI, Poulin E (2011) Concerted genetic, morphological and ecological diversification in Nacella limpets in the magellanic province. Molecular Ecology, 20, 1936-1951.

Gould AA (1846) Shells collected by the United States Exploring Expedition under the command of Charles Wilkes. Proceedings of the Boston Society of Natural History, 2, 148-152.

Gould AA (1852) Mollusca and shells. United States Exploring Expedition during the years 1838, 1839, 1840, 1841, 1842. Under the command of Charles Wilkes, U.S.N. 12. Gould \& Lincoln, Boston.

Haines JA, Crampton JS (2000) Improvements to the method of Fourier analysis as applied in morphometric studies. Palaeontology, 43, 765-783.

Hoffmann JI, Peck LS, Hilliard G, Zieritz A, Clark MS (2010) No evidence for genetic variation between Antarctic limpet Nacella concinna morphotypes. Marine Biology, 157, 765-778.

Hombron JB, Jacquinot CH (1841) Suite de la description de quelques mollusques, provenant de la campagne de l'Astrolabe et de la Zélée. Annales des Sciences Naturelles 2, Zoologie, 16, 190-192.

Hutton FW (1873) Catalogue of the marine Mollusca of New Zealand, with diagnoses of the species. Didsbury, Government Printer, Wellington.

Hutton FW (1878) Révision des coquilles de la Nouvelle-Zélande et des Îles Chatham. Journal de Conchyliologie, 26, 5-57.

Hutton FW (1880) Manual of the New Zealand Mollusca. A systematic and descriptive catalogue of the marine and land shells, and of the soft mollusks and Polyzoa of New Zealand and the adjacent islands. Wellington: Hughes, Government Printer. 
Hutton, F.W. (1884). Revision of the Recent rhipidoglossate and docoglossate Mollusca of New Zealand. Proceedings of the Linnean Society of New South Wales 9, 354-378.

Iredale T (1915) A commentary on Suter's "Manual of the New Zealand Mollusca". Transactions of the New Zealand Institute, 47, 417-497.

Kass DA, Traill TA, Keating M, Altieri PI, Maughan WL (1987) Abnormalities of dynamic ventricular shape change in patients with aortic and mitral valvular regulation: assessment by Fourier shape analysis and global geometric indexes. Circulation Research, 62, 127-138.

Kirkendale LA, Meyer CP (2004) Phylogeography of the Patelloida profunda group (Gastropoda: Lottiidae): diversification in a dispersal-driven marine system. Molecular Ecology, 13, 2749-2762.

Krapivka S, Toro JE, Alcapán AC, Astorga M, Presa P, Pérez M, Guiñez R (2007) Shell-shape variation along the latitudinal range of the Chilean blue mussel Mytilus chilensis (Hupe 1854). Aquaculture Research, 38, 1770-1777.

Lindberg DR (1979) Variations in the limpet, Collisella ochracea, and the northeastern Pacific distribution of Notoacmea testudinalis (Acmaeidae). Nautilus, 93, 50-56.

Lindberg DR (1988) Systematics of the Scurriini (new tribe) of the northern Pacific Ocean (Patellogastropoda: Lottiidae). Veliger, 30, 387-394.

Lindberg DR (1990) Systematics of Potamacmaea fluviatilis (Blanford): a brackish water patellogastropod (Patelloidinae: Lottiidae). Journal of Molluscan Studies, 56, 309-316.

Lindberg DR, Hickman CS (1986) A new anomalous giant limpet from the Oregon Eocene (Mollusca: Patellidae). Journal of Paleontology, 60, 661-668. 
Linberg DR, Vermeij GJ (1985) Patelloida chamorrorum spec. nov.: a new member of the Tethyan Patelloida profunda group (Gastropoda: Acmaeidae). Veliger, 27, 411-417.

Lindberg DR (2008) Patellogastropoda, neritimorpha, and cocculinoidea, the lowdiversity gastropod clades. In: Phylogeny and Evolution of the Mollusca (eds Ponder WF, Lindberg DR), pp. 271-296. University of California Press, Berkeley, Los Angeles, London.

Marshall BA (1985) Recent and Tertiary deep-sea limpets of the genus Pectinodonta Dall (Mollusca: Gastropoda) from New Zealand and New South Wales. New Zealand Journal of Zoology, 12, 273-282.

McDonald JH, Seed R, Koehn RK (1991) Allozymes and morphometric characters of three species of Mytilus in the Northern and Southern Hemispheres. Marine Biology, 111, 323-333.

Nakano T, Spencer HG (2007) Simultaneous polyphenism and cryptic species in an intertidal limpet from New Zealand. Molecular Phylogenetics and Evolution, $45,470-479$.

Nakano T, Sasaki T (2011) Recent advances in molecular phylogeny, systematics and evolution of patellogastropod limpets. Journal of Molluscan Research, 77, 203-217.

Pfenninger M, Schwenk K (2007) Cryptic animal species are homogeneously distributed among taxa and biogeographical regions. BMC Evolutionary Biology, 7, 121.

Pilsbry HA (1891-1892) Acmaeidae, Lepetidae, Patellidae, Titiscaniidae. Manual of Conchology; structural and systematic, with illustrations of the species, 13. Academy of Natural Sciences, Philadelphia.

Powell AWB (1933) The marine Mollusca of the Chatham Islands. Records of the Auckland Institute and Museum, 1, 181-208. 
Powell AWB (1937) The shellfish of New Zealand: an illustrated handbook. Unity Press, Auckland.

Powell AWB (1946) The shellfish of New Zealand: an illustrated handbook [second edition]. Whitcombe and Tombs, Christchurch.

Powell AWB (1955) Mollusca of the southern islands of New Zealand. Cape Expedition Series Bulletin 15. Department of Scientific and Industrial Research, Wellington.

Powell AWB (1957) Shells of New Zealand: an illustrated handbook [third edition]. Whitcombe and Tombs, Christchurch.

Powell AWB (1962) Shells of New Zealand: an illustrated handbook [fourth edition]. Whitcombe and Tombs, Christhurch.

Powell AWB (1973) The patellid limpets of the world (Patellidae). Indo-Pacific Mollusca, 3, 75-205.

Powell AWB (1976) Shells of New Zealand: an illustrated handbook [fifth, revised edition]. Whitcoulls, Christchurch.

Powell AWB (1979) New Zealand Mollusca - Marine, land and freshwater Shells. Collins, Auckland.

Preston SJ, Harrison A, Lundy M, Roberts D, Beddoe N, Rogowski D (2010) Square pegs in round holes- the implications of shell shape variation on the translocation of adult Margaritifera margaritifera (L.). Aquatic Conservation: Marine and Freshwater Ecosystems, 20, 568-573.

Rasband WS (2008) ImageJ, US National Institutes of Health, Bethesda, Maryland, USA, http://rsb.info.nih.gov/ij/ 
Reeve L (1854-55) Monograph of the genus Patella. Conchologia iconica; or, illustrations of the shells of molluscous animals, 8 . Reeve, London.

Reisser CMO, Wood AR, Bell JJ, Gardner JPA (2011) Connectivity, small islands and large distances: the Cellana strigilis limpet complex in the Southern Ocean. Molecular Ecology, 20, 3399-3413.

Sasaki T (2000) Patellogastropoda. In Marine mollusks in Japan (Ed. Okutani, T), 24-33. Tokai University Press, Japan.

Sasaki T, Okutani T (1993) Anatomy and systematic position of Yayioacmea, a new genus for Japanese tiny limpet 'Collisella' oyamai Habe, 1955 (Gastropoda: Lottiidae). Venus, 52, 193-209.

Sasaki T, Okutani T, Fujikura K (2003) New taxa and new records of patelliform gastropods associated with chemoautosynthesis-based communities in Japanese waters. Veliger, 46, 189-210.

Schulz-Mirbach T, Ladich F, Riesch R, Plath M (2010) Otolith morphology and hearing abilities in cave- and surface-dwelling ecotypes of the Atlantic molly, Poecilia mexicana (Teleostei: Poeciliidae). Hearing Research, 267, 137-148.

Skibinski DOF (1983) Natural selection in hybrid mussel populations. In Protein polymorphism: adaptive and taxonomic significance (Eds Oxford, G.S. and Rollinson, D.). Systematics Association Special Volume, 24. London: Academic Press, 283-298.

Smith EA (1874) Mollusca. In The zoology of the voyage of H.M.S. Erebus and Terror, under the command of Captain Sir James Clark Ross, R.N., F.R.S., during the years 1839 to 1843 (Eds Richardson, J. and Gray, J.E.). Jason, London, 1-7.

Statsoft (1994) Statistica for windows manuals. Tulsa, Oklahoma: Statsoft. 
Suter H (1904) Mollusca. In Index Faunae Novae Zealandiae (Ed. Hutton, F.W.). Dulau, London, pp 57-95.

Suter H (1905). Revision of the New Zealand Patellidae, with descriptions of a new species and subspecies. Proceedings of the Malacological Society of London, 5, 346-355.

Suter H (1909) The Mollusca of the Subantarctic islands of New Zealand. In The Subantarctic islands of New Zealand. Reports on the geo-physics, geology, zoology, and botany of the islands lying to the south of New Zealand, based mainly on observations and collections made during an expedition in the Government steamer "Hinemoa" (Captain J. Bollons) in November 1907 (Ed. Chilton, C.), 1. Wellington: Philosophical Institute of Canterbury, pp 1-57.

Suter H (1913) Manual of the New Zealand Mollusca. With an atlas of quarto plates (1915). MacKay, Government Printer, Wellington.

Teske PR, Barker NP, MacQuaid CD (2007) Lack of genetic differentiation among four sympatric southeast African intertidal limpets (Siphonariidae): phenotypic plasticity in a single species? Journal of Molluscan Studies, 73, 223-228.

Vrijenhoek RC (2009) Cryptic species, phenotypic plasticity, and complex life histories: Assessing deep-sea faunal diversity with molecular markers. DeepSea Research II, 56, 1713-1723.

West-Eberhard MJ (2005) Developmental plasticity and the origin of species differences. Proceedings of the National Academy of Sciences USA, 102, 6543-6549.

Wingstrand KG (1985) On the anatomy and relationships of Recent Monoplacophora. Galathea Report, 16, 7-94. 
Witt JDS, Threloff DL, Herbert PDN (2006) DNA barcoding reveals extraordinary cryptic diversity in an amphipod genus: implication for desert spring conservation. Molecular Ecology, 15, 3073-3082.

Yoshioka Y, Iwata H, Ohsawa R, Ninomiya S (2004) Analysis of petal shape variation of Primula sieboldii by elliptic Fourier descriptors and principal component analysis. Annals of Botany, 94, 657-664. 



\title{
CHAPTER IV
}

\section{ISOLATION AND CHARACTERIZATION OF POLYMORPHIC MICROSATELLITE MARKERS FOR THE INTERTIDAL SEA SNAIL NERITA MELANOTRAGUS E.A. SMITH, 1884.}

\begin{abstract}
The genus Nerita is commonly found on diverse type of substrates on tropical shores, with a few species living in temperate waters. Its relatively long pelagic larval duration and its cosmopolitan distribution make this genus a good candidate for population connectivity studies. However, as it is often the case with non-model species, very little effort has been put into developing suitable specific markers for this type of study. Here, I developed 10 highly variable microsatellite markers for $N$. melanotragus, a temperate species occurring in eastern Australia, New Zealand, as well as Norfolk, Lord Howe and the Kermadec islands. Seven of these ten markers are subsequently used in the following chapter to study population connectivity and self-recruitment levels across New Zealand and the Kermadec Islands.
\end{abstract}




\subsection{Introduction}

The genus Nerita consists of approximately 70 extant species and represents one of the most prominent intertidal groups along tropical shores, and although most species inhabit tropical regions, a few species can be found on temperate coastlines. It is believed that the genus extends back to the late Cretaceous (Saul and Squires, 1997; Bandel and Kiel, 2003). Nerita species have colonised diverse habitats such as mangroves, muddy cobble, sand, but are mostly found on rocky substrates. While interspecific variation in larval duration appears to exist (Kano, 2006), most Nerita species produce veliger larvae that spend weeks to months in the plankton (Lewis, 1960; Underwood, 1975), suggesting extensive dispersal potential. Their extended pelagic larval duration (PLD) and near cosmopolitan distribution highlight the suitability of Nerita species for biogeography and dispersal studies.

Nerita melanotragus E.A. Smith, 1884, also known as the Black Nerite, is an intertidal cosmopolitan sea snail present on the rocky shore of eastern Australia, Lord Howe Island, Norfolk islands, the Kermadec Islands and New Zealand. Its PLD of 5 to 6 months (inferred by Waters et al. 2005) and its widespread distribution across the Tasman Sea are highly suitable for the study of connectivity in this area of the world.

Study of connectivity requires the use of highly polymorphic markers, such as microsatellites, to characterize genetic diversity and population differentiation. Here I developed 10 microsatellite markers to study the connectivity and self-recruitment level in populations of N. melanotragus from the Kermadec islands and the North Island of New Zealand.

\subsection{Material and Methods}

\subsubsection{Sample collection and storage}

Samples of $N$. melanotragus were collected during two independent research trips in 2002 and 2004 in the Kermadec Islands Marine Reserve (KIMR). In total, 275 individuals were sampled from six different populations around the northern part of KIMR (Fig 4.1). Samples were preserved in ethanol and then stored at $4^{\circ} \mathrm{C}$. 


\subsubsection{DNA extraction}

High quality genomic DNA was extracted from $24 \mathrm{~N}$. melanotragus individuals collected in the Kermadec Islands, using the High Pure PCR Template preparation kit (Roche). A volume of $50 \mu \mathrm{L}$ of saturated $\mathrm{KCl}$ solution $(34.5 \mathrm{~g} / 100 \mathrm{ml})$ was added to the digested DNA in order to precipitate the polysaccharides contained in the mucus. The mix was centrifuged at $14 \mathrm{rpm}$ for 15 minutes and the supernatant was removed and used in the next steps of the DNA extraction following Roche's instruction. DNA samples were then ran on a $1 \%$ ethidium bromide stained gel against a high mass ladder to estimate template DNA concentration.

\subsubsection{Roche 454 GS FLX template preparation and sequencing}

Approximately 100ng of DNA from one individual (Dayrell Island, Kermadec Islands, New Zealand) showing the best DNA quality was picked for a sixteenth of a run on a Roche 454 GS-FLX instrument (High-Throughput DNA Sequencing Unit, Department of Anatomy and Structural Biology, University of Otago, Dunedin, New Zealand). The DNA library was constructed by fractioning the genomic DNA into smaller fragments (300-800 base pairs) and blunting (polishing) each end. The bluntended, double-stranded DNA fragments were then subjected to adapter ligation followed by isolation of the single-stranded template DNA (sstDNA). Subsequently, DNA library fragments were captured onto beads and clonally amplified within individual emulsion droplets (emPCR). The emulsions were disrupted using isopropanol and beads containing amplified DNA fragments were enriched and recovered for sequencing. The recovered sstDNA beads were packed onto a quarter division of a $70 \mathrm{~mm} \times 75 \mathrm{~mm}$ PicoTiterPlate (454 Life Sciences), loaded onto the GSFLX sequencing system and sequenced following King \& Scott-Horton (2008) pyrosequencing procedure. The run yielded 68758 reads comprised between $49 \mathrm{bp}$ and $1200 \mathrm{bp}$ and with a mean of $525 \mathrm{bp}$ (Fig.4.2).

\subsubsection{Reads screening for STR motifs}

I screened the 68,758 reads for sequence quality and removed the $14 \mathrm{bp}$ primers used for 454 sequencing. Subsequently, the trimmed data were screened for STR sequences using iQDD V1.3 (Meglecz et al 2010). This PERL program 


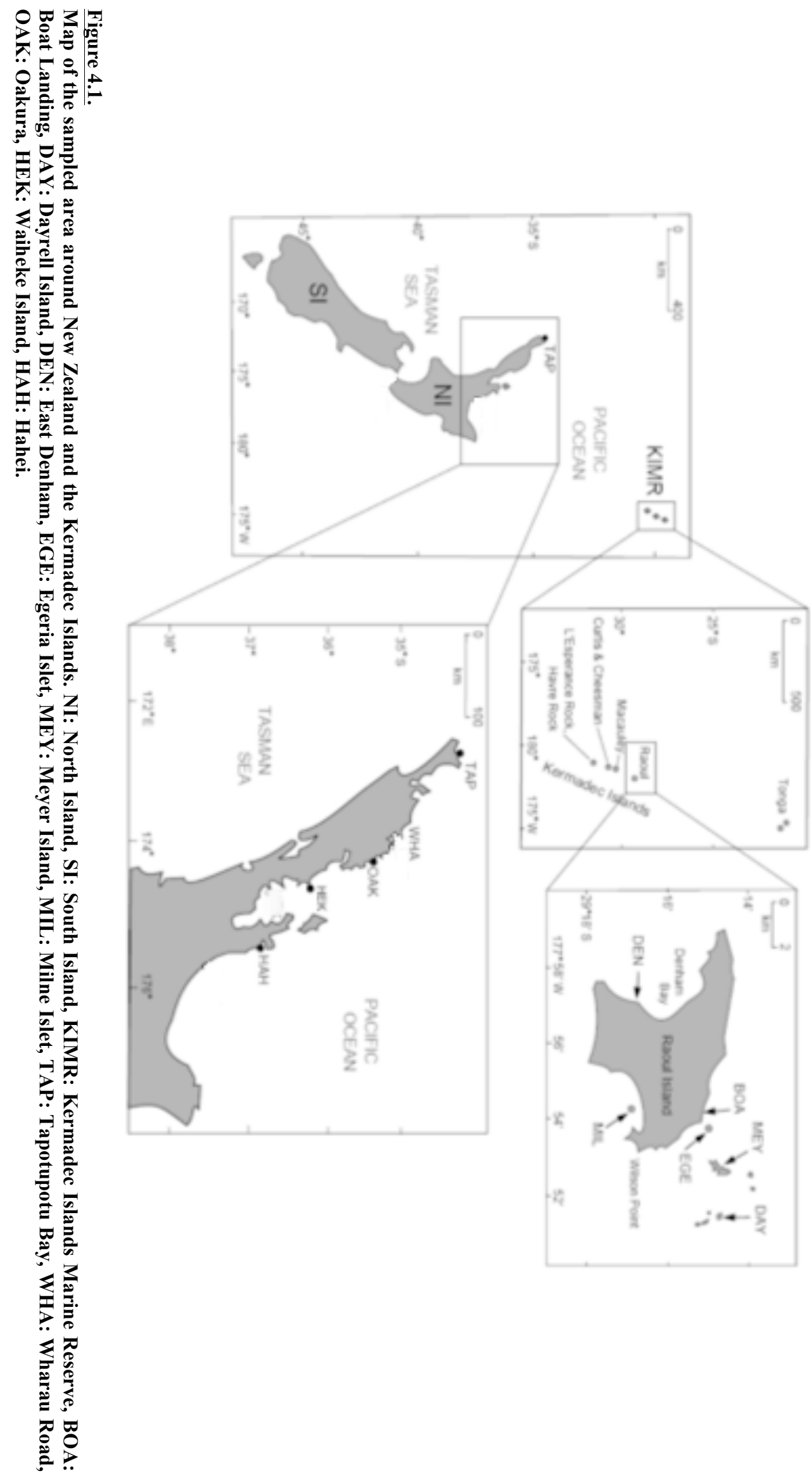


combines the use of Blast, Clustal and Primer3 to trim the sequences, detect STR and design possible primer pairs for PCR amplification. Minimum sequence length and minimum PCR product size were set to $100 \mathrm{bp}$ and $90 \mathrm{bp}$ respectively. Minimum repeat length was set to $8,6,4$ and 4 for di-, tri-, tetra- and pentanucleotide motifs respectively. A total of $411 \mathrm{di}-$, tri-, tetra- and pentanucleotide repeat sequences were detected, and 3,157 primer pairs were created by Primer3. Only the best primer pair for each STR sequence was retained. The pairs were later organized according to their penalties and PCR product size, and 60 of them were retained for PCR testing according to their potential for multiplexing (Table 4.1).

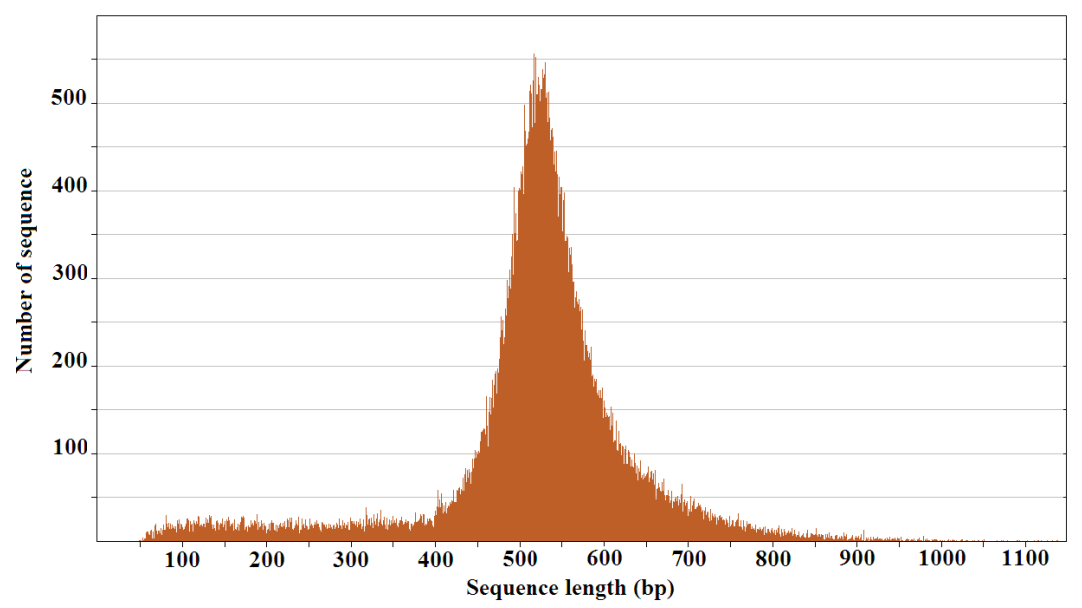

Figure 4.2.

Length-frequency graph of the 68,758 reads obtained with a $1 / 16^{\text {th }}$ run on a 454 GS FLX machine.

\subsubsection{PCR amplification and genotyping}

Four randomly selected individuals from the Dayrell Island population were tested with each primer, using two different types of PCR protocols: a gradient PCR and a Touchdown PCR. Cycles for both protocols are shown in Table 5.2. Gradient PCR is a useful method to identify the optimum primer annealing temperature (Prezioso \& Jahns 2000). Touchdown PCR is a protocol allowing increased specificity and sensitivity in PCR amplification (Korbie \& Mattick 2008). PCR products were run on a $1 \%$ Ethidium Bromide stained agarose gel and visualized using a Gel Logic system. Although both PCR successfully amplified 36 STRs, the Touchdown protocol gave the highest product concentration and quality and was thus retained for further amplifications. 


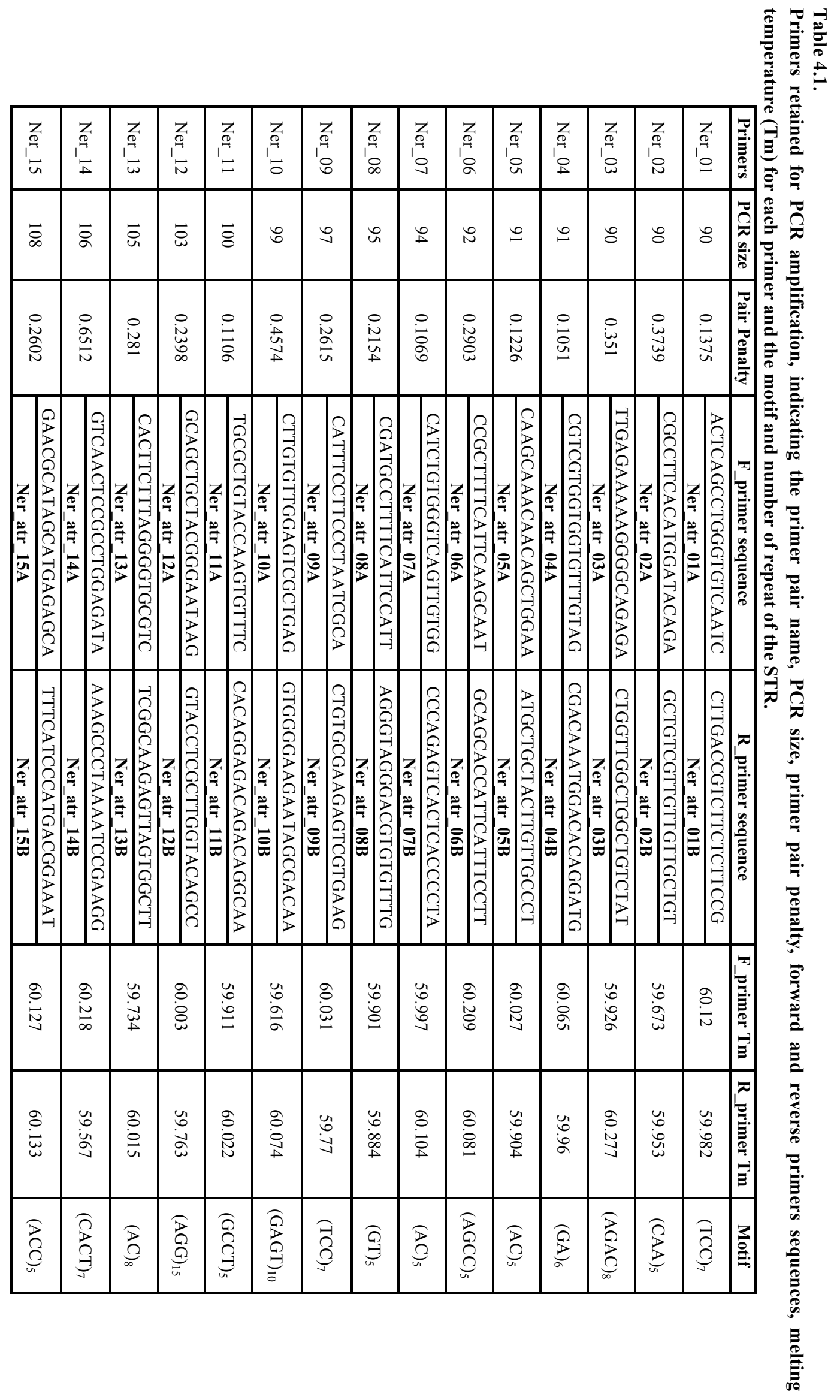




\begin{tabular}{|c|c|c|c|c|c|c|c|c|c|c|c|c|c|c|c|}
\hline 总 & 总 & 总 & 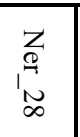 & 总 & 西 & 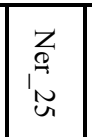 & 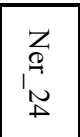 & 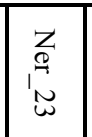 & $\mid \begin{array}{l}\text { 童 } \\
\text { 总 }\end{array}$ & 总 & 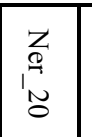 & 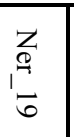 & 夯 & 惌 & $\begin{array}{ll}z \\
\stackrel{z}{g} \\
\sigma\end{array}$ \\
\hline $\bar{\varpi}$ & $\overline{\mathcal{J}}$ & $\bar{్}$ & $\vec{\sim}$ & $\bar{v}$ & $\bar{w}$ & $\bar{N}$ & $\vec{b}$ & $\Xi$ & $\bar{\sigma}$ & $\overline{\bar{n}}$ & $\bar{F}$ & $\bar{F}$ & $\bar{\xi}$ & $\bar{\omega}$ & \\
\hline do & 善 & 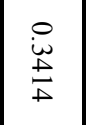 & 苦 & 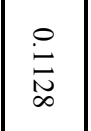 & 产 & 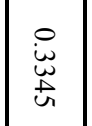 & $\begin{array}{l} \\
\vdots \\
\vdots \\
0\end{array}$ & 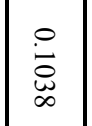 & 咅 & 竘 & 总 & 总 & 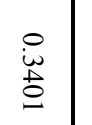 & $\begin{array}{l}8 \\
\dot{0} \\
0 \\
0\end{array}$ & 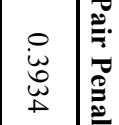 \\
\hline & 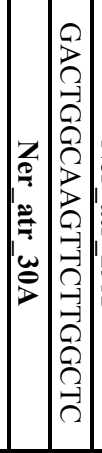 & 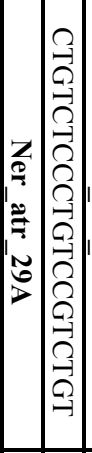 & & 章 & 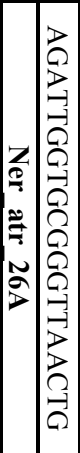 & & 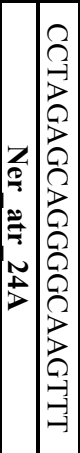 & 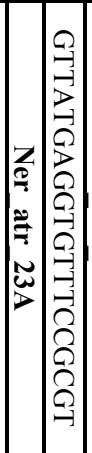 & 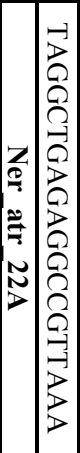 & 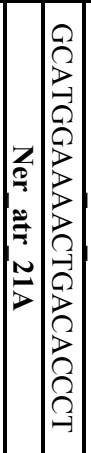 & 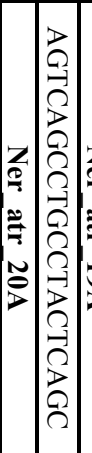 & & & & 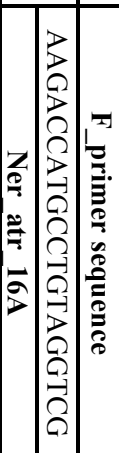 \\
\hline & 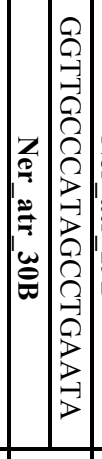 & 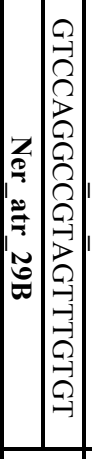 & 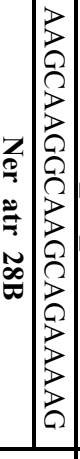 & 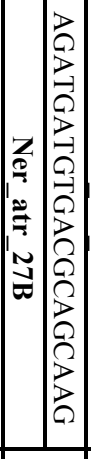 & 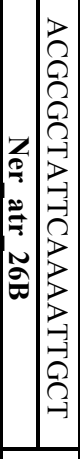 & 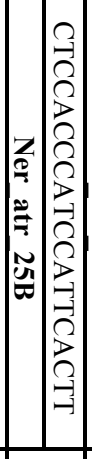 & 童 & 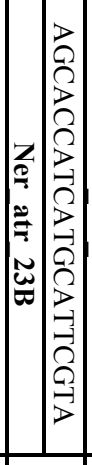 & 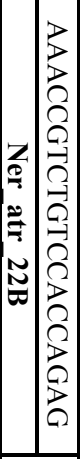 & 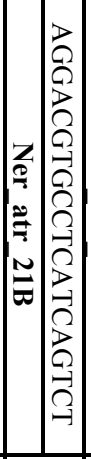 & 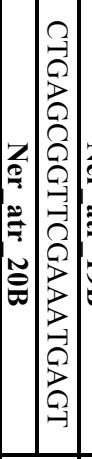 & 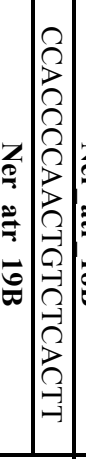 & 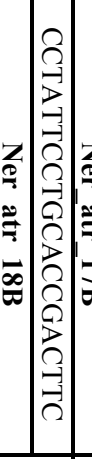 & 告 & 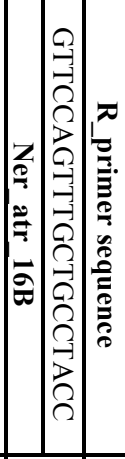 \\
\hline $\begin{array}{l}\text { 岁 } \\
\stackrel{0}{\circ}\end{array}$ & 岁 & 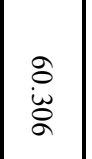 & 岕 & 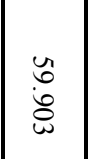 & 总 & 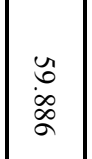 & 悹 & 8 & 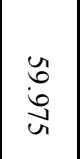 & 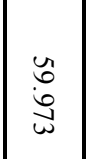 & 岁 & 誌 & 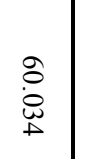 & iे & 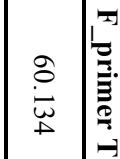 \\
\hline 怠 & $\begin{array}{l}\text { 岁 } \\
\text { : }\end{array}$ & 总 & 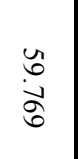 & $\frac{\partial}{\partial}$ & 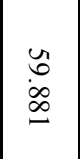 & 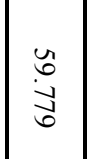 & 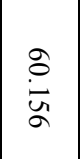 & $\begin{array}{l}8 \\
8 \\
\vdots \\
\vdots\end{array}$ & 兽 & 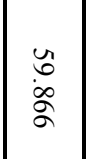 & 总 & 言 & $\begin{array}{l}\text { 总 } \\
0 \\
0\end{array}$ & : & 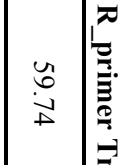 \\
\hline $\begin{array}{l}\widehat{\widehat{a}} \\
\hat{3} \\
\end{array}$ & 高 & 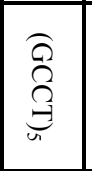 & $\begin{array}{l}\widehat{\hat{a}} \\
\hat{a} \\
\hat{\omega}\end{array}$ & $\begin{array}{l}\hat{3} \\
\stackrel{3}{0} \\
\underline{3}\end{array}$ & 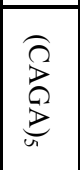 & \begin{tabular}{|l|}
$\vec{A}$ \\
$\hat{D}$ \\
总
\end{tabular} & 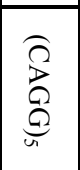 & $\widehat{\widehat{g}}$ & 产 & $\begin{array}{c}\hat{\mathrm{a}} \\
\mathrm{d} \\
\mathrm{o}\end{array}$ & 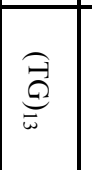 & 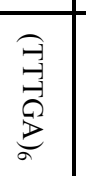 & 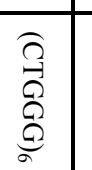 & $\widehat{\widehat{G}}$ & 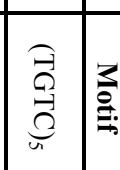 \\
\hline
\end{tabular}




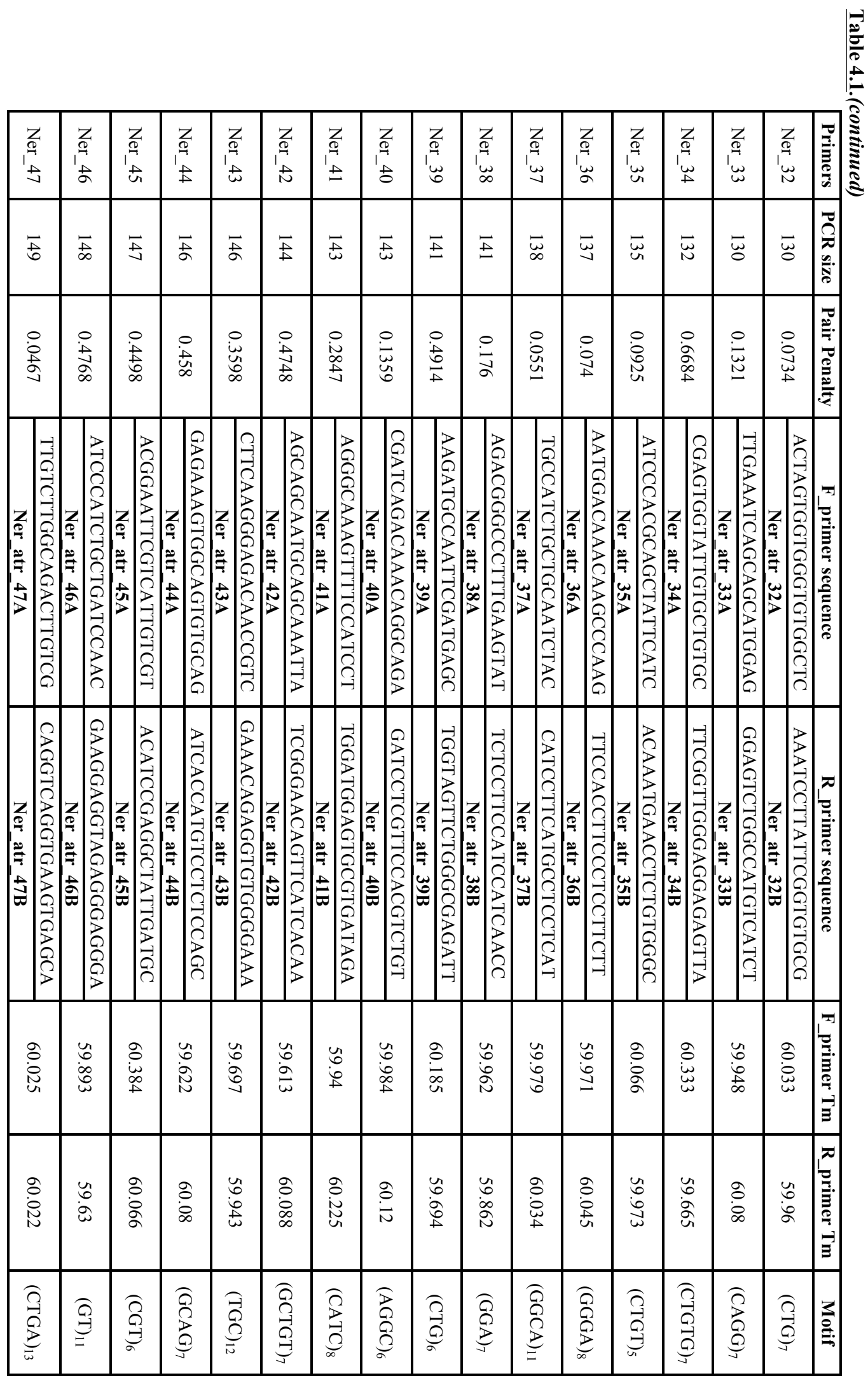




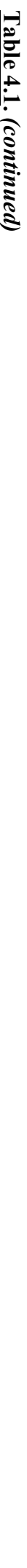


Table 4.2.

PCR cycles of both Touchdown (T-down) and gradient PCRs, tested on N. melanotragus.

\begin{tabular}{|c|c|c|c|c|}
\hline & Initial Denaturation & \multicolumn{2}{|r|}{$\begin{array}{c}\text { Denaturation } \\
\text { Annealing } \\
\text { Elongation } \\
\end{array}$} & Final Elongation \\
\hline Gradient & $2 \mathrm{~min}$ at $94^{\circ} \mathrm{C}$ & $30 \mathrm{x}$ & $\begin{array}{l}20 \mathrm{sec} \text { at } 94^{\circ} \mathrm{C} \\
30 \mathrm{sec} \text { at } 45 / 57^{\circ} \mathrm{C}^{*} \\
30 \mathrm{sec} \text { at } 72^{\circ} \mathrm{C}\end{array}$ & $7 \mathrm{~min}$ at $72^{\circ} \mathrm{C}$ \\
\hline \multirow[t]{3}{*}{ T-down } & \multirow[t]{3}{*}{$2 \mathrm{~min}$ at $96^{\circ} \mathrm{C}$} & $20 \mathrm{x}$ & \multirow{3}{*}{$\begin{array}{l}20 \mathrm{sec} \text { at } 94^{\circ} \mathrm{C} \\
30 \mathrm{sec} \text { at } 55 / 45^{\circ} \mathrm{C}^{* *} \\
30 \mathrm{sec} \text { at } 72^{\circ} \mathrm{C} \\
20 \mathrm{sec} \text { at } 94^{\circ} \mathrm{C} \\
30 \mathrm{sec} \text { at } 45^{\circ} \mathrm{C} \\
30 \mathrm{sec} \text { at } 72^{\circ} \mathrm{C}\end{array}$} & \\
\hline & & then & & \\
\hline & & $25 \mathrm{x}$ & & $7 \mathrm{~min}$ at $72^{\circ} \mathrm{C}$ \\
\hline
\end{tabular}

* Annealing temperature is raised by $1^{\circ} \mathrm{C}$ from one column to another on the PCR block

** Annealing temperature is progressively lowered of $0.5 \mathrm{C}$ every cycles for all samples

Four randomly selected individuals from the Dayrell Island population were tested with each primer using a Touchdown (TD) PCR protocol (Table 1). The $12.5 \mu \mathrm{L}$ reaction mix contained $\sim 50-100 \mathrm{ng}$ of DNA template, $6.25 \mu \mathrm{L}$ of Bioline MyTaq Mix ${ }^{\circledR}(0.11$ units/ $\mu \mathrm{L}$ Taq DNA polymerase $82.5 \mathrm{mM}$ Tris-Hcl $\mathrm{pH} 8.5,22 \mathrm{mM}$ (NH4)SO4, $1.65 \mathrm{mM} \mathrm{MgCl} 2,0.22 \mathrm{mM}$ dNTPs), $0.5 \mu \mathrm{L}$ of Forward and Reverse primers and $d d \mathrm{H} 2 \mathrm{O}$ to volume. PCR products were run on a $2 \%$ ethidium bromide stained agarose gel and visualized using a Gel Logic system. A total of 36 primer pairs $(60 \%)$ amplified successfully and were consequently tested on four randomly chosen individuals from five different populations across the east coast of New Zealand North Island (Fig. 4.1). A total of 16 pairs were retained after displaying a high level of polymorphism among individuals. The 5'ends of the Forward primers were tagged with fluorochrome labels 6-FAM, NED, PET, and VIC and organised into 4 multiplex groups using Multiplex Manager V1.0. (Table 5.3) (Holleley \& Geerts 2009) to be sent for genotyping on an ABI3730 Genetic Analyzer (Massey Genome Service, Palmerston North, New Zealand) using 500LIZ size standard. PCR products were high quality and had to be diluted 200 times to obtain the optimum peak amplitude for microsatellite scoring. Subsequently, those 16 primers were used on 31 individuals from Oakura Bay and tested for linkage disequilibrium and departure from Hardy Weinberg equilibrium, in GENEPOP (Rousset 2008). P-values were adjusted to control for the False Discovery Rate (FDR) (Benjamini \& Hochberg 122 
1995). Possible reasons for deviation of HWE were investigated with MICROCHECKER (Van Oosterhout et al 2004)

\subsection{Results and discussion:}

Among the 16 primer pairs tested, five (Ner_atr_25, 28, 40, 44, and 53) showed significant scoring issues, with individuals displaying 3 peaks or over for more than half of the dataset, and had to be discarded. The generated chromatographs of the 10 remaining pairs were consistent with expected tri-, tetra- and

Table 4.3.

Fluorescent tagging and multiplex group organization of the 15 primers retained in the analysis.

\begin{tabular}{|c|c|c|c|}
\hline Group & Primer name & Primer sequence & Fluorescence \\
\hline \multirow{4}{*}{1} & Ner_06A & CCGCTTTTCATTCAAGCAAT & NED \\
& Ner_15A & GAACGCATAGCATGAGAGCA & 6-FAM \\
& Ner_21A & GCATGGAAAACTGACACCCT & PET \\
& Ner_42A & AGCAGCAATGCAGCAAATTA & VIC \\
& Ner_48A & ATCCCAGCAGAGGCGTAGTA & 6-FAM \\
\hline \multirow{6}{*}{2} & Ner_18A & AAGGAGCCGGGAGAAAATTA & 6-FAM \\
& Ner_28A & AAATTTGCTTTCGCCTGTGT & PET \\
& Ner_35A & ATCCCACGCAGCTATTCATC & VIC \\
& Ner_37A & TGCCATCTGCTGCAATCTAC & NED \\
& Ner_55A & TGAAGTCAGTCGGCTTCTCA & 6-FAM \\
\hline \multirow{3}{*}{3} & Ner_32A & ACTAGTGGTGGGTGTGGCTC & 6-FAM \\
& Ner_49A & CCGGGTGTTTTGTCATTAGG & VIC \\
\hline \multirow{6}{*}{4} & Ner_25A & GTCATAGGATGGGAGACGGA & 6-FAM \\
& Ner_40A & CGATCAGACAAACAGGCAGA & HEX \\
& Ner_44A & GAGAAAGTGGCAGTGTGCAG & HEX \\
& Ner_53A & TTAAGACACGCCTTCTGCCT & 6-FAM \\
\hline
\end{tabular}

pentanucleotide STR patterns. Summary statistics for the 10 loci are presented in Table 5.4. Three loci showed significant departure from HWE and there was no linkage disequilibrium among the loci. MICRO-CHECKER attributed this disequilibrium to scoring mistakes due to stuttering and/or the presence of null alleles. Microsatellite null alleles are widespread, but some groups, especially marine invertebrates, demonstrate particularly high frequencies of null alleles (Hare et al. 1996; Bester et al 2004; Hedgecock et al. 2004). However, this disequilibrium could 


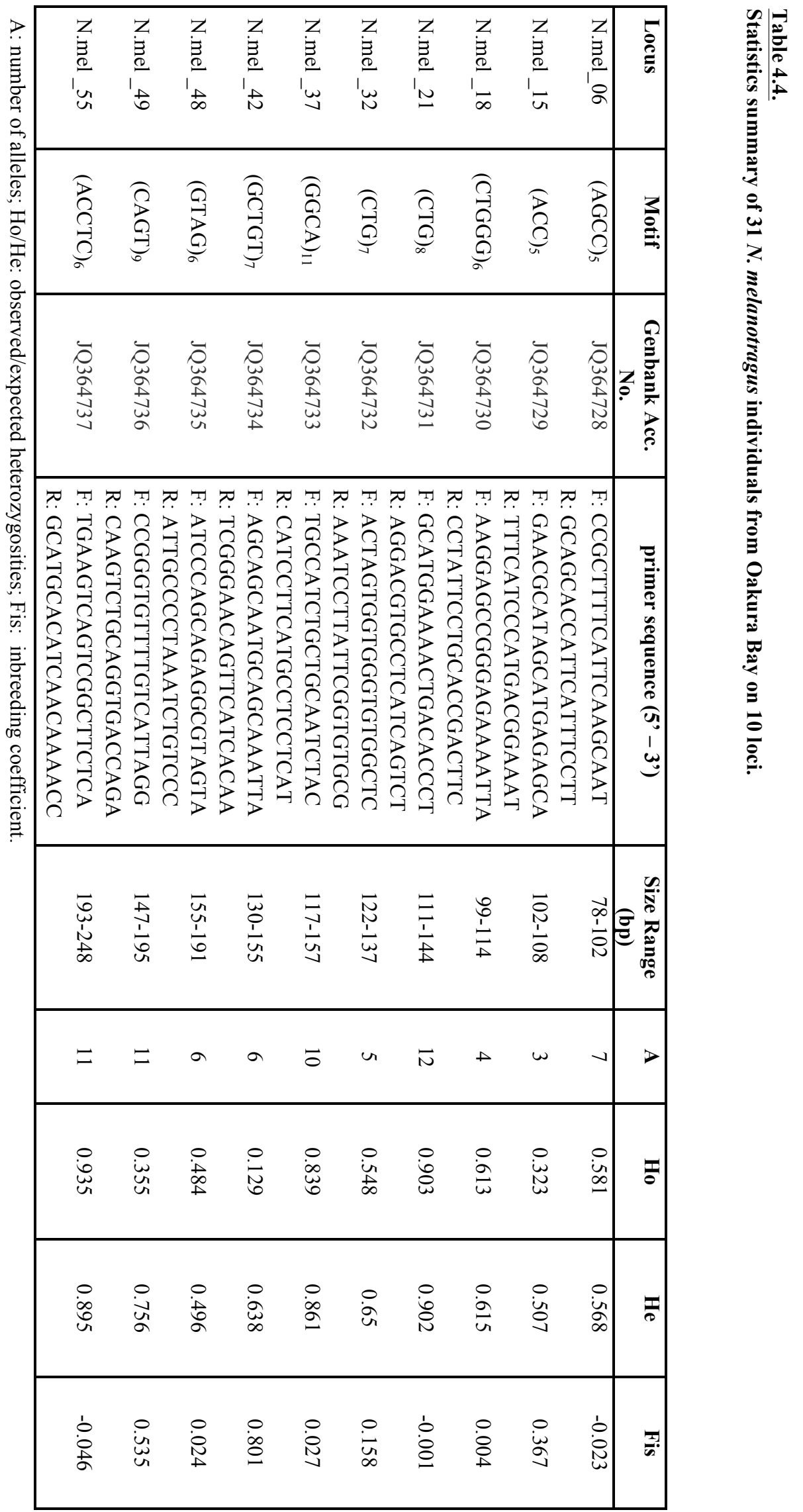


be due to selection or environmental pressure on the population investigated. The addition of new individuals from different population will address this concern: the 10 loci will be used in the next chapter for population genetics analysis of $N$. melanotragus across 15 populations from New Zealand and the Kermadec Islands.

\subsection{References:}

Bandel K, Kiel S (2003) Relationships of Cretaceous Neritimorpha (Gastropoda, Mollusca), with the description of seven new species. Bulletin of the Czech Geological Survey, 78, 53-65.

Benjamini Y, Hochberg Y (1995) Controlling the false discovery rate: a practical and powerful approach to multiple testing. Journal of the Royal Statistical Society. Series B (Methodological), 57, 289-300.

Bester AE, Slabbert R, D'amato ME (2004) Isolation and characterization of microsatellite markers in the South African abalone (Haliotis midae). Molecular Ecology Notes, 4, 618-619.

Hare MP, Karl SA, Avise JC (1996) Anonymous nuclear DNA markers in the American oyster and their implications for the heterozygote deficiency phenomenon in marine bivalves. Molecular Biology and Evolution, 13, 334 345.

Hedgecock D, Li G, Hubert S, Bucklin K, Ribes V (2004) Widespread null alleles and poor cross-species amplification of microsatellite DNA loci cloned from the pacific oyster, Crassostrea gigas. Journal of Shellfish Research, 23, 379-385.

Holleley CE, Geerts PG (2009) Multiplex Manager 1.0: a crossplatform computer program that plans and optimizes multiplex PCR. BioTechniques, 46, 511-517.

Kano Y (2006) Usefulness of the opercular nucleus for inferring early development in neritimorph gastropods. Journal of Morphology, 267, 1120-1136. 
King C., Scott-Horton T. (2008). Pyrosequencing: A Simple Method for Accurate Genotyping. Journal of Visualized Experiments, 11, 630. doi: 10.3791/630.

Korbie DJ, Mattick JS (2008) Touchdown PCR for increased specificity and sensitivity in PCR amplification. Nature Protocols, 3, 1452-1456.

Lewis JB (1960) The fauna of rocky shores of Barbados, West Indies. Canadian Journal of Zoology, 38, 391-435.

Meglécz E, Costedoat C, Dubut V, Gilles A, Malausa T, Pech N, Martin JF (2010) QDD: a user-friendly program to select microsatellite markers and design primers from large sequencing projects. Bioinformatic, 26, 403-404.

Powell AWB (1979) New Zealand Mollusca: Marine, Land and Freshwater. Collins, Auckland.

Prezioso VR, Jahns A (2000) Using gradient PCR to determine the optimum annealing temperature. Bioresearch Online, http://www.bioresearchonline.com/article.mvc/Using-Gradient-PCR-toDetermine-the-Optimum-A-0001.

Rousset F (2008) GENEPOP'007: a complete re-implementation of the GENEPOP software for Windows and Linux. Molecular Ecology Resources, 8, 103-106.

Saul LR, Squires RL (1997) New species of neritid gastropods from Cretaceous and lower Cenozoic strata of the Pacific Slope of North America. Veliger, 40, $131-147$.

Underwood AJ (1975) Comparative studies on the biology of Nerita atramentosa Reeve, Bembicium nanum (Lamarck) and Cellana tramoserica (Sowerby) (Gastropods: Prosobranchia) in S.E. Australia. Journal of Experimental Marine Biology and Ecology, 18, 153-172. 
Van Oosterhout CV, Hutchinson WF, Wills DPM, Shipley P (2004) MICROCHECKER: software for identifying and correcting genotyping errors in microsatellite data. Molecular Ecology Notes, 4, 535-538.

Waters JM, King TM, O’Loughlin PM, Spencer HG (2005) Phylogeographical disjunction in abundant high-dispersal littoral gastropods. Molecular Ecology, 14, 2789-2802. 



\title{
CHAPTER V
}

\section{MULTI-SCALE SPATIAL CONNECTIVITY OF AN INTERTIDAL GASTROPOD, NERITA MELANOTRAGUS, IN THE SOUTH PACIFIC OCEAN}

\begin{abstract}
Whether marine populations are "open or closed" has been and remains a matter of debate in the literature. However, recent reports of higher than expected indicate that marine populations might not be as open as previously thought. Recent studies reported high levels of genetic differentiation and self-recruitment among populations of numerous species separated by a short geographical distance. Other studies also demonstrated that at a similar geographic scale, island populations show a higher genetic structuring than mainland populations. One explanation for this pattern is that islands themselves, by their fragmented nature, create local currents or eddies that might entrap the larvae and retain them close to home.

Here, I investigated the genetic structuring of $N$. melanotragus populations from the Kermadec Islands and mainland New Zealand, and compared the genetic structuring among populations within each group and between the two groups. Results showed a complete lack of genetic structuring within and between both groups, with low Fst values and an absence of isolation by distance. Hence, the theory that islands themselves increase genetic structuring could not be tested. However, the genetic homogeneity found here raises interesting questions regarding the connectivity potential of remote habitats.
\end{abstract}




\subsection{Introduction}

One of the most fundamental debates between marine biologists in recent decades concerns the degree to which populations are "open or closed" (Swearer et al. 1999, Cowen et al. 2000). In an "open" population, migration (based on the export and import of larvae/adults) is sufficient to generate low or non-existent levels of genetic differentiation between the source and the receiving populations. In contrast, in a "closed" population, migration is insufficient to promote genetic homogeneity, leaving the populations genetically differentiated from each other (Cowen 2000, Cowen \& Sponaugle 2009). Here, I consider a population to be a group of individuals of the same species that co-occur in space and time and have an opportunity to interact with each other (Waples \& Gaggioti 2006). Early research on marine connectivity considered most populations of marine species to be open, because of the continuous fluid nature of the oceans and life-history characteristics of marine organisms (particularly the dominating presence of a dispersive larval stage and/or adults with great capacity to move). As a result, post-metamorphic individuals, larvae and spores are likely to be transported many kilometres away from their natal sites, thus allowing migration to other populations (Scheltema 1986). However, there is increasing evidence to support the presence of barriers to gene flow, as well as population differentiation, sometimes even at the scale of only a few kilometres (Swearer et al. 1999, Wright et al. 2000, Taylor \& Hellberg 2003, Bell \& Okamura 2005, Cowen et al. 2006, Johnson \& Black 2006, Wood \& Gardner 2007), leading to the conclusion that marine populations may not be as "open" as previously thought.

Oceanic island populations represent an interesting model for the study of population connectivity. By definition, oceanic islands are not part of continental shelf areas; they are not and have never been connected to any continent. Hence, species occurring on those islands originated from the historical or still ongoing dispersion of continental species, some of which subsequently evolved on the island. However, the fact that many remote island biotas differ greatly from those of continents (i.e. they are taxon-poor and yet rich in endemic species) seems to indicate that self-recruitment occurs on a regular basis in their populations and that immigration of larvae/adults via dispersal from more distance sources might be 
limited. For example, in his study conducted in northern Europe (Ireland, United Kingdom, and Wales) Bell (2008) found that connectivity between islands and the mainland was limited compared to connectivity between different mainland locations, implying that island populations rely mostly on local recruitment and self-recruitment.

Knowing the challenges that survival represents for an oceanic island endemic species with a larval stage, their presence on many isolated archipelagos is intriguing, and a growing number of publications are focusing on comparing levels of selfrecruitment and genetic structuring among islands populations and between island and continental populations (e.g. Parson 1996, Johnson \& Black 2006, Bird et al. 2007, Wood \& Gardner 2007, Bell 2008). In their studies on Austrocochlea constricta, Johnson and Black (2006) compared island population subdivision to mainland population subdivision in the Houtman Abrolhos Islands and the coast of Western Australia. They found that population subdivision of several species was much higher in the islands than along the mainland coast at comparable geographic distances. One of the theories proposed by these authors is that islands themselves, because of their fragmented structure, create local currents or eddies, which entrap locally produced larvae and retain them on a scale of two kilometres or less. Similar conclusions were reached by Wood \& Gardner (2007), who focussed only on island populations and detected small-scale genetic structuring in two endemic species of the Kermadec Islands. Hence, island populations appear more "closed" than continental populations at an equivalent spatial scale.

To test whether island populations showed a higher genetic structuring and levels of self-recruitment than continental populations, I investigated the genetic diversity, genetic structuring and levels of connectivity of Nerita melanotragus, an intertidal marine gastropod occurring within the remote Kermadec Islands Marine Reserve (KIMR) and on the North Island coasts (NI) of New Zealand. Nerita is a genus of widely occurring snails (Neritidae, Gastropoda, Mollusca) found mainly along the tropical and subtropical coasts, but with a few species including $N$. melanotragus occurring in temperate regions. N. melanotragus, also known as the Black Nerite, has a pelagic larval duration (PLD) of 5 to 6 months (inferred in Waters et al. 2005) and has been taxonomically separated from its sister species $N$. atramentosa after recent phylogenetic investigation (Spencer et al. 2007). N. 
melanotragus occurs on the intertidal rocky shores of eastern Australia, northern New Zealand, Lord Howe Island, Norfolk Island and the Kermadec Islands.

The Kermadec Islands are a subtropical island arc in the South Pacific Ocean, composed of 11 islands approximately 0.6 to $1.4 \mathrm{M}$ yr old (Gabites Appendix 2 in Lloyd \& Nathan 1981). They are divided in to three groups: the northern group $\left(29^{\circ}\right.$ $\left.15^{\prime} \mathrm{S}, 177^{\circ} 55^{\prime} \mathrm{W}\right)$ with Raoul Island and its outlying islets, the middle group $\left(30^{\circ}\right.$ $\left.14^{\prime} \mathrm{S}, 178^{\circ} 25^{\prime} \mathrm{W}\right)$ with Curtis and Macauley Islands, and the southern group $\left(31^{\circ}\right.$ $21^{\prime} \mathrm{S}, 178^{\circ} 48^{\prime} \mathrm{W}$ ) with L'Esperance Rock. The Kermadec biota is recognized as unique and species rich, its marine environment providing important links between the temperate waters of mainland New Zealand and tropical waters. The islands have been protected by the Department of Conservation (DOC) since 1990 through the designation of the Kermadec Islands Marine Reserve (KIMR). It is NZ's largest marine reserve and the protection zone covers 745,000 hectares $\left(7450 \mathrm{~km}^{2}\right)$.

As with most remote habitats, relatively few studies have taken place on the Kermadec Islands, and those that have been conducted mainly focussed on physiology (Creese et al. 1990) and species distribution and abundance patterns (Schiel et al. 1986 and Gardner et al. 2006 on benthic organisms; Cole 2001 on herbivorous fishes, and Francis et al. 1987 and Eddy et al. 2011 on coastal fishes; Brook 1999 on coral communities; Wicks et al. 2010 on zooxanthellae; Brook 1998 on molluscs). Only two studies have investigated levels of population connectivity and genetic diversity within the Kermadec archipelago (Wood \& Gardner 2007; Wicks et al. 2010). However, the mix of warm temperate, tropical and subtropical components that characterizes KIMR biodiversity indicates that species of this archipelago are likely to be, or have been in the past, connected with other landmasses and islands such as NZ and Tonga.

This study is the first to investigate genetic connectivity between KIMR and mainland NZ, and to compare levels of population connectivity and genetic structuring among the two groups. The levels of population connectivity were investigated at three different spatial scales: (1) the micro-scale level (geographic separation ranging from 0.7 to 15 kilometres) within the northern island group of KIMR, (2) the meso-scale level (from 14 to 1100 kilometres) along the NZ North Island (NI) coasts, and (3) the macro-scale level (from 1000 to 2000 kilometres) between KIMR and NI. 


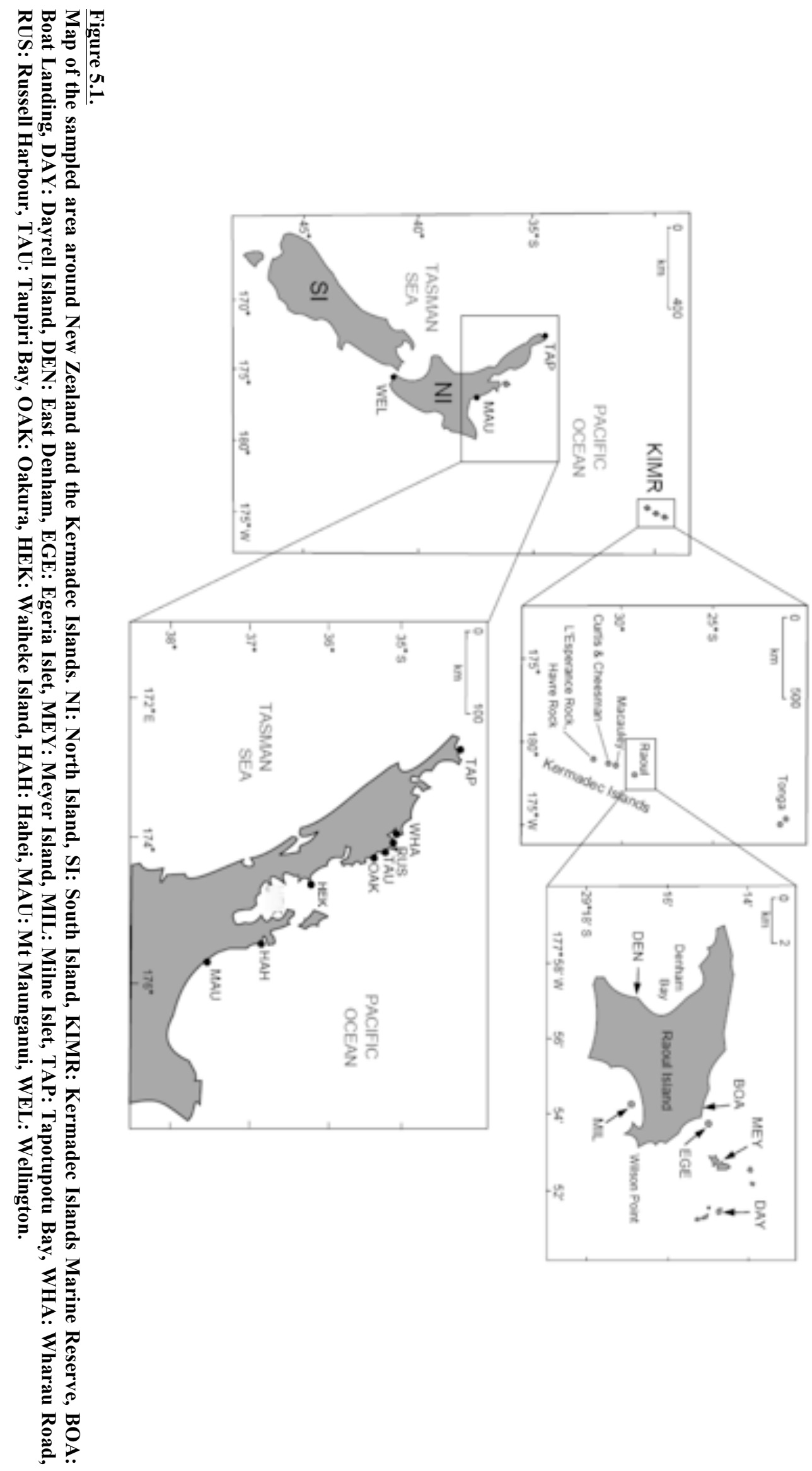




\subsection{Materials and Methods}

\subsubsection{Sample collection and storage}

Samples of N. melanotragus were collected between 2002 and 2006 for the NZ North Island populations (NI) and during two independent research trips in 2002 and 2004 for the Kermadec Islands populations (KIMR) (Fig.5.1 and 5.2). In total, 275 individuals were sampled from six different populations around the northern part of KIMR and 299 individuals were sampled from nine different populations along the NI (see Table 5.1). Samples were preserved in ethanol and then stored at $4^{\circ} \mathrm{C}$.

\subsubsection{DNA extraction}

Each individual was removed from its shell. Genomic DNA was extracted from $\sim 2$ to $4 \mathrm{~mm}^{3}$ of foot tissue, directly under the operculum, using the High Pure PCR Template preparation kit (Roche) following the manufacturer's instructions. DNA concentration was estimated by running each sample against a High DNA Mass ladder (Invitrogen) on an ethidium bromide-stained 1\% agarose gel. DNA was subsequently stored at $-20^{\circ} \mathrm{C}$.

\subsubsection{Primer amplification and genotyping}

I used ten fluorescently labelled microsatellite primer pairs specifically designed for N. melanotragus, and divided them into three multiplex groups (Table 5.2). Amplifications were carried out using a Touch-Down PCR protocol described in Table 5.3. Allele scoring was automated in GENEMARKER (SoftGenetics, State College, PA) after the creation of allele binary files specific to each microsatellite marker. Departure from HWE was estimated in GENEPOP'007 (Rousset 2008). Preliminary results showed that three loci (Ner_15, Ner_42 and Ner_49) deviated significantly from HWE. MICRO-CHECKER version 2.2.3 (Van Oosterhout et al. 2004) attributed this deviation to the presence of null alleles and stuttering. Hence, the 
subsequent genetic analyses used seven microsatellite markers: Ner_06, Ner_21, Ner_48, Ner_18, Ner_37, Ner_55 and Ner_32.

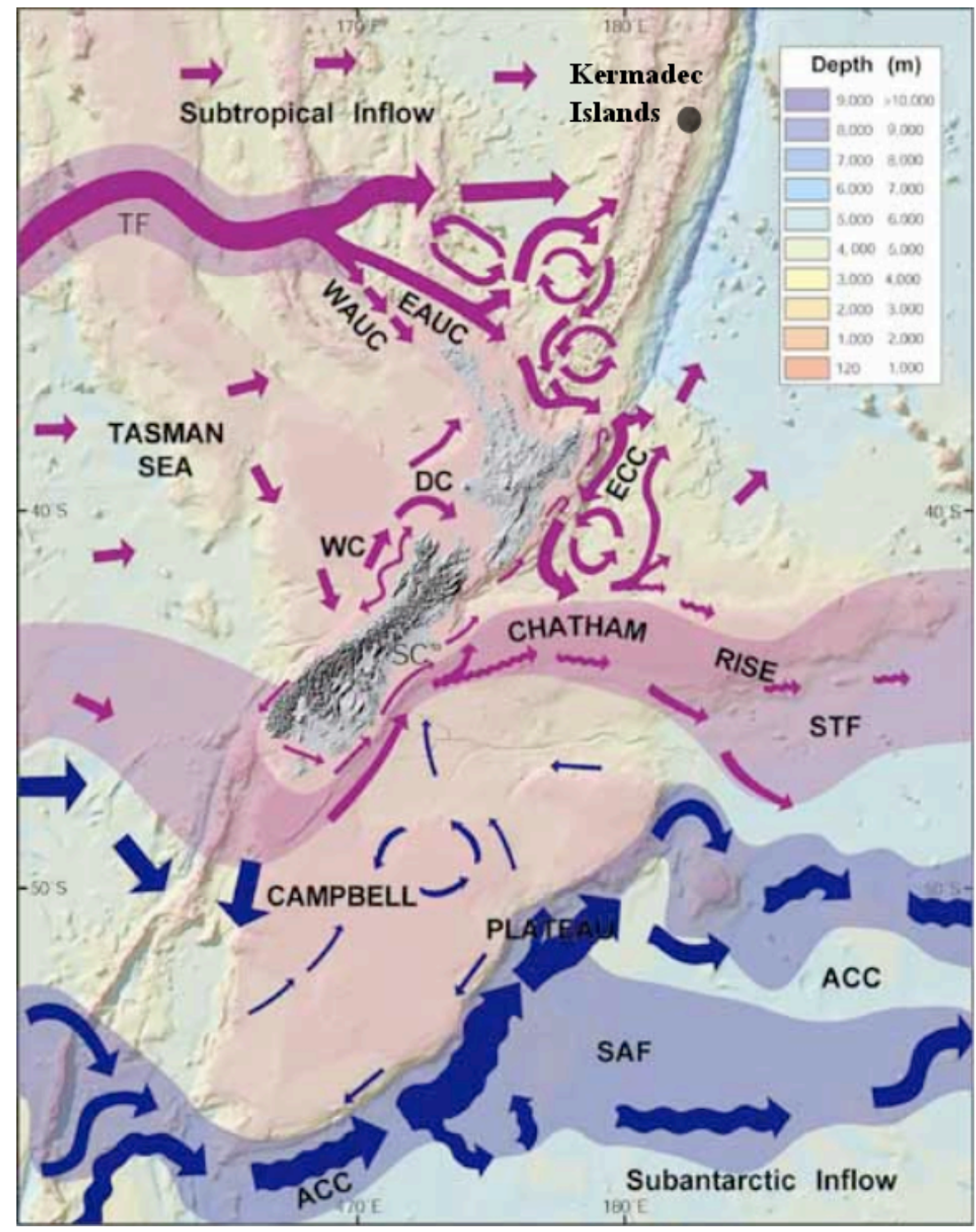

Figure 5.2.

New Zealand major coastal and offshore currents. ACC: Antarctic Circumpolar Current, DC: D'Urville Current, EAUC: East-Auckland Current, ECC: East Cape Current; ECE: East Cape Eddy, NCE: North Cape Eddy, SAF: Subantarctic Front, SC: Southland Current, STF: Subtropical Front, TF: Tasman Front, WAUC: West Auckland Current, WC: Westland Current, WCC: Wairapa Coastal Current, WE: Wairapa Eddy. Taken from Will \& Gemmell (2008), modified from Laing \& Chiswell (2003). 


\begin{tabular}{|c|c|}
\hline 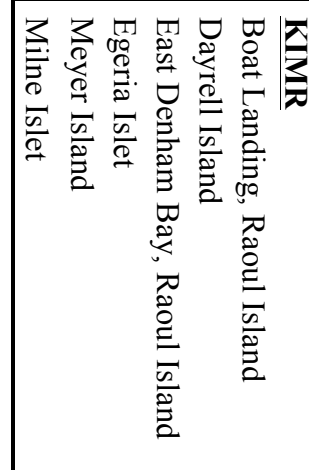 & 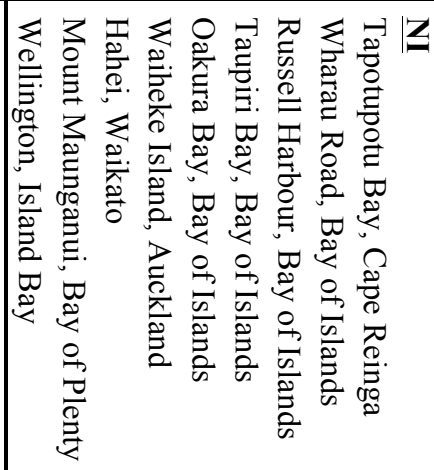 \\
\hline 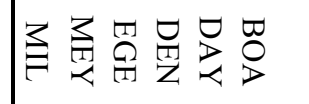 & 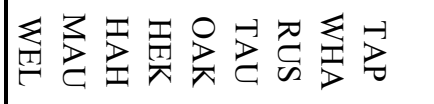 \\
\hline t & 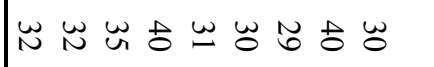 \\
\hline 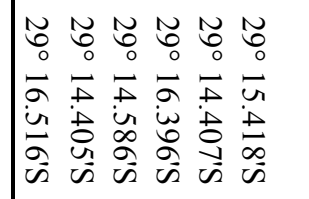 & 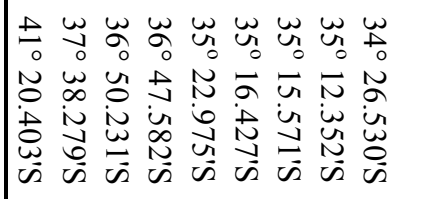 \\
\hline 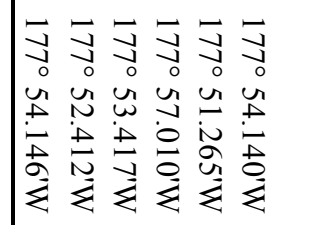 & 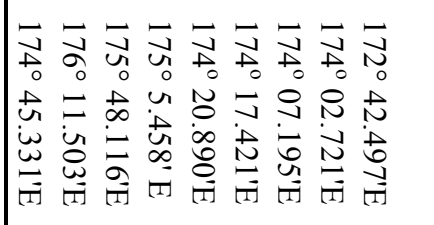 \\
\hline 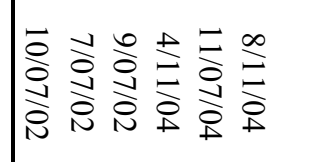 & 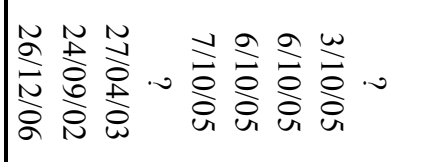 \\
\hline
\end{tabular}

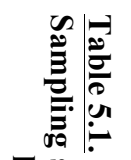

응.

og.

है ?

政

흐응

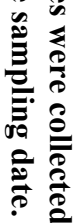

苛

苗

$\stackrel{0}{=}$

อ

E

范 
Table 5.2.

Fluorescent tagging and multiplex group organization of the 10 primers used in the analysis.

\begin{tabular}{|c|c|c|c|}
\hline Group & Primer name & Primer sequence & Fluorescence \\
\hline \multirow{6}{*}{1} & Ner_06A & CCGCTTTTCATTCAAGCAAT & NED \\
& Ner_15A & GAACGCATAGCATGAGAGCA & 6-FAM \\
& Ner_21A & GCATGGAAAACTGACACCCT & PET \\
& Ner_42A & AGCAGCAATGCAGCAAATTA & VIC \\
& Ner_48A & ATCCCAGCAGAGGCGTAGTA & 6-FAM \\
\hline \multirow{3}{*}{2} & Ner_18A & AAGGAGCCGGGAGAAAATTA & 6-FAM \\
& Ner_28A & AAATTTGCTTTCGCCTGTGT & PET \\
& Ner_35A & ATCCCACGCAGCTATTCATC & VIC \\
& Ner_37A & TGCCATCTGCTGCAATCTAC & NED \\
& Ner_55A & TGAAGTCAGTCGGCTTCTCA & 6-FAM \\
\hline \multirow{2}{*}{3} & Ner_32A & ACTAGTGGTGGGTGTGGCTC & 6-FAM \\
& Ner_49A & CCGGGTGTTTTGTCATTAGG & VIC \\
\hline
\end{tabular}

Table 5.3.

PCR Touchdown cycles used with the ten microsatellite primer pairs.

\begin{tabular}{|c|c|c|c|}
\hline Initial Denaturation & & $\begin{array}{c}\text { Denaturation } \\
\text { Annealing } \\
\text { Elongation } \\
\end{array}$ & Final Elongation \\
\hline \multirow[t]{3}{*}{2 min at $96^{\circ} \mathrm{C}$} & $20 \mathrm{x}$ & $\begin{array}{l}20 \mathrm{sec} \text { at } 94^{\circ} \mathrm{C} \\
30 \mathrm{sec} \text { at } 55 / 45^{\circ} \mathrm{C}^{* *} \\
30 \mathrm{sec} \text { at } 72^{\circ} \mathrm{C}\end{array}$ & \\
\hline & then & & \\
\hline & $25 \mathrm{x}$ & $\begin{array}{l}20 \mathrm{sec} \text { at } 94^{\circ} \mathrm{C} \\
30 \mathrm{sec} \text { at } 45^{\circ} \mathrm{C} \\
30 \mathrm{sec} \text { at } 72^{\circ} \mathrm{C}\end{array}$ & 7 min at $72^{\circ} \mathrm{C}$ \\
\hline
\end{tabular}

** Annealing temperature is progressively lowered by $0.5^{\circ} \mathrm{C}$ every cycle for all samples

\subsubsection{Data analysis}

\subsubsection{Genetic diversity}

Allelic diversity (A), observed (Ho) and expected $\left(\mathrm{H}_{\mathrm{E}}\right)$ heterozygosities under Hardy Weinberg equilibrium (HWE), and the inbreeding coefficient (Fis) were estimated using GENEPOP'007 for each population and averaged over all the populations for comparison of the two geographic groups (KIMR and NI). Tests for 
linkage disequilibrium were performed in GENEPOP using a likelihood-ratio test with a level of significance determined by permutation (Markov Chain parameters: 10000 dememorization steps, 5000 batches, 10000 iterations per batch). Statistical significance (P-values) was corrected for multiple testing using the False Discovery Rate (FDR) procedure (Benjamini \& Hotchberg 1995). Allelic richness [Ar(g)] standardized for sample sizes was calculated by HPrare V1.0 (Kalinowski 2005) using a rarefaction method, with the minimum number of genes $(\mathrm{g})$ being estimated by the software and set to a value of 46 (for NI), 76 (for KIMR) and 520 (for $\mathrm{KIMR}+\mathrm{NI})$. Mean $\operatorname{Ar}(\mathrm{g})$ was calculated for each population and then compared across groups using a Kruskal-Wallis test for non-parametric data.

\subsubsection{Population genetic structuring and relationship}

Population pairwise Fst values were estimated by Arlequin 3.1 (Excoffier et al. 2005) and their significance was assessed after 10,000 permutations. Fisher's exact tests of differentiation between pairs of loci (Raymond \& Rousset 1995) were performed by Arlequin, with 10,000 permutations. All p-values were adjusted using the FDR procedure.

Additional insights into the patterns of gene flow were provided by Bayesian analysis of genotypic admixture using STRUCTURE version 2.2 (Pritchard et al. 2000, Falush et al. 2003, 2007). The number of potential clusters (K) was estimated from 3 independent runs with K ranging from 2 to 6 for KIMR, 2 to 9 for NI and 2 to 15 for analysis of the whole dataset. For each run, uninformed priors were used with a 50,000 burn-in period followed by 500,000 Markov Chain Monte Carlo (MCMC) replications under the admixture ancestry model and the assumption of correlated allele frequencies among samples.

To visualize the genetic relationship of each populations within KIMR, within NI and between KIMR and NI, an unweighted pair group method and an arithmetic mean (UPGMA) dendogram was constructed, based on the Nei's minimum distance (Nei 1972) using the program Tools for Population Genetics Analysis (TFPGA Miller 1997). Statistical nodal support was evaluated by bootstrap analysis using 1000 pseudoreplicates. 


\subsubsection{Estimation of self-recruitment and first generation migrants}

Assignment methods are complementary to Fst estimates, in the sense that they provide a specific assessment of contemporary migration, whereas Fst methods assess average levels of gene flow over long timescales (see Manel et al 2005 for full discussion). To determine levels of contemporary dispersal and self-recruitment in each population within each group, and averaged from all populations between groups, assignment tests were carried out with GENECLASS2 (Piry et al 2004) following Paetkau et al. (2004) "leave one-out" methodology. Probability of assignment was based on 10,000 simulated individuals and an exclusion threshold of $\mathrm{P}<0.05$. Individuals that were excluded from their populations of collection were reassigned to another sampled population when $\mathrm{P}>0.1$. The difference between the exclusion threshold and the reassignment threshold allows for the presence of individuals originating from non-sampled populations (Underwood et al 2007). When the results indicated more than one possible population of origin $(\mathrm{P}>0.1)$, the individual was assigned to population showing the highest probability. Firstgeneration migrants were detected using the "L-home" likelihood computation method to allow for the possibility of individuals coming from unsampled populations. Probability of assignment was based on 10,000 simulated individuals and an exclusion threshold of $\mathrm{P}<0.05$. Individuals identified as first generation migrants were removed from the dataset and the remaining individuals were used to create references populations and identify the most likely source population of those migrants (see Piry et al. 2004 for more information).

\subsubsection{Spatial genetic structuring}

Any genetic signature of isolation-by-distance was investigated with a Mantel test, performed by the software ISOLDE, through Genepop (online based form). The Mantel test examines the correlation between genetic differentiation (pairwise Fst/(1Fst) values) and geographic location (using the logarithm of geographical distances among populations).

In order to test for the presence of random, clumped, or uniform spatial distributions of alleles, I used the software package Alleles in Space (AIS; Miller 2005) and performed an allelic aggregation index analysis (AAIA) based on the analysis of individuals' genotypes (and not alleles despite the name of the analysis), 
to test non-random patterns of spatial genetic diversity (null hypothesis that genotypes are distributed at random across a landscape; see Clark \& Evans 1954, and Miller 2005 for modifications). Estimation of the "physical area" encompassed by the samples used a rectangle defined by the maximum and minimum coordinates provided in the dataset's coordinate file (default option in AIS). An allele-specific aggregation index $R_{j}$ was calculated for each allele at each locus, and was used to obtain an average allelic aggregation index $R_{j}^{A V E}$. Significance of $R_{j}$ and $R_{j}^{A V E}$ was tested through the use of 1000 permutations.

\section{$5.3 \quad$ Results}

\subsubsection{Overall genetic diversity}

Rarefied allelic richness ranged from 2.998 to 14.000 with 10 private alleles (Table 5.4a) in the KIMR group, from 2 to 12.124 with 15 private alleles for the NI dataset (Table 5.4b), and from 4.952 to 16.786 with 22 private alleles for the KIMR+NI dataset (Table 5.4c). No significant linkage disequilibrium was observed for any pairs of loci after FDR correction. Two other loci showed a deviation from HWE: Ner_32 in Oakura Bay, Waiheke Island, Hahei and Egeria Islet; Ner_55 in Dayrell Island and Russell Harbour. However, because this deviation was only detected in a subset of populations and their associated P-values were often near the significance level of 0.05 (ranging from 0.0530 to 0.0808), Ner_32 and Ner_55 were kept in the analysis.

\subsubsection{Genetic structuring in the KIMR dataset}

Mean rarefied allelic richness calculated over the seven loci revealed no significant difference among the six sampled populations (Kruskal-Wallis, $\mathrm{P}=0.416$ ). All pairwise Fst estimates of the KIMR analysis were not significant (Table 5.5a) with values ranging from -0.0097 to 0.0052 . Fisher's exact tests of differentiation between pairs of loci gave the same results $(P>0.999)$. The results from the STRUCTURE analysis were congruent with the Fst and Fisher's exact tests and showed an absence of genetic differentiation among populations for all values of $\mathrm{K}$ (Fig.5.3.). 


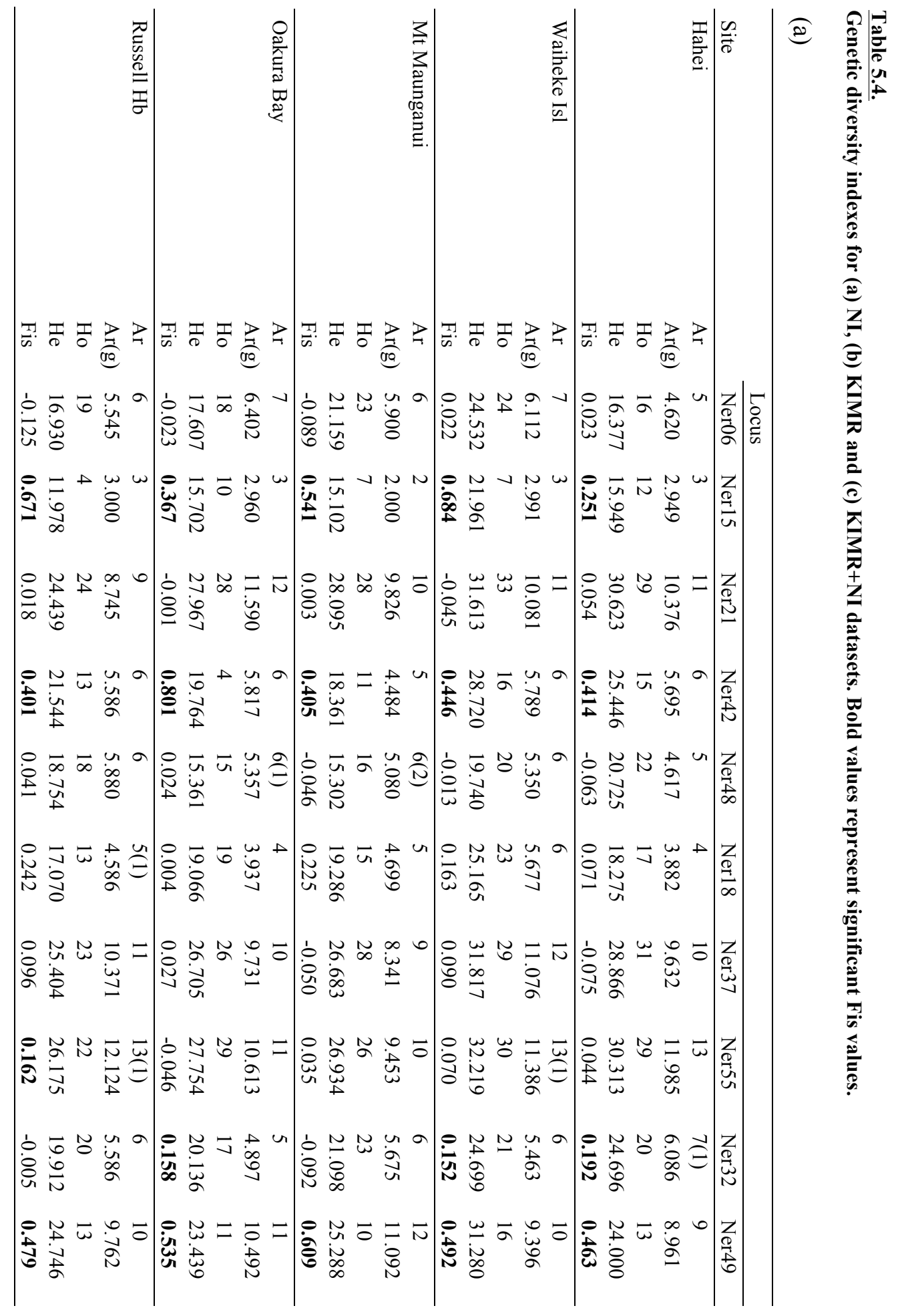




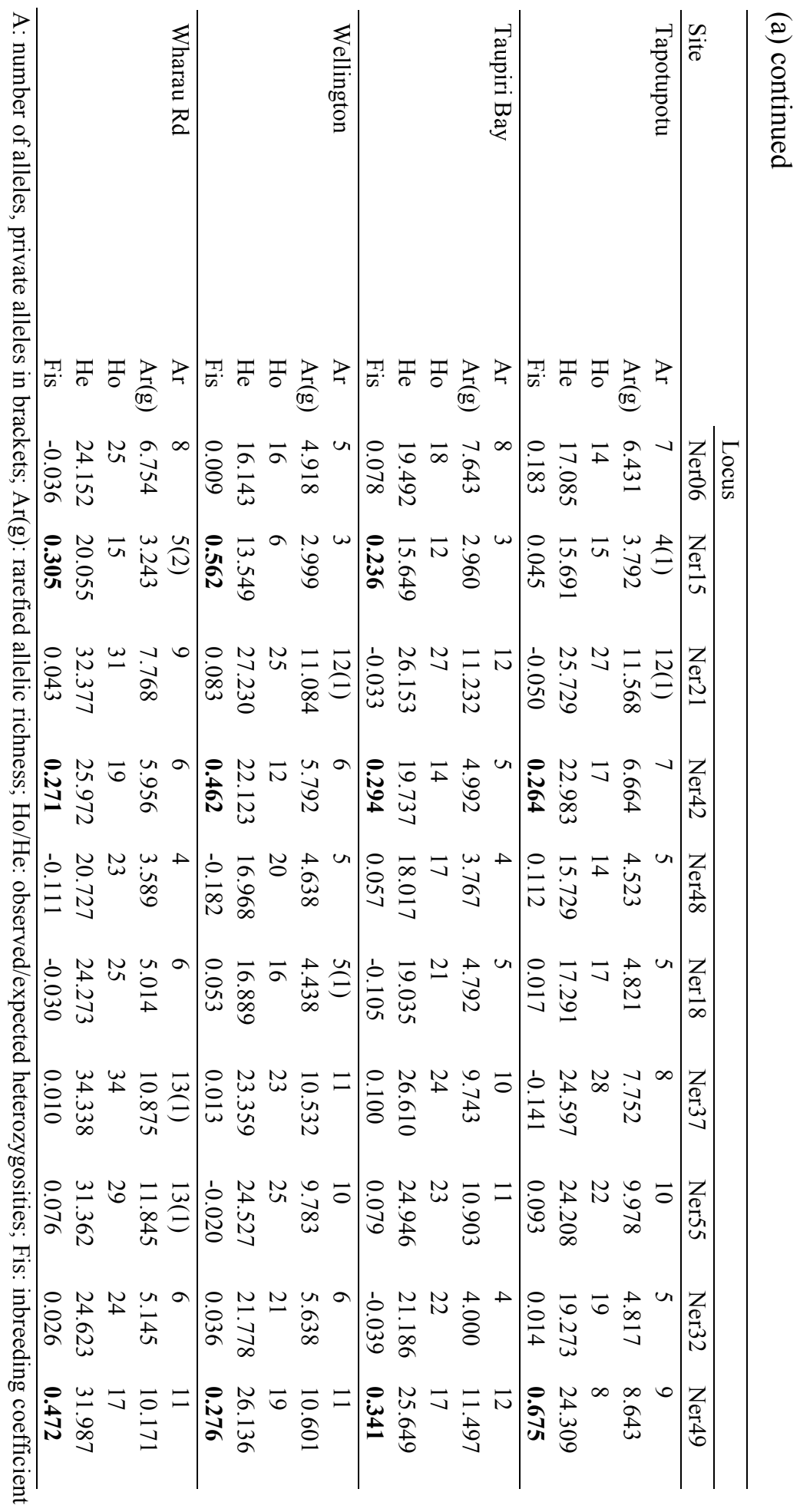




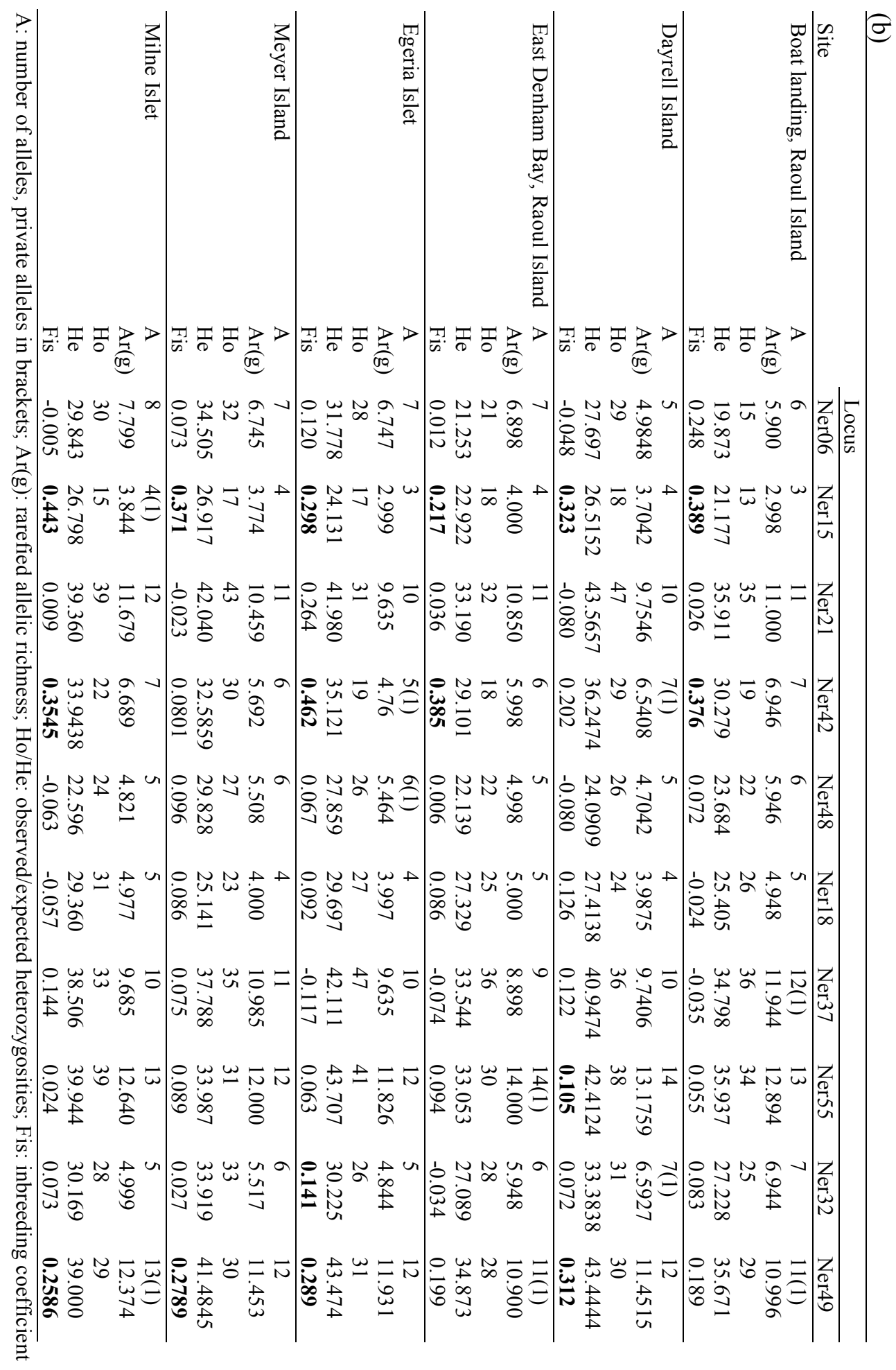




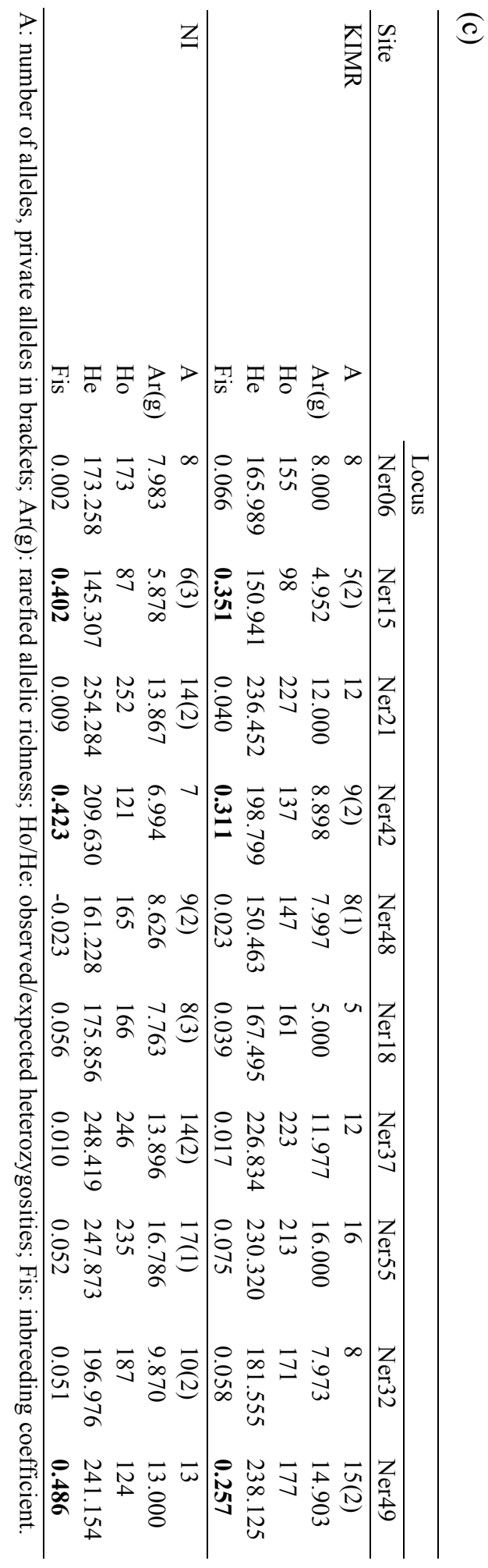


The UPGMA analysis resulted in globally weak grouping support (i.e. no evidence of structure), with a highest bootstrap value of 57.14\% (Fig.5.4a). There was low bootstrap support $(28.57 \%)$ for the separation of the East Denham population from all other KIMR populations. Assignment tests successfully classified 45 individuals to their sampled populations, with assignment success ranging from 7.5\% (East Denham) to 33\% (Milne Islets). A total of 230 individuals were assigned to other populations, among which six remained unassigned. Twenty-six individuals were identified as first generation migrants, representing between 6.8\% (East Denham Bay) and 21.9\% (Dayrell Island) of the total recruitment per population (Table 5.6a, Table 5.7a). Isolation by distance analysis revealed no correlation between genetic distance and geographic distance $\left(\mathrm{R}^{2}=0.0013\right)$. The AAIA analysis showed no significant allelic aggregation within the KIMR sample set $\left(\mathrm{R}_{\mathrm{AVE}}=\right.$ $0.874, \mathrm{P}=0.197)$.

Table 5.5.

Population pairwise Fst values for (a) KIMR, (b) NI, and (c) KIMR+NI dataset. Above diagonal: p-value after correction for FRD; below diagonal: Fst value

(a)

\begin{tabular}{l|cccccc} 
& BOA & DAY & DEN & MEY & MIL & EGE \\
\hline BOA & - & 0.894 & 0.883 & 0.721 & 0.530 & 0.826 \\
DAY & -0.004 & - & 0.347 & 0.088 & 0.735 & 0.546 \\
DEN & -0.004 & 0.001 & - & 0.581 & 0.247 & 0.717 \\
MEY & -0.002 & 0.005 & -0.001 & - & 0.870 & 0.999 \\
MIL & 0.000 & -0.002 & 0.002 & -0.004 & - & 0.877 \\
EGE & -0.003 & 0.000 & -0.002 & -0.010 & -0.003 & -
\end{tabular}

(b)

\begin{tabular}{l|ccccccccc} 
& TAP & WHA & RUS & TAU & OAK & HEK & HAH & MAU & WEL \\
\hline TAP & - & 0.600 & 0.644 & 0.979 & 0.747 & 0.506 & 0.858 & 0.791 & 0.849 \\
WHA & -0.002 & - & 0.566 & 0.789 & 0.644 & 0.482 & 0.103 & 0.483 & 0.420 \\
RUS & -0.002 & -0.001 & - & 0.956 & 0.612 & 0.324 & 0.637 & 0.301 & 0.483 \\
TAU & -0.009 & -0.004 & -0.007 & - & 0.603 & 0.569 & 0.504 & 0.429 & 0.775 \\
OAK & -0.004 & -0.003 & -0.002 & -0.002 & - & 0.707 & 0.610 & 0.966 & 0.902 \\
HEK & -0.001 & 0.000 & 0.002 & -0.001 & -0.003 & - & 0.093 & 0.847 & 0.526 \\
HAH & -0.005 & 0.006 & -0.002 & -0.001 & -0.002 & 0.006 & - & 0.267 & 0.569 \\
MAU & -0.004 & -0.001 & 0.002 & 0.000 & -0.008 & -0.005 & 0.003 & - & 0.640 \\
WEL & -0.006 & 0.000 & 0.000 & -0.004 & -0.006 & -0.001 & -0.002 & -0.003 & -
\end{tabular}

(c)

\begin{tabular}{l|cc} 
& NI & KIMR \\
\hline NI & - & 0.489 \\
KIMR & -0.001 & -
\end{tabular}




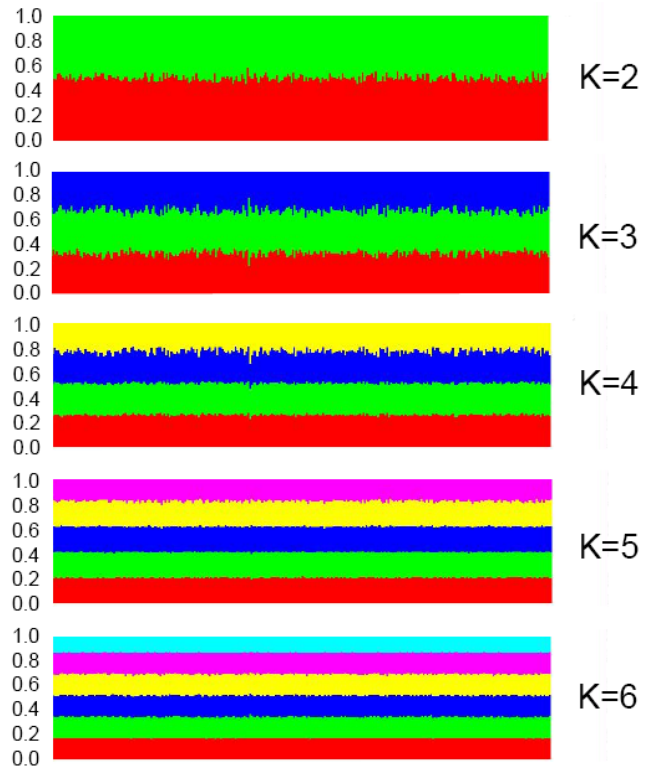

Figure 5.3.

STRUCTURE analysis of KIMR, NI and KIMR+NI datasets. Results presented here were similar for the three analyses. Results are presented for a theoretical number of populations ranging from 2 to 6 . Vertical bars represent individuals.

\subsubsection{Genetic structuring in the NI dataset}

There was no significant difference in allelic richness among the nine sampled populations (Kruskal-Wallis, $\mathrm{P}=0.433$ ). Pairwise Fst values ranged from -0.0087 to 0.0056 and no values were statistically significant (Table 5.5b). Fisher's exact tests of differentiation between pairs of loci confirmed these results $(\mathrm{P}>0.999)$. STRUCTURE analysis results were congruent with Fst and Fisher's exact tests and revealed an absence of genetic differentiation among populations for all values of K (Fig.5.3.). The UPGMA analysis identified globally weak grouping support (i.e. no apparent structure), with $14.29 \%$ as the highest bootstrap value and many nodes lacking support (Fig.5.4b). Assignment test correctly classified 30 individuals to their sampled populations, with an assignment success ranging from $0 \%$ (Wellington Coast) to $26.7 \%$ (Taupiri Bay). A total of 267 individuals were classified to other populations, among which 2 remained unassigned. Thirty-two first generation migrants were identified, representing between 3.3\% (Wellington Coast) and 33.3\% (Taupiri Bay) of the total recruitment per population (Tables $5.6 \mathrm{~b}$ and $5.7 \mathrm{~b}$ ). Isolation by distance analysis revealed no correlation between genetic distance and geographic distance $\left(\mathrm{R}^{2}=0.0013\right)$. The AAIA analysis showed no significant allelic aggregation within the NI sample set $\left(\mathrm{R}_{\mathrm{AVE}}=\right.$ $0.751, \mathrm{P}=0.303)$. 
(a)

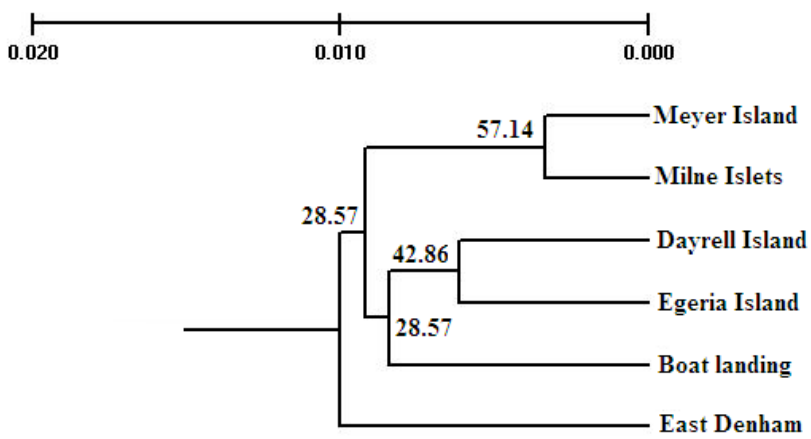

(b)

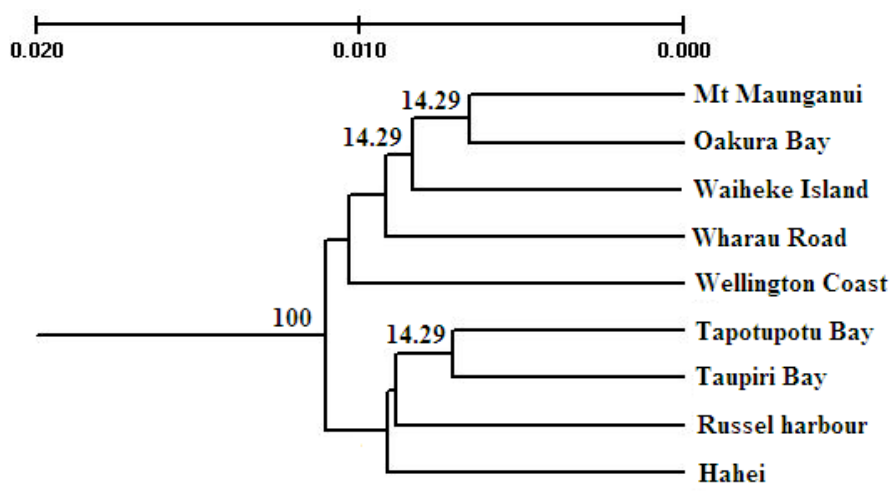

(c)
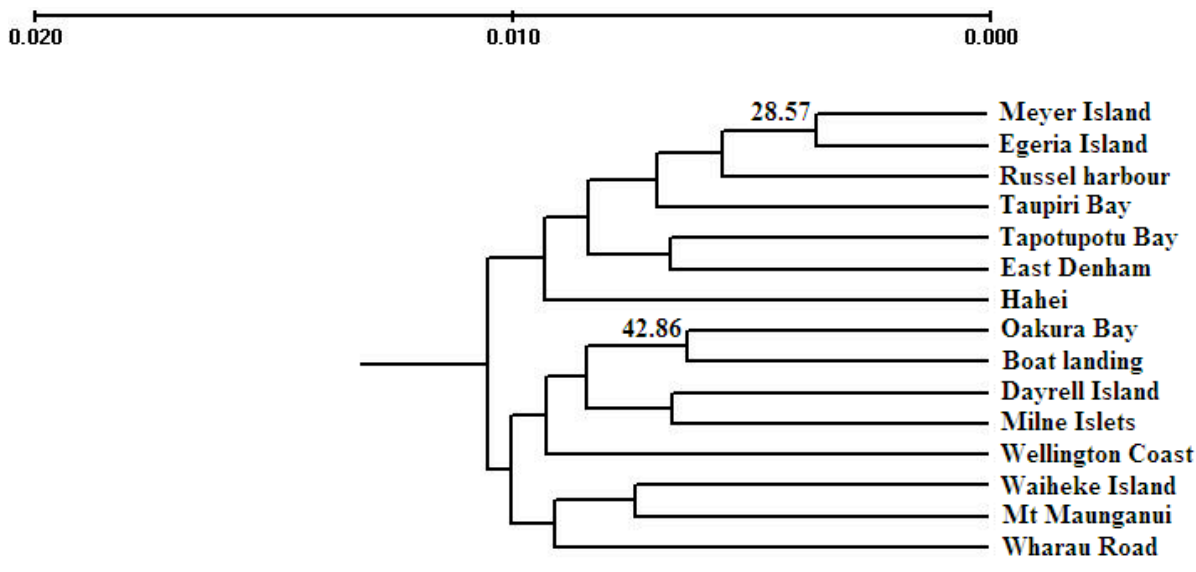

Figure 5.4.

UPGMA tree of the relationship among the different populations in (a) KIMR, (b) NI and (c) KIMR+NI dataset. The scale represents Nei's distance values.Values at nodes represent the percentage bootstrap support. Nodes with no values have a bootstrap support of zero. 
Table 5.6.

Assignment test results showing percentage of individuals successfully assigned for: (a) KIMR, (b) NI, and (c) KIMR+NI datasets. Boldface shows correct assignments. The symbol (*) indicates populations with at least one non-assigned individual.

(a)

\begin{tabular}{l|rrrrrr} 
& BOA & DAY & DEN & MEY & MIL & EGE \\
\hline BOA* $^{*}$ & $\mathbf{3 0 . 0}$ & 15.0 & 2.5 & 7.5 & 32.5 & 10.0 \\
DAY* $^{*}$ & 36.0 & $\mathbf{8 . 0}$ & 6.0 & 8.0 & 32.0 & 8.0 \\
DEN* $^{*}$ & 20.0 & 15.0 & $\mathbf{7 . 5}$ & 10.0 & 25.0 & 20.0 \\
MEY* & 12.0 & 12.0 & 6.0 & $\mathbf{1 4 . 0}$ & 40.0 & 12.0 \\
MIL & 17.8 & 15.6 & 4.4 & 24.4 & $\mathbf{3 3 . 3}$ & 4.4 \\
EGE* $^{*}$ & 20.0 & 12.0 & 8.0 & 16.0 & 34.0 & $\mathbf{8 . 0}$
\end{tabular}

(b)

\begin{tabular}{l|ccccccccc} 
& TAP & WHA & RUS & TAU & OAK & HEK & HAH & MAU & WEL \\
\hline TAP* & $\mathbf{1 3 . 3}$ & 3.3 & 10.0 & 33.3 & 16.7 & 0.0 & 10.0 & 6.7 & 3.3 \\
WHA & 0.0 & $\mathbf{7 . 5}$ & 22.5 & 32.5 & 12.5 & 5.0 & 2.5 & 15.0 & 2.5 \\
RUS* & 3.4 & 3.4 & $\mathbf{1 0 . 3}$ & 37.9 & 13.8 & 3.4 & 6.9 & 13.8 & 3.4 \\
TAU & 3.3 & 0.0 & 13.3 & $\mathbf{2 6 . 7}$ & 26.7 & 6.7 & 13.3 & 6.7 & 3.3 \\
OAK & 6.5 & 0.0 & 19.4 & 19.4 & $\mathbf{1 6 . 1}$ & 3.2 & 3.2 & 29.0 & 3.2 \\
HEK & 10.0 & 7.5 & 10.0 & 30.0 & 15.0 & $\mathbf{7 . 5}$ & 5.0 & 15.0 & 0.0 \\
HAH & 8.6 & 2.9 & 14.3 & 28.6 & 14.3 & 0.0 & $\mathbf{5 . 7}$ & 20.0 & 5.7 \\
MAU & 3.1 & 3.1 & 15.6 & 28.1 & 31.3 & 3.1 & 9.4 & $\mathbf{6 . 3}$ & 0.0 \\
WEL & 6.3 & 0.0 & 18.8 & 25.0 & 18.8 & 15.6 & 0.0 & 15.6 & $\mathbf{0 . 0}$
\end{tabular}

(c)

\begin{tabular}{l|cc} 
& NI & KIMR \\
\hline NI & $\mathbf{6 0 . 5}$ & 39.5 \\
KIMR & 51.5 & $\mathbf{4 9 . 5}$
\end{tabular}

\subsubsection{Genetic structuring between KIMR and NI dataset}

The Kruskal-Wallis test did not show any significant difference in allelic richness between NI and KIMR groups $(\mathrm{P}=1.0)$. The Fst value between KIMR and NI was not significant (Table 5.5c). Fisher's exact tests of differentiation between pairs of loci also gave non-significant results $(\mathrm{P}>0.999)$. STRUCTURE analysis results were congruent with Fst and Fisher's exact tests and revealed a lack of genetic differentiation among populations for all values of K (Fig.5.3.). The UPGMA analysis resulted in globally weak grouping support, with $42.79 \%$ as the highest bootstrap value (Fig.5.4c), and many nodes had a bootstrap 
support of zero. A total of 316 individuals were correctly assigned to their sampled geographic group, with a $49.5 \%$ success for KIMR and $60.5 \%$ for NI.

\section{Table 5.7.}

First generation migrants at (a) KIMR, (b)NI and (c) KIMR+NI datasets. The table should be read with the population of origin in the first column, and the destination in the first row. The tables also present the percentage of first generation migrants from the total number of recruits per population.

(a)

\begin{tabular}{l|cccccc} 
& BOA & DAY & DEN & MEY & MIL & EGE \\
\hline BOA & - & 4 & & & 1 & \\
DAY & 1 & - & 2 & 1 & 1 & 2 \\
DEN & & 1 & - & 1 & 1 & \\
EGE & & 2 & & 1 & 3 & - \\
MEY & 1 & & & - & & 1 \\
MIL & & & & 3 & - & \\
\hline$\%$ recr. & 6.9 & 21.9 & 6.7 & 13 & 15.8 & 7.3
\end{tabular}

(b)

\begin{tabular}{l|ccccccccc} 
& TAP & WHA & RUS & TAU & OAK & HEK & HAH & MAU & WEL \\
\hline TAP & - & & 1 & 3 & & & 1 & & \\
WHA & & - & 1 & 1 & & 1 & & 1 & \\
RUS & & 1 & - & 2 & & & & & \\
TAU & 2 & 1 & & - & & & & 1 & \\
OAK & & & & & - & 2 & 1 & & 1 \\
HEK & & & & 1 & 3 & - & & & \\
HAH & & & 1 & 1 & 1 & & - & & \\
MAU & & & & & 1 & & 1 & - & \\
WEL & & & 1 & 1 & & 1 & & & - \\
\hline$\%$ recr. & 8 & 6.3 & 15.4 & 33.3 & 17.2 & 11.1 & 9.7 & 6.7 & 3.3
\end{tabular}

(c)

\begin{tabular}{l|cc} 
& NI & KIMR \\
\hline NI & - & 10 \\
KIMR & 10 & - \\
\hline \% recr. & 7.1 & 7.7
\end{tabular}

Among the 258 misclassified individuals, 20 were labelled as first generation migrants representing $7.1 \%(\mathrm{NI})$ and $7.7 \%$ (KIMR) of the total recruitment per group (Table $5.4 \mathrm{c}$, Table 5.5c). Isolation by distance analysis showed no correlation between genetic distance and geographic distance $\left(\mathrm{R}^{2}=0.0009\right)$. The AAIA analysis revealed significant allelic aggregation within the KIMR $+\mathrm{NI}$ sample set $\left(\mathrm{R}_{\mathrm{AVE}}=0.686, \mathrm{P}=0.016\right)$, indicating the presence of clusters in the geographic distribution of individuals' genotypes. 


\subsection{Discussion}

Many studies have reported that island populations have a higher genetic diversity than mainland populations at a comparable geographic scale (Parson 1996, Johnson \& Black 2006, Bird et al. 2007, Wood \& Gardner 2007, Bell 2008). They have also reported the presence of coastal oceanographic features such as eddies that could reduce larval connectivity with the archipelagos. This study aimed to investigate the levels of genetic diversity, genetic structuring and levels of connectivity in a remote archipelago and also investigate possible connectivity with mainland New Zealand.

\subsubsection{The Kermadec islands: micro-scale connectivity}

The analysis of N. melanotragus in the Kermadec Islands showed a complete genetic homogeneity across all six populations. This lack of structuring is likely to result from high migration rates, as reflected by the relatively weak assignment success of individuals to their sampled population. Moreover, half of the populations had a proportion of first generation migrants over (or about) $10 \%$, a theoretical threshold by which immigration could lead to significant demographic impact in the receiving population (see Slatkin 1987, 1993 and Waples \& Gaggioti 2006 for more information). All the results presented here indicate that the KIMR populations are effectively panmictic, and could be considered as "open" at the scale of the Kermadec archipelago. These findings contrast with previous studies on two endemic species of limpets (Wood \& Gardner 2007) and on coral assemblage (Wicks et al. 2010), which both found small but significant structuring among KIMR populations. The genetic homogeneity observed here could be explained by the long PLD of $N$. melanotragus and the small estimated larval dispersal time required for connecting the different KIMR sites. PLD has often been used as an estimation of a species' potential to disperse and exchange larvae among its populations (Grantham et al. 2003, Ross et al. 2009, Kelly \& Palumbi 2010, White et al. 2010). Larvae of $N$. melanotragus can spend an average of five months in the water column before either dying or settling in a population (Waters et al. 2005). Sutton et al. (2009) studied the directionality and timing of virtual larval drift in the Kermadec region using oceanographic models and found that drifting larvae dispersed in a roughly circular pattern from each of the Kermadec Islands, with a slight eastward bias introduced by the mean flow. The timing of larval dispersion from Raoul Island to its 
neighbouring islands and seamounts averaged 1-3 days, and was in the order of 10 days for the most distant islands to the south of the Kermadec archipelago. These values are very small compared to the minimum estimated PLD of $N$. melanotragus and highlight the capacity of its larvae to disperse within KIMR and connect all its population, and may explain the global genetic homogeneity observed in my study.

\subsubsection{NZ North Island populations: meso-scale connectivity}

Similarly to the Kermadec Islands, genetic investigation of the nine populations across the NZ North Island revealed complete historical and contemporary genetic homogeneity of $N$. melanotragus. Five of the nine populations had a number of potential first generation migrants over (or about) the 10\% threshold indicating the possibility for a significant impact of the migrants on the genetic composition of receiving populations. Hence, NI populations seem to be panmictic and may be considered as "open" at the scale of the North Island of New Zealand. These results are congruent with many connectivity studies that have reported high levels of genetic homogeneity associated with extensive gene flow among populations occurring as far south as $41.5^{\circ} \mathrm{S}$, the geographical extent of NZ's North Island (Mladenov et al.. 1997, Apte \& Gardner 2001, Star et al. 2003, Waters \& Roy 2003, Hendry 2004, Waters et al. 2005, Gardner et al. 2011).

As for KIMR populations, the high levels of connectivity observed among NI populations could be explained by the long PLD of $N$. melanotragus coupled with the short estimated dispersal times across the sampled sites, ranging from 11 to 144 days (Chiswell et al. 2011; Table 5.8). It is also worth noting that despite the presence of a directional current

Table 5.8.

Dispersal time between New Zealand ports calculated as the 1 percentile dispersal time from inverseGaussian fits to temporal kernels (modified from Chiswell et al. 2011)

\begin{tabular}{l|cccc} 
& Bay of Islands & Auckland & Tauranga & Wellington \\
\hline Bay of Islands & - & 13 & 11 & 103 \\
Auckland & 24 & - & 24 & 144 \\
Tauranga & & & - & 85 \\
Wellington & & & & -
\end{tabular}

The table is to be read along the rows. For example, the minimum dispersal time from Bay of Islands to Tauranga is 11 days, and there is no dispersal from Tauranga to Bay of Islands. 
pattern along the east coast of NI (East Auckland Current flowing southward; Sutton et al. 2009) no particular directionality in migration was detected in the present study (131 individuals assigned to the south of their sampled populations versus 136 individuals assigned to the north), potentially indicating the presence of localised oceanographic features trapping larvae and allowing them to disperse against the mean flow.

\subsubsection{Across the South Pacific Ocean: macro-scale connectivity}

As it was the case within KIMR and within the NI, the 15 populations showed a lack of historical and contemporary genetic structuring between KIMR and NI. Of the numerous analyses carried out, only the allelic aggregation analysis showed a small but significant difference between regions. This could be explained by the presence of private alleles in the two groups (7 in KIMR and 15 in NI).

A total of 20 individuals were identified as first generation migrants, representing an average of $7.3 \%$ of the total number of recruits. Both migrants and first generation migrants were equally distributed between the KIMR and NI sites, implying that individuals from both groups are well mixed. This indicates the presence of a bidirectional exchange across the South Pacific Ocean, consistent with estimations of larval dispersal time from Raoul Island (KIMR) to Cape Reinga (NI) and in the reverse direction (over 1.5 months, and about a month respectively; Sutton et al. 2009) and the PLD of N. melanotragus. It is worth noting that the proportion of first generation migrants between KIMR and NI was less than among NI populations and among KIMR populations (7.3\% compared to $9.5 \%$ and $11 \%$ respectively), and could be a reflection of the greater distances and the presence of open oceans between the two regions, and the presence of a number of private alleles in each group.

\subsubsection{Pelagic larval duration: a predictor for genetic structuring?}

This study is one of the few to focus on assessing the level of gene flow among remote habitats and with continental landmasses (but see Glynn et al. 2007, Hoareau et al. 2007, Crandall et al. 2010). The high levels of gene flow between N. melanotragus populations within each of the KIMR and NI groups could be deemed "expected", considering the species' long PLD. Indeed, similar high levels of gene flow have been 
detected previously at large spatial scales in members of the Nerita genus and other gastropods (Hoareau et al. 2007, Crandall et al. 2010). However, the effectiveness of PLD to estimate a species' dispersal potential and predict its genetic structuring has been recently questioned (Shanks et al. 2003, Siegel et al. 2003, Kinlan et al. 2005). A simple prediction concerning levels of connectivity for benthic species having a pelagic larval stage is that the longer the PLD, the further larvae might disperse, leading to a reduction of the genetic structuring between adjacent populations (Sheltema 1986). For benthic species (termed demersal or sessile), the primary means for connectivity is the dispersal phase typically associated with the earliest life history stage (spore, egg, or larva). Extensive studies have attempted to assess whether PLD is a good predictor of population genetic structuring (Shulman 1998, Bowen et al. 2006, Weersing \& Toonen 2009). For example, Shanks et al. (2003) and Shanks (2009) have described an overall positive correlation between propagule duration and dispersal distance (based primarily on invertebrates and algae, with a few fish species included). Other studies also reported that 60 to $90 \%$ of the variation in dispersal distances can be explained by the length of the pelagic developmental period (Siegel et al. 2003, Kinlan et al. 2005). However, as pointed out by Weersing \& Toonen (2009), those previous studies included direct developing species (see also Waples 1987, Doherty et al. 1995), which is likely to strengthen the reported correlations of life history on population structuring (Bay et al. 2006, Bowen et al. 2006), as does the inclusion of very long PLD species. Although no clear consensus was reached on the correlation between average length PLD (a few days to a month) and genetic structuring, most authors agreed that direct developers and long PLD species (more than 2 months) showed a positive correlation with genetic structuring. Many recent studies employing long PLD species, including this one, seem to be consistent with this statement (e.g: Levinton \& Koehn 1976, Levinton \& Suchanek 1978, Sarver \& Foltz 1993, Waters et al. 2007, Addison et al. 2008, Crandall et al. 2010).

However, to test this hypothesis further, the integration of the Australian populations of $N$. melanotragus in the dataset would be an interesting complement. A previous study by Waters et al. (2007) used COI sequences of $N$. melanotragus individuals from New Zealand and Australia and did not find any difference between the two locations. Although this earlier result could be due to the type of marker used, the authors associated the lack of differentiation with a possible but rare trans-Tasman Sea larval dispersal event, following estimations of minimum dispersal times between Australia and NZ (Chiswell et al. 2003). In 
the present study, estimated dispersal time between the most distant locations was still within the PLD of $N$. melanotragus. However, according to Chiswell et al. (2003), it would take around 700 days (more than 4 times the PLD of $N$. melanotragus) for a larva to travel from Australia to NZ and it is thought that about $6 \%$ of successfully dispersed larvae originating in New South Wales and $0.2 \%$ of successfully dispersed larvae originating in Bass Strait can potentially arrive in New Zealand (Chiswell et al. 2003). Now that high gene flow among $N$. melanotragus individuals from the Kermadecs and New Zealand has been investigated, it would be interesting to see how connected the Australian and NI/KIMR populations are, its implications for the origins of recruits and population dynamics of intertidal communities across the South Pacific Ocean.

\subsection{Conclusions}

This study aimed to investigate and compare the diversity and levels of genetic connectivity of islands and mainland populations of an intertidal marine gastropod, using seven microsatellite loci. All the tests employed in this study support the high genetic homogeneity of N. melanotragus populations within KIMR, and within NI. This lack of genetic structuring is most likely to be explained by low levels of self-recruitment and high levels of migration among the different populations. Assignment tests gave similar results in term of assignment success within KIMR and within NI, possibly pointing to similar (and reduced) levels of self-recruitment in the two groups. However, these results need to be tempered because of the potential bias introduced by the high genetic homogeneity found within the groups.

\subsection{References}

Addison JA, Ort BS, Mesa KA, Pogson GH (2008) Range-wide genetic homogeneity in the California sea mussel (Mytilus californianus): a comparison of allozymes, nuclear DNA markers, and mitochondrial DNA sequences. Molecular Ecology, 17, 42224232. 
Apte S, Gardner JPA (2001) Absence of population genetic differentiation in the New Zealand greenshell mussel, Perna canaliculus, as assessed by allozyme variation. Journal of Experimental Marine Biology \& Ecology, 258, 173-194.

Bay LK, Crozier RH, Caley MJ (2006) The relationship between population genetic structure and pelagic larval duration in coral reef fishes on the Great Barrier reef. Marine Biology, 149, 1247-1256.

Bell JJ, Okamura B (2005) Low genetic diversity in a marine reserve: reevaluating diversity criteria in reserve design. Proceedings of the Royal Society: Biological Sciences, 272, 1067-1074.

Bell JJ (2008) Similarity in connectivity patterns for two gastropods species lacking pelagic larvae. Marine Ecology Progress Series, 357, 185-194.

Benjamini Y, Hochberg Y (1995) Controlling the false discovery rate: a practical and powerful approach to multiple testing. Journal of the Royal Statistical Society. Series B, 57, 289-300.

Bird CE, Holland BS, Bowen BW, Toonen RJ (2007) Contrasting population structure in three endemic Hawaiian limpets (Cellana spp.) with similar life histories. Molecular Ecology, 16, 3173-3187.

Bowen BW, Bass AL, Muss A, Carlin J, Robertson DR (2006) Phylogeography of two Atlantic squirrelfishes (Family Holocentridae): exploring links between pelagic larval duration and population connectivity. Marine Biology, 149, 899-913.

Brook FJ (1998) The coastal molluscan fauna of the northern Kermadec Islands, southwest Pacific Ocean. Journal of The Royal Society of New Zealand, 28, 185-233.

Brook FJ (1999) The coastal scleractinian corals of the Kermadec Islands, southwestern Pacific Ocean. Journal of the Royal Society of New Zealand, 29, 435-460 
Chiswell SM, Rickard GJ (2011) Larval connectivity of harbours via ocean currents: A New Zealand study. Continental Shelf Research, 31, 1057-1074.

Chiswell SM, Wilkin J, Booth JD, Stanton B (2003) Trans-Tasman sea-larval transport: is Australia a source for New Zealand rock lobsters? Marine Ecology Progress Series, 247, 173-182.

Clark PJ, Evans FC (1954) Distance to nearest neighbor as a measure of spatial relationships in populations. Ecology, 35, 445-453.

Cole RG (2001) Patterns of abundance and population size structure of herbivorous fishes at the subtropical Kermadec Islands and in mainland New Zealand. New Zealand Journal of Marine and Freshwater Research, 35, 445-456.

Cowen RK, Lwiza KMM, Sponaugle S, Paris CB, Olson DB (2000) Connectivity of marine populations: open or closed? Science, 287, 857-859.

Cowen RK, Paris CB, Srinivassan A (2006) Scaling of connectivity in marine populations. Science, 311, 522-527.

Cowen RK, Sponaugle S (2009) Larval dispersal and marine population connectivity. Annual Review of Marine Science, 1, 443-466.

Crandall ED, Taffel JR, Barber PH (2010) High gene flow due to pelagic larval dispersal among South Pacific archipelagos in two amphidromous gastropods (Neritomorpha: Neritidae). Heredity, 104, 563-572.

Creese RG, Schiel DR, Kingsford MJ (1990) Sex change in a giant endemic limpet, Patella kermadecensis, from the Kermadec Islands. Marine Biology, 104, 419-426.

Doherty PJ, Planes S, Mather P (1995) Gene flow and larval duration in seven species of fish from the Great Barrier Reef. Ecology, 76, 2373-2391. 
Excoffier L, Laval G, Schneider S (2005) Arlequin (version 3.0): an integrated software package for population genetics data analysis. Evolutionary Bioinformatics Online, 1, 47-50.

Falush D, Stephens M, Pritchard JK (2003) Inference of population structure using multilocus genotype data: linked loci and correlated allele frequencies. Genetics, 164, 1567-1587.

Falush D, Stephens M, Pritchard JK (2007) Inference of population structure using multilocus genotype data: dominant markers and null alleles. Molecular Ecology Notes, 7, 574-578.

Francis MP, Grace RV, Paulin CD 1987. Coastal fishes of the Kermadec Islands. New Zealand Journal of Marine and Freshwater Research, 21, 1-13.

Gardner JPA, Curwen MJ, Long J, Williamson RJ, Wood AR (2006) Benthic community structure and water column characteristics at two sites in the Kermadec Islands Marine Reserve, New Zealand. NZ Journal of Marine and Freshwater Research, 40, 179-194.

Gardner JPA, Bell JJ, Constable HB, Hannan D, Ritchie PA, Zuccarello GC (2010) Multispecies coastal marine connectivity: a literature review with recommendations for further research. New Zealand Aquatic Environment and Biodiversity Report No. 58.

Glynn, P.W., G.M. Wellington, B. Riegl, D.B. Olson, E. Borneman \& E.A. Wieters. 2007. Diversity and Biogeography of the Scleractinian Coral Fauna of Easter Island (Rapa Nui). Pacific Science 61: 67-90.

Grantham BA, Ecker GL, Shanks AL (2003) Dispersal potential of marine invertebrates in diverse habitats. Ecological Applications, 13, 108-116.

Hendry R (2004) An assessment of the spatial extent and relative importance of nurseries and of the genetic structure among nurseries of rig (Mustelus lenticulatus), an 
endemic New Zealand shark. MSc Victoria University of Wellington, Wellington, 210 pp.

Hoareau TB, Bosc P, Valade P, Berrebi P (2007) Gene flow and genetic structure of Sicyopterus lagocephalus in the southwestern Indian Ocean, assessed by intronlength polymorphism. Journal of Experimental Marine Biology and Ecology, 349, 223-234.

Johnson M, Black R (2006) Islands increase genetic subdivision and disrupt patterns of connectivity of intertidal snails in a complex archipelago. Evolution, 60, 2498-2506.

Jones G, Milicich M, Emslie M, Lunow C (1999) Self-recruitment in a coral reef fish population. Nature, 402, 802-804.

Kalinowski ST (2005) HP-RARE 1.0: a computer program for performing rarefaction on measures of allelic richness. Molecular Ecology Notes, 5, 187-189.

Kelly RP, Palumbi S (2010) Genetic structure among 50 species of the northeastern Pacific rocky intertidal community. PLoS One, 5, 1-13.

Kinlan BP, Gaines SD (2003) Propagule dispersal in marine and terrestrial environments: a community perspective. Ecology, 84, 2007-2020.

Kinlan, BP, Gaines SD, Lester SE (2005) Propagule dispersal and the scales of marine community process. Diversity and Distributions, 11, 139-148.

Levinton JS, Koehn RK (1976) Population genetics of mussels. In: Marine Mussels: Their Ecology and Physiology (eds Bayne BL), pp. 357-384. Cambridge University Press, Cambridge, UK.

Levinton JS, Suchanek TH (1978) Geographic variation, niche breadth and genetic differentiation at different geographic scales in the mussels Mytilus californianus and M. edulis. Marine Biology, 49, 363-375. 
Lloyd EF, Nathan S (1981) Geology and tephrochronology of Raoul Island, Kermadec Group, New Zealand. NZ Geological Survey Bulletin, 95, 1-105.

Manel S, Gaggioti OE, Waples RS (2005) Assignment methods: matching biological questions with appropriate techniques. Trends in Ecology and Evolution, 20, 136142.

Miller MP (1997) Tools for population genetic analyses (TFPGA 1.3): a windows program for the analysis of allozyme and molecular population genetic data, online resource: http://www.marksgeneticsoftware.net/tfpga.htm

Miller MP (2005) Alleles In Space (AIS): Computer software for the joint analysis of interindividual spatial and genetic information. Journal of Heredity, 96, 722 - 724.

Miller MP, Bellinger MR, Forsman ED, Haig SM (2006) Effects of historical climate change, habitat connectivity, and vicariance on genetic structure and diversity across the range of the red tree vole (Phenacomys longicaudus) in the Pacific Northwestern United States. Molecular Ecology, 15, 145 - 159.

Mladenov PV, Allibone RM, Wallis GP (1997) Genetic differentiation in the New Zealand sea urchin Evechinus chloroticus (Echinodermata: Echinoidea). New Zealand Journal of Marine and Freshwater Research, 31, 261-269.

Nei M (1972) Genetic distance between populations. American Naturalist, 106, 283-292.

Piry S, Alapetite A, Cornuet, J.-M., Paetkau D, Baudouin, L., Estoup, A. (2004) GeneClass2: A software for genetic assignment and first-generation migrant detection. Journal of Heredity 95:536-539.

Pritchard JK, Stephens M, Donnelly P (2000) Inference of population structure using multilocus genotype data. Genetics, 155, 945-959. 
Raymond M, Rousset F (1995) An exact test for population differentiation. Evolution, 49, 1280-1283.

Ross PM, Hogg ID, Pilditch C, Lundquist CJ (2009) Phylogeography of New Zealand's coastal benthos. New Zealand Journal of Marine and Freshwater Research, 43, $1009-1027$.

Rousset F (2008) GENEPOP'007: a complete re-implementation of the GENEPOP software for Windows and Linux. Molecular Ecology Resources, 8, 103-106.

Sarver SK, Foltz DW (1993) Genetic population structure of a species' complex of blue mussels (Mytilus spp.). Marine Biology, 117, 105-112.

Scheltema RS (1971) Larval dispersal as a means of genetic exchange between geographically separated populations of shoalwater benthic marine gastropods. Biological Bulletin, 140, 284-322.

Scheltema RS (1986) On dispersal and planktonic larvae of benthic invertebrates: an eclectic overview and summary of problems. Bulletin of Marine Science, 39, 290-322.

Schiel DR, Kingsford MJ, Choat JH (1986) Depth distribution and abundance of benthic organisms and fishes at the subtropical Kermadec Islands. NZ Journal of Marine and Freshwater Research, 20, 521-535.

Shanks AL (2009) Pelagic larval duration and dispersal distance revisited. Biological Bulletin, 216, 373-385.

Shanks AL, Grantham BA, Carr MH (2003) Propagule dispersal distance and the size and spacing of marine reserves. Ecological Applications, 13, 159-169.

Shulman, M. J. 1998. What can population genetics tell us about dispersal and biogeographic history of coral-reef fishes? Australian Journal of Ecology, 23, 216-225. 
Siegel DA, Kinlan BP, Gaylord B, Gaines SD (2003) Lagrangian descriptions of marine larval dispersion. Marine Ecology-Progress Series, 260, 83 - 96.

Slatkin M (1987) Gene flow and the geographic structure of natural populations. Science, 236, 787 _ 792 .

Slatkin, M. 1993. Isolation by distance in equilibrium and non- equilibrium populations. Evolution, 47, 264-279.

Spencer HG, Waters JM, Eichhorst TE (2007) Taxonomy and nomenclature of black nerites (Gastropoda: Neritimorpha: Nerita) from the South Pacific. Invertebrate Systematics, 21, 229-237.

Star B, Apte S, Gardner JPA (2003) Genetic structuring among populations of the greenshell mussel Perna canaliculus revealed by analysis of randomly amplified polymorphic DNA. Marine Ecology Progress Series, 249, 171-182.

Sutton P, Chiswell S, Gorman R, Kennan S, Rickard G (2009) Physical marine environment of the Kermadec Islands region. Unpublished report prepared for the Department of Conservation, Wellington, New Zealand.

Swearer S, Caselle J, Lea D, Warner RR (1999) Larval retention and recruitment in an island population of a coral-reef fish. Nature, 402, 799-802.

Taylor MS, Hellberg M (2003) Larvae retention: Genes or oceanography? Response. Science, 300, 1657-1658.

Underwood JN, Smith LD, van Oppen MJH, Gilmour JP (2007) Multiple scales of genetic connectivity in a brooding coral on isolated reefs following catastrophic bleaching. Molecular Ecology, 16, 771-784 . 
Van Oosterhout CV, Hutchinson WF, Wills DPM, Shipley P (2004) MICRO-CHECKER: software for identifying and correcting genotyping errors in microsatellite data. Molecular Ecology Notes, 4, 535-538.

Waples RS (1987) A multispecies approach to the analysis of gene flow in marine shore fishes. Evolution, 41, 385-400.

Waples RS, Gaggioti O (2006) What is a population? An empirical evaluation of some genetic methods for identifying the number of gene pools and their degree of connectivity. Molecular Ecology, 15, 1419-1439.

Waters JM, Roy MS (2003) Marine biogeography of southern Australia: phylogeographical structure in a temperate sea-star. Journal of Biogeography, 30, 1787-1796.

Waters JM, King TM, O'Loughlin PM, Spencer HG (2005) Phylogeographical disjunction in abundant high-dispersal littoral gastropods. Molecular Ecology, 14, 2789-2802.

Waters JM, McCulloch GA, Eason JA (2007) Marine biogeographical structure in two highly dispersive gastropods: implications for trans-Tasman dispersal. Journal of Biogeography, 34, 678-687.

Weersing K, Toonen RJ (2009) Population genetics, larval dispersal, and connectivity in marine systems. Marine Ecology Progress Series, 393, 1-12.

White C, Selkoe KA, Watson J, Siegal DA, Zacherl, DC, Toonen RJ (2010) Ocean currents help explain population genetic structure. Proceedings of the Royal Society of London (Series B), 277, 1685-1694.

Whittaker RJ, Fernandez-Palacios JM (2007) Island Biogeography: Ecology, Evolution, and Conservation. Oxford University Press, Oxford, United Kingdom. 
Wicks LC, Gardner JPA, Davy SK (2010) Spatial patterns and regional affinities of coral communities at the Kermadec Islands Marine Reserve, New Zealand - a marginal high-latitude site. Marine Ecology Progress Series, 400, 101-113.

Wood AR, Gardner JPA (2007) Small spatial scale population genetic structure in two limpet species endemic to the Kermadec Islands, New Zealand. Marine Ecology Progress Series, 349, 159-170.

Wright JT, Zuccarello GC, Steinberg PD (2000) Genetic structure in the subtidal red alga Delisea pulchra. Marine Biology, 136, 439-448. 



\section{CHAPTER VI}

\section{GENERAL DISCUSSION}

This $\mathrm{PhD}$ thesis highlights the complex nature of island connectivity and the importance of knowing the correct taxonomy of island species to understand the historical and contemporary dynamics of these habitats. Two major points result from this thesis: (1) the necessity of integrating taxonomic surveys in management and protection programs; and (2) the need to consider rafting and mediated dispersal (other than larval dispersal) in integrated models of dispersal and conduct surveys on its impact on population connectivity. 


\subsection{Importance of taxonomy in the management and protection of natural resources}

\subsubsection{Reputation of taxonomy in contemporary science}

In recent decades, cladistics and evolutionary biology have been largely flourishing, while taxonomy has suffered a continuous decline in interest and resources allocated to its study and practice (Dubois 2003). Moreover, many scientists now consider taxonomy to be a discipline outside of science, being mostly descriptive, and have turned toward the two other systematics disciplines.

Not only is taxonomy deemed to be subjective (Morrison et al. 2009), there is also a bias in coverage, with some taxa being more studied than others. This bias could be due to where the species live, as it is more likely for it to be reviewed and listed if it is accessible to taxonomists. Also, species will tend to be more described if they are charismatic or economically important (Isaac et al. 2004). For example, a recent review of 2700 conservation articles showed that vertebrate species were the focus of $69 \%$ of the studies, while vertebrates represent only $3 \%$ of the total number of species on Earth (Clark \& May, 2002).

Another problem encountered in taxonomy concerns the "random" circumstances in which taxonomic mistakes are discovered and the lack of subsequent taxonomic reconsideration. Now, most taxonomic errors (e.g., cryptic species) are detected by molecular work where the aim of the study was not to test for the taxonomic exactitude of a particular group of organisms. In such a case, the authors mention the need for taxonomic reconsideration but subsequent work in order to have the taxonomy reconsidered is usually not carried out (e.g. Goldstien et al. 2009). Hence, not only are the taxonomists "under-used", but the taxonomy remains officially unchanged, leading to incongruent taxonomic publications and a risk of flawed research in terms of sampling design and data analysis. This $\mathrm{PhD}$ research stresses the importance of developing a scientific collaboration between evolutionary biologists and taxonomists, in order to ensure that taxonomic updates happen at the same speed as the discoveries for the need to consider taxonomic revisions. 


\subsubsection{Importance of taxonomy for natural resource management and conservation}

Taxonomy is the basis for characterizing organisms, and is complementary and necessary for natural resource management and conservation planning. Indeed, our attempt to understand the impacts of environmental change is compromised if we cannot recognize and describe the interacting components of natural ecosystems (Mace 2004). The importance of taxonomy in conservation is also reflected by the way protection agencies communicate about endangered species, with the creation of the CITES list and IUCN red list, using a species-level classification.

The impact of taxonomy on management and conservation was brought to attention by May in 1990 with an article published in Nature, entitled "Taxonomy as destiny". This paper explained how an iguana-like reptile, the Brother's Island tuatara (Sphenodon guntheri) off the coast of New Zealand, was not recognized as a distinct species from Sphenodon punctatus and had therefore been ignored by protective legislation. May's statement was highlighted by the title on the journal's cover: “'Bad taxonomy can kill”. Following its publication, numerous papers followed the idea that “bad" taxonomy can hinder conservation (Gittleman \& Pimm 1991; McNeely 2002; Russello et al. 2005; Khuroo et al. 2007). However, nobody actually described what a good or a bad taxonomy was.

It is generally recognized that a good taxonomy is a "recent" taxonomy, supposedly based on better sampling and newer and up-to-date methods (Morrison et al. 2009). Taxonomy, much like many fields of biology, is a constantly evolving discipline, and as such, has built-in instabilities that result in name and rank changes over time. Thus, the names and the number of species fluctuate according to the study effort of researchers on a considered taxon (Morrison et al. 2009). Conservation planning and resource management depends on the number of species and their subdivision, reflecting richness, diversity, endemism, connectivity and many other attributes that can be compared across taxa and geographic areas (Isaac et al. 2004).

A recent review tried to assess the impact of taxonomic modifications on resource-management conservation, and if conservation policies were taking into account changes made to taxonomy (Morrison et al. 2009). The conclusion was that changes in taxonomy do not have consistent and predictable impacts on conservation policies and resource management. Taxonomic changes had three major trends 
depending on the type of changes and the species under consideration: (1) taxonomic changes have a positive impact on conservation when it involves species splitting; (2) they have low to non-existent impact when it involves charismatic or iconic species; and (3) they have detrimental impacts when they involve species amalgamation (lumping) or reveal the hybrid nature of a species.

In this $\mathrm{PhD}$, I worked in collaboration with Bruce Marshall on the taxonomic description of the two newly recognized species of Cellana in the NZ subantarctic island. This new taxonomy provided important insights into historical and contemporary connectivity of the NZ subantarctic islands, showing that the colonisation history and the impact of the last glacial maximum differed among the islands. Also, this $\mathrm{PhD}$ revealed the presence of highly structured and diverse populations on each island, which is of great importance for the management and protection planning of the NZ subantarctic group, as explained in the next section.

\subsection{Genetic markers, connectivity and protection of marine species}

\subsubsection{Genetic markers and their efficiency to detect connectivity}

A distinct drawback to allele-frequency approaches is that small levels of gene flow (a few migrants per generation) will prevent population genetic divergence (Slatkin 1987, 1993), leading to genetic homogeneity of the populations. Hence, despite the fact that classical genetics can give important insights on the existence of factors limiting gene flow, the impossibility of estimating the magnitude of dispersal among populations when there are more than a few migrants per generation led many researchers to question the use of genetic markers to study population connectivity (Waples 1998, Hellberg 2009). However, the presence of genetic homogeneity among populations of a marine species might not indicate that the populations are significantly demographically connected. Implicit in the definition of demographic connectivity is that the level of exchange must be sufficient to impact the demographic rates of the local population(s). The level of such ecologically relevant exchange is several orders of magnitude larger than the level of exchange required for the maintenance of genetic homogeneity among subpopulations. Indeed, low migration rates (when the number of migrants per generation, $\mathrm{m}<0.001$ ) can result in 
a substantial number of migrant individuals when local population sizes are in the millions, resulting in $\mathrm{F}_{\mathrm{ST}}$ values near zero. The proportion of migrants necessary to lead to a significant demographic connectivity among populations is arbitrary, and strongly dependent on the conditions in the receiving population (e.g. adult density, predation). Waples \& Gaggiotti (2006) suggested setting the threshold at $10 \%$ of the total recruitment $(\mathrm{m}=0.1)$ of a population in order to indicate a significant (but somewhat arbitrary) demographic connectivity.

Linked with the criticism of the inference of demographic connectivity from genetic markers, estimations of a population's recruitment from allelic frequencies have also been questioned. As stated above, classical genetics provides a view of genetic connectivity taking place over many generations, with the result that separating historical from recent exchange is often difficult (Benzie 1999, Neilsen \& Wakeley 2001). However, recent applications of Bayesian analytical techniques have demonstrated the potential to discern small spatial patterns in demographically relevant connectivity (e.g., Baums et al. 2005, Hare et al. 2006, Richards et al. 2007, Underwood et al. 2007). Also, assignment tests designed for use with co-dominant markers have been developed (Manel et al. 2005), and can detect possible $1^{\text {st }}$ generation migrants within the total migrant pool of a given population (Piry et al. 2004).

A common problem with the use of genetic markers in connectivity studies is the absence of consensus on the type of markers to be used in such studies. Different classes of genetic markers such as allozymes, mitochondrial DNA sequences, microsatellites and more recently SNPs loci have been used interchangeably to estimate population differentiation. However, it is now widely agreed that quantitative results from different classes of genetic markers are rarely directly comparable (Hutchison \& Templeton 1999, Whitlock \& McCauley 1999; Grosberg \& Cunningham 2001, Bazin et al. 2006). Weersing \& Toonen (2009) compared results in terms of quantitative population structure (Fst) to the type of markers used in different studies. They found that mitochondrial markers generally resulted in higher Fst values compared to nuclear markers, and indicated that multiple factors, inherent to the markers (e.g. mtDNA's uniparental inheritance, mutation rate, degree of polymorphism and relative resolving power of loci) or due to a statistical consequence 
of standardization when estimating Fst (see Jost 2008, Hedricks 2005) are responsible for the lack of congruence among markers classes and studies.

Most of the recent connectivity studies have used microsatellites (e.g. Bell \& Okamura 2005, Bell 2008b, Díaz-Viloria et al. 2009, Díaz-Ferguson et al. 2010) including a recent study on tropical Nerita species (Crandall 2010), and the recent development of the $2^{\text {nd }}$ - generation sequencing coupled with a significant drop in cost make their development easy and time effective. This $\mathrm{PhD}$ used 454 Roche sequencing technologies to develop microsatellite markers (Chapter IV) to study multi-scale connectivity of N. melanotragus in the South Pacific Ocean. Hence, levels of connectivity will be comparable with other connectivity studies based on microsatellites worldwide and taxon-wide.

\subsubsection{Application of genetics to conservation and management of marine} species

Conservation planning and species management operate at many levels, from whole ecosystems and communities down to individual organisms. At each of these levels, molecular genetic techniques provide appropriate tools to evaluate processes and develop management strategies. Darwin (1896) was the first to consider the importance of genetics in the survival potential of natural populations. The modern concern for genetics in conservation began approximately 40 years ago when Frankel (1970) raised alarm about the loss of primitive crop varieties and their replacement by genetically uniform cultivars. During the 1980s, conservation genetics had become an important and expanding discipline with a strong theoretical framework (Soule and Wilcox 1980, Frankel and Soule 1981, Schonewald-Cox et al. 1983). However, in the late 1990s, many scientists questioned whether inbreeding and loss of genetic variation were trivial contributors to extinction risk in small populations compared to demographic and environmental factors, and thus if genetic factors had any significance for conservation (Caro \& Laurenson 1994, Lande 1988, Caughley 1994, Harcourt 1995). Ultimately, it has been demonstrated that the viability (resilience and adaptation capacity) of a species to short term demographic and environmental threats is linked with the amount of genetic diversity it possesses (Frankham et al. 2002, Partridge \& Brufford 1994). As previously stated, the reduction of a species genetic 
diversity has been observed following inbreeding. Another scenario influencing levels of genetic diversity is hybridization among species. Hybridization, also termed interbreeding, sometimes leads to increased levels of genetic diversity, introducing new alleles in both species. However, it can be of concern for endemic or rare species/populations as it might threaten their genetic integrity (Waples and Teel 1990). When considering the management of species and captive breeding programs, genetic screening is presently a good way of identifying hybridization in wild and captive stocks (Baensch \& Tamaru 2009, Neaves et al. 2010).

I explained above how genetic markers were useful for studying population connectivity. Connectivity plays an important part in conservation planning, and especially in the implementation of Marine Protected Area (MPA) networks. Protecting both important species and their habitats has become a priority in conserving and managing marine ecosystems. Protected areas have often been established on an individual ad hoc basis rather than through a systematic planned process. For an area to be considered as a MPA, it needs to meet the general International Union for Conservation of Nature (IUCN) definition of a MPA, which is as follows: 'Any area of intertidal or subtidal terrain, together with its overlying water and associated flora, fauna, historical and cultural features which has been reserved by law or other effective means to protect part or all of the enclosed environment' (Kelleher, 1999). Following the widespread voicing of concerns about anthropogenic threats to the marine environment efforts have been directed toward an increased spatial management of populations and ecosystems, with the goal to design effective marine reserves. The importance of population connectivity and its implication in spatial management was raised by Roberts (1997), and has later been recognized in the value and design of MPA networks (e.g., Crowder et al. 2000, Botsford et al. 2001, Sala et al. 2002, Gaines et al. 2003, Hastings \& Botsford 2003, Halpern \& Warner 2003, Kritzer \& Sale 2004, Fogarty \& Botsford 2007).

The term 'network' is used in most of the conservation literature to describe a group of protected areas spread across a country or region that work co-operatively at different spatial scales, and operating with a range of protection levels that are designed to meet the goals that a single MPA cannot achieve (IUCN/WCPA, 2008). A network is commonly a group of protected areas that are connected through larval, juvenile or adult movement. Although the topology of a network of MPAs can be 
complex, all networks should have four key features that play a fundamental role in their functioning: the span of the network (the length of coastline or area of habitat between the most distant protected units), the size and shape of individual reserve units, their number, and their placement. Together these features determine other critical network features including the amount of area dedicated to protection and connectivity among reserve units (Lubchenco 2003). Compared to an individual MPA, a network of MPAs represents a 'scaling up' of conservation and provides resilience (here, the capacity of a system to absorb disturbance and reorganize while undergoing change so as to still retain essentially the same function, structure and identity; Walker et al. 2004). More specifically, the amount of connectivity between different sites determines the buffering an MPA is afforded from catastrophes through external recruitment and the usefulness of the MPA as a source of recruitment to nonMPA populations via larval export and/or adult spill-over and also the genetic differentiation between the sites considered (Bell \& Okamura 2005). Thus, a network acts as an important insurance policy: for example, if one site is lost due to disturbance, then others can still contribute to the re-establishment of a species. MPA networks can also ensure that many types of biodiversity (both species and ecosystems) are protected, helping to maintain the natural range of species, and ensuring the protection of unique, endemic, rare and threatened species.

There are now 34 marine reserves established in New Zealand waters, which collectively protect approximately $8 \%$ of New Zealand's territorial sea, and over $99 \%$ of the territorial sea around isolated offshore island groups (the subantarctic islands and the Kermadec islands). Additional reserves are planned by the NZ Department of Conservation (DOC) in an effort to create a bioregional MPA network protecting over $10 \%$ of $\mathrm{NZ}$ territorial sea. This $\mathrm{PhD}$ contributed to this effort by investigating levels of genetic connectivity among NZ island MPAs. Chapter II gave important insights on the historical and contemporary importance of the subantarctic islands for the biodiversity of the Southern Ocean, and on levels of genetic connectivity among the NZ subantarctic islands. When this research began, marine protection around NZ's subantarctic consisted of a single marine reserve/marine mammal sanctuary 12 nautical miles around Auckland/Motu Maha islands, and commercial fishing restrictions and legal protection to various marine animals in New Zealand waters. The low levels of connectivity reported in Chapter II demonstrate the need for the 
implementation of a set of MPAs around each island, which was done in January 2011 (DOC communication). Chapter V contributed to the better understanding of connectivity levels within the largest NZ MPA, located around the Kermadec islands, and also revealed for the first time potentially high level of genetic connectivity between the Kermadec islands and NZ North Island. Thus, the Kermadec Islands Marine Reserve (KIMR) shows resilience capacity, regarding its connection with other MPAs in mainland NZ, both as a source and a sink population (exporting and receiving). KIMR would then be a great asset in the context of the ongoing bioregional New Zealand MPA policy and implementation effort on MPA network. However, those results are to be considered carefully, as I used a model species with a relatively long PLD, and it has been proven that different taxa have different histories that will reflect different patterns of genetic structure, and also have different life histories (e.g. larval dispersal or lack thereof, length of PLD, type of larval foraging; Cowen 2000).

\subsection{Mediated dispersal}

\subsubsection{Mediated dispersal, a component to take into account}

When considering species with a larval stage, such as many marine benthic species, the term "dispersal" is very often associated with "larval dispersal", which is a classic restriction of the term. Guppy (1917) was among the first scientists who addressed the possibility of larval recruitment onto flotsam such as pumice, plant propagules, floating shells or kelp. Mediated dispersal of marine species, including juveniles and adults stages, can occur in many different ways, via natural aided means (e.g. rafting on natural substrates) but can also be the result of accidental or deliberate anthropogenic introduction (e.g. hitchhiking in ballast water, hull-fouling on boats, or purposeful introduction for recreational activities, amelioration of environmental conditions, or biological control of a non-native species).

The real impact of mediated dispersal on dispersal capacities and range expansion of species became important in marine science after the publication of an article entitled "The paradox of Rockall: why is a brooding gastropod (Littorina saxatilis) more widespread than one having a planktonic larval dispersal stage ( $L$. 
littorea)?" by Johannesson (1988), demonstrating that adult dispersal on rafts was possible for marine species. A recent review of the ecology of marine rafting offers an overview of the taxa involved with rafting, as well as the importance and frequency of rafting events in the marine realm (Thiel \& Gutow 2005). The authors confirmed that the phenomenon was far from isolated and infrequent, and that it involved all types of organisms and rafts (e.g. Masó et al. 2003 for unicellular organisms; Fraser et al. 2011 for epifaunal coastal invertebrates; Mortensen 1933 in Thiel and Gutow 2005, Fell 1967 for echinoderms; Cornelius 1992, Boero \& Bouillon 1993 for hydroids; Worchester 1994 for ascidians; Knight-Jones \& Knight-Jones 1984 for polychaetes; Aliani \& Molcard 2003 for western Mediterranean macrobenthic species; Nikula et al. 2010 for crustacean; Censky et al. 1998, Raxworthy et al. 2002 for reptiles; Prescott 1959 in King 1962, Hafner et al. 2001 for small mammals). Relevant to Chapter 2, Cellana strigilis has been identified on multiple kelp rafts in the region of the subantarctic islands. Those rafts were still at sea or had been washed up on NZ South Island beaches (Fraser et al. 2011).

In addition to the "sea-mediated dispersal" described above, a newly published study also confirmed the possibility for marine species (here marine gastropods) to disperse via the air: the article, entitled "Flying shells: historical dispersal of marine snails across central America", demonstrated that sea snails and more generally many intertidal organisms may be able to "fly" with shorebirds across the Mexican Atlantic and Pacific coasts, stuck to their legs or riding on their bellies (Miura et al. 2011). The "flying shells" phenomenon had already been hypothesized by Darwin, who speculated that migratory birds could transport land snails to distant places. However, Miura et al. (2011) gave the first report of a marine snail "flying" from one ocean to another.

Chapter II of this $\mathrm{PhD}$ also stresses the possibility for marine rocky shore invertebrates to disperse on kelp rafts, and that species do not need to be usually associated with the type of raft they are using (i.e. Cellana strigilis has never been associated with kelp forest habitat). 


\subsubsection{Mediated dispersal as a threat to remote Island biotas}

Island biotas are a product of dispersal events and in situ diversification. Natural colonisation and extinction rates are known to be broadly related to the geographical isolation of an island, its surface area and the life histories of the dispersing taxa (MacArthur and Wilson 1967). After an initial phase of colonisation or competitive redistribution of niches, the geographical isolation of oceanic islands and their virgin ecology provides the impetus for an evolutionary radiation of unique biological forms (neoendemics), though endemism can also arise through the extinction of the ancestral and continental taxa (palaeoendemics; Whittaker and Fernández-Palacios 2007). Biodiversity on young islands, close to continents, tends to be the result of colonisation, while on old remote islands, speciation occurs faster than colonisation (Heaney 1986). Hence, the evolution and ultimately the persistence of island endemics depend on a relative environmental stability over time (Jansson 2003). This stability can however be lost when non-native species get introduced in the ecosystem.

Numerous negative impacts of introduced species on biodiversity and native species have been reported in many different environments (see review by Lowe et al. 2000). The spread of the green macroalgae species Caulerpa taxifolia in the Mediterranean Sea after its accidental introduction is a good example of the devastating effects a non-native species can have on local biodiversity (Verlaque $\&$ Fritayre 1994, Bellan-Santini et al. 1996). Insular species however, are believed to be more susceptible to non-native species due to intrinsic characteristics such as naturally small population sizes and high levels of habitat specialization derived from evolution in isolation (Sodhi et al. 2004). As such, they generally show reduced competitive abilities and are also described as being predator-naive (Darwin 1839; Lack 1947; Curio 1966). Animals on isolated islands typically show little escape response towards potential predators in comparison with animals on the mainland. The mechanism underlying this loss is hypothesized to result from a reduction of predation risk on islands either because islands are able to support fewer top predators than adjacent mainland sites, because islands lost predators following Pleistocene sealevel changes, or as a consequence to the founder effect (Blumstein 2002). In contrast to island species that experience relaxed predation pressure, mainland species are 
faced with a fierce multitude of predators (Berger et al. 2007). They can quickly alter their behaviour and initiate efficient escape manoeuvres in response to increased predation risk by sympatric as well as newly emerging predator species (Lima \& Dill 1990; Maloney \& McLean 1995). Whether and how quickly island species can develop/regain the ability to perceive introduced species as life-threatening predators is still a matter of debate (Cayot et al. 1994; Maloney \& McLean 1995).

Coupled with the appearance of introduced species/new predators, pest species are also moving with their hosts, and the small size and naïve nature of most island populations render them particularly prone to extinction facing new introduced pathogens (Atkinson et al. 1995, Cole et al. 1995). Several mechanisms are blamed for the predisposition of island populations to exotic pathogens. Both theoretical and empirical evidence suggests that small host populations on isolated islands support only impoverished parasite communities (Dobson et al. 1992, Dobson \& McCallum 1997). This is because resident parasites are subject to the same constraints that limit host diversity. They are also subject to additional demographic and genetic constraints dictated by the small population sizes of their hosts. As a result, island endemics have been exposed to few parasites and other pathogens during their recent evolutionary history (Wikelski et al. 2004).

In the previous part, mediated dispersal was introduced as a potential important component of population connectivity, and although it remains largely ignored in connectivity studies, the potential threat it represent as a means to introduce non-native species has already been recognized (Barnes, 2002). The recent increase of studies reporting evidence of mediated dispersal could be linked with a serious augmentation of potential rafts of anthropogenic origin in oceans across the world (e.g. augmentation of boat traffic, but also increased number of plastic debris, manufactured wood, tar balls from oil industry etc.; see Carpenter et al. 1972, Gregory et al. 1984, Ryan \& Moloney 1993). Although the number of "natural" rafts may vary on a regular seasonal basis (e.g., macroalgae, plants), or may even be less predictable and less frequent (e.g., driftwood, pumice, and animal remains), anthropogenic rafts are delivered to the world's oceans on a much more regular basis than most natural floating items. Surveys carried out on many remote island shores have also shown a dramatic increase of stranding debris on those islands. Microplastic fragments have already been found in the sediments around the remote Southern 
Ocean island of South Georgia (Thompson et al., 2009). The fact that plastics are floating into the remotest of localities is a strong measure of human influence on the surface of the planet. Plastic is an ideal substratum not only for concentrating persistent organic pollutants (POPs) but also for fouling organisms. Thus both POPs and organisms can be distributed widely to new localities across the planet (Mato et al. 2001). This is of particular importance to Southern Ocean biodiversity as it is the last big area where non-indigenous animal species are not yet known to be established. Knowing that temporal variability in supply of floating items does have strong implications for rafting as an ecological process, the reported increase in anthropogenic debris at sea only enhances the need to consider mediated dispersal as a strong means to connect different habitats and a potential threat to remote island biodiversity.

\subsection{Conclusions}

Taxonomy and conservation go hand-in-hand, but the collaboration between the two fields remains limited. Taxonomy should also become an integral part of resource management and protection programs, and it is the role of biologists, conservationists and managers to promote taxonomy as part of "today's science". Efforts should be made by protection agencies and managers to take into account taxonomic changes, and accept the fact that taxonomic classification does fluctuate over time, because of past errors detected by further analysis (short time scale), or because of evolution (long time scale). As Isaac et al. (2004) so aptly stated: "acceptance of darwinism implies that evolution will result in a continuum of living organisms in space and time, modified by variable extinctions and intermediates. Species are part of this continuum, rather than being particularly unique taxonomic entities".

This Ph.D. allowed a better understanding of the historical and contemporary patterns of genetic connectivity in the $\mathrm{NZ}$ offshore islands. It illustrated how historical events such as the last glacial maximum can shape local genetic diversity, and how this historical pattern can be maintained because of limited contemporary gene exchange. Also, this thesis demonstrated that remote populations could be strongly connected to mainland populations, contributing to the resilience of both systems and 
confirming the necessity of integrating remote oceanic habitats in the creation of an effective MPAs network to protect the marine environment.

Also, there is an urgent need to consider mediated dispersal as a serious means of connecting populations. Research should be developed to quantify its importance, and to integrate it in conservation models, particularly those of remote islands.

\subsection{References}

Aliani S, Molcard A (2003) Hitch-hiking on floating marine debris: macrobenthic species in the Western Mediterranean Sea. Hydrobiologia, 503, 59-67.

Atkinson CT, Woods KL, Dusek RJ, Sileo LS, Iko WM (1995) Wildlife disease and conservation in Hawaii - Pathogenicity of avian malaria (Plasmodium relictum) in experimentally infected Iiwi (Vestiaria coccinea). Parasitology 111, 59-69.

Baensch FU, Tamaru CS (2009) Captive hybridization of two geographically isolated pygmy angelfish species, Centropyge fisheri and Centropyge resplendens. Journal of Fish Biology, 75, 2571-2584.

Barnes DKA (2002) Invasions by marine life on plastic debris. Nature, 416, 808-809.

Baums IB, Miller MW, Hellberg ME (2005) Regionally isolated populations of an imperiled Caribbean coral, Acropora palmata. Molecular Ecology, 14, 13771390.

Bazin E, Glémin S, Galtier N (2006) Population size does not influence mitochondrial genetic diversity in animals. Science, 312, 570-572.

Bell JJ (2008) Similarity in connectivity patterns for two gastropod species lacking pelagic larvae. Marine Ecology Progress Series, 357, 185-194. 
Bell JJ, Okamura B (2005) Low genetic diversity in a marine reserve: reevaluating diversity criteria in reserve design. Proceedings of the Royal Society: Biological Sciences, 272, 1067-1074.

Bellan-Santini D, Arnaud PM, Bellan G, Verlaque M (1996) The influence of the introduced tropical alga Caulerpa taxifolia, on the biodiversity of the Mediterranean marine biota. Journal of the Marine Biological Association of the United Kingdom, 76, 235-237.

Benzie JAH (1999) Genetic structure of coral reef organisms: ghosts of dispersal past. American Zoologist, 39, 131-145.

Berger S, Wikelshi M, Michael Romero L, Kalko EKV, Rödl T (2007) Behavioral and physiological adjustments to new predators in an endemic island species, the Galápagos marine iguana. Hormones and Behavior, 52, 653-663.

Blumstein DT (2002) Moving to suburbia: ontogenetic and evolutionary consequences of life on predator-free islands. Journal of Biogeography, 29, 685-692.

Boero F, Bouillon J (1993) Zoogeography and life cycle patterns of Mediterranean hydromedusae. Biological Journal of the Linnean Society, 48, 239-266.

Botsford LW, Hastings A, Gaines SD (2001) Dependence of sustainability on the configuration of marine reserves and larval dispersal distances. Ecology Letters, 4, 144-150.

Caro TM, Laurenson MK (1994) Ecological and genetics factors in conservation: a cautionary tale. Science, 263, 485-486.

Carpenter EJ, Anderson SJ, Harvey GR, Miklas HP, Bradford BP (1972) Polystyrene spherules in coastal waters. Science, 178, 749-750. 
Caughley G (1994) Directions in conservation biology. Journal of Animal Ecology, 63, 215-244.

Cayot LJ, Rassmann K, Trillmich F (1994) Are marine iguanas endangered on islands with introduced predators? Noticias de Galapagos, 53, 13-15.

Censky EJ, Hodge K, Dudley J (1998) Over-water dispersal of lizards due to hurricanes. Nature, 395, 556-560.

Clark JA, May RM (2002) Taxonomic bias in conservation research. Science, 297, 191-192.

Cole FR, Loope LL, Medeiros AC, Raikes JA, Wood CS (1995) Conservation implications of introduced game birds in high-elevation Hawaiian shrubland. Conservation Biology, 9, 306-313.

Cornelius PFS (1992) The Azores hydroid fauna and its origin, with discussion of rafting and medusa suppression. Arquipelago, 10, 75-99.

Crandall ED, Taffel JR, Barber PH (2010) High gene flow due to pelagic larval dispersal among South Pacific archipelagos in two amphidromous gastropods (Neritomorpha: Neritidae). Heredity, 104, 563-572.

Crowder LB, Lyman SJ, Figuera WF, Priddy J (2000) Source-sink dynamics and the problem of siting marine reserves. Bulletin of Marine Sciences, 66, 799-820.

Curio E (1966) How finches react to predators. Animals, 9, 142-143.

Darwin C (1839) Journal of researches into the geology and natural history of the various countries visited by H. M. S. Beagle, under the command of Captain Fitzroy, R. N. from 1832 to 1836. London: Henry Colburn. 
Darwin C (1896) The variation of animals and plants under domestication, Vol. II, D Appleton \& Co, New York.

Díaz-Ferguson E, Haney R, Wares J, Silliman B (2010) Population genetics of a trochid gastropod broadens picture of caribbean sea connectivity. PLoS ONE 5(9): e12675.

Díaz-Viloria N, Cruz P, Guzmán-Del Próo SA, Perez-Enriquez R (2009) Genetic connectivity among pink abalone Haliotis corrugata populations. Journal of Shellfish Research, 28, 599-608.

Dobson AP, Pacala SV, Roughgarden JD, Carper ER, Harris EA (1992) The parasites of Anolis lizards in the northern Lesser Antilles. I. Patterns of distribution and abundance. Oecologia, 91, 110-117.

Dobson AP, McCallum H (1997) The role of parasites in bird conservation. Pages 155-173. In Clayton DH, Moore J, editors. Host-parasite evolution: general principles and avian models. Oxford University Press, Oxford, UK.

Dubois A (2003) The relationships between taxonomy and conservation biology in the century of extinctions. Comptes Rendus Biologies, 326, 9-21.

Fell HB (1967) Cretaceous and Tertiary surface currents of the oceans. Oceanography and Marine Biology: An Annual Review, 5, 317-347.

Fogarty MJ, Botsford LW (2007) Population connectivity and spatial management of marine fisheries. Oceanography, 20, 112-123.

Frankel OH (1970) Genetic conservation in perspective. 479-489, in Frankel OH, Bennett E, eds. Genetic resources in plants - their exploration and conservation. Blackwell Scientific Publications, Oxford. 
Frankel OH, Soulé ME (1981) Conservation and evolution. Cambridge University Press, Cambridge, UK.

Frankham R, Ballou JD, Briscoe DA (2002) Introduction to conservation genetics. Cambridge University Press, Cambridge.

Fraser CI, Nikula R, Waters J (2011) Ocean rafting by a coastal community. Proceedings of the Royal Society B, 278, 649-655.

Gaines SD, Gaylord B, Largier JL (2003) Avoiding current oversights in marine reserve design. Ecological Applications, 15, 2180-2191.

Gittleman JL, Pimm SL (1991) Crying wolf in North- America. Nature, 351, 524525.

Goldstien SJ, Gemmell NJ, Schiel DR (2009) Colonisation and connectivity by intertidal limpets among New Zealand, Chatham and Sub-Antarctic Islands. I. Genetic connections. Marine Ecology Progress Series, 388, 111-119.

Gregory MR, Kirk RM, Mabin MCG (1984) Pelagic tar, oil, plastics and other litter in surface waters of the New Zealand sector of the Southern Ocean and on Ross Dependency shores. New Zealand Antarctic Record, 6, 12-28.

Grosberg RK, Cunningham CW (2001) Genetic structure in the sea: from populations to communities. In Bertness MD, Hay ME, Gaines SD (eds) Marine community ecology. Sinauer Associates, Sunderland, Massachusetts, p 61-84.

Guppy HB (1917) Plants, seeds, and currents in the West Indies and Azores. Williams and Norgate, London. $531 \mathrm{pp}$.

Hafner DJ, Riddle BR, Alvarez-Castaneda ST (2001) Evolutionary relationships of white-footed mice (Peromyscus) on islands in the Sea of Cortez, Mexico. Journal of Mammalogy, 82, 775-790. 
Halpern BS, Warner RR (2003) Matching reserve design to reserve objectives. Proceedings of the Royal Society of London Series B, 270, 1871-1878.

Harcourt AH (1995) Population viability estimates - theory and practice for a wild gorilla population. Conservation Biology, 9, 134-142.

Hare MP, Allen SK Jr, Bloomer P, Camara M, Carnegie RB, Murfree J, Luckenbach M, Meritt D, Morrison C, Paynter K, Reece KS, Rose CG (2006) A genetic test for recruitment enhancement in Chesapeake Bay oysters, Crassostrea virginica, after population supplementation with a disease tolerant strain. Conservation Genetics, 7, 717-734.

Hastings A, Botsford LW (2003) Are marine reserves for fisheries and biodiversity compatible? Ecological Applications, 13, 65-70.

Heaney LR (1986) Biogeography of mammals in SE Asia: estimates of rates of colonisation, extinction and speciation. Biological Journal of the Linnean Society, 28, 127-165.

Hedrick PW (2005) A standardized genetic differentiation measure. Evolution, 59, $1633-1638$.

Hellberg, M. E. 2009. Gene flow and isolation among populations of marine animals. Annual Review of Ecology, Evolution and Systematics, 40, 291-310.

Hutchison DW, Templeton AR (1999) Correlation of pairwise genetic and geographic distance measures: inferring the relative influences of gene flow and drift on the distribution of genetic variability. Evolution, 53, 1898-1914.

Isaac NJB, Mallet J, Mace GM (2004) Taxonomic inflation: its influence on macroecology and conservation. Trends in Ecology and Evolution, 19, 464469. 
Johannesson K (1988) The paradox of Rockall: why is a brooding gastropod (Littorina saxatilis) more widespread than one having a planktonic larval dispersal stage (L. littorea)? Marine Biology, 99, 507-513.

IUCN/WCPA (2008) Establishing Resilient Marine Protected Areas Networks Making it happen. IUCN World Commission on Protected Areas, National Oceanic and Atmospheric Administration and the Nature Conservancy. Washington DC. USA. 119pp.

Jansson R (2003) Global patterns in endemism explained by past climatic change. Proceedings of the Royal Society of London B, 270, 583-590.

Johnson MS, Black R (2006) Islands increase genetic subdivision and disrupt patterns of connectivity of intertidal snails in a complex archipelago. Evolution, 60, 2498-2506.

Jost L (2008) $G_{\mathrm{ST}}$ and its relatives do not measure differentiation. Molecular Ecology, 17, 4015-4026.

Kelleher G (1999) Guidelines for Marine Protected Areas. IUCN, Gland, Switzerland and Cambridge, UK.

King W (1962) The occurrence of rafts for dispersal of land animals into the West Indies. Quarterly Journal of the Florida Academy of Sciences, 25, 45-52.

Kinlan B, Gaines SD (2003) Propagule dispersal in marine and terrestrial environments: a community perspective. Ecology, 84, 2007-2020.

Khuroo AA, Dar GH, Khan ZS, Malik AH (2007) Exploring an inherent interface between taxonomy and biodiversity: current problems and future challenges. Journal for nature Conservation, 15, 256-261. 
Knight-Jones P, Knight-Jones EW (1984) Systematics, ecology and distribution of Southern Hemisphere spirorbids. In Proceedings of the First International Polychaete Conference, P.A. Hutchings (ed.). Sydney, New South Wales: Linnean Society, 196-210.

Kritzer JP, Sale PF (2004) Metapopulation ecology in the sea: from Levin's model to marine ecology and fisheries science. Fish and Fisheries, 5, 131-40.

Lack D (1947) Darwin's finches. Cambridge University Press.

Lande R (1988) Genetics and demography in biological conservation. Science, 241, 1455-1460.

Lima S, Dill L (1990) Behavioral decisions made under the risk of predation: a review and prospectus. Canadian Journal of Zoology, 68, 619-640.

Lowe S, Browne M, Boudjelas S, De Poorter M (2000) 100 of the World's Worst Invasive Alien Species A selection from the Global Invasive Species Database. Published by The Invasive Species Specialist Group (ISSG) a specialist group of the Species Survival Commission (SSC) of the World Conservation Union (IUCN), 12pp.

Lubchenco J, Palumbi SR, Gaines SD, Andelmas S (2003) Plugging a hole in the ocean: the emerging science of Marine Reserves. Ecological Applications, 13, 3-7.

Mace GM (2004) The role of taxonomy in species conservation. Philosophical Transactions of the Royal Society of London B, 359, 711-719.

Maloney RF, McLean IG (1995) Historical and experimental learned predator recognition in free-living New Zealand robins. Animal Behaviour, 50, 11931201. 
Manel S, Gaggioti OE, Waples RS (2005) Assignment methods: matching biological questions with appropriate techniques. Trends in Ecology and Evolution, 20, $136-142$.

Masó M, Garces E, Pages F, Camp J (2003) Drifting plastic debris as a potential vector for dispersing Harmful Algal Bloom (HAB) species. Scientia Marina, 67, 107-111.

Mato Y, Isobe T, Takada H, Kahnehiro H, Ohtake C, Kaminuma T (2001) Plastic resin pellets as a transport medium for toxic chemicals in the marine environment. Environmental Science and Technology, 35, 318-324.

May RM (1990) Taxonomy as destiny. Nature, 347, 129-130.

McNeely JA (2002) The role of taxonomy in conserving biodiversity. Journal for Nature Conservation, 10, 145-153.

Miura O, Torchin ME, Bermingham E, Jacobs DK, Hechinger RF (2011) Flying shells: historical dispersal of marine snails across Central America. Proceedings of the Royal Society of London B, doi: 10.1098/rspb.2011.1599

Morrison III WR, Lohr JL, Duchen P, Wilches R, Trujillo D, Mair M, Renner SS (2009) The impact of taxonomic change on conservation: does it kill, can it save, or is it just irrelevant? Biological Conservation, 142, 3201-3206.

Mortensen T (1933) Papers from Dr. Th. Mortensen's Pacific Expedition 1914-16. LXVI. The echinoderms of St. Helena (other than Crinoids). Videnskabelige Meddelelser fra Dansk Naturhistorisk Forening i KjøbenhavnI, 93, 401-473.

Neaves LE, Zenger KR, Cooper DW, Eldridge MDB (2010) Molecular detection of hybridization between sympatric kangaroo species in south-eastern Australia. Heredity, 104, 502-512. 
Neilsen R, Wakeley J (2001) Distinguishing migration from isolation: a Markov Chain Monte Carlo approach. Genetics, 158, 885-896.

Nikula R, Fraser CI, Spencer HG, Waters JM (2010) Circumpolar dispersal by rafting in two subantarctic kelp-dwelling crustaceans. Marine Ecology Progress Series, 405, 221-230.

Parsons KE (1996) The genetic effects of larval dispersal depend on spatial scale and habitat characteristics. Marine Biology, 126, 403-414.

Partridge L, Bruford M (1994) A crash course in survival. Nature, 372, 318-320.

Piry S, Alapetite A, Cornuet, J.-M., Paetkau D, Baudouin, L., Estoup, A (2004) GeneClass2: A Software for Genetic Assignment and First-Generation Migrant Detection. Journal of Heredity, 95, 536-539.

Prescott JH (1959) Rafting of jack rabbit on kelp. Journal of Mammalogy 18, 443444.

Raxworthy CJ, Forstner MR, Nussbaum RA (2002) Chameleon radiation by oceanic dispersal. Nature, 415, 784-787.

Richards VP, Thomas JD, Stanhope MJ, Shivji MS (2007) Genetic connectivity in the Florida reef system: comparative phylogeography of commensal invertebrates with contrasting reproductive strategies. Molecular Ecology, 16, 139-157.

Roberts CM (1997) Connectivity and management of Caribbean coral reefs. Science, 278, 1454-1457.

Russello MA, Glaberman S, Gibbs JP, Marquez C, Powell JR, Caccone A (2005) A cryptic taxon of Galapagos tortoise in conservation peril. Biology Letters, $\mathbf{1}$, 287-290. 
Ryan PG, Moloney CL (1993) Marine litter keeps increasing. Nature, 361, 23.

Sala E, Aburto-Oropeza O, Paredes G, Parra I, Barrere JC, Dayton PK (2002) A general model for designing networks of marine reserves. Science, 298, 11911193.

Schonewald-Cox CM, Chambers SM, MacBryde B, Thomas WL (1983) Genetics and Conservation. Benjamin/Cummings, Menlo Park, CA.

Slatkin M (1987) Gene flow and the geographic structure of natural populations. Science, 236, 787-792.

Slatkin M (1993) Isolation by distance in equilibrium and nonequilibrium populations. Evolution 47, 264-279

Sodhi NS, Liow LH, Bazzaz FA (2004) Avian extinctions from tropical and subtropical forests. Annual Review of Ecology, Evolution and Systematics, 35, 323-345.

Soulé ME, Wilcox BM (1980) Conservation Biology: an evolutionary-ecological perspective. Sinauer Associates, Sunderland, Massachusetts.

Thiel M, Gutow L (2005) The ecology of rafting in the marine environment. II The rafting organisms and community. Oceanography and Marine Biology: An Annual Review, 43, 279-418.

Thompson RC, Moore CJ, vom Saal FS, Swan S (2009) Plastics, the environment and human health. Philosophical Transactions of the Royal Society B, 364, 215366.

Underwood JN, Smith LD, Van Oppen MJH, Gilmour JP (2007) Multiple scales of genetic connectivity in a brooding coral on isolated reefs following catastrophic bleaching. Molecular Ecology, 16, 771-784. 
Verlaque M, Fritayre P (1994) Modifications des communautés algales mediterranéennes en présence de l'algue envahissante Caulerpa taxifolia (Vahl) C. Agardh. Oceanologica Acta, 17, 659-672.

Walker B, Holling CS, Carpenter SR, Kinzig A (2004) Resilience, adaptability and transformability in social-ecological systems. Ecology and Society, 9, 5-13.

Waples, R. S. 1998. Separating the wheat from the chaff: patterns of genetic differentiation in high gene flow species. Journal of Heredity, 89, 438-450.

Waples RS, Teel DJ (1990) Conservation genetics of pacific salmon I. Temporal changes in allele frequency. Science, 241, 1455-1460.

Waples RS, Gaggiotti O (2006) What is a population? An empirical evaluation of some genetic methods for identifying the number of gene pools and their degree of connectivity. Molecular Ecology, 15, 1419-1439

Weersing K, Toonen RJ (2009) Population genetics, larval dispersal and connectivity in marine systems. Marine Ecology Progress Series, 393, 1-12.

Whitlock MC, McCauley DE (1999) Indirect measures of gene flow and migration: $F_{\text {ST }}$ does not equal $1 /(4 N \mathrm{~m}+1)$. Heredity, 82, 117-125.

Whittaker RJ, Fernandez-Palacios JM (2007) Island Biogeography: Ecology, Evolution, and Conservation. Oxford University Press, Oxford, United Kingdom.

Wikelski M, Foufopoulos J, Vargas H, Snell H (2004) Galápagos Birds and Diseases: Invasive Pathogens as Threats for Island Species. Ecology and Society, 9(1), 5.

Worcester SE (1994) Adult rafting versus larval swimming: dispersal and recruitment of a botryllid ascidian on eelgrass. Marine Biology, 121, 309-317. 
Wood AR, Gardner JPA (2007) Small spatial scale population genetic structure in two limpets (Scutellastra kermadecensis and Siphonaria raoulensis) endemic to the Kermadec Islands, New Zealand. Marine Ecology Progress Series, 349, 159-170. 


\title{
APPENDIX 1
}

\section{APPLICATION OF TWO MORPHOMETRIC TECHNIQUES, TRAITS MORPHOMETRIC ANALYSIS AND FAST FOURIER TRANSFORM (FFT), FOR THE DESCRIPTION OF NZ SUBANTARCTIC CELLANA SPECIES}

\begin{abstract}
Before the era of genetics, most taxonomy was based on the morphological traits of organisms. Species were described according to colour, form, texture and numerous anatomical attributes. Gastropods are known for their morphological plasticity and their species-level classification has to be regularly updated. This chapter focuses on the Cellana strigilis complex, which is endemic to the New Zealand subantarctic islands. This complex has been classified into 6 subspecies based on morphological characters, although two recent genetic studies (Goldstien et al 2009 and Chapter 2 of this thesis) revealed that the complex comprises two lineages, with strong genetic differentiation within lineages. This chapter aims to identify possible morphological differences between these two newly described species that would be congruent with the molecular data, using two morphometric techniques (a multivariate traits analysis of the length, width, height, dry mass and thickness of the shells and a Fast Fourier Transform (FFT) analysis of shell shape), I observed a significant difference in shell shape between the two lineages using both techniques. Moreover, the very high power of discrimination of the FFT technique compared with shell traits makes it highly suitable for biological samples where DNA is lacking (fossils) or degraded (museum collections).
\end{abstract}




\section{A1.1 Introduction}

Patellogastropods are known for their high levels of phenotypic plasticity. Colour, texture, patterns, spires, scars, ribs, as well as length, width, height and apex position are the most commonly used shell characters in species' descriptions. However, patellogastropods' highly variable shell morphologies have led to enormous confusion in their taxonomy (Nakano \& Osawa 2007; Goldstien et al. 2009; Nakano et al. 2009; Reisser et al. 2011). The lack of genetic differentiation among individuals with different morphs has already been reported in syphonariid limpets of the South African coasts, with four morphologically different sympatric intertidal limpets consisting in reality of two closely related lineages and a division according to the geography rather than the morphology (Teske et al. 2007). The situation can also be reversed, with genetically distinct species showing a high morphologic similarity (Kemp \& Bertness 1984, Sokolova \& Berger 2000, Liu 2003, Nakano et al. 2009). However, it is important to note that cryptic species and phenotypic plasticity can occur simultaneously in the same taxonomic family. For example, Nakano \& Spencer (2007) reported the existence of five cryptic species within the limpet species known as Notoacmea helmsi, with at least one of these species (corresponding to N. scapha), consisting of individuals having two highly distinct shell morphologies.

The question of how useful shell morphology is in describing differences and resolving phylogenetic relationship among closely related species of marine gastropods is a matter of debate. Previous genetic analysis of the Cellana strigilis complex revealed the existence of two different lineages of what was previously described as a single species with six different subspecies (Powell, 1955, see Chapter 2 for molecular analysis). The two lineages are geographically isolated from each other with no migration between. Powell's description was based on internal and external shell colour, aperture shape of the shell, position of the apex, presence and structure of ribs and a description of the spatula. This description allowed him to differentiate specimens from the different islands. However, some of these attributes (e.g: shell external colour and exact position of the apex) are hard to quantify or estimate in natural populations, for example, because the shell may be eroded and covered in epibionts. Nonetheless, based on Powell's description, one character seems to discriminate the two species: the shell's aperture shape. The southwestern 
populations (Auckland, Campbell, Snares and Stewart islands and New Zealand South Island) have a broadly ovate shell, whereas the northeastern populations (Antipodes, Bounty and Chatham islands) have a narrowly ovate shell (Powell, 1979).

I conducted a morphometric analysis of the shells from the two newly recognized lineages in order to test for any significant differences between them. For this, I took common geometric measurements of the shells: the length, width, height and dry mass, as well as the apex position. I tested for aperture shape (ovality) differences using a Fast Fourier Transform analysis. Recently, Fourier analysis has grown in popularity for analysing the shape of diverse organism features, ranging from fish otoliths to flower petals and ventricular shape in humans (Kass et al 1987, Yoshioka et al 2004, Costa et al 2008, Schulz-Mirbach et al 2010), as well as in numerous bivalve and gastropods species (Gardner \& Thompson 2009, de Arenzamendi et al. 2010, Hoffman et al. 2010, Preston et al. 2010).

This study has two aims: (1) to test for morphometric differences between the two lineages, and for island-based morphometric specificity by testing for withinspecies differences; (2) compare the discriminant power of the two techniques employed here.

\section{A1.2 Material and Methods}

I measured 5 traits on each of the 160 shells also used in Chapter 3. Length (L), width (W) and height $(\mathrm{H})$ measurements were obtained using digital callipers with a precision of $\pm 0.01 \mathrm{~mm}$. Dry mass $(\mathrm{M})$ was obtained using a scale to the nearest $0.01 \mathrm{~g}$. To obtain the most accurate results for the location of the apex, digital pictures of the dorsal view of the shells were taken using a Sony Alpha 300 DSLR camera, and the apex position was identified using the original shells and marked on the pictures. Measurements of the apex position were recorded to the nearest $0.5 \mathrm{~mm}$. Because $\mathrm{W}, \mathrm{H}$ and $\mathrm{M}$ are size-dependant, I standardized them by L. In an attempt to normalise the data, I tested four transformations ( $\log 10$, square root, reciprocal and Arcsin square root) on the dataset. According to the Shapiro-Wilks test for normality, the Arcsin square root transformation was the most successful, with 25 normal observations out of 36 tests ( $70 \%$ of the total dataset is thus normally distributed) and only 4 observations with a p-value less than 0.001 . 
Discriminant function analysis (DFA) was carried out with Statistica V6.0 (Statsoft 1994) and Wilk's $\lambda$, which ranges from 0 (perfect discrimination between or among groups) to 1 (no discrimination), was estimated. Although one of the requirements for DFA analysis is the normality of the dataset, non-normality is not critical for the analysis, meaning that the resultant significance tests are still trustworthy (Statistica textbook at http://www.statsoft.com/textbook/discriminantfunction-analysis/?button=1). Moreover, for all but 3 observations, the deviation from a non-normal distribution was not profound. Pairwise Mahalanobis Distance (D) values were calculated between populations or species and used to perform an assignment test (proportion of individuals correctly assigned to their original population / lineage). Canonical Analysis of Principal Component Coordinates (CAPCC) was employed to examine multi-trait differences among individuals and their populations based on Euclidean distances by CAP12 (Anderson 2004). Matrices of assignment and scatter plots of individuals grouped per population and per species were obtained from the DFA and CAPCC, respectively.

\section{A1.3 Results}

\section{A1.3.1 Morphometric differentiation between lineages}

CAPCC on the four shell traits allowed partial segregation of the two lineages, with the southwestern lineage exhibiting negative canonical values, and the northeastern lineage showing mainly positive canonical values, and partly overlapping with the former (Fig. A1.1a). CAPCC observations were congruent with the results of the DFA showing a significant but incomplete differentiation between the two lineages $(\lambda=0.505, F=37.923, p<0.0001)$. Southwestern and northeastern individuals were correctly classified with $88.39 \%$ and $72.92 \%$ accuracy respectively (Table A1.1a). The difference in assignment success can be explained by the fact that the non-overlapping range of the southwestern individuals is more important than for the northeastern individuals. 
(c)
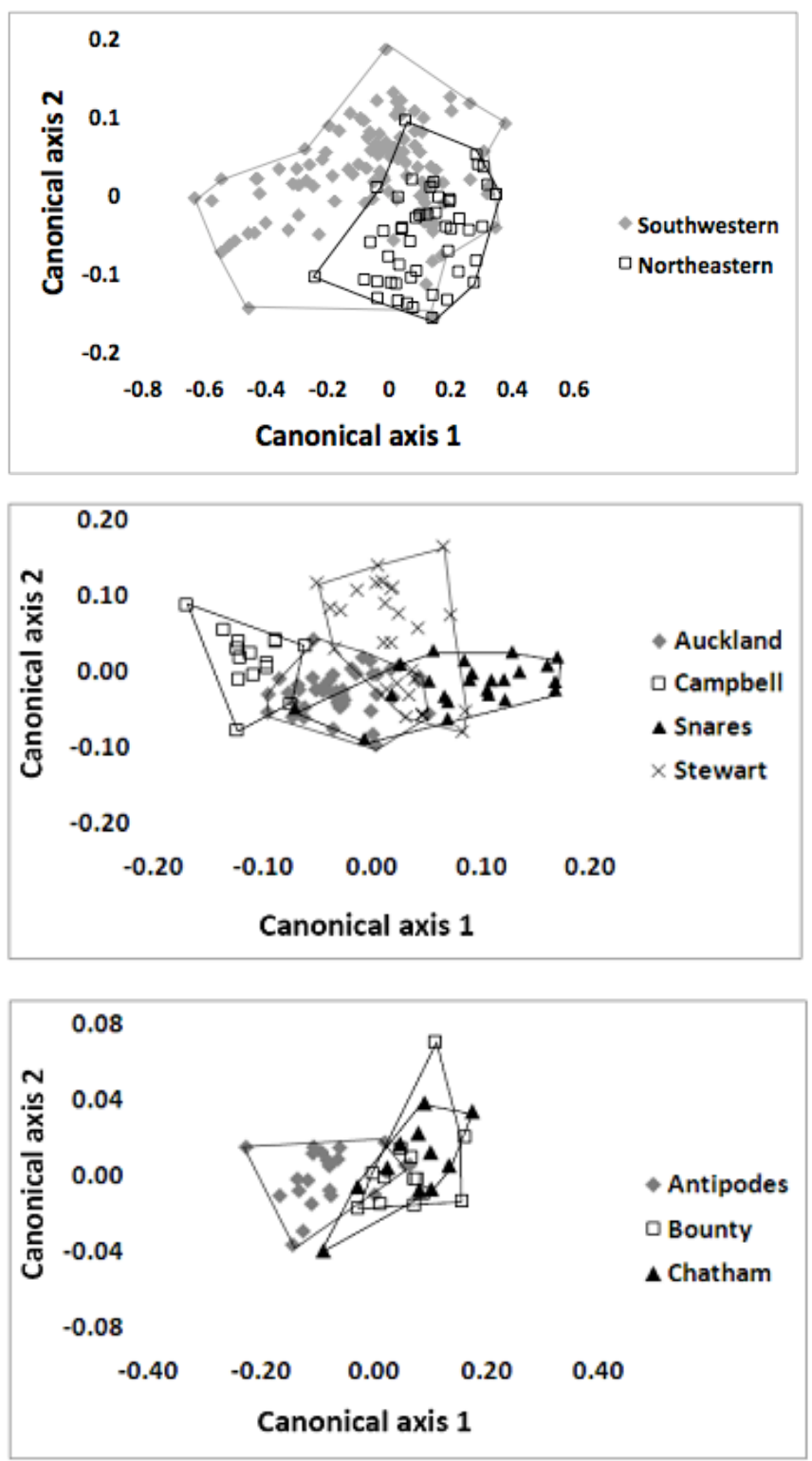

Figure A1.1.

Canonical Analysis of Principal Coordinates on multivariate shell traits (a) between lineage, (b) among the southwestern lineage populations and (c) among the northeastern lineage populations. 
Table A1.1.

Matrix of assignment from DFA of shell multivariate traits, with the percentage of correct assignment for each group (populations or lineage), and the probability "p" of population affiliation by chance based on population size and global sample size: division by lineage (a), by

(a) populations within the southwestern lineage (b) and by populations within the northeastern lineage (c). Boldface represents correct assignment.

(a)

\begin{tabular}{|l|lll|}
\hline Lineage & $\begin{array}{l}\text { Percent } \\
\text { correct }\end{array}$ & $\begin{array}{l}\text { Southwestern } \\
p=0.700\end{array}$ & $\begin{array}{l}\text { Northeastern } \\
p=0.300\end{array}$ \\
\hline Southwestern & 88.393 & $\mathbf{9 9}$ & 13 \\
Northeastern & 72.917 & 13 & $\mathbf{3 5}$ \\
\hline Total & 83.750 & 112 & 48 \\
\hline
\end{tabular}

(b)

(b)

\begin{tabular}{|l|lllll|}
\hline Population & Percent & Auckland & Campbell & Snares & Stewart \\
& correct & $p=0.393$ & $p=0.143$ & $p=0.223$ & $p=0.241$ \\
\hline Auckland & 90.91 & $\mathbf{4 0}$ & 2 & 0 & 2 \\
Campbell & 81.25 & 3 & $\mathbf{1 3}$ & 0 & 0 \\
Snares & 84.00 & 3 & 0 & $\mathbf{2 1}$ & 1 \\
Stewart & 62.96 & 6 & 0 & 4 & $\mathbf{1 7}$ \\
\hline Total & 81.25 & 52 & 15 & 25 & 20 \\
\hline
\end{tabular}

(c)

\begin{tabular}{|l|llll|}
\hline Population & Percent & Antipodes & Bounty & Chatham \\
& correct & $p=0.479$ & $p=0.292$ & $p=0.229$ \\
\hline Antipodes & 82.61 & $\mathbf{1 9}$ & 3 & 1 \\
Bounty & 64.29 & 3 & $\mathbf{9}$ & 2 \\
Chatham & 36.36 & 2 & 5 & $\mathbf{4}$ \\
\hline Total & 66.67 & 24 & 17 & 7 \\
\hline
\end{tabular}




\section{A1.3.2 Morphometric differentiation within lineages}

Within the southwestern lineage, populations were not successfully differentiated with CAPCC (Fig.A1.1b). However, DFA revealed reduced but significant differences among islands $(\lambda=0.191, \mathrm{~F}=20.112, \mathrm{p}<0.001)$, and correctly assigned $81.25 \%$ of the individuals to their original population. The highest assignment success was $90.90 \%$ for the Auckland Islands, and the lowest success was $62.96 \%$ for Stewart Island (Table A1.1b).

Within the northeastern lineage, populations showed more differentiation than the southwestern lineage populations using CAPCC. While the Chatham and Bounty islands populations still overlapped, Antipodes Island samples clustered separately (Fig.A1.1c). This observation is reflected in the DFA, and while the $\lambda$ value is high ( $\lambda$ $=0.4591, \mathrm{~F}=5.003, \mathrm{p}<0.001)$ there was a high assignment success of $82.61 \%$ for Antipodes individuals. However, only $36.36 \%$ of the Chatham Island individuals (close to what is expected by chance alone) were correctly assigned, lowering the overall assignment success for the northeastern lineage populations to $66.67 \%$ (Table A1.1c).

\section{A1.4 Discussion}

The aims of this chapter were to test for shell trait and shape differences between two closely related lineages of the $C$. strigilis limpet complex, as well as among their respective populations, and to compare the discrimination power of two morphometric approaches. Here, I found that results of the shell morphometry were congruent with molecular evidence, and that FFT had a higher discrimination power than shell trait morphometry.

\section{A1.4.1 Traits and shape variation between the southwestern and northeastern lineage}

The DFA on the different populations revealed considerable trait and shape heterogeneity within both lineages. The high variation observed in term of assignment success among populations is likely to be due to variation of local environmental conditions, with some islands having a range of environmental conditions that some 
others do not have. This higher variability could lead to an increased variance in shell shape within a single population, and in turn reduce the individuals' assignment success when performing DFA.

When comparing the two lineages, both techniques detected a significant morphometric difference. However, FFT analysis allowed for a better discrimination of shape difference ( $99.38 \%$ success for FFT versus $83.75 \%$ for shell traits). It is also worth noticing that both techniques misclassified different individuals, meaning that the difference in assignment success is rather due to inherent discrimination power than due to outlier samples.

\section{A1.4.2 Description and source of shape variation}

The northeastern lineage of the $C$. strigilis complex exhibits, on average, a narrower shell aperture than the southwestern lineage. The phenotypic plasticity of patellogastropods is known to be high and has been studied for many years. However, it is often very hard to explain a particular feature and link it with evolutionary meaningful or environmental reasons for why the shells differ phenotypically (Urdy et al. 2010). Variations in limpet shell shape and attributes have sometimes been explained by environmental factors. Adaptation for desiccation resistance has been proposed as a source of shell variation in multiple articles: morphological features such as high spiring (Bird 2011), light pigmentation (Etter 1988, Sokolova \& Berger 2000), narrow aperture shape (Lowell 1984, Harley 2009), and shell architecture (e.g. ribs and nodules; De Wolf 1997, Harley 2009) could help reducing water loss and heat conduction when a limpet sits on a hot surface. However, the same features are used to explain adaptations to hydrodynamic and predation pressure. A low-spired shell and a maximised foot surface area will reduce hydrodynamic drag and augment the grip of the animal on the substrate (Savini et al. 2004, Guerra-Valera et al. 2009). Also, a low-spired smooth shell reduces predation because birds and cannot easily peck at the shell margins and crabs cannot easily grip smooth shells (Lowell 1986).

With the advent of computational technology, researchers began to formulate mathematical models of gastropod shell form. In 1838, Moseley established a geometric model of shell coiling based on the logarithmic spiral (in Meinhardt 2009, pp167). Raup used Moseley's work as a basis for developing a new logarithmic 
model using 4 parameters (Raup \& Michelson 1965): the shape of the generating curve, the whorl expansion rate, the position of the generating curve in relation to the coiling axis and the rate of whorl translation. Apart from the statistical description of shell shape, numerous researchers have attempted to identify the biological origin of shell morphometric variation. Some of them managed to create numerous shell shapes by altering the growth rate of a model feature called the "aperture map". The aperture map refers to the pattern of relative rate of shell accretion for each point around the aperture of the shell (Huxley 1932, in Rice 1998). In 1991, Checa developed a model that allowed differential growth of different parts of the aperture during the animal's growth, leading to different aperture shapes. Rice (1998) combined Checa's previous work with additional biological parameters and modelled the biogeometry of gastropods shells.

The aperture map, that is the rate of shell accretion around the aperture of the shell, is likely to be determined at the cellular and molecular level, and could be genetically influenced and therefore passed to the next generation. Thus, some shape differences could be predominantly due to genetic factors, as opposed to environmental factors. The question of how much environmental and/or genetic factors affect phenotypic plasticity is still a matter of debate. Working on two intertidal gastropods, Austrocochlea constricta and Bembicium vittatum, Parsons (1997) showed that phenotypic plasticity was due to different factors according to the species and the life history considered, and that part is due to genetic and part to environmental conditions. Urdy et al. (2010) also highlighted that although mathematical models show where/how the variation occurs to produce different phenotypes, it can only provide a description of the underlying factors (shape and growth rate). The exact molecular mechanisms controlling growth rate are still largely unknown, and it is impossible to separate the genetic input from the environmental input when considering shell shape.

Here, no conclusions can be drawn regarding the genetic contribution or the environmental input on the Cellana shell shape. Also, no putative adaptative benefits of this difference in shape can be proposed. Because of their remote locations and their protected status, no translocation studies can be carried out on the field to test hypotheses about environmental versus genotypic contributions. In addition, precise data on the environmental conditions at the collection sites (wave exposure, wind, 
exact position of the animal in the intertidal zone) are not available. It would thus be imprudent to correlate the shape variation to either genetic or environmental factors, and further studies are necessary to assess both contributions to shell shape.

\section{A1.4.3 Advantages and possible applications of FFT analysis}

When trying to discriminate between the two lineages, both techniques gave significant results. However, Fourier shape analysis was the most successful, with only one of 160 individuals being misclassified. The first advantage of FFT compared to multivariate trait analysis is that the data collection is automated, limitating the error accumulation linked with multiple measurements and subjective reading. Overall, the addition of all the manual tasks and the data transformation / normalisation before analysis makes this approach time-consuming. Fourier analysis however, requires only a picture of the animal and no data transformation before data analysis.

The second advantage of FFT is the possibility to localise and identify the source of variation between / among groups and visually observe the differences. Because multivariate trait analysis generally requires that the dataset be transformed, the values being worked with are completely changed, with the result that values to be used in the analysis may not have any biological meaning. Hence, multivariate analysis of shell traits gives a statistical result in terms of discrimination (presence or not of a statistically significant difference), but does not highlight the origin of the difference (what is the difference between/among samples). The creation of the HCURVE program by Crampton \& Haines (2000) allows for the extraction of a visual representation of the source of the discrimination from a suite of FCs, and thus provides essential information about shape differences. The opportunity to use the program to reconstruct a population's shape average, or to compare individual extremes is a great advantage to quantify the amount of difference between/among groups.

The third advantage of FFT analysis, compared to the general shell trait measurements, concerns its very high level of accuracy. Its discriminant capacity has important implications in many areas such as conservation and biosecurity. Indeed, Fourier analysis could provide a means to identify morphologically cryptic sympatric 
species with no need for molecular analysis. Although nowadays molecular analyses are not too onerous, they can still represent a considerable cost for conservation agencies. Also, depending on the targeted organism and/or tissue to be sampled, the removal of tissue/blood can sometimes lead to physiological stress or even death (e.g., when the minimum amount of tissue to be taken requires the whole animal to be used). In some instances, tissues containing DNA information are too degraded or have been removed from samples such as fossils or shell collections in museums. It is for this type of situations, when molecular work is impossible, that FFT is an essential tool and may provide new information in phylogenetic and palaeontological studies. The acquisition of the necessary information to carry out FFT analysis (here a picture of a particular feature) is very straight forward and does not require extensive handling by the operator of an individual in contrast to the situation for the measurement of shell traits. Thus, Fourier shape analysis reduces the time for data processing and makes data collection easy. The implementation of a common standardised online database using individuals already sequenced / identified according to their DNA profile (e.g., the "Barcode of Life" programme based on sequencing of the COI gene) along with their corresponding FCs for a particular feature would allow for species discrimination. In the field, only a picture of the targeted feature (e.g. shell outline, wing shape, petal shape) would be needed. Once the FCs are extracted, they could be inserted into the online database and a DFA would be carried out. The sample individual would be assigned to a particular species with a given level of confidence based on assignments made by comparison to the internationally recognised database. This technique would be particularly interesting for biosecurity applications, where a direct identification in the field would be available (e.g. detection of a non-native plant, survey of shells picked up from the beach, airport customs and control). However, one should keep in mind that shape analysis gives a relative likelihood value and not an absolute value. It is thus necessary to be careful when interpreting the results.

Overall, FFT is a very fast and efficient technique. The time required to analyse 100 shells, from the measurements to the results of the DFA is half that required for the traits analysis described in the present chapter (personal observation). Its computational data treatment reduces the error rate of the analysis and provides highly reliable results with no extra cost involved. 


\section{A1.5 Conclusions}

This chapter aimed to study shell shape of two recently described lineages of the $C$. strigilis complex using two different morphometric techniques. I found a significant difference between them. This difference was detected by the two morphometric techniques used here, and it was shown that the northeastern lineage had a narrower aperture than the southwestern lineage. My results show the very high discriminant accuracy of the FFT analysis compared to multivariate shell traits analysis. The advantage of FFT resides in its level of automation and its suitability for forms lacking pre-established or identifiable homologous points (landmarks). This advantage, coupled with the high efficiency of the technique offers new possibilities for the study of endangered or seemingly morphologically similar species, as well as unclassified Museum specimens, and could have a large impact on conservation and biosecurity studies.

\section{A1.6 References:}

Anderson MJ (2004) CAP: a FORTRAN computer program for canonical analysis of principal coordinates. Department of Statistics, University of Auckland, New Zealand.

Bird CE (2011) Morphological and behavioral evidence for adaptive diversification of sympatric Hawaiian limpets (Cellana spp.) Integrative and Comparative Biology, 51, 466-73.

Checa A (1991) Sectorial expansion and shell morphogenesis in molluscs. Lethaia, 24, 97-114.

Costa C, Aguzzi J, Menesatti P, Antonucci F, Rimatori V, Mattoccia M (2008) Shape analysis of different populations of clams in relation to their geographical structure. Journal of Zoology 276, 71-80. 
De Aranzamendi MC, Martinez JJ, Sahade R (2010) Shape differentiation and characterization in the two morphotypes of the Antarctic limpet Nacella concinna using Elliptical Fourier analysis of shells. Polar Biology, 33, 11631170.

De Wolf H, Backeljau T, Medeiros R, Verhagen R (1997) Microgeographical shell variation in Littorina striata, a planktonic developing periwinkle. Marine Biology, 129, 331-342.

Etter RJ (1988) Physiological stress and colour polymorphism in the intertidal snail Nucella lapillus. Evolution, 42, 660-680.

Gardner JPA, Thompson RJ (2009) Influence of genotype and geography on shell shape and morphometric trait variation among North Atlantic blue mussels (Mytilus spp.) populations. Biological Journal of the Linnean Society, 96, 875897.

Goldstien SJ, Gemmell NJ, Schiel DR (2009) Colonisation and connectivity by intertidal limpets among New Zealand, Chatham and Sub-Antarctic Islands. I. Genetic connections. Marine Ecology Progress Series, 388, 111-119.

Guerra-Valera J, Colson I, Backeljau T, Breugelmans K, Hughes RN, Rolan-Alvarez E (2009) The evolutionary mechanism maintaining shell shape and molecular differentiation between two ecotypes of the dogwhelk Nucella lapillus. Evolutionary Ecology, 23, 261-280.

Haines JA, Crampton JS (2000) Improvements to the method of Fourier analysis as applied in morphometric studies. Palaeontology 43: 765-783.

Hoffmann JI, Peck LS, Hilliard G, Zieritz A, Clark MS (2010) No evidence for genetic variation between Antarctic limpet Nacella concinna morphotypes. Marine Biology, 157, 765-778. 
Huxley J (1932) Problems of relative growth. Methuen, London.

Kass DA, Traill TA, Keating M, Altieri PI, Maughan WL (1987) Abnormalities of dynamic ventricular shape change in patients with aortic and mitral valvular regulation: assessment by Fourier shape analysis and global geometric indexes. Circulation Research 62, 127-138.

Kemp P, Bertness MD (1984) Snail shape and growth rates: evidence for plastic shell allometry in Littorina littorea. Proceedings of the National Academy of Sciences USA, 81, 811-813.

Liu HP, Hershler R, Clift K (2003) Mitochondrial DNA sequences reveal extensive cryptic diversity within a western American springsnail. Molecular Ecology 12, 2771-2782.

Lowell RB (1984) Desiccation of intertidal limpets: effects of shell size, fit to substratum, and shape. Journal of Experimental Marine Biology and Ecology, 77, 197-207.

Lowell RB (1986) Crab predation on limpets: predator behavior and defensive features of the shell morphology of the prey. Biological Bulletin, 171, 577596.

Meinhardt H (2009) The algorithmic beauty of sea shells, 4th edn. Springer, Tubingen, Germany.

Nakano T, Ozawa T (2007) Worldwide phylogeography of limpets of the order Patellogastropoda: molecular, morphological and paleontological evidence. Journal of Molluscan Studies, 73, 79-99.

Nakano T, Spencer HG (2007) Simultaneous polyphenism and cryptic species in an intertidal limpet from New Zealand. Molecular Phylogenetics and Evolution, 45, 470-479. 
Nakano T, Marshall B, Kennedy M, Spencer HG. (2009) The phylogeny and taxonomy of New Zealand Notoacmea and Patelloida species (Mollusca: Patellogastropoda: Lottiidae) inferred from DNA sequences. Molluscan Research, 29, 33-59.

Parsons K (1997) Role of dispersal ability in the phenotypic differentiation and plasticity of two marine gastropods. I. Shape. Oecologia, 110, 461-471.

Powell AWB (1955) Mollusca from the Southern Islands of New Zealand. Vol 15. New Zealand Department of Sciences and Industrial Research, Wellington

Powell AWB (1979) New Zealand Mollusca - Marine, Land and Freshwater Shells, Collins, Auckland.

Preston SJ, Harrison A, Lundy M, Roberts D, Beddoe N, Rogowski D (2010) Square pegs in round holes - the implications of shell shape variation on the translocation of adult Margaritifera margaritifera (L.). Aquatic Conservation: Marine and Freshwater Ecosystems, 20, 568-573.

Raup DM, Michelson A (1965) Theoretical morphology of the coiled shell. Science, 147, 1294-1295.

Reisser CMO, Wood AR, Bell JJ, Gardner JPA (2011) Connectivity, small islands and large distances: the Cellana strigilis limpet complex in the Southern Ocean. Molecular Ecology, 20, 3399-3413.

Rice S (1998) The bio-geometry of mollusc shells. Paleontological Society, 24, 133149.

Savini D, Castellazzi M, Favruzzo M, Occhipinti-Ambrogi A (2004) The alien mollusc Rapana tenosa (Valenciennes, 1846; Gastropoda, Muricidae) in the Northern Adriatic Sea: population structure and shell morphology. Chemistry and Ecology, 20, 411-424. 
Schulz-Mirbach T, Ladich F, Riesch R, Plath M (2010) Otolith morphology and hearing abilities in cave- and surface-dwelling ecotypes of the Atlantic molly, Poecilia mexicana (Teleostei: Poeciliidae). Hearing Research 267, 137-148.

Sokolova IM, Berger VJa (2000) Physiological variation related to shell colour polymorphism in White Sea Littorina saxatilis. Journal of Experimental Marine Biology and Ecology, 245, 1-23.

Statsoft (1994) Statistica for windows manuals. Tulsa, OK: Statsoft.

Teske PR, Barker NP, MacQuaid CD (2007) Lack of genetic differentiation among four sympatric southeast African intertidal limpets (Siphonariidae): phenotypic plasticity in a single species? Journal of Molluscan Studies, 73, 223-228.

Urdy S, Goudemand N, Bucher H, Chirat R (2010) Growth-dependant phenotypic variation of molluscan shells: implications for allometric data interpretation. Journal of Experimental Zoology, 314B, 303-326.

Yoshioka Y, Iwata H, Ohsawa R, Ninomiya S (2004) Analysis of petal shape variation of Primula sieboldii by Elliptic Fourier Descriptors and Principal Component Analysis. Annals of Botany 94, 657-664. 